ISSN e: $2317-7748$

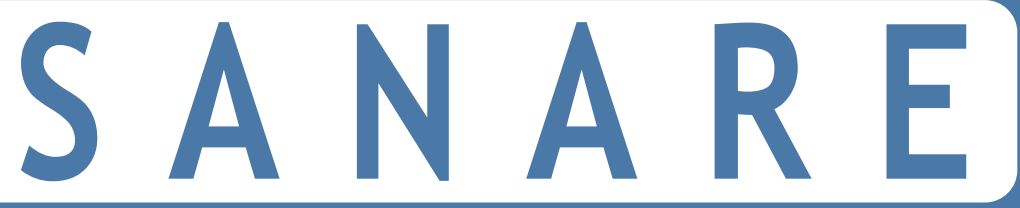

REVISTA DE POLÍTICAS PÚBLICAS

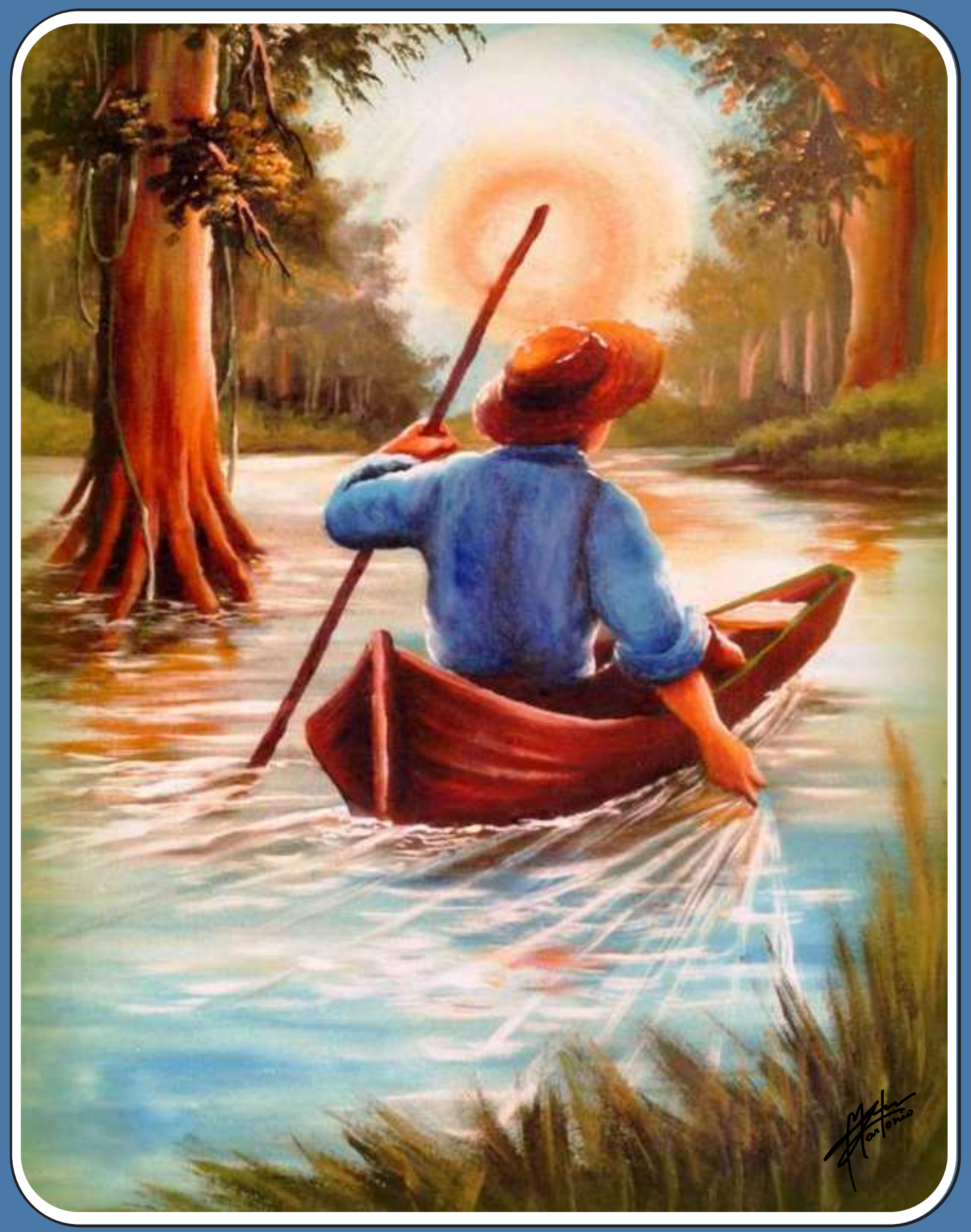




\section{SANARE}

Revista de Políticas Públicas de Sobral/CE v.18, n.1, p.01-109, Jan./Jun. 2019

Tornar sã, em latim, SANARE é uma revista de políticas públicas de Sobral/CE que tem por finalidade divulgar experiências em políticas públicas na área de saúde coletiva como forma de contribuir com o processo de elaboração e sistematização de novos paradigmas sobre gestão governamental.

\section{CONSELHO EDITORIAL}

\section{NACIONAL/NATIONAL}

Adriana Gomes N. Ferreira - UFMA, Imperatriz-MA Aluisio Ferreira de Lima - PUCSP,Fortaleza-CE Ana Cecilia Silveira Lins Sucupira - USP, São Paulo-SP Ana Mattos Brito de Almeida - ESP/CE, Fortaleza-CE Andrea Silvia Walter de Aguiar - UFC, Fortaleza-CE Ant. Germane Alves Pinto - URCA, Juazeiro do Norte - CE Anya Pimentel Gomes F. V. Meyer - FIOCruz, Fortaleza-CE Betise Mery Alencar S. Macau Furtado - UPE, Recife-PE Camilla Araújo Lopes Vieira - UFC, Sobral-CE Camilo Darsi de Souza - UNISC, Sta Cruz do Sul - RS Carlos Leonardo F. Cunha - UFRJ, Rio de Janeiro - RJ Cibelly Aliny Siqueira Lima Freitas - UVA, Sobral-CE Cristianne Maria Famer Rocha - UFRGS, Porto Alegre - RS

Edson Holanda Teixeira - UFC, Fortaleza-CE Eliany Nazaré Oliveira - UVA, Sobral-CE

Érika Bárbara Abreu Fonseca Thomaz - UFMA, São Luís-MA Fabiane do Amaral Gubert - UFC, Fortaleza-CE Fernando Sérgio Pereira de Sousa - UFPI, Floriano-PI Francisco Arnoldo Nunes de Miranda - UFRN, Natal-RN Francisco Placido Nogueira Arcanjo - UFC, Sobral-CE

Fco Rosemiro Guimarães Ximenes Neto - UVA, Sobral-CE Geison Vasconcelos Lira - UFC, Sobral-CE Gerardo Cristino Filho - UFC, Sobral-CE Glauberto da Silva Quirino - URCA, Crato-CE Ivaldinete de Araújo Delmiro Gémes - UVA, Sobral-CE Izabelle Mont'Alverne N. Albuquerque - UVA, Sobral-CE Jeane Félix da Silva - UFRGS, Porto Alegre - RS José Jailson de Almeida Junior - UFRN, Santa Cruz-RN José Maria Ximenes Guimarães - UECE, Fortaleza-CE
José Olinda Braga - UFC, Fortaleza-CE José Reginaldo Feijão Parente - UVA, Sobral-CE Lucia de Fátima da Silva - UECE, Fortaleza-CE Luis Achilles Rodrigues Furtado - UFC, Sobral-CE Luiza Jane Eyre de Souza Vieira - UNIFOR, Fortaleza-CE Marcia Ma. Mont'Alverne de Barros - UFPB, João Pessoa-PB Maria Adelane Monteiro da Silva - UVA, Sobral-CE Maria Corina Amaral Viana - URCA, Crato-CE Maria da Conceição Coelho Brito - EFSFVS, Sobral-CE Maria de Fatima Antero Sousa Machado - URCA, Crato-CE Maria de Nazaré de Oliveira Fraga - UFC, Sobral-CE Maria Fátima de Sousa - UnB, Brasília-DF Maria Rocineide Ferreira da Silva - UECE, Fortaleza-CE Maria Socorro de Araújo Dias - UVA, Sobral-CE Maria Veraci Oliveira Queiroz - UECE, Fortaleza-CE Maristela Inês Osawa Vasconcelos - UVA, Sobral-CE Milena Rodrigues Soares Mota - UNICEL, Manaus-AM Mirna Marques Bezerra Brayner - UFC, Sobral-CE

Paulo Roberto Santos - UFC, Sobral-CE Roberta Cavalcante Muniz Lira - UFC, Sobral-CE Simone da Nóbrega Tomaz Moreira - UFRN, Natal-RN Vicente de Paulo Teixeira Pinto - UFC, Sobral-CE Yolanda Flores e Silva - UNIVALI, Itajaí- SC

\section{INTERNACIONAL/INTERNATIONAL}

Félix Fernando Monteiro Neto - Portugal

Francisco Antonio Loiola - Canadá

Mirella Maria Soares Veras - Canadá

Wilson Jorge Correia Pinto de Abreu - Portugal 


\section{PREFEITURA}

Ivo Ferreira Gomes

Prefeito

Gerardo Cristino Filho

Secretário da Saúde

Maria Socorro de Araújo Dias

Diretora da Escola de Formação em Saúde da Família Visconde de Sabóia

\section{PRODUÇÃO}

Núcleo de Estudos e Pesquisas em Saúde da EFSFVS

Maria Socorro de Araújo Dias

$$
\text { Editora Chefe }
$$

Maria da Conceição Coelho Brito

Editora Assistente

Antônio Felipe de Vasconcelos Neto

Diagramação
Evandro Lisboa Freire

Revisões de Português

e Tradução (Inglês, Espanhol)

Martônio Holanda

Capa

Versão Digital

S A N A R E, Revista de Políticas Públicas

v.18, n.1, Jan./Jun. 2019

- Sobral[CE]: Escola de Formação em Saúde da Família Visconde de Sabóia, 2018.

Semestral

ISSN $1676-8019$

ISSNe $2317-7748$

1. Políticas Públicas - Sobral. 2. Políticas Públicas - Periódicos

É permitida a reprodução do material publicado, desde que citada a fonte.

Av. John Sanford, no 1320 - Bairro Junco - Sobral/CE CEP: 62030-362 - Fone/Fax: (88) 3614.5520 


\section{SUMÁRIO}

\section{EDITORIAL}

6 SATISFAÇÃO DOS FAMILIARES COM A HUMANIZAÇÃO DA ASSISTÊNCIA EM UTI

FAMILY MEMBERS' SATISFACTION WITH HUMANIZATION OF CARE AT THE ICU

SATISFACCIÓN DE LOS FAMILIARES CON LA HUMANIZACIÓN DE LA ATENCIÓN EN UCI

Elisângela de Jesus Macêdo Araújo, Keila Maria de Azevedo Ponte, Lívia Mara de Araújo, Maria Sinara Farias

12 ANÁLISE DA DEMANDA FONOAUDIOLÓGICA DE UM HOSPITAL DE REFERÊNCIA EM CARDIOPNEUMOLOGIA

ANALYSIS OF THE SPEECH THERAPY NEEDS IN A REFERRAL HOSPITAL IN CARDIOPNEUMOLOGY

ANÁLISIS DE LA DEMANDA FONOAUDIOLÓGICA EN UN HOSPITAL DE REFERENCIA EN CARDIONEUMOLOGÍA

Bruna Rafaelle Pereira Ibiapina Coelho, Luana Pereira Ibiapina Coelho, Elizabeth Zayra Torres Sousa, Ana Virgínia Sales Monte Costa, Antonio Tiago da Silva Souza, Camila Fernandes Mendes

\section{CONHECIMENTO DOS MÉdICOS DA ATENÇÃO PRIMÁRIA À SAÚDE SOBRE RASTREAMENTO} DE CÂNCER

PRIMARY HEALTH CARE PHYSICIANS' KNOWLEDGE ON CANCER SCREENING

CONOCIMIENTO DE MÉDICOS DE LA ATENCIÓN PRIMARIA SOBRE RASTREO DE CÁNCER

Lorena Alves Trajano, José Francisco Igor Siqueira Ferreira, Miguel Marcelo Freire de Melo, Luiz Eduardo de Castro Batista

31 FATORES DE RISCO E COMPLICAÇÕES EM DIABÉTICOS/HIPERTENSOS CADASTRADOS NO HIPERDIA

RISK FACTORS AND COMPLICATIONS IN DIABETIC/HYPERTENSIVE PATIENTS REGISTERED IN THE HIPERDIA FACTORES DE RIESGO Y COMPLICACIONES EN DIABÉTICOS/HIPERTENSOS CADASTRADOS EN EL HIPERDIA Natanael Aguiar de Sousa, Joab da Silva Lima, Taynã Cesário Teixeira, Carlito Braga Linhares, João Vitor Lopes Montes, João Vitor Souza Marques

40 SIGNIFICADO DAS MÃES SOCIAIS ÀS MULHERES ASSISTIDAS NO PUERPÉRIO

MOTHER'S SOCIAL SIGNIFICANCE TO WOMEN ATTENDED IN THE PUERPERIUM SIGNIFICADO DE LAS MADRES SOCIALES A LAS MUJERES ASISTIDAS EN EL PUERTO

Patrícia Pimentel Alves, Maria da Conceição Coelho Brito, Maria Adelane Monteiro da Silva, Heliandra Linhares Aragão, Lielma Carla Chagas da Silva

50 ESTADO NUTRICIONAL DE MENORES DE 5 ANOS DE IDADE EM SOBRAL-CE

NUTRITIONAL STATUS OF CHILDREN UNDER 5 YEARS OF AGE IN SOBRAL, CEARÁ, BRAZIL ESTADO NUTRICIONAL DE MENORES DE 5 AÑOS DE EDAD EN SOBRAL, CEARÁ, BRASIL

Beatriz Mendes Alves, João Vitor Souza Marques, Cynara Carvalho Parente, Marcos Vinícius Souza Marques, Francisco Plácido Nogueira Arcanjo, Karyne Gomes Cajazeiras

59 EDUCAÇÃO ALIMENTAR E NUTRICIONAL COMO INTERVENÇÃO EM HÁBITOS ALIMENTARES SAUDÁVEIS NO AMBIENTE ESCOLAR

FOOD AND NUTRITION EDUCATION AS AN INTERVENTION IN HEALTHY EATING HABITS IN THE SCHOOL

ENVIRONMENT

EDUCACIÓN ALIMENTARIA Y NUTRICIONAL COMO INTERVENCIÓN EN HÁBITOS ALIMENTARIOS SALUDABLES EN

EL AMBIENTE ESCOLAR

Quitéria Vanessa Brito Magalhães, Jorge Luís Pereira Cavalcante 
EMERGÊNCIA DE UM “CAMPO DE AÇÃO ESTRATÉGICA”: ORDENAMENTO DA FORMAÇÃO E EDUCAÇÃO PERMANENTE EM SAÚDE

EMERGENCE OF A "STRATEGIC ACTION FIELD": FORMATION PLANNING AND CONTINUING EDUCATION IN HEALTH EMERGENCIA DE UN “CAMPO DE ACCIÓN ESTRATÉGICA”: ORDENACIÓN DE LA FORMACIÓN Y EDUCACIÓN PERMANENTE EN SALUD

Ricardo Burg Ceccim

81 PSICOLOGIA E CUIDADOS PALIATIVOS NA ATENÇÃO PRIMÁRIA À SAÚDE: REVISÃO INTEGRATIVA

PSYCHOLOGY AND PALLIATIVE CARE IN PRIMARY HEALTH CARE: AN INTEGRATIVE REVIEW

PSICOLOGÍA Y CUIDADOS PALIATIVOS EN ATENCIÓN PRIMARIA DE SALUD: UNA REVISIÓN INTEGRADORA

Ana Carina Rodrigues Gois, Joyce Hilario Maranhão

90 ATENÇÃO DOMICILIAR EM SAÚDE BUCAL: EXPERIÊNCIA DE INTEGRAÇÃO ENSINOSERVIÇO-COMUNIDADE EM CENTRO DE SAÚDE DA FAMÍLIA

HOME CARE IN ORAL HEALTH: TEACHING-SERVICE-COMMUNITY INTEGRATION EXPERIENCE AT A FAMILY HEALTH CENTER

ATENCIÓN DOMICILIARIA EN SALUD BUCAL: EXPERIENCIA DE INTEGRACIÓN ENSEÑANZA-SERVICIO-COMUNIDAD EN UN CENTRO DE SALUD DE LA FAMILIA

André Pereira de Lima, Timóteo Sousa Lopes, Atanara Freires Aguiar de Lima, Mariana Ramalho de Farias, Jacques Antonio Cavalcante Maciel

98 PREENCHIMENTO DA CADERNETA DE SAÚDE DA PESSOA IDOSA: RELATO DE EXPERIÊNCIA COMPLETION OF THE ELDERLY PERSON'S HEALTH RECORD: AN EXPERIENCE REPORT LLENADO DE LA LIBRETA DE SALUD DEL ANCIANO: UN RELATO DE EXPERIENCIA Alessandra Schmidt, Cenir Gonçalves Tier, Maria Eduarda Deitos Vasquez, Vanessa Alvez Mora da Silva, Caroline Bittencourt, Bethânia Mesquita Cabeda Maciel

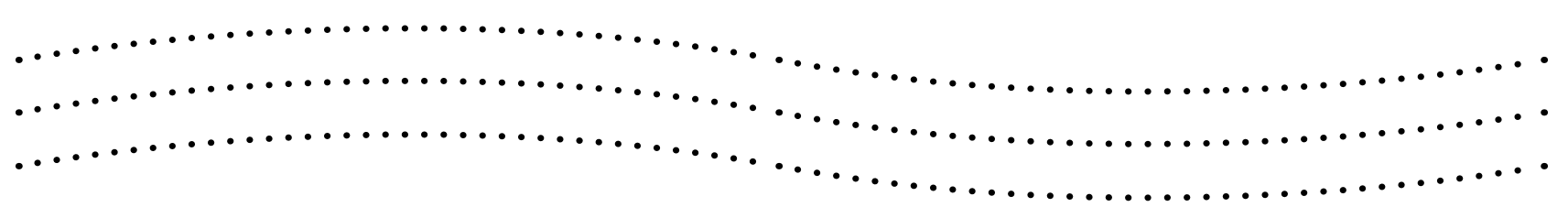




\section{EDITORIAL}

\section{Educação Interprofissional em Saúde (EIP): um caminho potente para o fortalecimento do SUS}

0 cenário brasileiro apresenta uma realidade marcada por mudanças que trazem repercussões de ordem social, política e econômica para o País. No campo da saúde, especificamente quando nos reportamos ao Sistema Único de Saúde (SUS), na sua forma operandis, princípios como da Universalidade, Equidade e Integralidade são postos em cheque a cada instante.

Direitos assegurados constitucionalmente pelo Estado tem sido contrariados por uma série de interesses de uma minoria burguesa que envida esforços diários no fomento de retrocessos que impactam diretamente na qualidade da atenção à saúde da população brasileira.

Diante desse realidade desafiante, enxergamos a formação em saúde e a qualificação dos trabalhadores para o SUS como um caminho potente para articularmos coletivos implicados, afetados e dispostos a permanecer e acreditar no sistema público de saúde brasileiro, que mesmo apresentando limites, especialmente em seu arcabouço jurídicoinstitucional, ainda se configura como uma das maiores políticas públicas de saúde do mundo, pelo seu caráter universal, equânime e integral, favorecendo o acesso a bens, serviços e direitos para todos.

Nesse contexto, insere-se a Educação Interprofissional em Saúde (EIP), que se expressa no Brasil, assim como em outros países do mundo, como uma estratégia educacional capaz de melhorar a qualidade da atenção à saúde no SUS, uma vez que busca o desenvolvimento de ações para a transformação da formação profissional em saúde com uma maior integração entre ensino, serviço e comunidade, vislumbrando uma prática mais colaborativa, que responda às necessidades de saúde complexas e dinâmicas da população, muitas vezes, mergulhada em um contexto de vulnerabilidades.

Os caminhos para uma prática colaborativa, interprofissional, interdisciplinar, intersetorial e de um trabalho em rede envolve uma série de desafios que compreendem desde as relações de poder entre as profissões, bem como a hierarquização destas e das instituições envolvidas na atenção à saúde. 0 fato é que precisamos nos integrar, dialogar e nos envolver no rompimento dos paradigmas do modelo clínico, biológico, excludente e flexneriano, historicamente hegemônico na implementação das políticas públicas de saúde brasileira.

É preciso resistir! É preciso acreditar que integrados podemos avançar na consolidação do SUS e enfrentar os grandes desafios de uma crise moral, social, política e econômica, nos comprometendo com a oferta de serviços de saúde com qualidade, fortalecendo a lógica da colaboração na dinâmica do trabalho em saúde.

Imbuídos desse desejo, convidamos aos leitores apropriarem-se das reflexões apresentadas pelos artigos que compõem o n.1, de 2019, da SANARE - Revista de Políticas Públicas.

Boa leitura!

\section{Cibelly Aliny Siqueira Lima Freitas}

Pós-doutorado em Enfermagem pela Universidade Federal do Paraná (UFPR)

Docente do Curso de Enfermagem da Universidade Estadual Vale do Acaraú (UVA) 


\section{SATISFAÇÃO DOS FAMILIARES COM A HUMANIZAÇÃO DA ASSISTÊNCIA EM UTI}

FAMILY MEMBERS' SATISFACTION WITH HUMANIZATION OF CARE AT THE ICU

SATISFACCIÓN DE LOS FAMILIARES CON LA HUMANIZACIÓN DE LA ATENCIÓN EN UCI

Elisângela de Jesus Macêdo Araújo ${ }^{1}$

Keila Maria de Azevedo Ponte ${ }^{2}$

Lívia Mara de Araújo 3

Maria Sinara Farias ${ }^{4}$

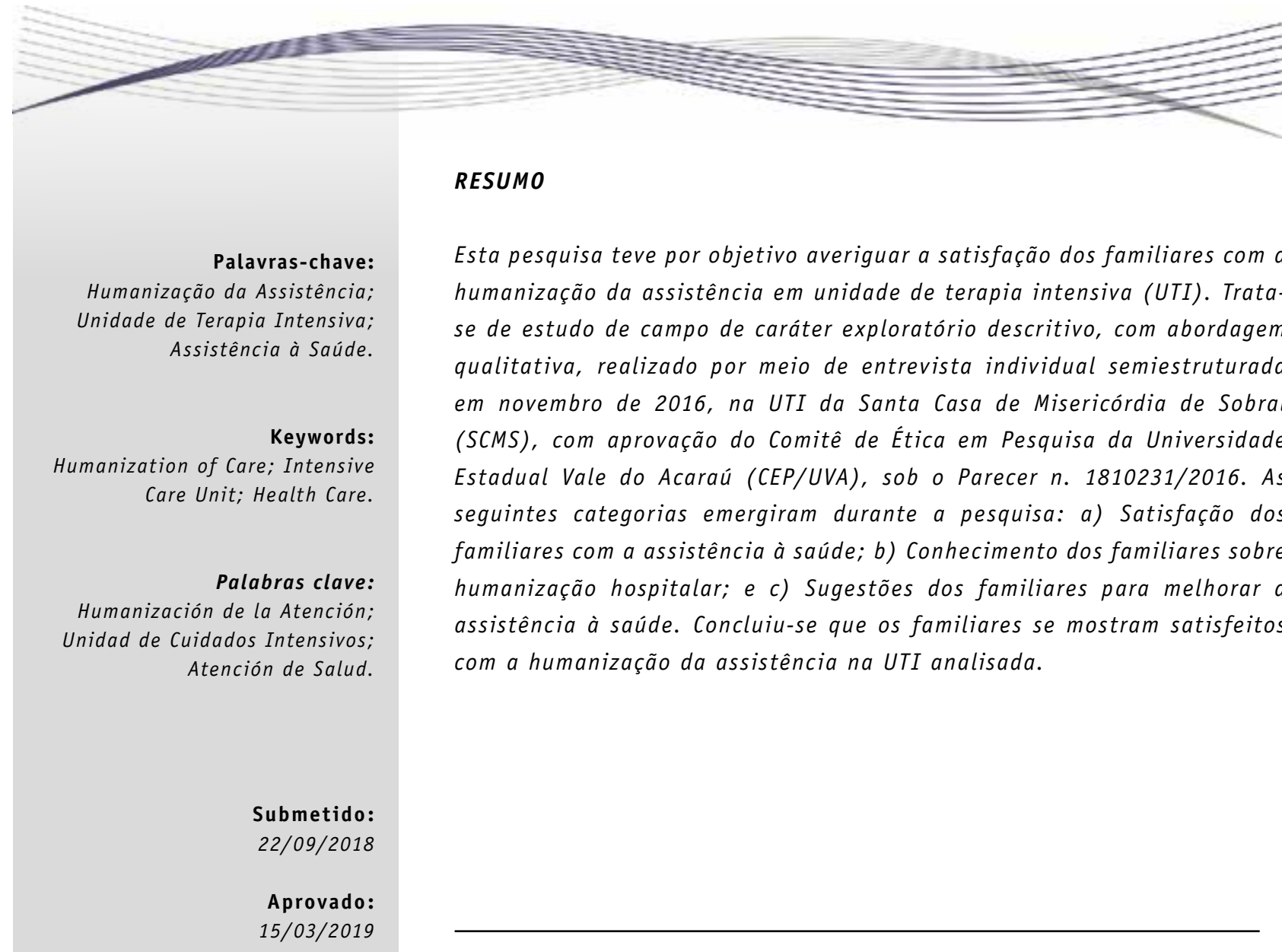

Autor(a) para Correspondência: Elisângela de Jesus Macêdo Araújo R. Prof. Manoel Pinto Filho, No 1077 - Padre Ibiapina Sobral (CE) - CEP: 62023-080 E-mail:eli_araujohc@hotmail.com

1. Enfermeira graduada pelo Centro Universitário Instituto Superior de Teologia Aplicada (UnInta). Professora no Instituto Centro de Ensino Tecnológico (CENTEC). Sobral (CE), Brasil.

2. Enfermeira. Professora no Curso de Graduação em Enfermagem da Universidade Estadual Vale do Acaraú (UVA). Sobral (CE), Brasil.

3. Enfermeira graduada pelo UnInta. Sobral (CE), Brasil.

4. Enfermeira. Aluna de Doutorado em Cuidados Clínicos de Enfermagem e Saúde na Universidade Estadual do Ceará (UECE). Fortaleza (CE), Brasil. 


\section{ABSTRACT}

This research aimed to investigate family members' satisfaction with humanization of care at the intensive care unit (ICU). This is a descriptive exploratory field study, with a qualitative approach, conducted by means of a semi-structured individual interview in November 2016, at the ICU of the Holy House of Mercy Hospital in Sobral (Santa Casa de Misericórdia de Sobral - SCMS), after approval by the Research Ethics Committee of the Ceará State University Vale do Acaraú (REC/Universidade Estadual Vale do Acaraú - UVA), under the Advisory Opinion No. 1810231/2016. The following categories emerged during the research: a) Family members' satisfaction with health care; b) Family members' knowledge on hospital humanization; and c) Family members' suggestions to improve health care. It was concluded that family members showed to be satisfied with humanization of care at the ICU under analysis.

\section{RESUMEN}

Esta investigación tuvo como objetivo investigar la satisfacción de los familiares con la humanización de la atención en unidad de cuidados intensivos (UCI). Este es un estudio de campo exploratorio descriptivo, con enfoque cualitativo, realizado mediante entrevista individual semi-estructurada en noviembre de 2016, en la UCI del Hospital de la Santa Casa de la Misericordia de Sobral (Santa Casa de Misericórdia de Sobral - SCMS), con aprobación del Comité de Ética en Investigación de la Universidad del Estado de Ceará Vale do Acaraú (CEI/ Universidade Estadual Vale do Acaraú - UVA), bajo la Opinión No. 1810231/2016. Las siguientes categorías surgieron durante la investigación: a) Satisfacción de los familiares con la atención de salud; b) Conocimiento de los familiares acerca de la humanización hospitalaria; y c) Sugerencias de los familiares para mejorar la atención de salud. Se concluyó que los familiares se muestran satisfechos con la humanización de la atención en la UCI bajo análisis.

\section{INTRODUÇÃO}

Cuidar do humano é um ato que exprime a necessidade do encontro de duas pessoas em certa situação ou determinado ambiente. Nessa perspectiva, os cuidados de enfermagem prestados ao paciente de modo objetivo, mediante técnicas e procedimentos padronizados, também se pautam por uma vertente subjetiva, balizada por sensibilidade, criatividade e intuição ${ }^{1}$.

Em tal contexto, o enfermeiro é o profissional responsável por coordenar e gerenciar o processo de assistência à saúde a ser desenvolvido com o paciente e tudo o que está envolvido no contexto hospitalar. A equipe de enfermagem desempenha um importante papel no cuidado direto ao paciente, por exemplo, na realização de procedimentos ${ }^{2}$. 0 paciente, com suas especificidades e necessidades com vistas à recuperação ou alta, constitui a principal razão da assistência à saúde - que pressupõe eficácia e eficiência, com comprometimento daqueles que dela participam, garantindo a qualidade do cuidado e, principalmente, a satisfação do paciente e de seus familiares ${ }^{3}$.

0 paciente que apresenta dependência da assistência à saúde, como é o caso da pessoa internada em unidade de terapia intensiva (UTI), recorre aos cuidados de familiares e da equipe de saúde - onde os profissionais de enfermagem assumem destaque.

A UTI é um ambiente hospitalar destinado a casos graves, pacientes que apresentam quadro clínico recuperável ou não. Esse cenário envolve procedimentos invasivos e risco de morte, podendo mostrar-se hostil e desalentador. Trata-se de um local onde atuam profissionais das mais variadas áreas da saúde, principalmente os profissionais de enfermagem, responsáveis por grande parte das atividades do cuidado intensivo, como: a) realização de procedimentos; b) monitorização constante; c) uso de tecnologia aplicada à saúde etc. ${ }^{4}$.

Diante dessa atmosfera, criou-se a Política Nacional de Humanização (PNH), com o propósito de demonstrar que o Sistema Único de Saúde (SUS) está pronto para fazer frente aos desafios e problemas relativos à efetivação da $\mathrm{PNH}$, os quais têm sido enfaticamente relatados por profissionais da saúde que apontam falta de condições para alcançar os objetivos almejados. Ressalta-se, ainda, que a humanização da assistência abrange circunstâncias sociais, éticas, educacionais e psíquicas dos relacionamentos humanos, que têm origem no âmbito da família 5 .

A família constitui o pilar fundamental das sociedades - trata-se da base sobre a qual a maioria 
dos seres humanos constrói sua personalidade. Essa célula primária apresenta valor inalienável, como reconhece a Declaração Universal dos Direitos Humanos (DUDH), que atesta sua importância no desenvolvimento dos indivíduos. Por isso, é essencial definir e consolidar um caminho para integrar a família aos cuidados hospitalares ${ }^{6}$.

Tendo em vista o panorama apresentado, esta pesquisa buscou averiguar a satisfação dos familiares com a humanização da assistência em UTI.

\section{METODOLOGIA}

Trata-se de estudo exploratório descritivo, com abordagem qualitativa, realizado na UTI da Santa Casa de Misericórdia de Sobral (SCMS), hospital de referência no norte do Ceará. Os dados foram coletados em novembro de 2016, com 10 familiares de pacientes internados nessa UTI.

Os critérios de inclusão adotados foram: a) familiares com primeiro, segundo ou terceiro grau de parentesco; e b) em caso de constante ausência de familiares, cuidadores que visitavam os pacientes com frequência e que se apresentavam como responsáveis por eles. Já o critério de exclusão foi: familiares menores de 18 anos.

0 s dados foram coletados por meio de entrevista semiestruturada, recorrendo às seguintes perguntas norteadoras:

- Qual é a satisfação dos familiares com a humanização da assistência em UTI?

- Qual é o conhecimento dos familiares sobre humanização hospitalar?

- Quais são as sugestões dos familiares para melhorar a assistência à saúde?

Os dados foram submetidos à técnica de análise de conteúdo temática ${ }^{7}$, com as seguintes etapas: a) fase exploratória, na qual se amadurece o objeto de estudo e se delimita o problema de investigação; b) coleta de dados, em que se recolhem informações para fazer frente ao problema de pesquisa; e c) análise de dados, com tratamento, por inferência e interpretação, dos dados obtidos.

Esta pesquisa - aprovada pelo Comitê de Ética em Pesquisa da Universidade Estadual Vale do Acaraú (CEP/UVA), sob o Parecer n. 1810231/2016 - cumpriu todos os princípios éticos da Resolução do Conselho Nacional de Saúde (CNS) n. 466/2012, que dispõe sobre as diretrizes e normas regulamentadoras de pesquisas envolvendo seres humanos.

\section{RESULTADOS E DISCUSSÃO}

Após a coleta dos dados, as informações foram analisadas e classificadas em categorias, a saber: a) Caracterização dos participantes; b) Satisfação dos familiares com a prática assistencial; e c) Conhecimento dos familiares sobre humanização hospitalar.

\section{Caracterização dos participantes}

Participaram deste estudo 10 familiares de pacientes internados em UTI há 72 horas ou mais. Houve $40 \%$ de participantes do sexo masculino e $60 \%$ do sexo feminino. No sexo masculino, a idade variou dos 29 anos (50\%) aos 66 anos (25\%); já no sexo feminino, a idade foi dos 25 anos $(16,6 \%)$ aos 45 anos $(16,6 \%)$.

No tocante à procedência, há representação de diversas localidades do Ceará, com prevalência de municípios do norte do estado. Quanto ao grau de parentesco, a distribuição entre primeiro, segundo e terceiro graus é equivalente ( 1 filho; 2 primas; 3 irmãos; 1 mãe; 1 tio; 1 esposa; e 1 sobrinha).

No que concerne ao grau de escolaridade, $10 \%$ dos participantes eram analfabetos, 30\% tinham Ensino Fundamental incompleto, 30\% tinham Ensino Médio incompleto e $30 \%$ tinham Ensino Médio completo. Quanto à religião, $20 \%$ eram evangélicos e $80 \%$ eram católicos. Considerando a profissão, $20 \%$ eram agricultores, $20 \%$ eram do lar, $10 \%$ eram porteiros, $20 \%$ eram auxiliares de produção, $10 \%$ eram cabeleireiros, $10 \%$ eram cozinheiras e $10 \%$ eram diaristas.

Ter um familiar internado em UTI causa anseio por informações detalhadas e contato direto com o paciente, sendo necessário o deslocamento até - local, em busca de conforto e esperança; o que mais importa é ver o familiar, tocá-lo e saber como vai a assistência da equipe de saúde, uma vez que

\section{...é essencial definir e consolidar um caminho para integrar a família aos cuidados hospitalares...}


os cuidados são delegados a profissionais que lidam com uma situação de vulnerabilidade.

Nesse cenário, durante a visita, observa-se o envolvimento familiar no âmbito hospitalar. A internação de um parente tende a desestruturar a família e é necessário que todos contribuam para alcançar um objetivo comum: restabelecer a saúde desse ente querido. Nesse momento, os membros da família tendem a se sensibilizar e apoiar um ao outro - observa-se a organização familiar em meio a dor, sofrimento, aflição e angústia, dentre outros sentimentos vivenciados de modo diferente por cada indivíduo.

Diante do exposto, constata-se que tanto a família quanto o paciente vivenciam extrema vulnerabilidade, com reduzido contato entre parentes, deixando a assistência à saúde aos cuidados de uma equipe multidisciplinar intensivista.

Assim, é a família que recebe suporte material e psicológico tanto em situações de maior estresse quanto na alternância entre saúde/doença, alegria/ tristeza, esperança/desespero etc. ${ }^{6}$.

\section{Satisfação dos familiares com a assistência à saúde}

Durante a entrevista, percebeu-se a satisfação dos familiares diante da assistência à saúde - cuja qualidade relatam ser excelente ou boa.

As falas abaixo ilustram a satisfação dos familiares com a assistência à saúde:

No momento, para mim está excelente, né? Porque já tive notícia, pela primeira vez que estou vindo aqui, mas já estou tendo notícia que ele está bem melhor, que os médicos estão fazendo o que podem para salvar a vida dele, e isso para nós já é excelente, estamos tendo um bom retorno aqui do hospital, isso já é o suficiente, um bom atendimento. (Familiar 01)

É um bom atendimento, né? A assistência que a gente recebeu é tudo que a gente precisa e é nesses momentos que a gente aprende cada vez mais que precisa um do outro. (Familiar 05)

Ao discorrer sobre a assistência à saúde, os familiares mencionam o médico com frequência, apresentando-o como principal integrante da equipe de saúde e responsável pela recuperação do

\section{...o único momento reservado ao contato dos familiares com os pacientes é o limitado per iodo de visita...}

paciente. As falas evidenciam que a enfermagem fica esquecida, apesar de sua crucial contribuição para o sucesso do tratamento e da recuperação do paciente; isso se deve à falta de diálogo aberto entre os profissionais de enfermagem e a família, que esquece de mencioná-los em suas falas por desconhecer o papel dessa categoria na assistência à saúde.

Tal fato reforça a necessidade de ações de educação em saúde, de modo que as informações pertinentes sejam oferecidas pelos profissionais no momento da visita, de forma clara e de fácil compreensão, o que requer dos profissionais da saúde habilidade de comunicação e compreensão da relação terapêutica no contato entre paciente, família e equipe de saúde.

Diante disso, percebe-se a necessidade e importância de avaliar a eficácia e eficiência da assistência à saúde junto com os usuários. A partir dessa avaliação, pode-se planejar mudanças nos procedimentos e nas condutas tanto da gerência do serviço como na equipe operacional - as atitudes são fatores que contribuem para a humanização da assistência tanto por parte dos profissionais da saúde quanto dos familiares que visitam seu ente querido. A enfermagem, categoria eminentemente cuidadora, é responsável por promover autonomia, equilíbrio, tranquilidade e bem-estar entre os pacientes e os demais usuários dos serviços disponíveis.

Assim, o único momento reservado ao contato dos familiares com os pacientes é o limitado período de visita - e é aí que os familiares "despejam" seus anseios e suas emoções, suas dúvidas quanto à doença, suas preocupações e reflexões sobre 0 impacto da internação nos papéis sociais. Em virtude disso, as informações fornecidas pelos profissionais da saúde no período de visita, geralmente por parte de médicos e enfermeiros, devem ser claras e empáticas ${ }^{8}$. 
Nesse contexto, a satisfação dos familiares é vital na avaliação da qualidade da assistência à saúde identificá-la é uma responsabilidade essencial dos profissionais que atuam em UTI ${ }^{9}$.

Nessa perspectiva, vale salientar que a comunicação é a pedra de toque na relação entre enfermeiro e usuário estabelecida na prática assistencial. Vivenciar a internação de um parente em UTI requer dos familiares a capacidade de compreender seus próprios sentimentos e elaborar estratégias para o enfrentamento do problema. Nesse momento se observa a necessidade do acolhimento, de repassar informações aos familiares confortandoos durante o horário de visita ${ }^{8}$.

\section{Conhecimento dos familiares sobre humanização hospitalar}

A humanização da assistência visa a garantir a autonomia e dignidade do paciente, assim, os profissionais da saúde o tratam com respeito, carinho e amor, respeitando seus limites, oferecendo orientações sobre sua patologia e os procedimentos adotados e cuidando não só da doença, mas da pessoa - o que demanda um olhar diferenciado.

Tal aspecto é evidenciado nessa categoria, como ilustram as seguintes falas dos familiares:

Não sei bem o foco, mas eu acho, assim, que pode ser a questão do atendimento, atenção, cuidado, eles são muito caridosos, fazem o que podem para controlar os familiares. (Familiar 02)

Pra mim, ali dentro está superlimpo eles estão cuidando do meu irmão, o que eu entendo é isso. (Familiar 03)

Para falar a verdade, eu não entendo quase nada, apesar de saber que é muito importante, mas eu não entendo quase nada, dificilmente tem alguém meu no hospital. (Familiar 05)

No tocante à categoria Conhecimento dos familiares sobre humanização hospitalar, ressalta-se que esse processo se relaciona a uma forma peculiar no trato com o ser humano. Nos hospitais públicos, esse processo se mostra ainda mais necessário, tendo em vista a necessidade dos usuários do SUS e as precariedades vivenciadas por eles ${ }^{10}$.

Nessa categoria, constata-se deficiência de conhecimento sobre humanização hospitalar

\section{humanização hospitalar, ressalta-se que esse processo se relaciona a uma forma peculiar no trato com o ser humano.}

entre os familiares, um aspecto importante que eles associam a caridade, cordialidade, bom atendimento, acolhimento e cuidado ao paciente, ressaltando, ainda, a limpeza do local. Nesse momento, faz-se necessário trabalhar a humanização entre profissionais, pacientes e familiares, para que possam conhecer o que a $\mathrm{PNH}$ propõe para as unidades hospitalares em benefício do paciente e/ ou familiar.

Nesse contexto, vale salientar a gestão participativa ou cogestão, proposta pela $\mathrm{PNH}$, na qual trabalhadores e usuários dos serviços de saúde são incluídos e valorizados no processo saúdedoença - com mudança da cultura de atenção aos usuários e dos processos de trabalho ${ }^{11}$.

Em virtude do desconhecimento sobre a humanização hospitalar evidenciado nas falas dos participantes deste estudo, constatou-se a necessidade de socializá-la, recorrendo a informações nos meios de comunicação, nas instituições de Ensino Superior, nas instituições hospitalares, nos serviços de saúde e nas comunidades em geral.

\section{CONCLUSÃO}

Diante da discussão desenvolvida, constatou-se satisfação com a humanização da assistência à saúde em UTI; os participantes relacionaram esse processo a ações bem realizadas, comunicação eficiente, apoio mútuo e trabalho em equipe. Eles relataram ter pouco conhecimento sobre humanização hospitalar, mas a associam a aspectos como ser caridoso(a), receber o outro com cordialidade e atenção, tratálo bem e prestar assistência à saúde com foco na eficácia e eficiência. Tudo isso ruma ao encontro da humanização hospitalar. Assim, as falas dos familiares de pacientes internados em UTI rumam ao encontro da humanização hospitalar em nosso meio.

Percebe-se a necessidade de maior envolvimento das equipes de enfermagem com os familiares, 
apresentando-se com frequência e discorrendo sobre suas funções com clareza no próprio ambiente de trabalho, visto que os familiares de pacientes internados em UTI não conseguem identificar os cuidados de enfermagem de modo espontâneo nesse cenário. As equipes de enfermagem podem aprimorar a visão global da população que busca os serviços de saúde por meio de novos comportamentos, novas atitudes e de uma postura ativa - pode-se dizer que a comunicação é fundamental para aumentar a qualidade dos serviços de saúde, com base em princípios, que envolvem a própria percepção dos aspectos envolvidos no processo saúde-doença.

Portanto, os familiares se mostram satisfeitos com a humanização da assistência em UTI, mas carecem de educação em saúde para compreender plenamente a humanização hospitalar. Isso exige que os profissionais da saúde saibam tanto lidar com a variedade de tarefas de seu trabalho cotidiano como gerir a comunicação com os familiares de pacientes hospitalizados.

\section{CONTRIBUIÇÃO DAS AUTORAS}

Elisângela de Jesus Macêdo Araújo contribuiu com a realização da pesquisa e o delineamento e a redação do manuscrito. Keila Maria de Azevedo Ponte e Lívia Mara de Araújo contribuíram com a redação do manuscrito. Maria Sinara Farias contribuiu com a revisão crítica do manuscrito.

\section{REFERÊNCIAS}

1. Duarte NE, Ferreira MA, Lisboa MTL. A dimensão prática do cuidado de enfermagem: representações sociais de acadêmicos de enfermagem. Esc Anna Nery Rev Enferm [serial on the internet]. 2012 [cited 2016 Feb 22];16(2):227-33. Available from: http:// www.scielo.br/pdf/ean/v16n2/03.pdf

2. Nascimento WSM, Silva LCC, Dias MSA, Brito MCC, Oliveira Neto JG. Cuidado da equipe de enfermagem na emergência pediátrica: revisão integrativa. Sanare (Sobral, Online) [serial on the internet]. 2017 [cited 2019 May 8];16(1):90-9. Available from: file:///D:/1099-2654-1-SM.pdf

3. Barbosa LR, Melo MRAC. Relações entre qualidade da assistência de enfermagem: revisão integrativa da literatura. Rev Bras Enferm [serial on the internet]. 2008 [cited 2016 Dec 8];61(3):366-70. Available from: http://www.scielo.br/pdf/reben/ $\underline{v 61 n 3 / a 15 v 61 n 3 . p d f}$
4. Camponogara $S$, Santos TM, Seiffert MA, Alves CN. 0 cuidado humanizado em unidade de terapia intensiva: uma revisão bibliografica. Rev Enferm UFSM [serial on the internet]. 2011 [cited 2016 Feb 23];1(1):124-32. Available from: https://periodicos. ufsm.br/reufsm/article/view/2237/1520

5. Brasil. Formação e intervenção. Brasília (DF): Ministério da Saúde; 2010. (Cadernos Humaniza SUS, Série B, v. 1).

6. Martins MM, Fernandes CS, Gonçalves LHT. A família como foco dos cuidados de enfermagem em meio hospitalar: um programa educativo. Rev Bras Enferm [serial on the internet]. 2012 [cited 2016 Nov 29];65(4):685-90. Available from: http://www. scielo.br/pdf/reben/v65n4/a20v65n4.pdf

7. Minayo MCS. Pesquisa social: teoria, método e criatividade. 29. ed. Petrópolis (RJ): Vozes; 2010. (Coleção Temas Sociais).

8. Félix TA, Ferreira FV, Oliveira EN, Eloia SC, Gomes BV, Eloia SMC. Prática da humanização na visita em unidade de terapia intensiva. Revista Enfermagem Contemporânea [serial on the internet]. 2014 [cited 2019 May 22];3(2):143-53. Available from: https:// www5.bahiana.edu.br/index.php/enfermagem/ article/view/381/342

9. Pelazza BB, Simoni RCM, Freitas EGB, Silva $B R$, Silva MJP. Visita de enfermagem e dúvidas manifestadas pela família em unidade de terapia intensiva. Acta Paul Enferm [serial on the internet]. 2015 [cited 2016 Nov 23];28(1):60-5. Available from: http://www.scielo.br/pdf/ape/v28n1/19820194-ape-028-001-0060.pdf

10. Ribeiro HSI, Silveira MGCC. Humanização hospitalar no Sistema Único de Saúde. Revista Interdisciplinar Ciências e Saúde [serial on the internet]. 2015 [cited 2016 Nov 23];2(3):19-24. Available from: http://www.ojs.ufpi.br/index.php/ rics/article/view/2040/2316

11. Chernicharo IM, Silva FD, Ferreira MA. Caracterização do termo humanização na assistência por profissionais de enfermagem. Esc Anna Nery Rev Enferm [serial on the internet]. 2014 [cited 2016 Nov 23];18(1):156-62, Available from: http://www.scielo.br/pdf/ean/v18n1/1414-8145ean-18-01-0156.pdf
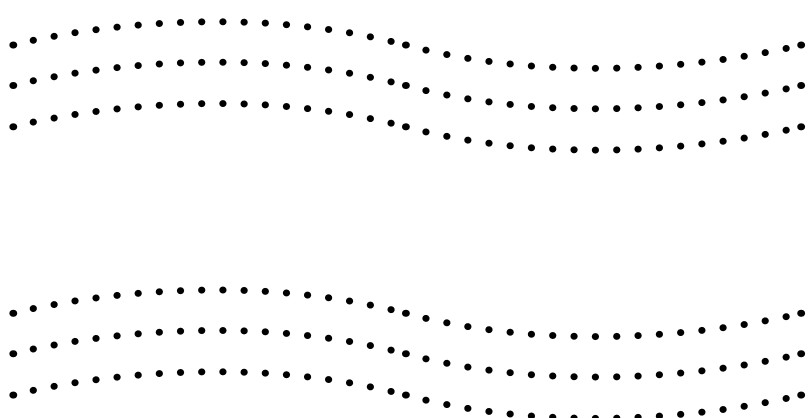


\section{ANÁLISE DA DEMANDA FONOAUDIOLÓGICA DE UM HOSPITAL DE REFERENNCIA EM CARDIOPNEUMOLOGIA}

ANALYSIS OF THE SPEECH THERAPY NEEDS IN A REFERRAL HOSPITAL IN CARDIOPNEUMOLOGY

ANÁLISIS DE LA DEMANDA FONOAUDIOLÓGICA EN UN HOSPITAL DE REFERENCIA EN CARDIONEUMOLOGÍA

Bruna Rafaelle Pereira Ibiapina Coelho ${ }^{1}$ Luana Pereira Ibiapina Coelho 2

Elizabeth Zayra Torres Sousa ${ }^{3}$

Ana Virgínia Sales Monte Costa 4

Antonio Tiago da Silva Souza ${ }^{5}$

Camila Fernandes Mendes 6

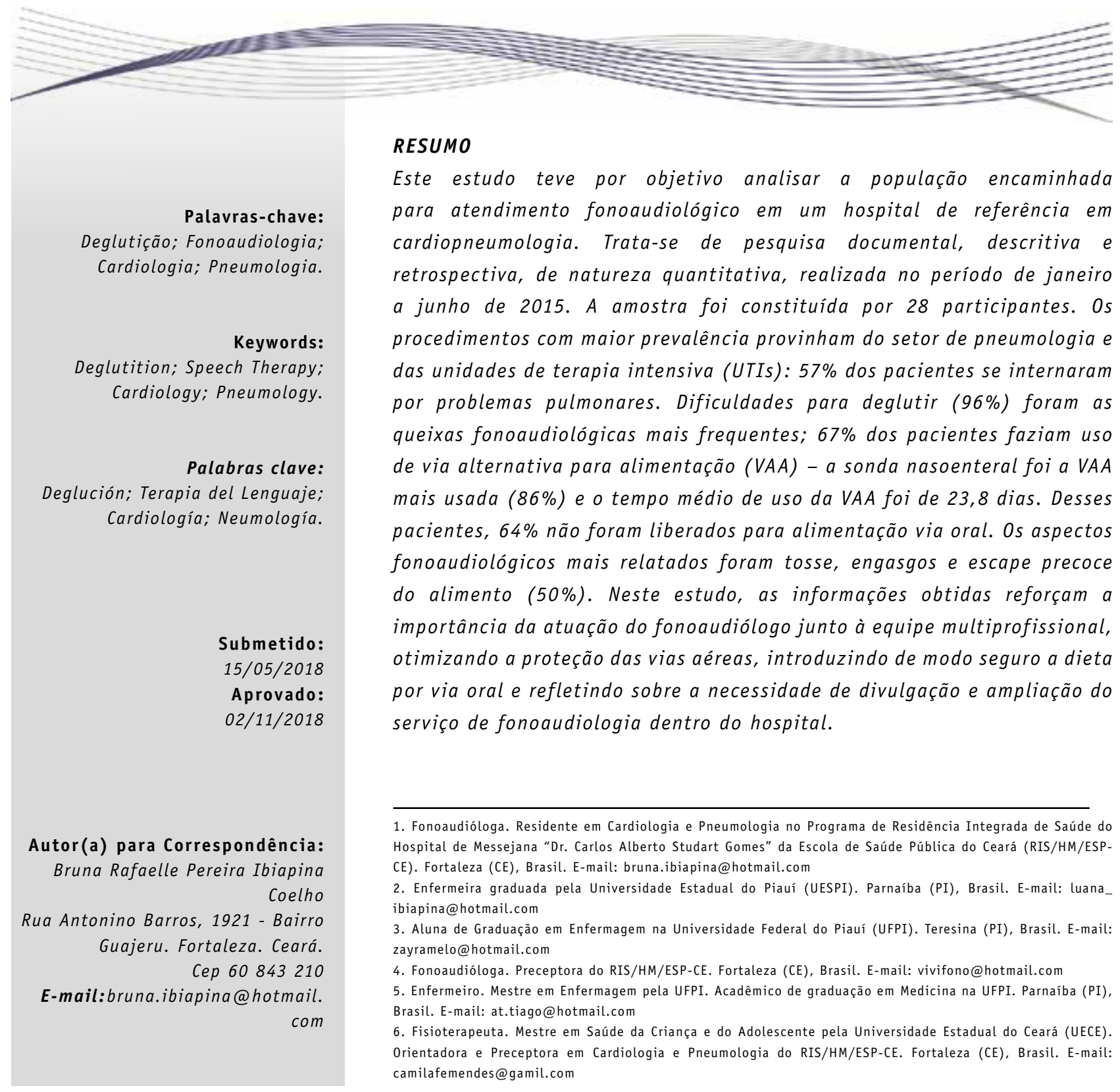

12 - SANARE, Sobral - V.18 n.01,p.12-21, Jan./Jun. - 2019 


\section{ABSTRACT}

This study aimed to analyze the population seeking speech therapy in a referral hospital in cardiopneumology. This is a documentary, descriptive, and retrospective research, of a quantitative nature, carried out within the period from January to June 2015. The sample consisted of 28 participants. The most prevalent procedures took place in the pulmonology sector and the intensive care units (ICUs): 57\% of the patients were hospitalized for lung issues. Difficulties in swallowing (96\%) were the most frequent speech therapy complaints; $67 \%$ of the patients used an alternative route for feeding (ARF) - the nasoenteral tube was the most used ARF ( $86 \%$ ) and the mean time of ARF use was 23.8 days. Out of these patients, $64 \%$ were not allowed to have oral feeding. The most commonly reported speech therapy issues were coughing, choking, and early food escape (50\%). In this study, the information obtained reinforces the importance of the speech therapist's work along with the multiprofessional team, increasing airway protection, safely introducing the oral diet, and thinking through the need to disseminate and expand the speech therapy services within the hospital.

\section{RESUMEN}

Este estudio tuvo como objetivo analizar la población que buscaba terapia del lenguaje en un hospital de referencia en cardioneumología. Se trata de una investigación documental, descriptiva y retrospectiva, de carácter cuantitativo, realizada en el período comprendido entre enero y junio de 2015. La muestra estuvo compuesta por 28 participantes. Los procedimientos más prevalentes se realizaron en el sector de neumología y en las unidades de cuidados intensivos (UCIS): el 57\% de los pacientes fueron hospitalizados por problemas pulmonares. Las dificultades para tragar (96\%) fueron las quejas más frecuentes en la terapia del lenguaje; el 67\% de los pacientes utilizaron una ruta alternativa para la alimentación (RAA) - el tubo nasoenteral fue la RAA más utilizada (86\%) y el tiempo medio de uso de la RAA fue de 23,8 días. De estos pacientes, al 64\% no se les permitió recibir alimentación oral. Los aspectos de terapia del lenguaje más comúnmente informados fueron la tos, la estrangulación y el escape prematuro del alimento (50\%). En este estudio, la información obtenida refuerza la importancia del trabajo del terapeuta del lenguaje junto con el equipo multiprofesional, aumentando la protección de las vías respiratorias, introduciendo de manera segura la dieta oral y pensando en la necesidad de difundir y ampliar los servicios de terapia del lenguaje dentro del hospital.

\section{INTRODUÇÃ 0}

As doenças cardiovasculares contribuem significativamente como grupo causal de mortalidade em todas as regiões do Brasil. Em 2000, essas doenças foram responsáveis pela principal alocação de recursos públicos em hospitalizações no país e foram a terceira causa de permanência hospitalar prolongada. Entre 1991 e 2000, os custos hospitalares atribuídos a elas aumentaram $176 \%{ }^{1}$.

As doenças cardiovasculares apresentam alta prevalência e complicações associadas, como o acidente cerebrovascular encefálico (ACE), a insuficiência cardíaca (IC) e o infarto agudo do miocárdio. Tais doenças têm considerável impacto na morbimortalidade das populações e são as principais causas de óbito no Brasil há algumas décadas².

$\mathrm{Na}$ vigência do pós-operatório das cirurgias cardíacas de alguns pacientes, estudos vêm alertando sobre a presença de distúrbios da deglutição, devido ao fato de eles se submeterem a procedimentos como intubação orotraqueal (IOT), ventilação mecânica (VM), circulação extracorpórea (CEC), traqueostomia (TQT) e ecocardiograma transesofágico transoperatório (ETT), que podem ocasionar alterações na dinâmica da deglutição ${ }^{3}$.

Segundo a Organização Mundial da Saúde (OMS), entende-se por doenças respiratórias crônicas as enfermidades crônicas de vias aéreas e de outras estruturas dos pulmões. Dentre as mais comuns se encontram a asma, a doença pulmonar obstrutiva crônica (DPOC), as doenças respiratórias alérgicas, as moléstias pulmonares ocupacionais e a hipertensão pulmonar4.

A DPOC vem tendo grande destaque no meio médico nos últimos anos, tendo em vista a tomada de consciência de sua importância como fator de morbimortalidade. No Brasil, ela já ocupa a $5^{\text {a }}$ posição entre as causas de óbito e envolve a internação de 290 mil pacientes anualmente, trazendo enorme gasto ao sistema de saúde do país ${ }^{5,6}$.

As complicações pulmonares pós-operatórios (CPPO) ocorrem em $25 \%$ a $50 \%$ dos procedimentos cirúrgicos de grande porte. A ocorrência de CPPO está 
ligada à existência dos fatores de risco descritos na literatura, tais como: a) idade avançada (> 60 anos); b) presença de doença pulmonar prévia, como DPOC ou outras comorbidades; c) classificação da American Society of Anesthesiologists (ASA) maior ou igual a II; d) tabagismo ativo; e) obesidade; f) desnutrição; g) tipo de anestesia; h) tempo de cirurgia ( $>3$ horas); i) tipo de cirurgia; j) valores espirométricos anormais; k) capacidade diminuída ao exercício; e l) tempo de internação pré-operatória prolongado ${ }^{7}$.

Pacientes com DPOC tendem a interromper sua respiração durante a deglutição, retomando-a na fase inspiratória e podendo, assim, aumentar o risco para aspiração. Em um estudo realizado com 14 pacientes com DPOC, relatou-se que os participantes apresentaram redução da habilidade de limpeza laríngea e de proteção da via aérea, resultando em aumento do risco para aspiração. Em outro estudo, relatou-se que pacientes com DPOC apresentavam alterações no reflexo de deglutição, sendo tal alteração sugestiva de fator de risco para a exacerbação da doença ${ }^{8}$.

Pacientes com doenças crônicas pulmonares podem ser suscetíveis a apresentar alteração na coordenação entre deglutição e respiração, devido a alterações funcionais ventilatórias ${ }^{9}$.

A fonoaudiologia hospitalar atua com o paciente ainda no leito, em caráter precoce, preventivo, intensivo, pré e pós-cirúrgico, proporcionando respaldo técnico e prático à equipe interdisciplinar em que atua ao esclarecer que seu maior objetivo é impedir ou diminuir as sequelas que a patologiabase possa deixar ${ }^{10}$.

A efetividade da intervenção fonoaudiológica tem sido demonstrada por meio de estudos, com associação entre menor tempo de internação hospitalar e realização do trabalho fonoaudiológico. Mesmo com pesquisas que mostram os benefícios dessa intervenção, muitos serviços não dispõem dessa prática, tampouco realizam encaminhamento dessa população de risco para acompanhamento fonoaudiológico precoce ${ }^{11,12}$.

0 objetivo da reabilitação no atendimento a pacientes com distúrbios da deglutição consiste na estabilização do estado nutricional e na eliminação dos riscos de complicações clínicas decorrentes da aspiração laringotraqueal ${ }^{13}$.

A deglutição tem como função fundamental a propulsão do alimento da boca para o estômago. É um processo contínuo no qual todos os músculos

\section{A disfagia (...) causa alto indice de morbimortalidade.}

relacionados com a cavidade oral entram em açã $0^{11}$. A deglutição se divide em três fases: a) oral; b) faríngea; e c) esofágica ${ }^{14,15}$.

A disfagia é um prejuízo no funcionamento de qualquer fase da deglutição. A coordenação entre deglutição e respiração se mostra essencial para prevenir a aspiração pulmonar e para manter a nutrição e a hidratação adequadas ${ }^{7}$.

Do ponto de vista etiológico, as disfagias podem ser divididas em: a) neurogênicas, quando causadas por alguma afecção no sistema nervoso central e/ou periférico; e b) mecânicas, quando desencadeadas por alterações anatômicas de qualquer origem. Quanto à gravidade, podem ser classificadas em leves, moderadas e severas ${ }^{14}$.

Pacientes com disfagia aumentam os custos de internação, prolongam seu tempo de internação e expõem-se ao risco de desnutrição, desidratação e complicações pulmonares, devido à broncoaspiração. A disfagia é considerada por vários autores um problema de saúde pública, uma vez que afeta grande parte da população e causa alto índice de morbimortalidade ${ }^{15}$.

A aspiração pulmonar pode ser fatal e a má nutrição pode ocorrer quando a alteração não é diagnosticada de modo correto, reduzindo a imunidade do paciente e deixando-o mais suscetível a contrair doenças ${ }^{13}$.

À medida que seu campo de atuação se amplia, novas especialidades surgem na área - uma das mais recentes é a disfagia, regulamentada pela Resolução do Conselho Federal de Fonoaudiologia (CFFa) $n$. 356, de 6 de dezembro de 2008, que “dispõe sobre a competência técnica e legal do fonoaudiólogo para atuar nas disfagias orofaríngeas". Denomina-se disfagia o distúrbio de deglutição que acomete todo o trato digestivo, que vai da boca até o estômago ou parte deste ${ }^{14}$.

Caracterizar o público que evolui com necessidade de acompanhamento fonoaudiológico se mostra importante para evidenciar os indivíduos que têm avançado comprometimento da deglutição.

Assim, esta pesquisa teve como finalidade 
analisar a população encaminhada para atendimento fonoaudiológico em um hospital de referência em cardiopneumologia. Secundariamente, objetivou-se relatar a procedência dos encaminhamentos, especificar a queixa fonoaudiológica e descrever os aspectos fonoaudiológicos identificados no período da solicitação do parecer fonoaudiológico.

\section{MÉTODOS}

Estudo documental, descritivo e retrospectivo, de natureza quantitativa, realizado por meio da análise de prontuários de pacientes com solicitação de parecer fonoaudiológico no período de janeiro a junho de 2015.

Foram coletados dados referentes a sexo, idade, procedimentos dos encaminhamentos (por unidade, setor e profissional solicitante), motivo da internação, se realizou procedimento cirúrgico, tempo de espera por atendimento fonoaudiológico, queixa fonoaudiológica, tempo e via alternativa para alimentação (VAA) utilizada, se for liberada alimentação via oral, aspectos fonoaudiológicos, uso de oxigenoterapia e tipo de via aérea artificial.

As informações foram registradas em um instrumento para coleta de dados desenvolvido no âmbito desta pesquisa. Excluíram-se os pacientes cujos prontuários não foram localizados ou estavam incompletos quanto às variáveis adotadas pelo estudo. Assim, dos 59 indivíduos identificados inicialmente, 28 foram selecionados para compor a amostra.

Os dados foram armazenados no software estatístico Microsoft Excel 2013, versão 15.0, sendo posteriormente consolidados para apresentação por médias e frequências.

Esta pesquisa foi aprovada pelo Comitê de Ética em Pesquisa do Hospital de Messejana "Dr. Carlos Alberto Studart Gomes" da Escola de Saúde Pública do Ceará (HM/ESP-CE), sob o Parecer n. 1.418.093/2016.

\section{RESULTADOS}

Dos 28 participantes da pesquisa, $64 \%$ eram do gênero masculino. Quanto à faixa etária, predominaram pacientes idosos (65 anos em média). Desses sujeitos, $82 \%$ procediam de Fortaleza-CE.

A maior parte dos pareceres fonoaudiológicos era solicitada do setor de pneumologia, como se observa na Figura 1.

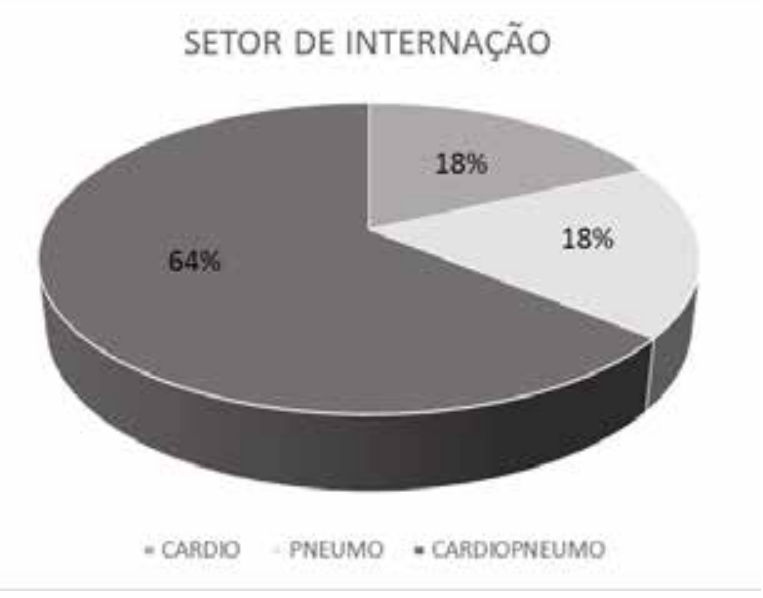

Figura 1. Solicitação de parecer fonoaudiológico por setor de internação $(n=28)$. Fortaleza, 2015.

Fonte: Elaborada pelos autores.

Em relação à distribuição dos pareceres fonoaudiológicos por unidades, $57 \%$ provieram das unidades de terapia intensiva (UTIs); $39 \%$ das enfermarias; e $4 \%$ do setor de emergência.

Quanto ao motivo de internação, verificou-se que $84 \%$ dos pacientes se internaram por problemas respiratórios e $16 \%$ por problemas cardíacos. Dos pacientes analisados, $57 \%$ realizaram algum tipo de procedimento cirúrgico.

0 tempo de espera para atendimento fonoaudiológico foi subdividido em dias: $71 \%$ dos pacientes foram avaliados em menos de 24 horas, $14 \%$ esperaram de 1 a 3 dias e $14 \%$ aguardaram mais de 3 dias. Dentre os profissionais que mais solicitaram parecer fonoaudiológico se destacam os médicos $(93 \%)$ e os nutricionistas (7\%).

As queixas fonoaudiológicas mais frequentes foram dificuldades para deglutir (96\%), relatadas pelos profissionais ao solicitarem parecer, como ilustra a Figura 2.

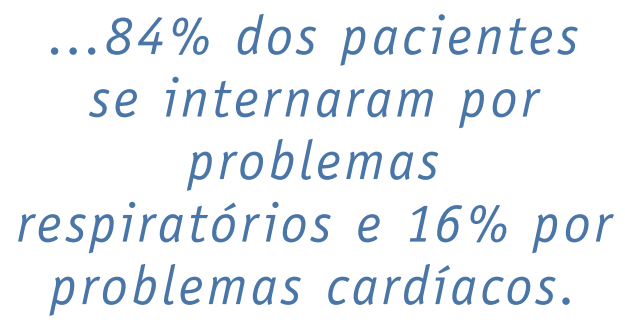




\section{QUEIXA FONOAUDIOLÓGICA}

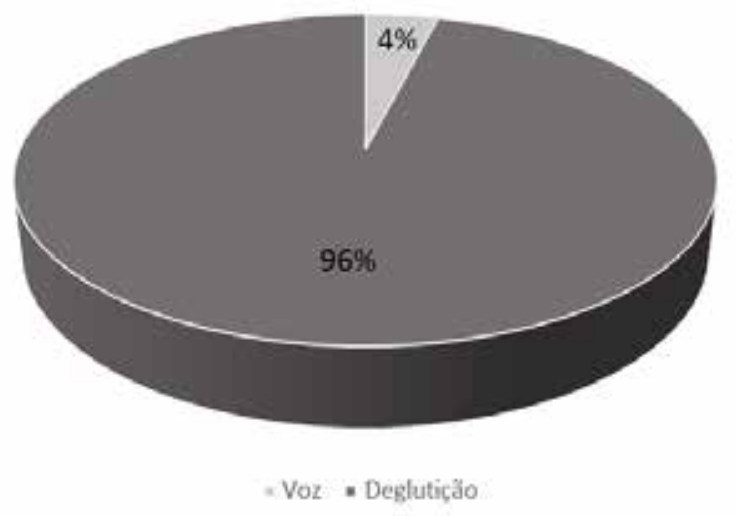

Figura 2. Principais queixas fonoaudiológicas no parecer fonoaudiológico $(n=28)$. Fortaleza, 2015. Fonte: Elaborada pelos autores.

No tocante às VAAs, $68 \%$ dos pacientes faziam uso desse recurso. A sonda nasoenteral (SNE) foi a VAA mais prevalente (57\%) - como mostra a Figura 3. 0 tempo médio de uso da VAA foi de 23,8 dias.

\section{Via Alternativa de Alimentação}

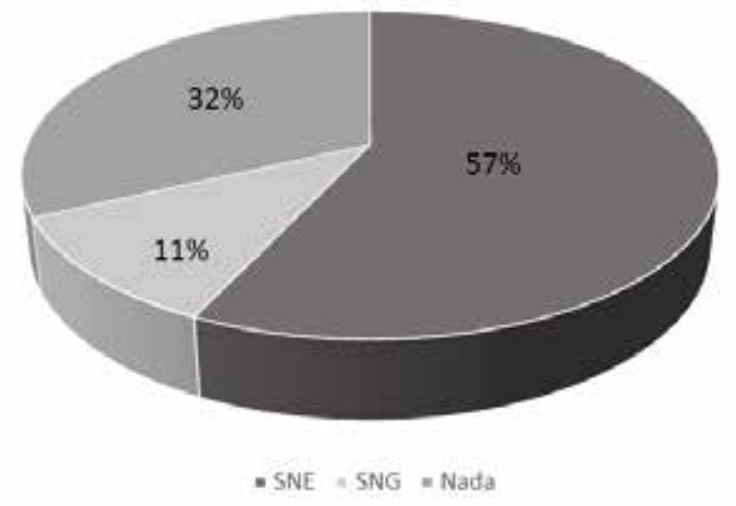

Figura 3. Distribuição da via alternativa utilizada no momento da avaliação $(n=28)$. Fortaleza, 2015. Fonte: Elaborada pelos autores.

Como mostra a Figura 4, 64\% dos pacientes analisados não foram liberados para alimentação via oral.

\section{Liberação de Alimentação por Via Oral}

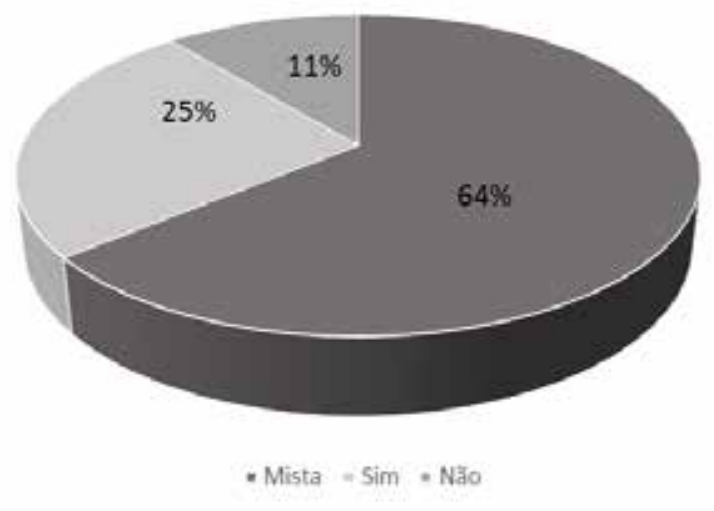

Figura 4. Distribuição quanto à liberação para alimentação via oral $(n=28)$. Fortaleza, 2015. Fonte: Elaborada pelos autores.

Dos pacientes avaliados, $61 \%$ faziam uso de oxigenoterapia, $36 \%$ deles por meio de cateter $0_{2}$, $18 \%$ em VM e $7 \%$ em ventilação não invasiva.

Quanto aos aspectos fonoaudiológicos mais descritos na avaliação, identificou-se tosse, engasgos e escape precoce do alimento, observados em $50 \%$ dos pacientes (Figura 5).

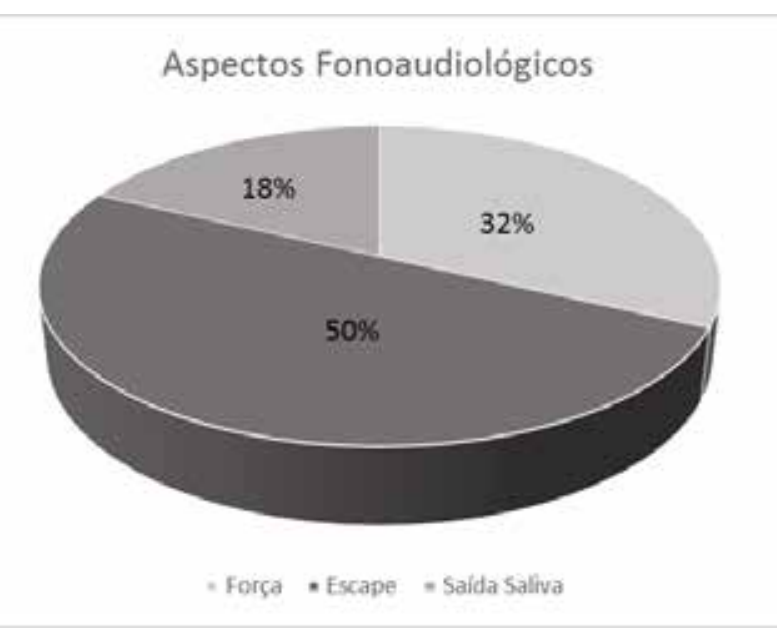

Figura 5. Distribuição quanto aos principais aspectos fonoaudiológicos na avaliação $(n=28)$. Fortaleza, 2015.

Fonte: Elaborada pelos autores.

\section{DISCUSSÃ 0}

Neste estudo, por meio do levantamento de prontuários, traçou-se uma análise da demanda fonoaudiológica em um hospital de referência em cardiopneumologia no período de janeiro a junho de 2015. 0 fato do número de atendimentos ter 
sido reduzido nesse intervalo pode justificar-se pelo desconhecimento dos profissionais acerca da existência do serviço de fonoaudiologia no hospital em estudo.

Aspectos como escolaridade, ocupação e estado civil não constam nos registros dos prontuários, mostrando-se impossivel uma análise criteriosa deles. Outro entrave durante a coleta de dados foi a dificuldade de localizar os prontuários dos pacientes selecionados.

No que diz respeito à análise da demanda, houve predomínio do sexo masculino. Segundo a Política Nacional de Atenção Integral à Saúde do Homem, observa-se que os sujeitos do sexo masculino são mais vulneráveis a doenças, sobretudo no que se refere a enfermidades graves e crônicas; nesse âmbito, a doença é considerada sinal de fragilidade, medo, dificuldade de acesso aos serviços sociais etc., por isso os homens não se preocupam tanto com sua própria saúde ${ }^{16}$.

Quanto à idade, houve maior incidência da população idosa (65 anos em média). Isso ocorre devido à sua maior suscetibilidade fisiológica e imunológica, particularmente às infecções, contribuindo para a redução de sua capacidade física e biológica ${ }^{17}$.

Esta pesquisa evidenciou prevalência de pacientes que moram na capital, porém, indivíduos que residem em outras cidades também são atendidos no hospital, possivelmente devido à carência do atendimento na rede pública de saúde de seus municípios ${ }^{18}$.

As demandas por serviços de saúde resultam da conjugação de fatores sociais, individuais e culturais prevalentes na população. A oferta está relacionada à disponibilidade, ao tipo e à quantidade de serviços e recursos destinados à atençã ${ }^{19}$.

0 motivo de internação com maior prevalência foi de paciente com problemas respiratórios, sendo o setor de pneumologia o que mais demandou atendimento fonoaudiológico. No entanto, notase que, para a população com 60 anos ou mais, esse indicador se apresenta mais elevado para internações por doenças respiratórias de pacientes do sexo masculino; acrescenta-se, ainda, que as hospitalizações por doenças respiratórias têm sido responsáveis, nos últimos anos, por $10 \%$ ou $11 \%$ do total de internações da população acima de 60 anos no Estado de São Paulo ${ }^{17}$.

As alterações no padrão respiratório e/ou ventilatório podem influenciar a coordenação entre deglutição e respiração, sendo que a sincronia entre

\section{A avaliação fonoaudiológica na UTI é indicada especialmente para pacientes \\ com suspeita de disfagia...}

elas é essencial para a proteção adequada de via aérea inferior. Portanto, pacientes com dificuldades respiratórias representam um grupo de risco expressivo para disfagia ${ }^{20}$.

0 fato das chances estatísticas de pacientes portadores de IC estarem no grupo de risco para disfagia se deve à dificuldade respiratória ser um dos sintomas mais comuns da IC, sendo esta a causadora de exacerbação respiratória e, por esse motivo, ela altera/descoordena os mecanismos de deglutição do paciente, principalmente no momento da pausa apneica ${ }^{15}$.

Houve maior número de pareceres para pacientes internados em UTIs. A avaliação fonoaudiológica na UTI é indicada especialmente para pacientes com suspeita de disfagia, considerando o ACE, a IOT prolongada e a TQT os principais fatores de risco, visando a identificar as possíveis alterações funcionais que interferem nas fases oral e faríngea da deglutição ${ }^{21}$.

Em estudos já realizados 22 se observa que houve aumento do número de fonoaudiólogos nas unidades de urgência e emergência no período analisado, sendo que, em 2005, dos 9.610 fonoaudiólogos atuantes nos estados brasileiros, 38 estavam alocados em unidades de urgência e emergência; em 2011, eles passaram para 69 , concentrados principalmente na região Sudeste, porém, uma quantidade insuficiente para atender à demanda existente no país.

Dos pacientes que passaram por algum procedimento cirúrgico, $57 \%$ foram avaliados pelo fonoaudiólogo. 0 tempo médio de espera para 0 atendimento dessa especialidade foi de $1 \mathrm{dia}$, sendo que $71 \%$ dos pacientes foram avaliados em menos de 24 horas após a solicitação.

Quanto à origem dos encaminhamentos, os médicos são os que mais realizam. 0 índice de encaminhamentos médicos talvez se justifique pelo fato de serem os profissionais que sabem o melhor momento do paciente para uma possível solicitação 
de avaliação especializada ${ }^{23}$.

A dificuldade de deglutir (96\%) foi a principal queixa fonoaudiológica relatada pelos profissionais quando solicitado parecer, em seguida aparecem as alterações vocais, especificamente a rouquidão, com apenas $4 \%$. 0 s resultados verificados neste estudo evidenciaram que a amostra foi constituída por idosos, população na qual o efeito do envelhecimento no processo de deglutição, associado a alterações da saúde, tornam o mecanismo mais vulnerável a distúrbios como a disfagia ${ }^{24}$.

Pacientes submetidos a cirurgias consideradas de grande porte podem apresentar inúmeras complicações, entre elas as de causa respiratória, que culminam com a necessidade de cuidados intensivos, bem como suporte ventilatório por tempo prolongado, isso pode acarretar alterações vocais ${ }^{25}$.

Entretanto, um dos sintomas mais frequentes apresentados pelos pacientes no periodo pósoperatório é a rouquidão, que pode estar presente em $14,4 \%$ a $50 \%$ dos pacientes submetidos a intubação orotraqueal. Esse sintoma, na maioria das vezes, é temporário, durando de 2 a 3 dias $^{26}$.

Em alguns estudos ${ }^{24}$ se observou que as vias de alimentação mais prevalentes foram sonda nasogástrica (SNG) $(82,53 \%)$ e a SNE $(11,79 \%)$. 0 que se contrapõe aos dados obtidos neste estudo, onde prevaleceu o maior número de pacientes usando SNE $(86 \%)$. Possivelmente por serem as vias mais comuns em quadros de distúrbios da deglutição crônicos e/ ou irreversíveis da amostra estudada.

0 s autores concluíram em suas pesquisas que 0 uso de VAA em pacientes sugere que parte dessa população seja disfágica ou apresente riscos para 0 desenvolvimento desse distúrbio ${ }^{24}$.

0 tempo médio de utilização da VAA da população em estudo foi de 23,8 dias. Estudos mostram ${ }^{27}$ que a média do tempo de uso de VAA, até a data do primeiro exame, foi de 16,4 dias.

Desse modo, pesquisadores ${ }^{28}$ relatam que 0 maior tempo de internação, aparentemente, tem uma relação direta com a necessidade de VAA, ou seja, quanto maior o tempo de internação, maior é a necessidade de VAA. Além disso, a patologia de base também influencia isso.

Neste estudo, houve prevalência no número de pacientes que não foram liberados da alimentação por via oral. A frequência foi semelhante à identificada em outro estudo ${ }^{29}$, onde foram avaliados todos os pacientes que deram entrada em hospital universitário de referência no período de um ano,

\section{...um dos sintomas \\ mais frequentes \\ apresentados pelos \\ pacientes no período \\ pósoperatório é a rouquidão...}

com análise objetiva da deglutição (61 pacientes). Foi observada incidência de disfagia em $76,5 \%$ dos pacientes avaliados.

Em estudo retrospectivo, realizado em um hospital geral, registrou-se a incidência de disfagia em 100 pacientes admitidos em período de 6 meses e determinou-se a presença de disfagia em $45 \%$ dos pacientes. Em outro estudo, que analisou 128 pacientes, no período de um ano, encontrou-se disfagia em $51 \%$ dos pacientes ${ }^{30}$.

Quanto ao uso de oxigenoterapia, encontrou-se uso de VM em $25 \%$ dos pacientes. Estudo mostra que $50 \%$ dos pacientes submetidos a VM por período superior a 7 dias desenvolvem anormalidades eletrofisiológicas, com incidência média de $25 \%$ de fraqueza muscular e mais de $20 \%$ de incidência de disfagia ${ }^{27}$.

Em relação aos aspectos fonoaudiológicos mais observados durante avaliação, destacam-se tosse, engasgos e escape precoce do alimento, seguido por alteração de tônus, força, mobilidade e sensibilidade oral diminuída e saída de saliva corada ou alimento corado em $18 \%$ dos pacientes avaliados.

No entanto, pacientes submetidos a intubação orotraqueal apresentam alterações frequentes, como penetração e aspiração laríngea, sendo comum a presença de mais de uma alteração para cada paciente $\mathrm{e}^{27}$.

Estudos recentes relatam que, dentre os efeitos que a intubação prolongada pode acarretar, as alterações sensoriais e motoras são justificadas por perda prematura do bolo e penetração e/ou aspiração antes, durante e/ou após a deglutição ${ }^{20}$.

Desse modo, a penetração e a aspiração laríngeas ocorrem pela diminuição ou falta de coordenação do fechamento laríngeo durante o processo da deglutição; são fatores de risco para pneumonias, podendo levar o paciente a comprometimentos pulmonares letais ${ }^{27}$.

Em relação à avaliação fonoaudiológica realizada 
em 17 pacientes, internados e submetidos a VM, pôde-se observar que os parâmetros referentes às estruturas orofaríngeas alteradas foram tonicidade de língua $(82,4 \%)$ e de lábios $(76,5 \%)$, amplitude reduzida do movimento de língua $(70,6 \%)$, de lábios $(64,7 \%)$ e de mandíbula $(58,8 \%)$.

0 s resultados demonstraram que os pacientes traqueostomizados dependentes do ventilador apresentam comprometimento das estruturas orofaríngeas como atrofia muscular e diminuição da mobilidade, possivelmente interferindo na coordenação da dinâmica da deglutição.

\section{CONCLUSÃO}

Embora o número de fonoaudiólogos seja insuficiente para cobrir a demanda de que o serviço necessita, atualmente, com apenas 3 fonoaudiólogas, o tempo de espera para cumprimento dos pareceres se mostrou curto, ou seja, os pacientes não esperavam receber o atendimento fonoaudiológico em poucos dias.

0 impacto da fonoaudiologia no ambiente hospitalar vem sendo comprovado cientificamente, proporcionando, inclusive, redução de custos hospitalares, visto que muitos dos pacientes conseguem progredir sua dieta para uma via oral segura, sendo ainda minimizados os riscos de complicações clínicas por broncoaspirações.

Neste estudo, as informações obtidas reforçam a importância do fonoaudiólogo junto à equipe multiprofissional, otimizando a proteção das vias aéreas e introduzindo de modo seguro a dieta por via oral, refletindo acerca da necessidade de divulgação e ampliação do serviço de fonoaudiologia dentro do hospital.

Mostra-se necessário ampliar este estudo para que a amostra tenha significância estatística e para que sejam cruzados os dados do estudo.

\section{CONTRIBUIÇÃO DOS AUTORES}

\section{Bruna Rafaelle Pereira Ibiapina Coelho,} Luana Pereira Ibiapina Coelho, Elizabeth Zayra Torres Sousa e Ana Virginia Sales Monte Costa contribuíram com a realização da pesquisa, além do delineamento do estudo e a revisão crítica do manuscrito. Antonio Tiago da Silva Souza e Camila Fernandes Mendes contribuíram com o delineamento do estudo e a redação do manuscrito.

\section{REFERÊNCIAS}

1. Castro LCV, Franceschini SCC, Priore SE, Peluzio MCG. Nutrição e doenças cardiovasculares: os marcadores de risco em adultos. Rev Nutr [serial on the internet]. 2004 [cited 2015 May 5];17(3):36977. Available from: http://www.scielo.br/pdf/rn/ v17n3/21886.pdf

2. Batista SRR, Jardim PCBV, Sousa ALL, Salgado CM. Hospitalizações por condições cardiovasculares sensíveis à atenção primária em municípios goianos. Rev Saúde Pública [serial on the internet]. 2012 [cited 2015 May 5];46(1):34-42. Available from: http://www.scielo.br/pdf/rsp/v46n1/2872.pdf

3. Werle RW, Steidl EMS, Mancopes R. Fatores relacionados à disfagia orofaríngea no pósoperatório de cirurgia cardíaca: revisão sistemática. CoDAS [serial on the internet]. 2016 [cited 2016 Jan 27];28(5):646-52. Available from: http:// www.scielo.br/pdf/codas/v28n5/2317-1782codas-2317-178220162015199.pdf

4. Mesquita RB, Morano MTAP, Landim FLP, Collares PMC, Pinto JMS. Rede de apoio social e saúde de idosos pneumopatas crônicos. Ciênc Saúde Colet [serial on the internet]. 2012 [cited 2015 May 5];17(5):112533. Available from: http://www.scielo.br/pdf/csc/ v17n5/a06v17n5.pdf

5. Sociedade Brasileira de Pneumologia e Tisiologia. II Consenso Brasileiro sobre Doença Pulmonar Obstrutiva Crônica (DPOC). Caracterização da doença pulmonar obstrutiva crônica (DPOC): definição, epidemiologia, diagnóstico e estadiamento. J Bras Pneumol. 2004;30(5):10-4. Available from: http://www.jornaldepneumologia.com.br/pdf/ suple $124 \quad 40$ dpoc completo finalimpresso.pdf

6. Volpe RCC, Fitipaldi R, Silva RWP, Lehn CN, Fava AS. Associação de doença pulmonar obstrutiva crônica (DPOC) e complicações em cirurgia de cabeça e pescoço. Braz J 0torhinolaryngol [serial on the internet]. 2011 [cited 2015 May 6];77(1):125-8. Available from: http://www.scielo.br/pdf/bjorl/ v77n1/v77n1a21.pdf

7. Silva DR, Gazzana MB, Knorst MM. Valor dos achados clínicos e da avaliação funcional pulmonar pré-operatórios como preditores das complicações pulmonares pós-operatórias. Rev Assoc Méd Bras [serial on the internet]. 2010 [cited 2015 May 6];56(5):551-7. Available from: http://www.scielo. $\underline{\mathrm{br} / \mathrm{pdf} / \mathrm{ramb} / \mathrm{v} 56 \mathrm{n} 5 / \mathrm{v} 56 \mathrm{n} 5 \mathrm{a} 16 . \mathrm{pdf}}$

8. Chaves RD, Carvalho CRF, Cukier A, Stelmach R, Andrade CRF. Sintomas indicativos de disfagia em portadores de DPOC. J Bras Pneumol [serial on the internet]. 2011 [cited 2015 May 10];37(2):176-83. Available from: http://www.scielo.br/pdf/jbpneu/ v37n2/v37n2a07.pdf 
9. O'Kane L, Groher M. Oropharyngeal dysphagia in patients with chronic obstructive pulmonary disease: a systematic review. Rev CEFAC [serial on the internet]. 2009 [cited 2016 Jan 27];11(3):449506. Available from: http://www.scielo.br/pdf/ rcefac/v11n3/42-09.pdf

10. Leite ICG, Simões AG, Clemente MCKC, Martins LS, Bittar AS, Bittar CL, et al. Fonoaudiologia hospitalar. Jornal Brasileiro de Fonoaudiologia [serial on the internet]. 2003 [cited 2015 May 10];4(17):[about 6 screens]. Available from: https://www.dtscience. com/wp-content/uploads/2015/10/FonoaudiologiaHospitalar.pdf

11. Monti MMF, Botega MBS, Lima MCMP, Kubota SMP. Demanda para intervenção fonoaudiológica em uma unidade neonatal de um hospital-escola. Rev CEFAC [serial on the internet]. 2013 [cited 2015 May 10];15(6):1540-51. Available from: http://www. scielo.br/pdf/rcefac/v15n6/v15n6a17.pdf

12. Medeiros EA, Maia RM, Cedro MO, Barbosa MLC, Correia RBF, Tavares PMB, et al. A inserção da fonoaudiologia na Estratégia Saúde da Família: vivências em Sobral-CE. Sanare (Sobral, Online) [serial on the internet]. 2009 [cited 2016 May 3];8(2):7-15. Available from: https://sanare. emnuvens.com.br/sanare/article/viewFile/14/11

13. Silverio CC, Hernandez AM, Goncalves MIR. Ingesta oral do paciente hospitalizado com disfagia orofaríngea neurogênica. Rev CEFAC [serial on the internet]. 2010 [cited 2015 May 15];12(6):964-70. Available from: http://www.scielo.br/pdf/rcefac/ v12n6/81-09.pdf

14. Faria CF, Pessoa ACN, Araujo LI, Paiva MLF. Perfil do paciente atendido pela fonoaudiologia na unidade de urgência e emergência de um hospital universitário. Audiol Commun Res [serial on the internet]. 2013 [cited 2015 May 10];18(4):30813. Available from: http://www.scielo.br/pdf/acr/ v18n4/12.pdf

15. Bassi D, Furkim AM, Silva CA, Coelho MSPH, Rolim MRP, Alencar MLA, et al. Identificação de grupos de risco para disfagia orofaríngea em pacientes internados em um hospital universitário. Rev Soc Bras Fonoaudiol [serial on the internet]. 2014 [cited 2015 Jun 10];26(1):17-27. Available from: http:// www.scielo.br/pdf/codas/v26n1/pt 2317-1782codas-26-01-00017.pdf

16. Rosado CV, Amaral LKM, Galvão AP, Guerra SD, Furia CLB. Avaliação da disfagia em pacientes pediátricos com traumatismo crânio-encefálico. Rev CEFAC [serial on the internet]. 2005 [cited 2015 Jun 12];7(1):34-41. Available from: http://www.redalyc. org/pdf/1693/169320490004.pdf
17. Francisco PMSB, Donalisio MR, Lattorre MRDO. Internações por doenças respiratórias em idosos e a intervenção vacinal contra influenza no Estado de São Paulo. Rev Bras Epidemiol [serial on the internet]. 2004 [cited 2016 Mar 2];7(2):220-7. Available from: http://www.scielo.br/pdf/rbepid/v7n2/18.pdf

18. Costa RG, Souza LBR. Perfil dos usuários e da demanda pelo serviço da clínica-escola de fonoaudiologia da UFBA. Rev Ciênc Méd Biol [serial on the internet]. 2009 [cited 2016 Mar 2];8(1):539. Available from: https://portalseer.ufba.br/index. $\mathrm{php/cmbio/article/view/4376/3200}$

19. Assis MMA, Jesus WLA. Acesso aos serviços de saúde: abordagens, conceitos, políticas e modelo de análise. Ciênc Saúde Colet [serial on the internet]. 2012 [cited 2016 Mar 2];17(11):2865-75. Available from: http://www.scielo.br/pdf/csc/v17n11/ v17n11a02.pdf

20. Furmann N, Costa FM. Critérios clínicos utilizados por profissionais para liberação de dieta via oral em pacientes adultos hospitalizados. Rev CEFAC [serial on the internet]. 2015 [cited 2016 Mar 4];17(4):127887. Available from: http://www.scielo.br/pdf/ rcefac/v17n4/1982-0216-rcefac-17-04-01278.pdf

21. Padovani AR, Andrade CRF. Perfil funcional da deglutição em unidade de terapia intensiva clínica. Einstein (São Paulo) [serial on the internet]. 2007 [cited 2016 Mar 4];5(4):358-62. Available from: http://www.fonovim.com.br/arquivos/784a647f7e 75 9641c32d76551d8be259-Perfil-funcional-da-degluti---o-em-unidade-de.pdf

22. Costa KN, Guimarães VC. Fonoaudiologia nos serviços de urgência e emergência do Brasil: série histórica de 2005 a 2011. Distúrb Comun [serial on the internet]. 2012 [cited 2016 Mar 4];24(1):69-75. Available from: http://revistas.pucsp.br/index.php/ dic/article/view/9707/7211

23. Hage SRV, Faiad LNV. Perfil de pacientes com alteração de linguagem atendidos na clínica de diagnóstico dos distúrbios da comunicação. Rev CEFAC [serial on the internet]. 2005 [cited 2016 Mar 4];7(4):433-40. Available from: http://www.redalyc. org/pdf/1693/169320507006.pdf

24. Nogueira SCJ, Carvalho APC, Melo CB, Morais EPG, Chiari BM, Gonçalves MIR. Perfil de pacientes em uso de via alternativa de alimentação internados em um hospital geral. Rev CEFAC [serial on the internet]. 2013 [cited 2016 Mar 7];15(1):94-104. Available from: http://www.scielo.br/pdf/rcefac/v15n1/13311.pdf

25. Arcêncio L, Souza MD, Bortolin BS, Fernandes CM, Rodrigues AJ, Evora PRB. Cuidados pré e pós-operatórios em cirurgia cardiotorácica: uma abordagem fisioterapêtica. Rev Bras Cir Cardiovasc [serial on the internet]. 2008 [cited 2016 Mar 7];23(3):400-10. Available from: http://www. scielo.br/pdf/rbccv/v23n3/v23n3a19.pdf 
26. Mota LAA, Carvalho GBC, Brito VA. Complicações laríngeas por intubação orotraqueal: revisão da literatura. Int Arch 0torhinolaryngol [serial on the internet]. 2012 [cited 2016 Mar 7];16(2):23645. Available from: http://www.scielo.br/pdf/iao/ v16n2/v16n2a14.pdf

27. Kunigk MRG, Chehter E. Disfagia orofaríngea em pacientes submetidos à entubação orotraqueal. Rev Soc Bras Fonoaudiol [serial on the internet]. 2007 [cited 2016 Mar 10];12(4):287-91. Available from: http://www.scielo.br/pdf/rsbf/v12n4/v12n4a06

28. Gregório JGR, Valério KD, Andrade WTL. Uso de via alimentar alternativa em pacientes admitidos na unidade de terapia intensiva de um hospital público da cidade de João Pessoa/PB [document on the internet]. 2010 [cited 2019 May 20]. Available from: http://www.redentor.inf.br/arquivos/pos/ publicacoes/15082012TCC\%20Jose $\% 20$ Geraldo.pdf

29. Schelp A0, Cola PC, Gatto AR, Silva RG, Carvalho LR. Incidência de disfagia orofaríngea após acidente vascular encefálico em hospital público de referência. Arq Neuropsiquiatr [serial on the internet]. 2004 [cited 2016 Mar 10];62(2):503-6. Available from: http://www.scielo.br/pdf/anp/v62n2b/a23v622b.pdf

30. Maciel JRV, Oliveira CJR, Tada CMP. Associação entre risco de disfagia e risco nutricional em idosos internados em hospital universitário de Brasília. Rev Nutr [serial on the internet]. 2008 [cited 2016 Mar 10];21(4):411-21. Available from: http://www. scielo.br/pdf/rn/v21n4/v21n4a05.pdf
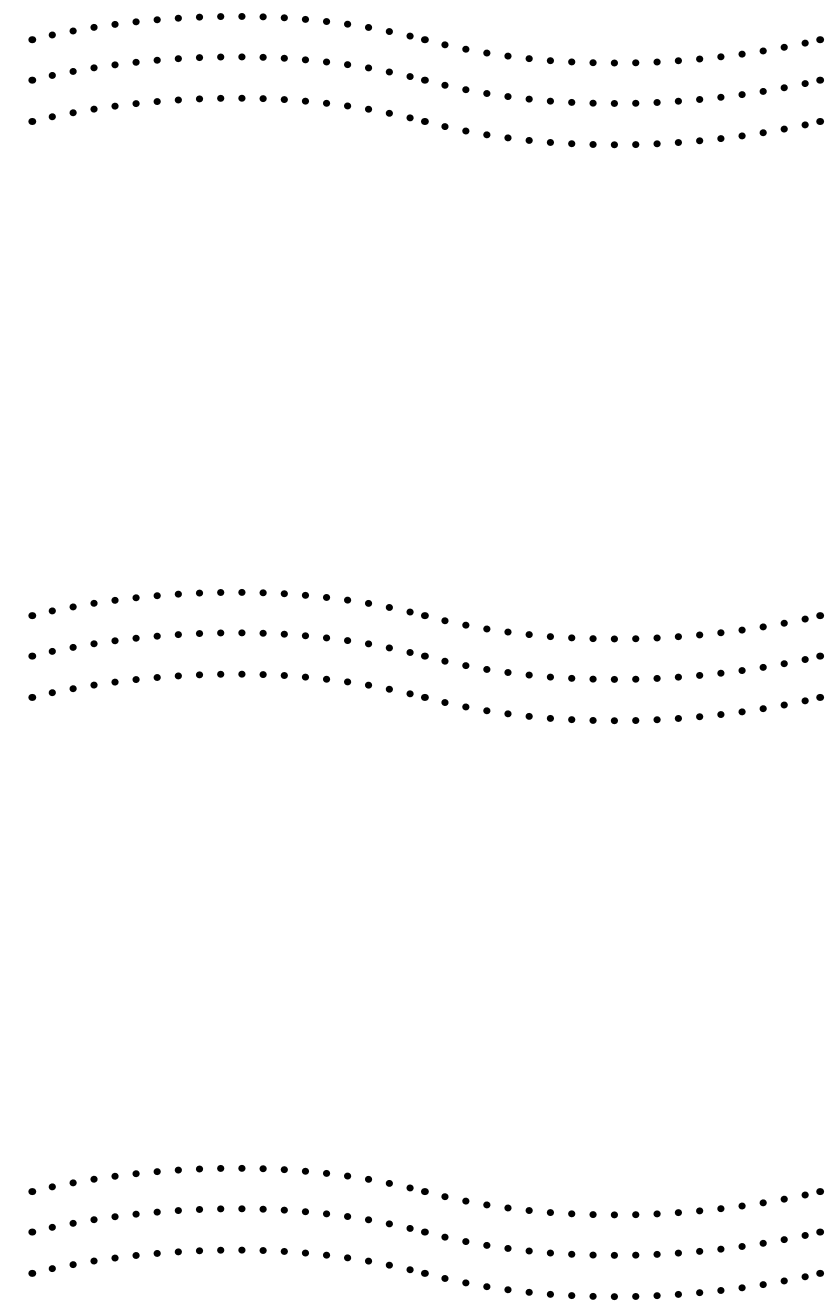
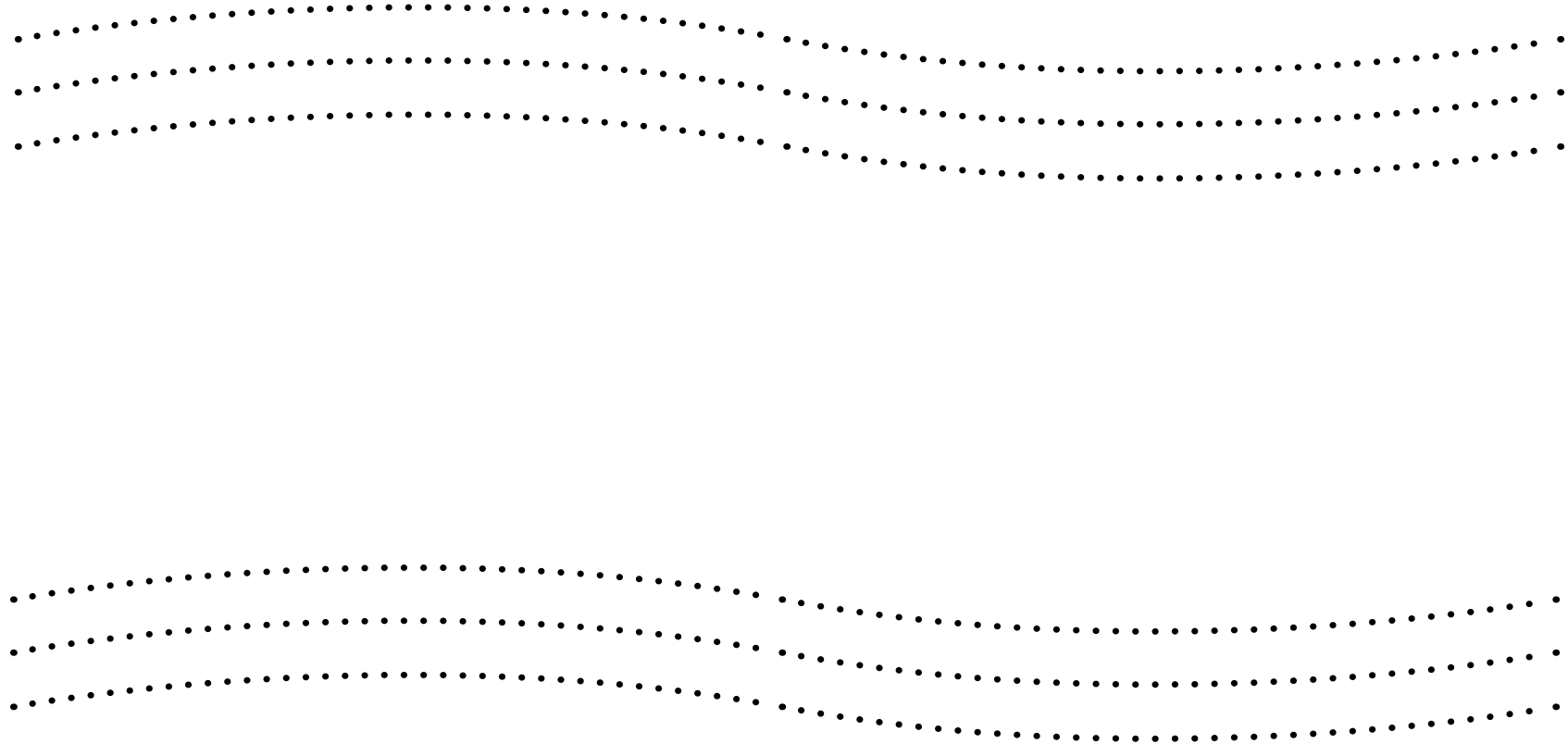


\section{CONHECIMENTO DOS MÉdICOS DA ATENÇÃO PRIMÁRIA À SAÚdE SOBRE RASTREAMENTO DE CÂNCER}

PRIMARY HEALTH CARE PHYSICIANS' KNOWLEDGE ON CANCER SCREENING

CONOCIMIENTO DE MÉdiCOS DE LA ATENCIÓN PRIMARIA SOBRE RASTREO DE CÁNCER

Lorena Alves Trajano ${ }^{1}$

José Francisco Igor Siqueira Ferreira ${ }^{2}$

Miguel Marcelo Freire de Melo ${ }^{3}$

Luiz Eduardo de Castro Batista 4

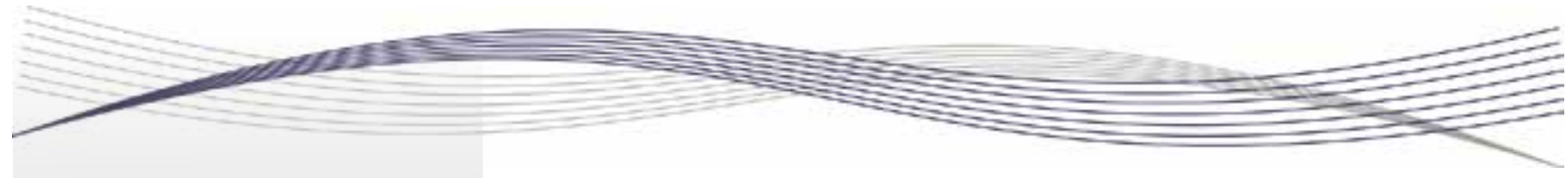

Palavras-chave:

Centros de Saúde; Programas de Rastreamento; Promoção da Saúde; Neoplasias; Conhecimento.

Keywords: Health Centers; Mass Screening; Health Promotion; Neoplasms; Knowledge.

Palabras clave: Centros de Salud; Tamizaje Masivo; Promoción de la Salud; Neoplasias; Conocimiento.

Submetido: $08 / 12 / 2019$

Aprovado: $15 / 05 / 2019$

Autor(a) para Correspondência: Lorena Alves Trajano R. Corina Dantas, 299 Derby Club - Sobral (CE) CEP: 62130-000 E-mail: loren.tj21@gmail.com

\section{RESUMO}

Este estudo avaliou o conhecimento dos médicos da atenção primária à saúde (APS) em Sobral-CE acerca das atuais recomendações para o rastreamento de câncer. Trata-se de estudo transversal, qualitativo, realizado com médicos da APS do município por meio de questionário que avaliou seu conhecimento sobre rastreamento dos tipos de câncer mais prevalentes no país. A análise das respostas se baseou nos consensos do Instituto Nacional do Câncer (INCA), da Organização Mundial da Saúde (OMS), da Sociedade Americana de Câncer (American Cancer Society - ACS) e da Força Tarefa Canadense em Assistência Preventiva à Saúde (Canadian Task Force on Preventive Health Care - (TFPHC). Os resultados indicam que a familiaridade com as diretrizes foi variável. Considerando os possiveis obstáculos observados na prevenção secundária, a preocupação com a falta de clareza nas recomendações para o rastreamento de câncer foi relatada por menos de $50 \%$ dos participantes, ao passo que os demais obstáculos foram citados por mais de 65\%. Concluiu-se ser necessário adotar esforços para aprimorar a educação médica em termos de prevenção secundária, com vistas a melhorar o diagnóstico precoce dos diversos tipos dessa doença.

1. Aluna de Graduação em Medicina na Universidade Federal do Ceará (UFC). Sobral (CE), Brasil. E-mail: Loren. tj21@gmail.com

2. Aluno de Graduação em Medicina na UFC. Sobral (CE), Brasil. E-mail: igorsqferreira@gmail.com

3. Aluno de Graduação em Medicina na UFC. Sobral (CE), Brasil. E-mail: migmarc2@gmail.com

4. Professor no Curso de Graduação em Medicina da UFC. Coordenador do Serviço de Oncologia e Hematologia da Santa Casa de Misericórdia de Sobral (SCMS). Sobral (CE),Brasil. E-mail: ledbatista@gmail.com 


\section{ABSTRACT}

This study assessed primary health care (PHC) physicians' knowledge in Sobral, Ceará, Brazil, on the current recommendations for cancer screening. This is a cross-sectional, qualitative, study carried out with PHC physicians in the municipality by means of a questionnaire that assessed their knowledge on screening of the most prevalent types of cancer in the country. The analysis of answers was based on consensuses of the National Cancer Institute (Instituto Nacional do Câncer - INCA), the World Health Organization (WHO), the American Cancer Society (ACS), and the Canadian Task Force on Preventive Health Care (CTFPHC). The results indicate that familiarity with the guidelines was variable. Considering the possible obstacles observed in secondary prevention, concern about the lack of clarity in recommendations for cancer screening was reported by less than 50\% of the participants, while the other obstacles were cited by more than 65\%. It was concluded that efforts are needed to improve medical education in terms of secondary prevention, with a view to improving the early diagnosis of various types of this disease.

\section{RESUMEN}

Este estudio evaluó el conocimiento de médicos de la atención primaria de salud (APS) en Sobral, Ceará, Brasil, acerca de las recomendaciones actuales para rastreo del cáncer. Este es un estudio transversal, cualitativo, realizado con médicos de la APS en el municipio mediante un cuestionario que evaluó su conocimiento sobre rastreo de los tipos de cáncer más prevalentes en el país. El análisis de respuestas se basó en los consensos del Instituto Nacional del Cáncer (Instituto Nacional do Câncer-INCA), de la Organización Mundial de la Salud (OMS), de la Sociedad Americana del Cáncer (American Cancer Society - ACS) y del Grupo de Trabajo Canadiense sobre el Cuidado Preventivo de Salud (Canadian Task Force on Preventive Health Care - CTFPHC). Los resultados indican que la familiaridad con las directrices fue variable. Teniendo en cuenta los posibles obstáculos observados en la prevención secundaria, la preocupación por la falta de claridad en las recomendaciones para rastreo del cáncer fue reportada por menos de $50 \%$ de los participantes, mientras que los otros obstáculos fueron citados por más de $65 \%$. Se concluyó que son necesarios esfuerzos para mejorar la educación médica en términos de prevención secundaria, con miras a mejorar el diagnóstico precoz de los varios tipos de esta enfermedad.

\section{INTRODUÇÃ 0}

As doenças não transmissiveis, como câncer, doenças cardiovasculares e diabetes mellitus, já superam as doenças infectocontagiosas no que concerne à incidência e à mortalidade em países de média renda, como o Brasil, principalmente em regiões que enfrentam problemas socioeconômicos, étnicos, geográficos e falta de acesso a serviços de saúde - a exemplo do Nordeste ${ }^{1,2}$.

No Brasil, segundo dados do Instituto Nacional do Câncer (INCA) estimados para 2016, excluindo os tipos de câncer de pele não melanoma, o câncer de mama é o de maior incidência entre as mulheres (cerca de 58 casos para 100.000 habitantes) e o câncer de próstata é o de maior incidência entre os homens (cerca de 61,2 casos para cada 100.000 habitantes). Em brasileiros do sexo masculino, a maior taxa de mortalidade se refere ao câncer de pulmão; já nas brasileiras, a mortalidade decorre, principalmente, do câncer de mama ${ }^{3}$. Para 2020, estima-se uma incidência de pouco mais de 500.000 casos de câncer no país (projeção de aumento de mais de 38\% em relação ao ano de 2009$)^{4}$.

Apresentando alguns dos piores índices socioeconômicos do país ${ }^{5}$, o Nordeste também acaba tendo dificuldades na prevenção e no diagnóstico de câncer. Quanto ao câncer de colo de útero, por exemplo, há dificuldade até para registrar a incidência da neoplasia nas áreas com os menores indices socioeconômicos, o que prejudica o acesso aos serviços voltados à prevenção, ao diagnóstico e ao tratamento ${ }^{6}$.

$\mathrm{Na}$ área oncológica, o diagnóstico precoce é uma estratégia que viabiliza terapias mais simples e efetivas, por contribuir para a redução do estágio de apresentação do câncer. Por essa razão, o conceito de diagnóstico precoce também é denominado downstaging. É importante que os profissionais da saúde reconheçam os sinais de alerta dos tipos de câncer mais comuns - passiveis de melhor prognóstico se descobertos no início?.

Basicamente, a prevenção primária de câncer consiste em evitar os fatores de risco que têm forte relação com tumores, como álcool, aspectos dietéticos, sedentarismo e exposição solar, sendo, 
por si, um meio efetivo que pode evitar de $1 / 3$ a $1 / 2$ dos casos de câncer. Já a prevenção secundária consiste no uso de métodos diagnósticos para detectar lesões predisponentes ao surgimento de câncer. Estudos mostram que a prevenção primária combinada à secundária é capaz de diminuir a morbimortalidade por câncer de colo de útero, além de reduzir em até $29 \%$ o número de mortes por câncer de mama ${ }^{8,9}$.

Atualmente, a indicação para o rastreamento está restrita aos casos de câncer de: a) mama; b) colo de útero; e c) cólon e reto. Entretanto, muitos outros tipos dessa doença, exceto câncer de pulmão e esôfago, são passíveis de diagnóstico precoce mediante avaliação e encaminhamento oportunos após os primeiros sinais e sintomas?

No Brasil, de acordo com o INCA, estima-se o surgimento de 600.000 novos casos no biênio 2016-2017, sendo 180.000 pacientes com câncer de pele não melanoma, logo, temos 420.000 novos casos de câncer propriamente ditos. Assim, o rastreamento precoce desses novos casos é crucial, com o propósito de intervir de modo incisivo desde o início, aumentando sobremaneira as chances de cura desses pacientes com diagnóstico oportuno ${ }^{3}$.

Um estudo semelhante foi realizado no Município de Sobral em 2005 - então se constatou que a maioria das recomendações dos médicos entrevistados não se adequava aos consensos adotados: as taxas de adequação a pelo menos um dos consensos variaram de 73,3\% (câncer de pele) a apenas 3,3\% (câncer de mama). Nesse estudo, em geral, as recomendações inadequadas mostravam nítida tendência ao excesso nos casos de câncer de colo de útero e de pulmão, e deficiência no rastreamento nos cânceres de mama e cólon e reto. Em relação às barreiras ao rastreamento adequado, $70 \%$ dos participantes consideraram de grande importância a falta de interesse do paciente e $66,6 \%$ apontaram a falta de educadores em saúde que atuam junto à população e a falta de verbas para custear os exames. Apesar da reconhecida importância desse tipo de estudo que aborda a aplicação das medidas de rastreamento por parte dos profissionais da saúde, a literatura nacional sobre o tema é escassa e a maioria dessas referências adotam pesquisas internacionais como base ${ }^{8}$.

Em razão disso, esta pesquisa avaliou 0 conhecimento dos médicos da atenção primária à saúde (APS) de Sobral sobre as recomendações mais atuais para o rastreamento de câncer, comparando os resultados obtidos aos de um estudo semelhante

\section{...rastreamento precoce desses novos casos é crucial, com o propósito de intervir de modo incisivo desde o início...}

realizado no ano de 2005, que não chegou a ser publicado, de modo a verificar se houve alguma evolução nestes últimos 15 anos, bem como quais deficiências ainda persistem, contribuindo para 0 planejamento, o desenvolvimento e a implementação de melhores estratégias para suprir as necessidades locais e sanar as deficiências existentes no norte do Ceará, sensibilizando lideranças governamentais e autoridades de saúde para buscar uma efetiva e constante melhoria dos serviços públicos.

Este estudo analisou, de modo qualitativo, o rastreamento dos casos de câncer na APS de Sobral executado pelos médicos - que buscam intervir positivamente tanto na vida dos usuários dos centros da Estratégia Saúde da Família (ESF) quanto no sistema de saúde como um todo, mediante a identificação de anormalidades em dois pontos principais: a) condutas de rastreamento de câncer; e b) pontos que prejudicam a execução desse rastreamento.

Dessa maneira, a pesquisa buscou identificar ações que precisam ser fortalecidas para aprimorar o rastreamento executado no âmbito da ESF, com o propósito de oferecer um serviço de saúde mais efetivo e eficar, diminuindo os números de novos casos de câncer a partir do reconhecimento de alterações pré-cancerígenas e de uma ação terapêutica adequada.

\section{METODOLOGIA}

Trata-se de estudo transversal qualitativo realizado com 30 médicos que atuam na APS de Sobral entre setembro 2016 e fevereiro de 2017; seu cenário consistiu em 17 centros da ESF. Vale salientar que 32 profissionais foram convidados a participar, mas 2 se recusaram.

As informações foram obtidas por meio de um questionário, intitulado "Médicos e Prevenção Secundária do Câncer", aplicado por acadêmicos do $4^{\circ}$ ao $11^{\circ}$ semestres do Curso de Graduação em 
Medicina da Universidade Federal do Ceará (UFC) campus de Sobral.

A abordagem aos médicos foi padronizada e os questionários foram preenchidos em unidades básicas de saúde (UBS), com a presença do aluno de graduação, sem consulta a qualquer bibliografia ou a terceiros por parte dos participantes.

Esse questionário coletou dados relativos a:

A. Idade e ano de graduação;

B. Condutas necessárias para rastrear os casos de câncer mais incidentes no Brasil (mama, colo de útero, próstata, cólon e reto e pele); e

C. Classificação dos obstáculos em "grande importância", "pouca importância" e "não considero uma barreira".

Alguns destes fatores foram enumerados (obstáculos 1 a 7 ):

i) Falta de agentes em promoção de saúde que orientem a população a procurar o médico;

ii) Falta de tempo do médico para realizar a prevenção secundária do câncer durante as consultas;

iii) Demora entre as consultas do mesmo paciente;

iv) Falta de interesse do paciente;

v) Falta de verba para custear os exames de prevenção; vi) Dificuldade para saber quando fazer o rastreamento; e

vii) Falta de conhecimento e/ou treinamento inadequado para empreender esse tipo de prevenção.

0 câncer de pulmão foi excluído do escopo deste estudo por conta de divergências quanto à eficácia de seu rastreamento ${ }^{7}$.

A análise das respostas se baseou nos consensos do INCA, da Organização Mundial da Saúde (OMS), da Sociedade Americana de Câncer (American Cancer Society - ACS) e da Força Tarefa Canadense em Assistência Preventiva à Saúde (Canadian Task Force on Preventive Health Care - (TFPHC).

Então, as condutas indicadas pelos entrevistados se classificaram em:

A. Adequada (quando os exames, a idade e a frequência indicados pelo entrevistado são exatamente 0 que preconiza 0 protocolo em comparação);

B. Inadequada deficiente (quando os exames recomendados pelo médico são insuficientes para um rastreamento satisfatório); e

C. Inadequada excessiva (que submete o paciente a estresse desnecessário, além de gerar custos adicionais ao sistema de saúde).

0 Quadro 1 sintetiza a classificação das respostas.

Quadro 1 - Classificação das respostas obtidas por meio dos questionários

\begin{tabular}{|c|c|c|c|}
\hline $\begin{array}{l}\text { Variáveis da conduta } \\
\text { indicada }\end{array}$ & Adequada & Inadequada deficiente & Inadequada excessiva \\
\hline Exames & $\begin{array}{l}\text { Idêntica ao } \\
\text { protocolo de } \\
\text { comparação. }\end{array}$ & $\begin{array}{c}\text { Pelo menos } 1 \text { dos exames } \\
\text { indicados no protocolo de } \\
\text { comparação não foi referido pelo } \\
\text { entrevistado. }\end{array}$ & $\begin{array}{l}0 \text { entrevistado referiu todos } \\
\text { os exames indicados pelo } \\
\text { protocolo de comparação e } \\
\text { algum(ns) outro(s) que não } \\
\text { consta(m) no protocolo. }\end{array}$ \\
\hline $\begin{array}{l}\text { Idade (de inicio/fim } \\
\text { de rastreamento) }\end{array}$ & $\begin{array}{l}\text { Idêntico ao } \\
\text { protocolo de } \\
\text { comparação. }\end{array}$ & $\begin{array}{l}0 \text { médico referiu idade de início } \\
\text { de rastreamento superior à } \\
\text { indicada pelo protocolo ou idade } \\
\text { em que rastreamento não deve } \\
\text { mais ser aplicado inferior à } \\
\text { preconizada. }\end{array}$ & $\begin{array}{l}0 \text { médico indicou início } \\
\text { precoce de rastreamento em } \\
\text { relação ao preconizado pelo } \\
\text { protocolo comparado ou fim do } \\
\text { rastreamento mais tardio do que } \\
\text { o recomendado. }\end{array}$ \\
\hline $\begin{array}{l}\text { Frequência (de } \\
\text { aplicação dos } \\
\text { exames) }\end{array}$ & $\begin{array}{l}\text { Idêntico ao } \\
\text { protocolo de } \\
\text { comparação. }\end{array}$ & $\begin{array}{l}0 \text { entrevistado indicou frequência } \\
\text { menor do que a preconizada } \\
\text { (o espaço de tempo entre um } \\
\text { exame e outro é maior do que o } \\
\text { recomendado). }\end{array}$ & $\begin{array}{l}\text { O entrevistado indicou } \\
\text { frequência maior do que a } \\
\text { preconizada (o espaço de tempo } \\
\text { entre um exame e outro é menor } \\
\text { do que o recomendado). }\end{array}$ \\
\hline
\end{tabular}

Fonte: Elaborado pelos autores.

Exames indicados pelos médicos para grupos de risco ou pacientes sintomáticos foram considerados procedimento de vigilância e não rastreamento, assim, essas respostas configuraram ausência de indicação de rastreamento pelo entrevistado. Já os médicos que deixaram de responder questões referentes às suas indicações para rastreamento de determinado tipo de câncer corresponderam à classificação “conduta 
inadequada deficiente". Adotou-se tal medida com base na hipótese de que o médico que não respondeu a uma questão específica, mesmo tendo notificado que a deixaria em branco, não tinha conhecimento sobre o que se recomenda para o rastreamento daquele tipo de câncer, não apresentando, portanto, nem uma conduta adequada nem uma conduta inadequada excessiva.

Não foi necessária a aplicação de testes estatísticos para o cálculo da amostra, uma vez que este estudo abrangeu um número próximo da totalidade dos médicos da APS de Sobral.

A pesquisa obteve aprovação do Comitê de Ética em Pesquisa, da Universidade Estadual Vale do Acaraú (UVA), sob o Parecer n. 3.056.527/2018, em consonância com a Resolução CNS n. 466/2012.

\section{RESULTADOS E DISCUSSÃO}

A partir dos dados coletados na primeira parte do questionário, avaliou-se o grau de informação dos profissionais da saúde que participaram do estudo sobre as práticas para rastreamento e diagnóstico precoce dos tipos de câncer com maior incidência em nosso país (mama, colo de útero, próstata, cólon e reto e pele). As recomendações dos principais consensos utilizados para o rastreamento de câncer são sintetizadas no Quadro 2.

Quadro 2 - Medidas de rastreamento por tipo de câncer preconizadas por cada consenso

\begin{tabular}{|c|c|c|c|c|c|c|c|c|}
\hline \multirow[b]{2}{*}{ Método } & \multicolumn{2}{|c|}{ INCA } & \multicolumn{2}{|c|}{ OMS } & \multicolumn{2}{|c|}{ СTFPHC } & \multicolumn{2}{|c|}{ ACS } \\
\hline & $\begin{array}{l}\text { Idade } \\
\text { (anos) }\end{array}$ & Frequência & $\begin{array}{l}\text { Idade } \\
\text { (anos) }\end{array}$ & Frequência & $\begin{array}{l}\text { Idade } \\
\text { (anos) }\end{array}$ & Frequência & $\begin{array}{l}\text { Idade } \\
\text { (anos) }\end{array}$ & Frequência \\
\hline \multicolumn{9}{|c|}{ Mama } \\
\hline Exame clínico & $>40$ & Anual & $\begin{array}{c}\text { Não } \\
\text { indica }\end{array}$ & Não indica & $>50$ & Anual & $>20$ & $\begin{array}{l}\text { Trienal para } \\
20-40 \text { anos } \\
\text { e anual para } \\
>40 \text { anos }\end{array}$ \\
\hline Autoexame & Não indica & Não indica & $\begin{array}{c}\text { Não } \\
\text { indica }\end{array}$ & Não indica & Não indica & Não indica & $\begin{array}{c}20 \\
\text { (opcional) }\end{array}$ & Opcional \\
\hline Mamografia & $>50$ & $\begin{array}{l}\text { Bienal, no } \\
\text { máximo }\end{array}$ & $>50$ & $\begin{array}{c}\text { A cada } 2 \text { ou } \\
3 \text { anos }\end{array}$ & $>50$ & Anual & $>40$ & Anual \\
\hline \multicolumn{9}{|c|}{ Colo de útero } \\
\hline Papanicolau & $\begin{array}{c}\text { Após } \\
\text { início da } \\
\text { atividade } \\
\text { sexual ou } \\
>25\end{array}$ & Anual & $>35$ & $\begin{array}{l}\text { Não refere } \\
\text { frequência }\end{array}$ & $\begin{array}{c}\text { Após } \\
\text { início da } \\
\text { atividade } \\
\text { sexual ou } \\
>18\end{array}$ & Anual & $\begin{array}{c}>21 \text { ou } 3 \\
\text { anos após } \\
\text { sexarca }\end{array}$ & Anual \\
\hline \multicolumn{9}{|c|}{ Próstata } \\
\hline $\begin{array}{l}\text { Antígeno } \\
\text { prostático } \\
\text { específico e } \\
\text { toque retal }\end{array}$ & Não indica & Não indica & $\begin{array}{l}\text { Indica } \\
\text { sem } \\
\text { referir } \\
\text { idade }\end{array}$ & $\begin{array}{l}\text { Indica sem } \\
\text { referir } \\
\text { idade }\end{array}$ & Não indica & Não indica & $>50$ & Anual \\
\hline \multicolumn{9}{|c|}{ Cólon e reto } \\
\hline Sangue oculto & $>50$ & Anual & $\begin{array}{c}\text { Não } \\
\text { indica }\end{array}$ & Não indica & $>50$ & $\begin{array}{c}\text { Máximo } 2 \\
\text { anos }\end{array}$ & $>50$ & Anual \\
\hline Colonoscopia & Não indica & Não indica & $\begin{array}{c}\text { Não } \\
\text { indica }\end{array}$ & Não indica & Não indica & $\begin{array}{c}\text { Máximo } 2 \\
\text { anos }\end{array}$ & $>50$ & $\begin{array}{c}\text { A cada } 10 \\
\text { anos }\end{array}$ \\
\hline \multicolumn{9}{|c|}{ Pele } \\
\hline Exame clínico & Não indica & Não indica & $\begin{array}{l}\text { Indica } \\
\text { sem } \\
\text { referir } \\
\text { idade }\end{array}$ & $\begin{array}{l}\text { Indica sem } \\
\text { referir } \\
\text { frequência }\end{array}$ & Não indica & Não indica & $>20$ & Ocasional \\
\hline
\end{tabular}

Fonte: Elaborado pelos autores. 
0s dados da Tabela 1 foram obtidos mediante classificação das condutas descritas. Constatou-se a adoção de conduta adequada em mais de $50 \%$ dos casos apenas em relação ao câncer de mama - achado similar ao de outro estudo realizado nos Estados Unidos da América (EUA) ${ }^{10}$. Entretanto, não se pode considerar tal índice um sinal de qualidade do atendimento, pois essa malignidade é a de maior incidência e mortalidade entre as mulheres, portanto, seu rastreamento deveria abranger toda a população indicada pelos consensos.

Tabela 1 - Índice de adequação das condutas indicadas pelos médicos para rastreamento dos principais tipos de câncer

\begin{tabular}{lccc}
\hline Tipo de câncer & Conduta adequada N (\%) & $\begin{array}{c}\text { Conduta inadequada } \\
\text { excessiva N (\%) }\end{array}$ & $\begin{array}{c}\text { Conduta inadequada } \\
\text { deficiente N (\%) }\end{array}$ \\
\hline Mama & $16(53,3 \%)$ & $9(30 \%)$ & $5(16,6 \%)$ \\
Colo de útero & $12(40 \%)$ & $6(20 \%)$ & $12(40 \%)$ \\
\hline Próstata & $3(10 \%)$ & $24(80 \%)$ & $3(10 \%)$ \\
Cólon e reto & $5(16,6 \%)$ & $6(20 \%)$ & $19(63,3 \%)$ \\
\hline Pele & $4(13,3 \%)$ & $14(46,6 \%)$ & $12(40 \%)$ \\
\hline
\end{tabular}

Fonte: Elaborada pelos autores.

Nos demais casos, chamam atenção o câncer de pele $(13,3 \%$ dos profissionais apontaram a conduta adequada), e as neoplasias de colo de útero e cólon e reto (nas quais houve tomada de conduta inadequada deficiente em $40 \%$ e $63 \%$ dos casos, respectivamente). Em tal situação, deve-se salientar que essas 3 estão entre as malignidades mais incidentes em nosso meio, justificando a necessidade dos profissionais da saúde atentarem ao rastreamento e diagnóstico precoce delas. No caso do câncer de colo de útero, por exemplo, o qual se comporta como malignidade de progressão lenta, com longo período de prevenção eficaz no sexo feminino, a conduta adequada foi adotada em apenas $40 \%$ dos casos, indicando elevado déficit de conhecimento dos profissionais sobre uma enfermidade relevante em nosso meio. Inclusive, um estudo realizado em Boa Vista-RR identificou que, apesar do déficit no rastreamento correto para outros tipos de câncer, o de colo de útero teve recomendação de condutas adequadas em $95,7 \%$ dos $\operatorname{casos}^{11}$. Deve-se investigar os motivos para tais diferenças em diferentes locais quanto à indicação do Papanicolau - exame realizado com frequência que deve ser dominado por todos os médicos da APS.

A detecção precoce de câncer pode salvar vidas, reduzir a morbidade associada ao curso da doença e diminuir os custos do tratamento das doenças no sistema de saúde. Ela deve ser estruturada na atenção à saúde, com clara definição de suas estratégias e efetiva incorporação de seus princípios técnicos e operacionais por parte dos profissionais da saúde. Segundo Aguiar et al. ${ }^{12}$, a efetividade do cuidado depende da reorganização dos processos de trabalho, observando-se a importância do médico realizar o diagnóstico nas fases iniciais para que os pacientes tenham encaminhamento efetivo aos serviços secundários e terciários.

A conduta inadequada excessiva foi observada, principalmente, no câncer de próstata $(80 \%)$, mas, ainda, no câncer de pele (quase $50 \%$ dos casos). Esse tipo de conduta também merece destaque, pois a intenção original da triagem é detectar o câncer nos estágios iniciais para melhorar os resultados de diagnóstico e tratamento e aumentar a sobrevida dos pacientes. Porém, quando há diagnóstico excessivo, definido como “diagnóstico de uma condição que não iria causar sintomas ou dano adicional, se não tratada, ao paciente durante o seu tempo de vida"13, o rastreamento não se torna custo-efetivo e pode trazer mais danos, por conta de procedimentos desnecessários, do que benefícios. Embora nenhum médico tenha a intenção de "tratar com excessos" ou "diagnosticar em excesso" o câncer, as triagens e a conscientização dos pacientes têm aumentado a chance de identificar um espectro de tipos de câncer, alguns dos quais não fatais e cujo diagnóstico precoce não altera a sobrevida.

Em relação ao mesmo estudo, também realizado em Sobral no ano de 2005, a taxa de adequação a pelo menos um consenso no caso do câncer de mama foi de 3,3\%; quanto ao câncer de pele, essa taxa foi de $73,3 \%$, com expressiva evolução no primeiro caso se contrapondo a relevante queda do índice no segundo. No geral, a maioria das recomendações não estava adequada aos consensos adotados, revelando 
um déficit permanente após 12 anos.

No interior dos EUA se realizou um estudo similar sobre o conhecimento dos médicos a respeito das recomendações da ACS quanto ao rastreamento e ao diagnóstico precoce de câncer e constatou-se que $70 \%$ dos médicos afirmam ter conhecimento dessas medidas. Entretanto, $77 \%$ consideram a educação médica insuficiente para proporcionar medidas de prevenção e $43 \%$ afirmam que as recomendações não são claras, de modo que $17 \%$ responderam incorretamente questões sobre as medidas de prevenção do câncer de cólon e reto. Ademais, $68 \%$ dos médicos acreditam que as recomendações para câncer de próstata consistam apenas na dosagem de antígeno prostático específico (prostale specific antigen - PSA), entre outras medidas que não preconizadas pela $\mathrm{ACS}^{14}$, o que sugere insuficiente conhecimento dos médicos sobre prevenção e rastreamento de câncer não só em nosso meio.

Mostra-se necessário aumentar a adesão dos médicos aos consensos, o que demanda recursos e esforços educativos. Entendemos ser indispensável um esforço multidisciplinar que enfatize a importância das medidas preventivas na educação médica. A Tabela 2 sintetiza os obstáculos descritos que constituíram a terceira parte do questionário aplicado, classificados em grande importância, pouca importância e não considero barreira.

Tabela 2 - Respostas da terceira parte do questionário aplicado

\begin{tabular}{lccc}
\hline \multirow{2}{*}{ Obstáculos } & \multicolumn{2}{c}{ Grau de importância apontado pelos médicos - N (\%) } \\
\cline { 2 - 4 } & Grande importância & Pouca importância & Não considero barreira \\
\hline Obstáculo 1 & $20(72 \%)$ & $10(14 \%)$ & $10(14 \%)$ \\
\hline Obstáculo 2 & $24(82 \%)$ & $6(14 \%)$ & $0(0 \%)$ \\
\hline Obstáculo 3 & $20(66 \%)$ & $9(32 \%)$ & $3(6 \%)$ \\
\hline Obstáculo 4 & $23(76 \%)$ & $4(18 \%)$ & $4(7 \%)$ \\
\hline Obstáculo 5 & $22(74 \%)$ & $4(19 \%)$ & $7(26 \%)$ \\
\hline Obstáculo 6 & $13(42 \%)$ & $9(32 \%)$ & $3(12 \%)$ \\
\hline Obstáculo 7 & $19(64 \%)$ & $7(24 \%)$ & $3(6)$ \\
\hline
\end{tabular}

Obstáculo 1: falta de agentes em promoção de saúde que orientem a população a procurar o médico.

Obstáculo 2: falta de tempo do médico para realizar a prevenção secundária de câncer durante as consultas.

Obstáculo 3: demora entre as consultas do mesmo paciente.

Obstáculo 4: falta de interesse do paciente.

Obstáculo 5: falta de verba para custear os exames de prevenção.

Obstáculo 6: dificuldade em saber quando fazer o rastreamento.

Obstáculo 7: pouco conhecimento e/ou treinamento inadequado para fazer esse tipo de prevenção.

Fonte: Elaborada pelos autores.

Assim, observa-se que, exceto no obstáculo 6, todos foram avaliados como de grande importância por mais de $50 \%$ dos participantes - um resultado positivo, pois esse pode ser o primeiro passo para vencer tais obstáculos, e aumentar o conhecimento e melhorar o trabalho dos profissionais da saúde no diagnóstico precoce de câncer.

0 fato das "recomendações para fazer rastreamento dessas doenças não serem muito claras" terem sido apontadas apenas por $42 \%$ dos profissionais como de grande importância indica que não há clareza quanto às recomendações dos consensos para o rastreamento e diagnóstico precoce. 0 déficit nesse aspecto, somado à falta de conhecimento dos médicos diante dessas recomendações, leva-nos a concluir que a melhoria dessa situação certamente resultaria na obtenção de bons resultados no campo da saúde.

Além desses fatores, outro aspecto relacionado à dificuldade dos profissionais para aderir às recomendações seria a própria alteração frequente nas diretrizes. Um estudo realizado com ginecologistas/ obstetras americanos, por exemplo, demonstrou que inclusive especialistas na área apresentaram dificuldade para acompanhar as mudanças de recomendações nas diretrizes de rastreamento para o câncer de mama ${ }^{15}$.

As demais barreiras foram referidas como de grande importância, a exemplo da falta de educadores em saúde que estimulem a procura dos médicos pela população, bem como a falta de interesse do paciente, são fatores relativos à própria população que dificultam sobremaneira a adequada prestação 
de serviços por parte dos médicos. Em outro estudo, realizado em 2005 na mesma cidade, 70\% dos participantes consideraram de grande importância a falta de interesse do paciente e $66,6 \%$ a falta de educadores em saúde. Esse estudo também apontou que $66,6 \%$ indicaram ser importante a falta de verba para custear exames, resultado permanente em nosso estudo (importante para $74 \%$ dos participantes).

Vale notar, ainda, que $64 \%$ dos médicos apontaram como de grande importância a falta de conhecimento e/ou treinamento adequado para proporcionar esse tipo de prevenção. Tais resultados evidenciam que os médicos reconhecem sua falta de conhecimento sobre as medidas corretas para prevenção de câncer e sentem dificuldade diante da falta de treinamento prévio que enfoque essa questão.

\section{CONCLUSÃO}

A partir dos dados discutidos, constata-se um elevado déficit de conhecimento que poderia melhorar os índices de mortalidade de uma doença tão relevante como o câncer em nosso meio. De modo geral, os médicos não dominam as medidas preconizadas pelos consensos adotados - isso deve mudar, em prol da saúde pública de nosso país.

Também se evidenciou interesse dos médicos no diagnóstico precoce e na prevenção das condições mais prevalentes em nosso meio, porém, eles apresentam dificuldade para seguir o que é preconizado pelos consensos de prevenção, seja por conta da não homogeneidade de tais consensos ou pela própria falta de conhecimento sobre eles. Concluímos que nosso meio demanda um esforço multidisciplinar com foco na medicina preventiva, opção de escolha no âmbito da APS, enfatizando a importância das medidas de rastreamento para a prevenção de doenças de extrema relevância no país.

Percebe-se, ainda, acentuada escassez de literatura sobre o tema no Brasil, lacuna que deve ser

\section{Percebe-se, ainda, acentuada escassez de literatura sobre$$
\text { o tema no }
$$$$
\text { Brasil... }
$$

superada para avaliar adequadamente o conhecimento dos médicos sobre medidas de rastreamento de câncer em diversas localidades, com vistas a prover subsídios para a evolução da educação médica e, consequentemente, a qualificação dos serviços de saúde nacionais.

\section{CONTRIBUIÇÃO DOS AUTORES}

Lorena Alves Trajano, José Francisco Igor Siqueira Ferreira, Miguel Marcelo Freire de Melo e Luiz Eduardo de Castro Batista contribuíram com a realização da pesquisa, o delineamento do estudo e a redação e revisão crítica do manuscrito.

\section{REFERÊNCIAS}

1. Organização Pan-Americana da Saúde. Condições de saúde e suas tendências. In: OPAS. Saúde nas Américas. Brasília (DF): OPAS; 2007. v. 1, p. 62-217. (Publicação Científica e Técnica OPAS n. 622).

2. Duncan BB, Chor D, Aquino EML, Bensenor IM, Mill JG, Schmidt MI, et al. Doenças crônicas não transmissiveis no Brasil: prioridade para enfrentamento e investigação. Rev Saúde Pública [serial on the internet]. 2012 [cited 2019 May 24];46(Suppl):126-34. Available from: http://www. scielo.br/pdf/rsp/v46s1/17.pdf

3. Brasil. Estimativa 2016: incidência de câncer no Brasil. Rio de Janeiro: Instituto Nacional de Câncer; 2015.

4. Goss PE, Lee BL, Badovinac-Cmjevic T, StrasserWeippl J, Chavarri-Guerra Y, St Louis J, et al. Planejamento do controle do câncer na América Latina e no Caribe. Lancet Oncol. 2013;14:391-436.

5. Instituto de Pesquisa Econômica Aplicada. Atlas do desenvolvimento humano no Brasil [document on the internet]. date unknown [cited on 8 Sep 2017]. Available from: http://www.atlasbrasil.org. $\mathrm{br} / 2013 / \mathrm{pt} / \mathrm{consulta/}$

6. Gamarra CJ, Valente JG, Silva GA. Magnitude da mortalidade por câncer do colo do útero na Região Nordeste do Brasil e fatores socioeconômicos. Rev Panam Salud Publica [serial on the internet]. 2010 [cited 2019 May 24];28(2):100-6. Available from: https://scielosp.org/pdf/rpsp/2010.v28n2/100$106 / p t$

7. Brasil. Caderno de atenção primária: rastreamento. Brasília (DF): Ministério da Saúde; 2010. 
8. Tucunduva LTCM, Sá VHLC, Koshimura ET, Prudente FVB, Santos AF, Samano EST, et al. Estudo da atitude e do conhecimento dos médicos não oncologistas em relação às medidas de prevenção e rastreamento do câncer. Rev Assoc Méd Bras [serial on the internet]. 2004 [cited 2019 May 24];50(3):257-62. Available from: http://www.scielo.br/pdf/ramb/ v50n3/21655.pdf

9. Vineis P, Wild CP. Global cancer patterns: causes and prevention. Lancet. 2014;(383):549-57.

10. Hinz EK, Kudesia R, Rolston R, Caputo TA, Worley MJ Jr. Physician knowledge of and adherence to the revised breast cancer screening guidelines by the United States Preventive Services Task Force. Am J Obstet Gynecol. 2011;(205):e1-e5.

11. Silva LMC, Fonseca AJ, Ferreira LP, Dalla-Benetta $A C$, Navarro C. Atitude e conhecimento de médicos da Estratégia Saúde da Família sobre prevenção e rastreamento do câncer. Rev Bras Cancerol [serial on the internet]. 2011 [cited 2019 May 24];57(4):52534. Available from: http://www1.inca.gov.br/ $\mathrm{rbc/n} 57 / \mathrm{v} 04 / \mathrm{pdf} / 09$ artigo atitude e conhecimento medicos estrategia saude familia sobre prevencao rastreamento cancer.pdf

12. Aguiar FAR, Sousa TC, Branco JG0, Costa FBC, Torres ARA, Arruda LP. Produção do cuidado na rede de atenção ao câncer de mama: revisão integrativa. Sanare (Sobral, Online) [serial on the internet]. 2018;17(1):84-92. Available from: https:// sanare.emnuvens.com.br/sanare/article/ view $/ 1226 / 657$

13. Kale MS, Korenstein D. Overdiagnosis in primary care: framing the problem and finding solutions. BMJ. 2018;(362):k2820.

14. Ashford A, Gemson D, Gorin SNS, Bloch S, Lantigua $R$, Ahsan $H$, et al. Cancer screening and prevention practices of inner-city physicians. Am J Prev Med. $2000 ;(19): 59-62$.

15. Anderson BL, Pearlman M, Griffin J, Schulkin J. Conflicting and changing breast cancer screening recommendations: survey study of a national sample of ob-gyns after the release of the 2009 USPSTF guidelines. J Healthc Qual Res. 2013;35(4):25-35.
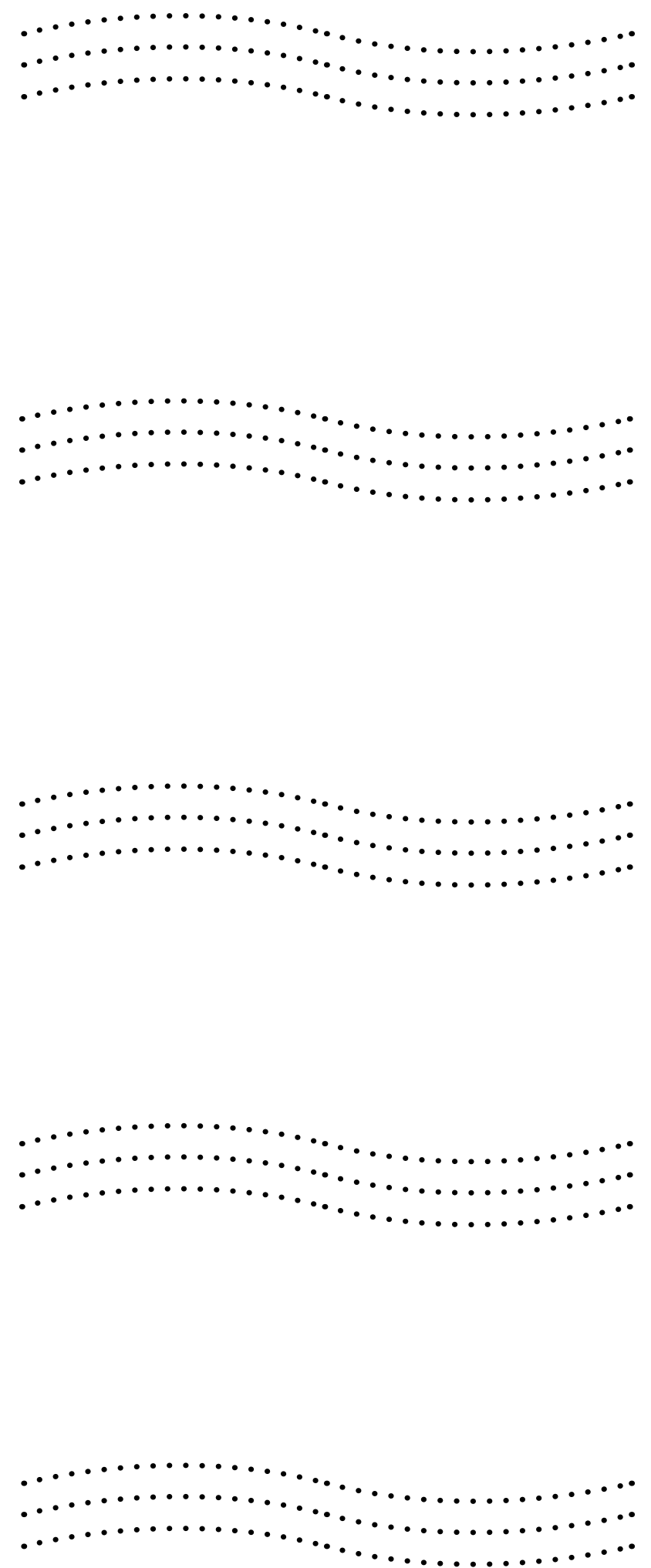

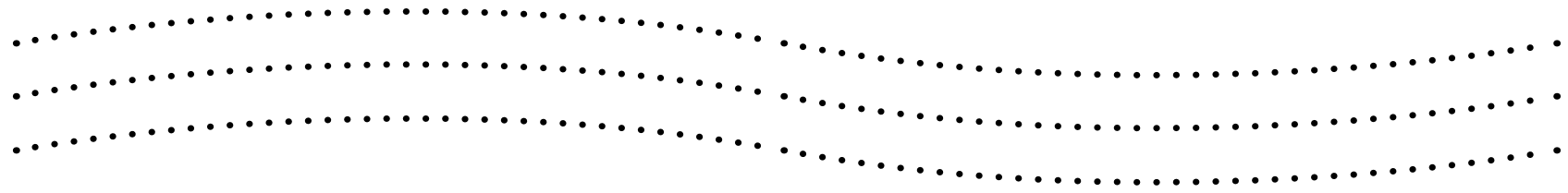




\title{
FATORES DE RISCO E COMPLICAÇÕES EM DIABÉTICOS/HIPERTENSOS CADASTRADOS NO HIPERDIA
}

RISK FACTORS AND COMPLICATIONS IN DIABETIC/HYPERTENSIVE PATIENTS REGISTERED IN THE HIPERDIA

FACTORES DE RIESGO Y COMPLICACIONES EN DIABÉTICOS/HIPERTENSOS CADASTRADOS EN EL HIPERDIA

Natanael Aguiar de Sousa ${ }^{1}$

Joab da Silva Lima 2

Taynã Cesário Teixeira ${ }^{3}$

Carlito Braga Linhares 4

João Vitor Lopes Montes 5

João Vitor Souza Marques 6

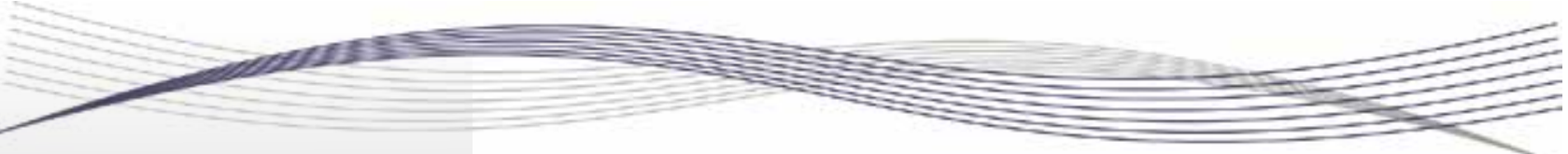

Palavras-chave:

Hipertensão; Diabetes Mellitus; Doenças Cardiovasculares; Fatores de Risco; Atenção Primária à Saúde.

Keywords:

Hypertension; Diabetes Mellitus; Cardiovascular Diseases; Risk Factors; Primary Health Care.

Palabras clave: Hipertensión; Diabetes Mellitus; Enfermedades Cardiovasculares; Factores de Riesgo; Atención Primaria de Salud.

Submetido: $12 / 01 / 2019$

\section{RESUMO}

As doenças cardiovasculares (DC) constituem a principal causa de morte no Brasil. A hipertensão arterial sistêmica (HAS) e o diabetes mellitus (DM) são os principais fatores de risco para esses agravos. 0 objetivo deste artigo é analisar os fatores de risco para HAS e DM, bem como as complicações que tais doenças podem causar, em Sobral, município no interior do Ceará. Trata-se de estudo descritivo transversal, realizado com os dados do Sistema de Cadastramento e Acompanhamento de Hipertensos e Diabéticos (HiperDia), de 2002 a 2013, com um total de 16.450 cadastrados. A análise estatística foi realizada de forma univariada (teste qui-quadrado). Encontrou-se prevalência do sexo feminino, entre 50 a 59 anos. 0 fator de risco mais frequente foi o sedentarismo, seguido por sobrepeso/obesidade e tabagismo. Observou-se associação estatisticamente significativa no tabagismo e em sobrepeso/obesidade. Já as complicações mais prevalentes, em ordem decrescente, foram: infarto agudo do miocárdio; acidente vascular encefálico; outras coronariopatias; e doença renal (DR), com associação estatisticamente significativa em todos os grupos, exceto na associação entre DR e DM. Os dados deste estudo podem constituir subsidios para o planejamento de ações tanto pelo poder público como pelos profissionais da saúde para acompanhar os pacientes hipertensos e diabéticos e, assim, evitar complicações.
\end{abstract}

Aprovado: 06/05/2019

Autor(a) para Correspondência: Natanael Aguiar de Sousa Rua Corina Dantas, 52, Bairro Derby, Sobral - CE, CEP: 62042220 E-mail:natan6521@gmail.com
1. Aluno de Graduação em Medicina na Universidade Federal do Ceará (UFC). Sobral (CE), Brasil. E-mail: natan6521@gmail.com

2. Aluno de Graduação em Medicina na UFC. Sobral (CE), Brasil. E-mail: joab98silva@gmail.com

3. Aluna de Graduação em Medicina na UFC. Sobral (CE), Brasil. E-mail: tayteixeira14@gmail.com

4. Aluno de Graduação em Medicina na UFC. Sobral (CE), Brasil. E-mail: carlitobraga22@gmail.com

5. Aluno de Graduação em Medicina na UFC. Sobral (CE), Brasil. E-mail: vitormontes41@gmail.com

6. Aluno de Graduação em Medicina na UFC. Sobral (CE), Brasil. E-mail: joao_vitorsm@hotmail.com 


\section{ABSTRACT}

Cardiovascular diseases (CDs) are the main cause of death in Brazil. Systemic arterial hypertension (SAH) and diabetes mellitus (DM) are the main risk factors for these issues. This article aims to analyze the risk factors for SAH and DM, as well as the complications that such diseases can cause, in Sobral, a municipality in the countryside of Ceará, Brazil. This is a cross-sectional descriptive study, carried out with data from the System for Registration and Follow-Up of Hypertensive and Diabetic Patients (Sistema de Cadastramento e Acompanhamento de Hipertensos e Diabéticos - HiperDia), within the period from 2002 to 2013, with a total of 16,450 patients registered. Statistical analysis was performed on a univariate basis (chi-square test). Prevalence was found in women between 50 and 59 years of age. The most frequent risk factor was sedentary lifestyle, followed by overweight/obesity and smoking. There was a statistically significant association in smoking and overweight/ obesity. In turn, the most prevalent complications, in descending order, were: acute myocardial infarction; stroke; other coronary diseases; and kidney disease (KD), with a statistically significant association in all groups, except in the association between KD and DM. The data from this study may be used as a means for planning both on the part of public power and health professionals to monitor hypertensive and diabetic patients, thus avoiding complications.

\section{RESUMEN}

Las enfermedades cardiovasculares (ECS) son la principal causa de muerte en Brasil. La hipertensión arterial sistémica (HAS) y la diabetes mellitus (DM) son los principales factores de riesgo para estos problemas. Este artículo tiene como objetivo analizar los factores de riesgo para HAS y DM, así como las complicaciones que estas enfermedades pueden causar, en Sobral, un municipio en el interior de Ceará, Brasil. Este es un estudio descriptivo transversal, realizado con datos del Sistema de Registro y Seguimiento de Hipertensos y Diabéticos (Sistema de Cadastramento e Acompanhamento de Hipertensos e Diabéticos - HiperDia), en el período de 2002 a 2013, con un total de 16.450 pacientes registrados. El análisis estadístico se realizó de forma univariada (prueba de chi-cuadrado). Se encontró prevalencia en mujeres entre 50 y 59 años de edad. El factor de riesgo más frecuente fue el estilo de vida sedentario, seguido por sobrepeso/obesidad y tabaquismo. Hubo una asociación estadísticamente significativa en tabaquismo y sobrepeso/obesidad. A su vez, las complicaciones más prevalentes, en orden descendente, fueron: infarto agudo de miocardio; accidente vascular encefálico; otras enfermedades coronarias; y enfermedad renal (ER), con una asociación estadisticamente significativa en todos los grupos, excepto en la asociación entre ER y DM. Los datos de este estudio pueden ser utilizados como subsidios para planificación de acciones tanto por el poder público como por los profesionales de la salud para acompañar a los pacientes hipertensos y diabéticos, y así evitar complicaciones.

\section{INTRODUÇÃO}

As doenças cardiovasculares (DCs) constituem a principal causa de morte no Brasil $(27,4 \%)$, segundo dados do Ministério da Saúde (MS). Dentre as causas cardiovasculares, o acidente vascular encefálico (AVE) e o infarto agudo do miocárdio (IAM) são as mais prevalentes. A hipertensão arterial sistêmica (HAS) e o diabetes mellitus (DM) constituem os principais fatores de risco populacional para esses agravos $^{1}$.

A HAS é uma condição clínica multifatorial caracterizada por elevação sustentada dos níveis pressóricos a valores iguais ou maiores que 140 e/ ou $90 \mathrm{mmHg}$, atingindo $32,5 \%$ dos indivíduos adultos no Brasil (cerca de 36 milhões) e mais de $60 \%$ dos idosos. Além de propiciar outras doenças, a HAS tem elevado impacto na perda da produtividade e renda do indivíduo acometido. É necessário um adequado controle pressórico, com medidas farmacológicas e não farmacológicas, cujo objetivo principal é reduzir o risco de lesões em órgãos-alvo ${ }^{2}$.

Já o DM é uma doença endócrino-metabólica de etiologia heterogênea, caracterizada por hiperglicemia crônica, resultante de anomalias da secreção (DM tipo 1) ou da ação da insulina (DM tipo 2). Seu diagnóstico se dá, principalmente, por meio da glicemia de jejum de 8 horas (2 valores maiores ou iguais a 126). Em 2010, o DM atingia 6,4\% da população adulta mundial (20 a 79 anos) ${ }^{3}$. Para 0 DM, é necessário um controle metabólico rigoroso, associado a medidas preventivas e curativas simples, capazes de prevenir ou retardar o surgimento de complicações crônicas. Para ambas as condições 
clínicas, mudanças no estilo de vida são essenciais ${ }^{4}$.

Tendo em vista a necessidade do controle dessas importantes comorbidades para a diminuição da mortalidade pelas DCs, criou-se o Plano de Reorganização da Atenção à Hipertensão Arterial e ao Diabetes Mellitus - que recorre a ações educativas e consultas médicas agendadas, entre outras medidas, com o propósito de reduzir o número de hospitalizações e instituir um melhor acompanhamento e tratamento dos pacientes na atenção primária à saúde (APS).

0 cadastro e o acompanhamento dos usuários portadores de HAS e/ou DM são realizados por meio do Sistema de Cadastramento e Acompanhamento de Hipertensos e Diabéticos (HiperDia), criado em $2002^{5}$. Trata-se de um programa que se destina ao cadastramento e acompanhamento de portadores de HAS e/ou DM atendidos na rede ambulatorial do Sistema Único de Saúde (SUS) ${ }^{6}$. 0 HiperDia é organizado com base nos municípios nele cadastrados. Seu principal objetivo é gerar informações cruciais para os gestores em todas as esferas administrativas (a própria unidade de saúde municipal, os gestores estaduais e o MS). Alguns dos dados que se pode obter no HiperDia são: a) perfil epidemiológico de determinada população, para posterior implementação de medidas preventivas, como os fatores de risco para o desenvolvimento de HAS e DM; b) presença ou ausência de tabagismo, sedentarismo e sobrepeso/obesidade; e c) presença ou ausência de complicações que o paciente apresenta, como IAM, AVE, doença renal (DR) e outras coronariopatias. 0 HiperDia também monitora o recebimento dos medicamentos prescritos ${ }^{7}$.

Entender os principais fatores de risco, as variáveis envolvidas no desenvolvimento desses agravos e suas complicações é crucial para a instituição de possíveis políticas preventivas em determinada população. Diante do exposto, o objetivo deste artigo é:

- Analisar os fatores de risco para hipertensão arterial sistêmica e diabetes mellitus, bem como as complicações que tais doenças podem causar, em Sobral, município no interior do Ceará.

\section{METODOLOGIA}

Trata-se de pesquisa descritiva transversal, realizada com dados do HiperDia. A população do estudo consistiu em pacientes cadastrados nesse sistema no município de Sobral, entre janeiro

\author{
Seu principal \\ objetivo é gerar \\ informações cruciais \\ para os gestores \\ em todas as esferas \\ administrativas...
}

de 2002 e abril de 2013. Ao final desse periodo, havia 16.450 usuários cadastrados (5.293 do sexo masculino e 11.157 do sexo feminino). Segundo o Censo de 2010, do Instituto Brasileiro de Geografia e Estatística (IBGE), Sobral tinha uma população de 188.233 habitantes (91.462 do sexo masculino e 96.771 do sexo feminino $)^{8}$. Para melhor compreensão, os pacientes foram divididos em 3 grupos ( $A, B$ e $C$ ), representando respectivamente HAS, DM e HAS/DM associadas.

As variáveis epidemiológicas estudadas foram: a) sociodemográficas (sexo e faixa etária), com frequência absoluta e frequência relativa; b) fatores de risco para DC já apontados pela literatura (sedentarismo, tabagismo e sobrepeso/obesidade); e c) complicações segundo as condições clínicas (IAM, AVE, DR e outras coronariopatias). Também se realizou a associação entre os fatores de risco e as complicações relacionadas às condições clínicas.

Para a análise de dados foram utilizados os programas computacionais Microsoft Excel, Bioestat 5.0 e Epi Info 7 e também se aplicou o teste qui-quadrado para avaliar se houve associação estatisticamente significativa entre as variáveis quando $p<0,05$ no universo dos pacientes cadastrados no HiperDia.

\section{RESULTADOS}

Um total de 16.450 usuários do SUS, dos centros da Estratégia Saúde da Família (ESF) do município de Sobral-CE, cadastraram-se no HiperDia no período de janeiro de 2002 a abril de 2013. Destes, 10.997 foram registrados como acometidos com HAS, 891 com DM e 4.562 como portadores das 2 comorbidades associadas. A análise desses dados possibilitou a descrição de algumas características sociodemográficas, como sexo e faixa etária, resumidas na Tabela 1 . Há prevalência do sexo feminino $(67,82 \%)$ e da faixa etária entre 50-59 anos 
$(24,70 \%) ; 23,94 \%$ dos cadastrados se encontram na faixa entre $60-69$ anos e $17,97 \%$ entre $70-79$ anos. Mais de $90 \%$ dos usuários se encontram acima dos 40 anos.

Tabela 1 - Caracterização dos usuários de Sobral cadastrados no HiperDia $(n=16.450)$

\begin{tabular}{lcc}
\hline Variáveis sociodemográficas & F & $\%$ \\
\hline Sexo & 5.293 & $32,18 \%$ \\
\hline Masculino & 11.157 & $67,82 \%$ \\
Feminino & & $0,63 \%$ \\
\hline Faixa etária & 104 & $1,67 \%$ \\
\hline 20 anos & 275 & $6,61 \%$ \\
\hline $20-29$ anos & 1.088 & $16,72 \%$ \\
\hline $30-39$ anos & 2.751 & $24,70 \%$ \\
\hline $40-49$ anos & 4.063 & $23,94 \%$ \\
\hline $50-59$ anos & 3.938 & $17,97 \%$ \\
\hline $60-69$ anos & 2.956 & $7,75 \%$ \\
\hline $70-79$ anos & 1.275 & \\
\hline
\end{tabular}

$\mathrm{F}=$ frequência absoluta; $\%=$ frequência relativa.

Fonte: Elaborada pelos autores.

As Tabelas 2 e 3 ilustram os fatores de risco e as complicações, respectivamente, e sua relação com HAS e/ ou DM na população em estudo. Utilizou-se o teste $x^{2}$ para verificar as possíveis associações entre as variáveis e, assim, avaliar a significância estatística.

Tabela 2 - Caracterização dos fatores de risco, segundo condições clínicas, em usuários de Sobral cadastrados no HiperDia $(n=16.450)$

\begin{tabular}{|c|c|c|c|c|c|c|c|c|}
\hline \multirow{3}{*}{$\begin{array}{l}\text { Fatores de } \\
\text { risco }\end{array}$} & \multicolumn{2}{|c|}{$\begin{array}{c}\text { HAS } \\
(\text { Grupo A) } \\
\end{array}$} & \multicolumn{2}{|c|}{$\begin{array}{c}\text { DM } \\
\text { (Grupo B) }\end{array}$} & \multicolumn{2}{|c|}{$\begin{array}{l}\text { HAS + DM } \\
(\text { Grupo C) }\end{array}$} & \multicolumn{2}{|c|}{ Total } \\
\hline & $\mathrm{F}$ & $\%$ & $\mathrm{~F}$ & $\%$ & $\mathrm{~F}$ & $\%$ & $\mathrm{~F}$ & $\%$ \\
\hline & & & & & & & & \\
\hline Sim & 2.504 & $15,22 \%$ & 202 & $1,23 \%$ & 1.388 & $8,44 \%$ & 4.094 & $24,89 \%$ \\
\hline Não & 8.493 & $51,63 \%$ & 689 & $4,19 \%$ & 3.174 & $19,29 \%$ & 12.356 & $75,11 \%$ \\
\hline Valor $p$ & \multicolumn{2}{|c|}{$<0,0001$} & \multicolumn{2}{|c|}{0,116} & \multicolumn{2}{|c|}{$<0,0001$} & & \\
\hline \multicolumn{9}{|c|}{ Sobrepeso/obesidade } \\
\hline Sim & 3.298 & $20,05 \%$ & 264 & $1,60 \%$ & 1.673 & $10,17 \%$ & 5.235 & $32,62 \%$ \\
\hline Não & 7.699 & $46,80 \%$ & 627 & $3,81 \%$ & 2.889 & $17,56 \%$ & 11.215 & $67,38 \%$ \\
\hline Valor $p$ & \multicolumn{2}{|c|}{$<0,0001$} & \multicolumn{2}{|c|}{0,009} & \multicolumn{2}{|c|}{$<0,0001$} & & \\
\hline \multicolumn{9}{|c|}{ Sedentarismo } \\
\hline Sim & 4.793 & $29,14 \%$ & 395 & $2,40 \%$ & 2.051 & $12,47 \%$ & 7.239 & $44,01 \%$ \\
\hline Não & 6.204 & $37,71 \%$ & 496 & $3,02 \%$ & 2.511 & $15,26 \%$ & 9.211 & $55,99 \%$ \\
\hline Valor $p$ & \multicolumn{2}{|c|}{0,122} & \multicolumn{2}{|c|}{0,839} & \multicolumn{2}{|c|}{0,127} & & \\
\hline
\end{tabular}

$F=$ frequência absoluta; $\%=$ frequência relativa.

Fonte: Elaborada pelos autores. 
Na população em estudo, 24,89\% apresentam o fator de risco tabagismo, sendo este o menos frequente. 0 tabagismo se apresenta com frequência maior no grupo A (15,22\%). Apesar da associação entre tabagismo e DM não apresentar significância estatística $(p=0,116)$, as outras 2 condições apresentaram $p<0,05$.

0 fator de risco sobrepeso/obesidade está presente em 32,62\% dos portadores das comorbidades em estudo. Esse fator mais presente no grupo A $(20,05 \%)$ e menos presente no grupo B (1,60\%). Ao verificar a associação estatística entre esse fator e as condições clínicas, todos apresentaram resultados significativos.

0 sedentarismo foi o fator de risco mais presente: 44,01\% não praticam atividade física regular; $29,14 \%$ dos sedentários apresentam HAS, enquanto $12,47 \%$ têm a associação HAS e DM e 2,40\% têm o DM isoladamente. Quanto às associações estatísticas, nenhuma apresentou $p<0,05$.

Tabela 3 - Caracterização das complicações segundo condições clínicas em usuários de Sobral cadastrados no HiperDia $(n=16.450)$

\begin{tabular}{|c|c|c|c|c|c|c|c|c|}
\hline \multirow[t]{2}{*}{ Complicações } & \multicolumn{2}{|c|}{$\begin{array}{c}\text { HAS } \\
\text { (Grupo A) }\end{array}$} & \multicolumn{2}{|c|}{$\begin{array}{c}\text { DM } \\
(\text { Grupo B }) \\
\end{array}$} & \multicolumn{2}{|c|}{$\begin{array}{l}\text { HAS + DM } \\
\text { (Grupo C) }\end{array}$} & \multicolumn{2}{|c|}{ Total } \\
\hline & $\mathrm{F}$ & $\%$ & $\mathrm{~F}$ & $\%$ & $\mathrm{~F}$ & $\%$ & $\mathrm{~F}$ & $\%$ \\
\hline \multicolumn{9}{|c|}{ Outras coronariopatias } \\
\hline Sim & 461 & $2,80 \%$ & 13 & $0,08 \%$ & 271 & $1,65 \%$ & 745 & $4,53 \%$ \\
\hline Não & 10.536 & $64,05 \%$ & 878 & $5,34 \%$ & 4.291 & $26,09 \%$ & 15.705 & $95,47 \%$ \\
\hline Valor $p$ & \multicolumn{2}{|c|}{0,003} & \multicolumn{2}{|c|}{$<0,0001$} & \multicolumn{2}{|c|}{$<0,0001$} & & \\
\hline \multicolumn{9}{|c|}{ Infarto agudo do miocárdio } \\
\hline Sim & 494 & $3,00 \%$ & 22 & $0,13 \%$ & 361 & $2,19 \%$ & 877 & $5,33 \%$ \\
\hline Não & 10.503 & $63,85 \%$ & 869 & $5,28 \%$ & 4.201 & $25,54 \%$ & 15.573 & $94,67 \%$ \\
\hline Valor $p$ & \multicolumn{2}{|c|}{$<0,0001$} & \multicolumn{2}{|c|}{$<0,0001$} & \multicolumn{2}{|c|}{$<0,0001$} & & \\
\hline \multicolumn{9}{|c|}{ Acidente vascular encefálico } \\
\hline Sim & 469 & $2,85 \%$ & 20 & $0,12 \%$ & 383 & $2,33 \%$ & 872 & $5,30 \%$ \\
\hline Não & 10.528 & $64,00 \%$ & 871 & $5,29 \%$ & 4.179 & $25,40 \%$ & 15.578 & $94,70 \%$ \\
\hline Valor $p$ & \multicolumn{2}{|c|}{$<0,0001$} & \multicolumn{2}{|c|}{$<0,0001$} & \multicolumn{2}{|c|}{$<0,0001$} & & \\
\hline \multicolumn{9}{|l|}{ Doença renal } \\
\hline Sim & 307 & $1,87 \%$ & 29 & $0,18 \%$ & 209 & $1,27 \%$ & 545 & $3,31 \%$ \\
\hline Não & 10.690 & $64,98 \%$ & 862 & $5,24 \%$ & 4.353 & $26,46 \%$ & 15.905 & $96,69 \%$ \\
\hline Valor $p$ & \multicolumn{2}{|c|}{$<0,0001$} & \multicolumn{2}{|c|}{0,918} & \multicolumn{2}{|c|}{$<0,0001$} & & \\
\hline
\end{tabular}

$F=$ frequência absoluta; $\%=$ frequência relativa.

Fonte: Elaborada pelos autores.

As complicações associadas às condições clínicas em estudo também foram analisadas no âmbito do HiperDia, sendo o IAM e o AVE os mais frequentes ( $5,33 \%$ e $5,30 \%$, respectivamente). As doenças coronarianas, o IAM e AVE estão mais presentes no grupo $A(2,80 \%, 3,00 \%, 2,85 \%$, respectivamente) e apresentaram significância estatística nos 3 grupos $(p<0,05)$. A DR foi a menos frequente $(3,31 \%)$ e, mediante teste, evidenciou-se associação estatística apenas nos grupos $\mathrm{A}(p<0,0001)$ e $C(p<0,0001)$, ao passo que no grupo B se obteve $p=0,918$.

Para finalizar, também se averiguou associação entre os fatores de risco e as complicações e aplicou-se o teste $x^{2}$ para verificar se há significância estatística, como resume a Tabela 4 . 
Tabela 4 - Associação entre fatores de risco e complicações relacionadas às condições clínicas em usuários de Sobral cadastrados no HiperDia $(\mathrm{n}=16.450)$

\begin{tabular}{|c|c|c|c|c|c|c|c|c|c|c|c|c|c|}
\hline \multirow{3}{*}{$\begin{array}{l}\text { Fatores de } \\
\text { risco }\end{array}$} & & \multicolumn{12}{|c|}{ Complicações } \\
\hline & & \multicolumn{3}{|c|}{$\begin{array}{c}\text { Outras } \\
\text { coronariopatias }\end{array}$} & \multicolumn{3}{|c|}{ IAM } & \multicolumn{3}{|c|}{ AVE } & \multicolumn{3}{|c|}{ Doença renal } \\
\hline & & $\mathrm{H}$ & DM & $\begin{array}{l}\mathrm{H}+ \\
\mathrm{DM} \\
\end{array}$ & H & DM & $\begin{array}{l}\mathrm{H}+ \\
\mathrm{DM}\end{array}$ & H & DM & $\begin{array}{l}\mathrm{H}+ \\
\mathrm{DM}\end{array}$ & $\mathrm{H}$ & DM & $\begin{array}{l}\mathrm{H}+ \\
\mathrm{DM}\end{array}$ \\
\hline \multirow{3}{*}{ Tabagismo } & $\mathrm{F}$ & 144 & 6 & 115 & 187 & 11 & 178 & 204 & 12 & 188 & 125 & 9 & 92 \\
\hline & $\%$ & 0,88 & 0,04 & 0,70 & 1,14 & 0,07 & 1,08 & 1,24 & 0,07 & 1,14 & 0,76 & 0,05 & 0,56 \\
\hline & Valor $p$ & \multicolumn{3}{|c|}{$<0,0001$} & \multicolumn{3}{|c|}{$<0,0001$} & \multicolumn{3}{|c|}{$<0,0001$} & \multicolumn{3}{|c|}{$<0,0001$} \\
\hline \multirow{3}{*}{$\begin{array}{l}\text { Sedenta- } \\
\text { rismo }\end{array}$} & $\mathrm{F}$ & 224 & 8 & 135 & 213 & 12 & 157 & 227 & 12 & 162 & 116 & 11 & 108 \\
\hline & $\%$ & 1,36 & 0,05 & 0,82 & 1,29 & 0,07 & 0,95 & 1,38 & 0,07 & 0,98 & 0,71 & 0,07 & 0,66 \\
\hline & Valor $p$ & \multicolumn{3}{|c|}{0,003} & \multicolumn{3}{|c|}{0,783} & \multicolumn{3}{|c|}{0,226} & \multicolumn{3}{|c|}{0,671} \\
\hline \multirow{3}{*}{$\begin{array}{l}\text { Sobrepeso/ } \\
\text { obesidade }\end{array}$} & $\mathrm{F}$ & 146 & 4 & 102 & 155 & 8 & 147 & 141 & 5 & 163 & 92 & 3 & 75 \\
\hline & $\%$ & 0,89 & 0,02 & 0,62 & 0,94 & 0,05 & $0,89 \%$ & 0,86 & 0,03 & 0,99 & 0,56 & 0,02 & 0,46 \\
\hline & Valor $p$ & \multicolumn{3}{|c|}{0,013} & \multicolumn{3}{|c|}{0,001} & \multicolumn{3}{|c|}{0,001} & \multicolumn{3}{|c|}{0,027} \\
\hline
\end{tabular}

$F=$ frequência absoluta; \% = frequência relativa.

Fonte: Elaborada pelos autores.

Ao aplicar o teste, verificou-se que o tabagismo apresentou associação estatística com todas as complicações e mostrou-se mais frequente no grupo que tem AVE como complicação (2,45\%). 0 fator de risco sedentarismo também foi mais frequente no grupo com AVE (2,43\%) e obteve associação estatística apenas quando relacionado às doenças arteriais coronarianas $(p=0,003)$. 0 sobrepeso/ obesidade está relacionado mais frequentemente a IAM e AVE (1,88\% cada). E esse fator de risco está estatisticamente associado a outras coronariopatias $(p=0,013)$, com $\operatorname{IAM}(p=0,001)$ e $\operatorname{AVE}(p=0,001)$, não apresentando associação estatística com a DR.

Vale destacar, ainda, que os maiores percentuais foram obtidos na associação do fator de risco sedentarismo, nos portadores de HAS isoladamente (Grupo A), com as complicações doenças arteriais coronarianas $(1,36 \%)$, IAM $(1,29 \%)$ e AVE $(1,38 \%)$.

\section{DISCUSSÃO}

0 sobrepeso/obesidade representa $32,62 \%$ dos indivíduos cadastrados no HiperDia. Nota-se forte relação desse fator de risco com o quadro de HAS e DM. Indivíduos com obesidade têm mais chances de ser hipertensos do que os indivíduos com peso considerado normal ${ }^{9}$. A prevalência de sobrepeso/ obesidade tem aumentado em todo o mundo e é considerado importante fator de risco para a HAS $^{9}$. Com o aumento do índice de massa corporal (IMC), o risco de desenvolver DM tipo 2 fica mais pronunciado, justificado pelo aumento da resistência periférica à insulina, que, por consequência, aumenta a glicemia ${ }^{10}$. Um estudo realizado com 170 pacientes para avaliar a prevalência de sobrepeso e obesidade em DM tipo 1 mostrou que a frequência de obesidade, sobrepeso e/ou risco de sobrepeso foi de $21,2 \%{ }^{11}$, resultado que corrobora os deste estudo.

Ao analisar a quantidade de pacientes tabagistas, observa-se que esse fator foi o menos frequente dos 3 fatores de risco e nota-se, ainda, que dentre os 3 grupos, o A foi o que teve maior frequência $(15,22 \%)$, também apresentando associação estatística. Isso corrobora os resultados de outros estudos que mostram fumantes e ex-fumantes apresentando maior prevalência de $\mathrm{HAS}^{9,12}$. Tabagismo e HAS se relacionam por meio de uma complexa interação entre fatores hemodinâmicos, sistema nervoso autonômico e múltiplos mediadores vasoativos. Hipertensos tabagistas têm pior prognóstico cardiovascular, mesmo quando tratados adequadamente ${ }^{13}$.

Em relação às complicações, vale ressaltar o fato da HAS, como condição clínica isolada, estar mais intimamente relacionada a possíveis complicações do que o DM, visto que teve maior prevalência em todas as categorias analisadas. 0 IAM foi a complicação mais frequente no estudo. Cerca de metade dos pacientes com essa complicação faz parte do grupo dos que têm HAS isoladamente, essa condição está fortemente associada à complicação. Constatou-se em um estudo com infartados que 55\% deles eram hipertensos e em outro similar esse achado alcançou 
$52 \%^{14,15}$. 0 DM, quando comparado a essa complicação, também mostrou resultado significativo $(p<0,05)$. 0 estudo FRICAS detectou $19,7 \%$ de diabéticos entre os infartados e $9,93 \%$ nos casos controle ${ }^{15}$.

A segunda complicação mais frequente foi o AVE, também mostrando resultados estatisticamente significativos, com prevalência maior no grupo $A$, o que corrobora estudos que concluíram que a HAS é o principal fator de risco para $\operatorname{AVE}^{16,17}$. Um deles evidenciou que a HAS foi detectada em $94,1 \%$ dos pacientes portadores de $A_{V E}{ }^{17}$. 0 DM e o AVE também são duas entidades patológicas intimamente relacionadas. Uma das principais complicações crônicas da DM é a doença vascular. Um estudo com 134 acometidos por AVE mostrou que 30,6\% tinham diagnóstico prévio de $D M^{18}$.

Em relação à $D R$, o grupo $B$ foi o único que não apresentou significância estatística $(p=0,918)$, - que ratifica a importante relação da HAS com a apresentação de acometimento renal nesses pacientes. Um estudo com maior associação entre DR e o grupo com HAS corrobora esse resultado, onde a prevalência de reduzida filtração glomerular $(<60$ $\mathrm{ml} / \mathrm{min}$ ) foi de $24,6 \%$ no grupo com HAS sem DM e $18,3 \%$ no grupo com as 2 doenças associadas ${ }^{19}$.

As outras coronariopatias apresentaram associação significativa com as doenças em estudo ( $p$ $<0,05)$. Dentre os portadores dessas complicações, metade eram hipertensos isoladamente e os demais tinham HAS e DM. Um estudo semelhante realizado no Nordeste brasileiro evidenciou resultado equivalente ${ }^{20}$.

Também se obtém resultados interessantes ao traçar um paralelo entre complicações e fatores de risco. Em primeiro lugar, observa-se maior relação do sedentarismo com as outras coronariopatias, sendo esse fator de risco mais prevalente em relação a essa complicação. 0s dados deste estudo, embora mostrem maior associação de sedentarismo a complicações do que em relação ao tabagismo (em números absolutos), são questionáveis devido à significância estatística, visto que os valores demonstrados para sedentarismo se mostraram menos confiáveis do que os encontrados para tabagismo. 0 tabagismo mostrou significância estatística para todas as complicações estudadas, ao passo que o sedentarismo mostrou significância estatística somente no grupo de outras coronariopatias. Estudo semelhante realizado com os usuários de Fortaleza-CE cadastrados no HiperDia não mostrou associação do sedentarismo com nenhuma das complicações ${ }^{20}$.

\section{O tabagismo mostrou significância estatística para todas as complicações estudadas...}

Por fim, sobrepeso/obesidade se mostrou o fator de risco com menor prevalência ao associar as complicações em comparação aos outros 2 apresentados. 0 sobrepeso/obesidade mostrou significância estatística em relação ao IAM e ao AVE, o que não ocorreu com o sedentarismo em relação a essas 2 complicações. Logo, o sobrepeso/ obesidade se mostra um importante fator de risco e está associado, principalmente, nos casos de HAS ou nas 2 comorbidades associadas. 0 aumento do consumo de alimentos de alto valor energético e a diminuição da prática de atividade física têm tornado a obesidade cada vez mais prevalente, pois se trata de um fator importante no desenvolvimento de HAS, DM, cardiopatias e até alguns de tipos de câncer ${ }^{21,22}$. Reitera-se, assim, a necessidade de controle do peso para prevenir futuras complicações.

Os dados utilizados para compor esta pesquisa são os mesmos disponiveis para consulta e planejamento de ações por parte das instituições de saúde responsáveis por acompanhar e estabelecer políticas públicas para essas comorbidades, assim, este estudo pode contribuir com o aprimoramento da análise dessas condições clínicas crônicas na população, importantes causas de complicações que poderiam ser prevenidas na APS, o que evitaria excessivos custos com cuidados nos níveis secundário e terciário de atenção à saúde.

\section{CONCLUSÃO}

Este estudo identificou que a prevalência epidemiológica dos usuários de Sobral cadastrados no HiperDia, no período de janeiro de 2002 a abril de 2013, recaiu sobre o sexo feminino, na faixa etária de 50 a 59 anos. Dentre os fatores de risco avaliados, o mais frequente foi o sedentarismo, seguido por sobrepeso/obesidade e, por último, tabagismo. Houve associação estatisticamente significativa no tabagismo e em sobrepeso/ obesidade. Já as complicações mais prevalentes 
identificadas, em ordem decrescente, foram: IAM, $A V E$, outras coronariopatias e $D R$, com associação estatisticamente significativa em todos os grupos, exceto na associação entre DR e DM.

Os dados obtidos neste estudo comprovam a necessidade de proporcionar promoção à saúde por meio da equipe multiprofissional, incentivando 0 abandono do tabagismo, a perda de peso e a atividade física, bem como o acompanhamento rigoroso desses pacientes nas consultas, priorizando a adesão ao tratamento para evitar futuras complicações. Mostrase indispensável, inclusive, formular políticas de saúde com vistas ao diagnóstico precoce de DM e HAS, diminuindo o risco de morbimortalidade, pois parte dos pacientes já apresentam complicações no momento do diagnóstico.

Portanto, os dados deste estudo podem constituir subsídios para o planejamento de ações tanto por parte do poder público como pelos profissionais da saúde para acompanhar os pacientes hipertensos e diabéticos e, assim, evitar complicações, internações hospitalares e gastos desnecessários de recursos públicos voltados ao setor saúde.

\section{CONTRIBUIÇÃO DOS AUTORES}

Natanael Aguiar de Sousa contribuiu com a realização da pesquisa e o delineamento e a redação do manuscrito. Joab da Silva Lima e Carlito Braga Linhares contribuíram com a redação do manuscrito. Taynã Cesário Teixeira e João Vitor Lopes Montes contribuíram com a realização da pesquisa. João Vitor Souza Marques contribuiu com a revisão crítica do manuscrito.

\section{REFERÊNCIAS}

1. Brasil. Hipertensão arterial sistêmica e diabetes mellitus - protocolo. Brasília (DF): Ministério da Saúde; 2001. (Cadernos de Atenção Básica n. 7).

2. Malachias MVB, Souza WKSB, Plavnik FL, Rodrigues CIS, Brandão AA, Neves MFT, et al. $7^{\text {a }}$ Diretriz Brasileira de Hipertensão Arterial. Rio de Janeiro: Sociedade Brasileira de Cardiologia; 2016.

3. Brasil. Portaria Conjunta n. 8, de 15 de março de 2018. Aprova o Protocolo Clínico e Diretrizes Terapêuticas da Diabete Melito Tipo 1 [document on the internet]. 2018. [cited 2018 0ct 8]. Available from: http://portalarquivos2.saude.gov.br/images/ pdf/2018/marco/19/Portaria-Conjunta-n-8.pdf
4. Sociedade Brasileira de Hipertensão. III Consenso Brasileiro de Hipertensão Arterial. Arq Bras Endocrinol Metab [serial on the internet]. 1999 [cited 2019 May 23];43(4):257-86. Available from: http://www.scielo.br/pdf/abem/v43n4/11752.pdf

5. Silva JVM, Mantovani MF, Kalinke LP, Ulbrich EM. Avaliação do Programa de Hipertensão Arterial e Diabetes Mellitus na visão dos usuários. Rev Bras Enferm [serial on the internet]. 2015 [cited $20180 \mathrm{ct}$ 8];68(4):626-32. Available from: http://www.scielo. $\mathrm{br} / \mathrm{pdf} / \mathrm{reben} / \mathrm{v} 68 \mathrm{n} 4 / 0034-7167-$ reben-68-04-0626. $\underline{p d f}$

6. HiperDia. [homepage on the internet]. c2001 [cited 2018 0ct 12]. Available from: http:// datasus.saude.gov.br/sistemas-e-aplicativos/ epidemiologicos/hiperdia

7. Reis A, Cesarino C. Fatores de risco e complicações em usuários cadastrados no HiperDia de São José do Rio Preto. Ciênc Cuid Saúde [serial on the internet]. 2016 [cited 2019 May 23];15(1):118-24. Available from: http://periodicos.uem.br/ojs/index.php/ CiencCuidSaude/article/view/24235/16986

8. Instituto Brasileiro de Geografia e Estatística. Brasil/Ceará: Sobral [document on the internet]. c2017. [cited 2018 0ct 8]. Available from: https:// cidades.ibge.gov.br/brasil/ce/sobral/panorama

9. Radovanovic CAT, Santos LA, Carvalho MDB, Marcon SS. Hipertensão arterial e outros fatores de risco associados às doenças cardiovasculares em adultos. Rev Latinoam Enferm [serial on the internet]. 2014 [cited 2019 May 23];22(4):54753. Available from: http://www.scielo.br/pdf/rlae/ v22n4/pt 0104-1169-rlae-22-04-00547.pdf

10. Escobar FA. Relação entre obesidade e diabete mellitus tipo II em adultos. Cadernos UnifoA [serial on the internet]. 2009 [cited 2019 May 23];4(11):6972. Available from: http://revistas.unifoa.edu.br/ index.php/cadernos/article/view/1004/878

11. Moraes CM, Portella RB, Pinheiro VS, Oliveira MMS, Fuks AG, Cunha EF, et al. Prevalência de sobrepeso e obesidade em pacientes com diabetes tipo 1. Arq Bras Endocrinol Metab [serial on the internet]. 2003 [cited 2019 May 23];47(6):677-83. Available from: http://www.scielo.br/pdf/abem/v47n6/a09v47n6. $p d f$

12. Nascente FMN, Jardim PCBV, Peixoto MRG, Monego ET, Barroso WKS, Moreira HG, et al. Hipertensão arterial e sua associação com índices antropométricos em adultos de uma cidade de pequeno porte do interior do Brasil. Rev Assoc Méd Bras [serial on the internet]. 2009 [cited 2019 May 23];55(6):71622. Available from: http://www.scielo.br/pdf/ramb/ v55n6/17.pdf 
13. Sousa MG. Tabagismo e hipertensão arterial: como o tabaco eleva a pressão. Rev Bras Hipertens [serial on the internet]. 2015 [cited 2019 May 23];22(3):7883. Available from: http://docs.bvsalud.org/ biblioref/2018/03/881231/rbh v22n3 78-83.pdf

14. Siviero IMPS, Scatena MCM, Costa Jr. ML. Fatores de risco numa população de infartados. Rev Enferm UERJ [serial on the internet]. 2005 [cited 2019 May 23];13:319-24. Available from: http://www.facenf. uerj.br/v13n3/v13n3a05.pdf

15. Silva MAD, Souza ACMR, Schargodsky H. Fatores de risco para infarto do miocárdio no Brasil: estudo FRICAS. Arq Bras Cardiol [serial on the internet]. 1998 [cited 2019 May 23];(74):667-75. Available from: http://www.scielo.br/pdf/abc/v71n5/a05v71n5.pdf

16. Correia JN, Oliveira MZ. Avaliação do risco de acidente vascular cerebral em pacientes com hipertensão arterial sistêmica. Ciência et Praxis [serial on the internet]. 2011 [cited 2019 May 23];4(7):21-6. Available from: http://revista.uemg. br/index.php/praxys/article/view/2202/1187

17. Brito ES, Pantarotto RFR, Costa LRLG. A hipertensão arterial sistêmica como fator de risco ao acidente vascular encefálico (AVE). J Health Sci Inst [serial on the internet]. 2011 [cited 2019 May 23];29(4):265-8. Available from: https://www. unip.br/presencial/comunicacao/publicacoes/ics/ edicoes/2011/04 out-dez/V29 n4 2011 p265-268. $p d f$

18. Monteiro AM, Cabral C, Fernandes V, Alves M, Marques 0. Diabetes mellitus e AVC isquémico: estudo prospetivo em doentes internados no Hospital de Braga. XI Congresso Português de Diabetes; 2014; Loulé, PT. Loulé: Heartbrain; 2014.

19. França AKTC, Santos AM, Calado IL, Santos EM, Cabral PC, Salgado JVL, et al. Filtração glomerular e fatores associados em hipertensos atendidos na atenção básica. Arq Bras Cardiol [serial on the internet]. 2010 [cited 2019 May 23];94(6):77987. Available from: http://www.scielo.br/pdf/abc/ v94n6/aop01710.pdf

20.Santos JC, Moreira TMM. Fatores de risco e complicações em hipertensos/diabéticos de uma regional sanitária do Nordeste brasileiro. Rev Esc Enferm USP [serial on the internet]. 2012 [cited 2019 May 23];46(5):1125-32. Available from: http:// www.scielo.br/pdf/reeusp/v46n5/13.pdf

21. Carlucci EMS, Gouvêa JAG, Oliveira AP, Silva JD, Cassiano ACM, Bennemann RM. Obesidade e sedentarismo: fatores de risco para doença cardiovascular. Comun Ciênc Saúde [serial on the internet]. 2013 [cited 2019 May 23];24(4):37584. Available from: http://bvsms.saude.gov.br/ bvs/artigos/ccs/obesidade_sedentarismo_fatores risco cardiovascular.pdf
22. Lima RCA, Carnevali Júnior LC, Ferreira LLR, Bezerra LTL, Bezerra TTL, Lima BC. Principais alterações fisiológicas decorrentes da obesidade: um estudo teórico. Sanare (Sobral, Online) [serial on the internet]. 2018 [cited 2019 May 7];17(2):5665. Available from: https://sanare.emnuvens.com. $\mathrm{br} / \mathrm{sanare} /$ article/view/1262/670
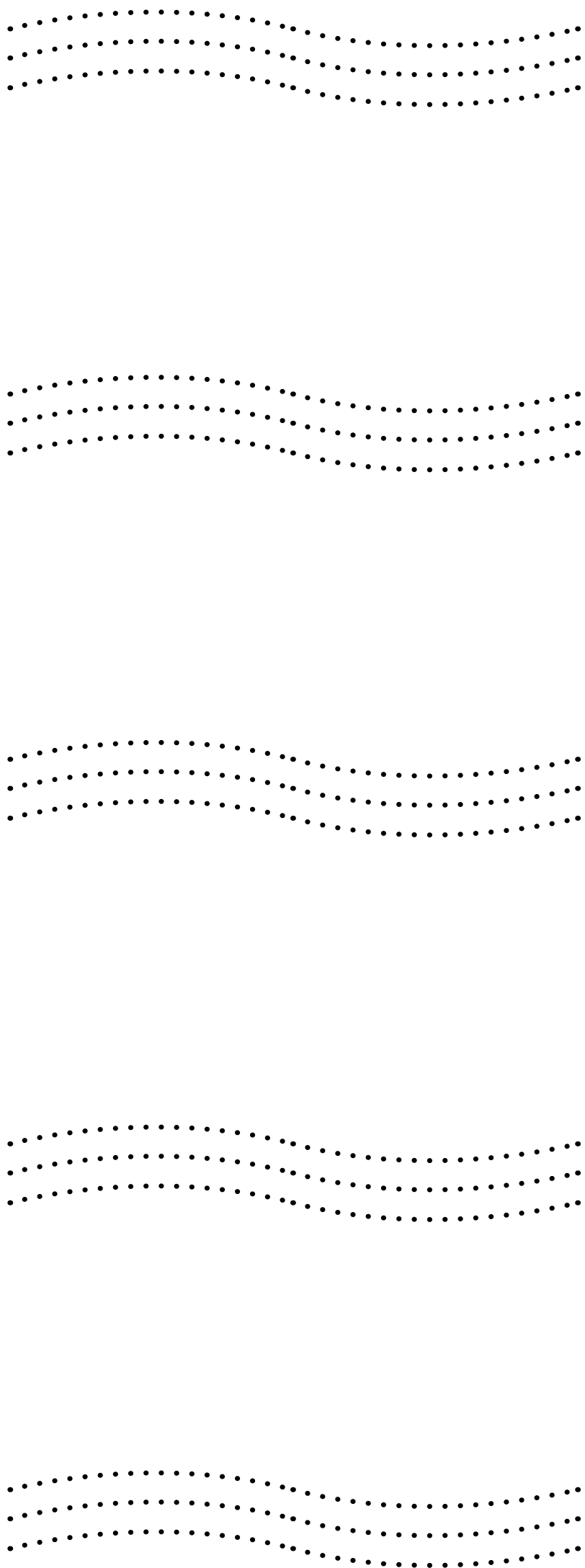

SANARE, Sobral - V.18 n.01,p.31-39, Jan./Jun. - 2019 


\section{SIGNIFICADO DAS MÃES SOCIAIS ÀS MULHERES ASSISTIDAS NO PUERPÉRIO}

MOTHER'S SOCIAL SIGNIFICANCE TO WOMEN ATTENDED IN THE PUERPERIUM

SIGNIFICADO DE LAS MADRES SOCIALES A LAS MUJERES ASISTIDAS EN EL PUERTO

Patrícia Pimentel Alves ${ }^{1}$

Maria da Conceição Coelho Brito ${ }^{2}$

Maria Adelane Monteiro da Silva ${ }^{3}$

Heliandra Linhares Aragão 4

Lielma Carla Chagas da Silva ${ }^{5}$

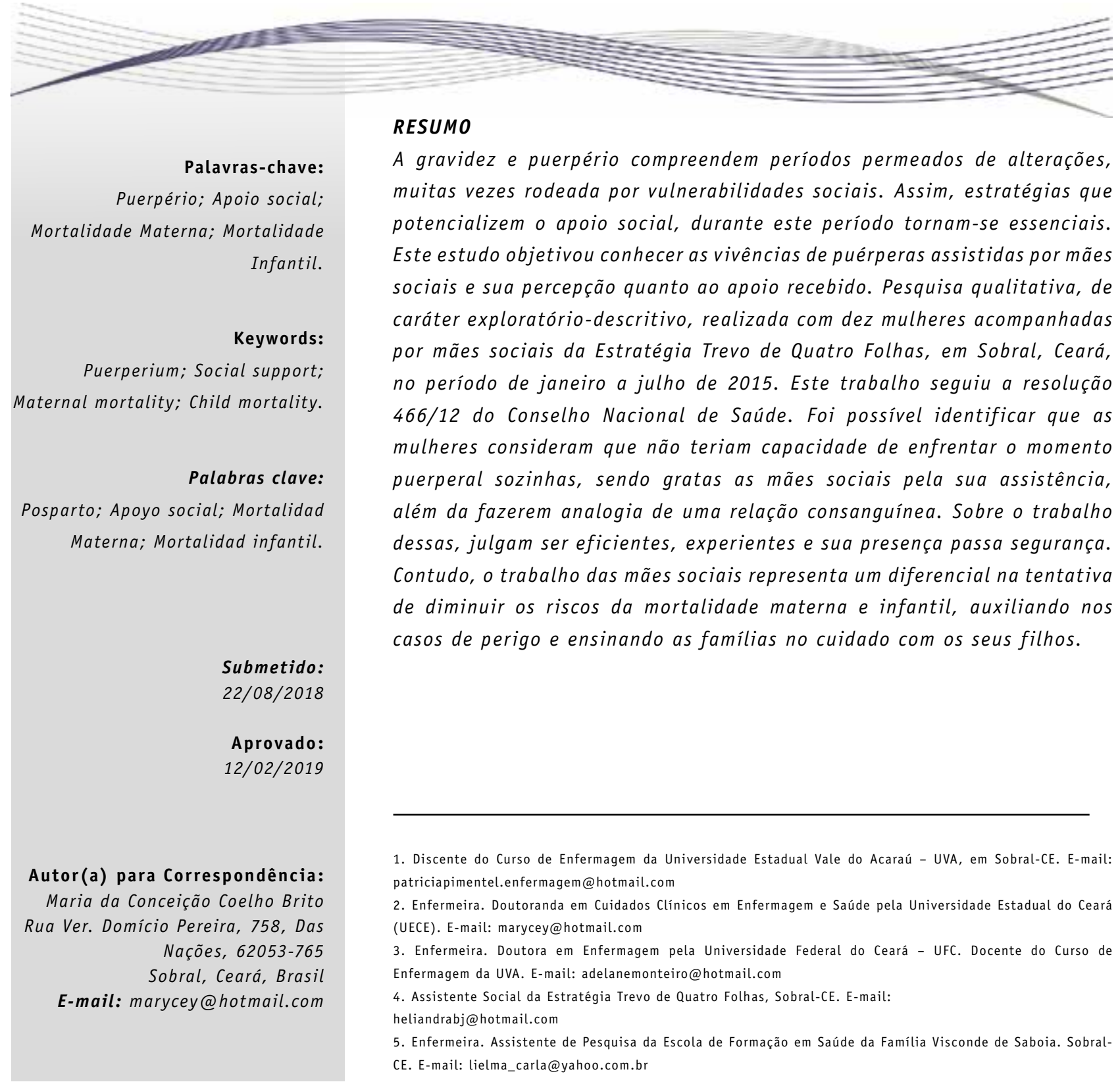

40 - SANARE, Sobral - V.18 n.01,p.40-49, Jan./Jun. - 2019 


\section{ABSTRACT}

Pregnancy and the puerperium comprise periods permeated by changes, often surrounded by social vulnerabilities. Thus, strategies that enhance social support during this period become essential. This study aimed to know the experiences of puerperae assisted by social mothers and their perception of the support received. Qualitative exploratory-descriptive research carried out with ten women accompanied by social mothers of the Four Leaf Clover Strategy, in Sobral, Ceará, from January to July 2015. This work followed Resolution 466/12 of the National Council of Cheers. It was possible to identify that the women consider that they would not be able to face the puerperal moment alone, being the social mothers thankful for their assistance, besides making analogy of an inbred relationship. About the work of these, they think to be efficient, experienced and their presence passes security. However, the work of social mothers represents a differential in the attempt to reduce the risks of maternal and child mortality, helping in cases of danger and teaching families to care for their children.

\section{RESUMEN}

El embarazo y el puerperio abarcan períodos impregnados de alteraciones, muchas veces rodeadas por vulnerabilidades sociales. Así, estrategias que potencian el apoyo social, durante este período se vuelven esenciales. Este estudio objetivó conocer las vivencias de puérperas asistidas por madres sociales y su percepción en cuanto al apoyo recibido. La investigación cualitativa, de carácter exploratorio-descriptivo, realizada con diez mujeres acompañadas por madres sociales de la Estrategia Trevo de Cuatro Hojas, en Sobral, Ceará, en el período de enero a julio de 2015. Este trabajo siguió la resolución 466/12 del Consejo Nacional de salud. Es posible identificar que las mujeres consideran que no tendrían capacidad de enfrentar el momento puerperal por sí solas, siendo agradecidas a las madres sociales por su asistencia, además de hacer analogía de una relación consanguínea. Sobre el trabajo de esas, juzgan ser eficientes, experimentados y su presencia pasa seguridad. Sin embargo, el trabajo de las madres sociales representa un diferencial en el intento de disminuir los riesgos de la mortalidad materna e infantil, ayudando en los casos de peligro y enseñando a las familias en el cuidado con sus hijos.

\section{INTRODUÇÃO}

0 puerpério compreende um período de retorno de alterações geradas pela gravidez e o parto. Nesta fase, podem ocorrer complicações irreversíveis, a exemplo dos óbitos maternos, muitas vezes, ocasionados por fatores evitáveis. As doenças relacionadas na gestação, parto e puerpério apresentam-se entre as 10 causas de mortes de mulheres, sendo que $92 \%$ destes casos poderiam ser evitáveis ${ }^{1}$.

Considera-se morte materna o óbito de mulheres até 42 dias após o parto, causada por fatores relacionados ou agravados pela gravidez. As principais causas estão relacionadas aos problemas obstétricos diretos com destaque para síndromes hemorrágicas e hipertensivas, desencadeados por uma baixa qualidade do pré-natal, intervenções desnecessárias, omissões e tratamentos incorretos ${ }^{2}$.

No Brasil, a razão de mortalidade materna em 2000 foi de 73,3, sendo que em 2011 passou para 64,8 , totalizando, neste mesmo ano, cerca de 1.610 óbitos maternos ${ }^{3}$. Apesar da redução dos indicadores, a problemática no Brasil gera um reconhecimento na fragilidade dos agravos que afetam este contingente populacional.
Analogamente, outro fator que requer atenção são os óbitos infantis. Conforme informações da Organização Mundial de Saúde (OMS), a redução da mortalidade infantil configura-se um desafio para os serviços de saúde e sociedade como um todo, sendo umas das metas do milênio, assumida pelos países integrantes das nações unidas ${ }^{4}$.

Dados epidemiológicos brasileiros indicam uma redução da taxa da mortalidade infantil, no ano de 2011, estimada em 15,3, sendo que no ano de 2000 era $26,1^{3}$. Contudo, os óbitos infantis continuam sendo um problema de saúde pública incompativel com o desenvolvimento do País, considerando características de óbitos em classes sociais mais baixas, o que denuncia desigualdades de saúde entre grupos sociais específicos ${ }^{5}$.

No Brasil, com o reconhecimento desses indicadores de saúde materna e infantil, surgiram questionamentos sobre as causas das mortes, com ênfase nas mal definidas, envolvendo mulheres e crianças. Com isso, em 2007, criaram-se formulários padronizados para investigação de óbitos, por meio do método de autópsia verbal, principalmente em áreas subnotificadas e com poucas informações sobre as causas das mortes. Salienta-se que o acesso 
às informações das causas serve como estatísticas de saúde, sendo útil para avaliação, monitoramento e planejamento de políticas de saúde ${ }^{4}$.

Em 2001, o município de Sobral, situado na região Noroeste do Ceará, iniciou a utilização da autópsia verbal, por meio do Comitê de Prevenção da Mortalidade Materna, Perinatal e Infantil, como mecanismo/estratégia para compreender as ocorrências das mortes, e conhecer a versão da família sobre os óbitos. Diante disso, foram identificadas algumas fragilidades na assistência materna e infantil no Município.

Dentre as fragilidades apontadas, destacavam-se aquelas que se originavam na assistência pré-natal, passando pelo puerpério até o acompanhamento da criança até os dois anos de idade, captação tardia de gestantes, número consultas pré-natais inferior a seis, exames incompletos, além de aspectos no âmbito das vulnerabilidades identificadas durante as visitas domiciliares realizada nos primeiros dias de vida. 0 u seja, os óbitos não estavam relacionados somente a fatores biológicos, mas, também, a aspectos sociais dos quais as famílias vivenciavam. Tal descoberta permitiu avaliar e impulsionar o planejamento de estratégias para reverter a referida situação ${ }^{6}$.

Foi, então, formulada e implantada, em dezembro de 2001, a Estratégia Trevo de Quatro Folhas. A simbologia de um Trevo reflete as quatro fases que se relacionam aos cuidados na gestação, no parto e nascimento, no puerpério e no acompanhamento de crianças. A Estratégia se propunha a atender mulheres e crianças, prestando serviço no combate à mortalidade materna e infantil, e com suas ações ganhou notoriedade a nível nacional e internacional ${ }^{6}$.

Uma parcela considerável dos casos atendidos pela Estratégia Trevo de Quatro Folhas são mulheres que não possuem apoio familiar, vivendo em possiveis situações de risco clínico e social. Reconhece-se que a mortalidade materna e infantil está associada aos problemas sociais, sendo a pobreza, falta de acesso à água tratada e desnutrição alguns determinantes socioeconômicos que culminam na problemática, tratando-se da determinação social como uma verdade clássica da saúde pública(7-8).

Estudo aponta que a saúde reprodutiva e neonatal é prejudicada quando algumas iniquidades sociais são vivenciadas, como empregos precários, ausência de cobertura social, moradia informal e insegura, baixa escolaridade, parceiro ausente do lar, risco psicossocial associado a apoio familiar insuficiente, sintomas depressivos, violência de gênero, abuso de substâncias e conflitos com a maternidade 9 .

Partindo da dimensão social como um fator que predispõe fragilidades, os determinantes sociais apontam a necessidade da assistência e formulação de políticas que minimizem os impactos gerados pelas vulnerabilidades acometidas. Assim, a Estratégia Trevo oferece apoio social para gestantes, parturientes, puérperas e crianças com até dois anos de idade que se encontram em situação de risco clínico e social, por meio atuação de mães sociais e apoio alimentar ${ }^{10}$.

As mães sociais são mulheres que podem residir na comunidade rural ou urbana. Elas são selecionadas e capacitadas para atuar em jornada de trabalho, com carga horária de $8 \mathrm{~h}$ em domicílios e $12 \mathrm{~h}$ em ambiente hospitalar, no acompanhamento daquelas famílias que atendem aos critérios clínicos e sociais definidos pela Estratégia, tais como dificuldades ou impossibilidades de gestantes ou mães de realizarem os cuidados necessários com a gravidez ou com bebê, devido à situação de risco social e de carências nutricionais ${ }^{10}$.

0 papel desempenhado pelas mães sociais se fundamenta no apoio social, que se refere a estratégias que vislumbrem diversas dimensões do cuidado, permeando desde conforto, assistência e estratégias para estabelecimento de vínculos e aquisição de recursos que são oferecidos, sendo fundamental para evitar fatalidades no cotidiano, principalmente em períodos com diversas modificações psicológicas e fisiológicas ${ }^{11}$.

Este estudo tem, portanto, o objetivo de conhecer as vivências de puérperas assistidas por mães sociais e sua percepção quanto ao apoio recebido.

\section{METODOLOGIA}

Pesquisa qualitativa, de caráter exploratóriodescritivo, realizada com mulheres acompanhadas por mães sociais da Estratégia Trevo de Quatro 
Folhas na cidade de Sobral-CE. Foram identificadas 12 mulheres assistidas pela Estratégia nos meses de janeiro à julho de 2015, período da coleta. Contudo, 10 foram as que participaram do estudo em razão de duas não mais residirem no domicílio onde receberam assistência.

As mulheres participantes do estudo eram maiores de 18 anos, que foram acompanhadas em seu domicílio, com um convívio mínimo de uma semana com as mães sociais, com residência no bairro Cidade Doutor José Euclides, conhecido como Terrenos Novos, na referida cidade do estudo. 0 território selecionado foi devido ao maior número de mães sociais atuantes, além de uma demanda significativa de casos que necessitam da atuação.

A coleta de informações foi iniciada junto aos prontuários e banco de dados da Estratégia Trevo de Quatro Folhas mediante roteiro de análise documental, para identificação das mulheres acompanhadas no período vigente, além de obtenção de informações sobre aspectos socioeconômicos. Posteriormente, realizaram-se entrevistas semiestruturadas, por meio de visitas domiciliares, em um único momento com cada mulher, buscando compreender os valores e sentidos que atribuiam ao trabalho da mãe social. 0s relatos foram identificados com nomes femininos representativos para história mundial, correlacionando aspectos de lutas e representações vividas.

A análise das informações foi realizada mediante Análise Temática ${ }^{12}$, que consiste em descobrir os núcleos de sentido que compõem uma comunicação, cuja presença ou frequência signifiquem alguma coisa para o objeto analítico visado. Seguindo as etapas propostas de pré-análise, retomando as hipóteses e os objetivos iniciais da pesquisa; exploração do material, visando alcançar o núcleo da compreensão do texto; tratamento dos resultados, inferência e a interpretação, propondo inferências e realizando conclusões.

...as mulheres entrevistadas viviam com um rendimento pecuniário de no máximo um salário mínimo...
Estudo orientou-se pela Resolução $N^{0} 466 / 12$ do Conselho Nacional de Saúde e foi aprovado pelo Comitê de Ética em Pesquisa - CEP, da Universidade Estadual Vale do Acaraú - UVA, sob Parecer $N^{0} 1.318 .979 / 2015$.

\section{RESULTADOS E DISCUSSÕES}

Os resultados desvelam os significados atribuídos às mães sociais por 10 mulheres assistidas, que tiveram idades variando entre 21 a 42 anos. Das participantes, oito tinham mais de um filho e moravam em casa própria. Sobre a escolaridade, cinco possuíam ensino fundamental completo e as demais o ensino médio concluído. Quanto à situação conjugal, cinco moravam com seus cônjuges, sendo civilmente casadas, duas mantinham uma relação estável com seus companheiros, e três foram abandonadas pelos seus respectivos companheiros, após o nascimento da criança. Duas tinham uma ocupação profissional e as outras eram, exclusivamente, donas de casas e dependiam financeiramente do pai da criança e/ou de programas assistênciais do governo, a exemplo do Bolsa Família. Todas as mulheres entrevistadas viviam com um rendimento pecuniário de no máximo um salário mínimo e nenhuma possuía apoio familiar.

As características dessas mulheres norteiam aspectos indicativos de possíveis acometimentos de morte materna e infantil, partindo de estudos que indicam que a rede causal encontrada inclui domicílios inadequados, baixo nível de escolaridade, uniões de curta duração, dificuldades econômicas, além de uma ausência de suporte social no seu ciclo gravídico-puerperal e assistência pré-natal ausente ou inexistente ${ }^{13}$.

Ademais, com as entrevistas foi possivel refletir sobre as subjetividades que permearam - período puerperal assistido pelas mães sociais e os significados do papel destas, permitindo intepretações e concepções dos sujeitos envolvidos de acordo com suas realidades. Desse modo, a análise se desvelou nas categorias: A experiência de ser mãe $e$ as necessidades de cuidado; 0 papel da estratégia trevo e a atuação das mães sociais; Mães sociais... Significados atribuidos pelas mulheres.

\section{A experiência de ser mãe e as necessidades de cuidado}

Sobre as experiências após o nascimento da criança, as mães demonstraram uma satisfação e 
realização como mulher. E mesmo reconhecendo diversas dificuldades enfrentadas no período puerperal, verbalizaram ser um momento intenso e de sentimentos afetivos nunca sentidos.

"[...] Me sinto uma mulher de verdade depois do nascimento dos meus filhos" (Cleópatra).

"Foi um sonho realizado, senti algo inexplicável, uma criança é uma benção de Deus" (Madre Teresa de Calcutá).

Contrariamente, a experiência inicial da maternidade para duas mulheres do estudo foi enfrentada de forma negativa. 0 ajustamento da maternidade é influenciado por características socioeconômicas, nível de aceitação e desejo da gravidez ${ }^{14}$. A fase de aceitação de uma nova realidade, envolvida com emoções conflituosas e perda do companheiro motivada pela gestação, dificulta o estabelecimento afetivo. 0s vínculos mãefilho foram expressos, pincipalmente, no decorrer do período puerperal, após convivência com a criança.

“[...]fui abandonada pelo pai da criança, não conseguia ter amor por ela quando estava na minha barriga. Estava decidida, vou doar minha filha, porém quando ela nasceu foi tudo diferente, mas só depois de uns dias consegui me apegar" (Joana D’arc).

“Não queria engravidar, não tinha condições financeiras. Hoje, minha filha é tudo para mim" (Irmã Dulce)

0 conflito gerado, visualizado pelos depoimentos, permite refletir sobre as necessidades de cuidados impostas por um período difícil de aceitação, agravadas por problemas sociais e ausência paterna. 0 rompimento amoroso, além das outras problemáticas de acometimento deste público estudado, predispõe a mulher de sentir-se desamparada, solitária e com responsabilidades de cuidar de uma criança, podendo gerar situações de adoecimento da puérpera e comprometer o desenvolvimento do neonato. 0s indicadores de morte infantil são compreendidos nas diversas condições de vida, incluindo aspectos biológicos, sociais, econômicos e de assistência em saúde ${ }^{15}$.

Por consequência, expressam de forma potencial algumas adversidades vivenciadas no puerpério,

\section{0 rompimento}

amoroso (...)

predispõe a

mulher a sentir-se

desamparada...

relacionados ao bem-estar da criança que acaba de nascer, além da preocupação com o provimento financeiro dos outros membros da família, sendo adicionados contratempos no aspecto da ausência de domicílio fixo, falta de alimentação e enfrentamento de desemprego de entes familiares. Esse grupo populacional não deve ser compreendido sob a ótica reducionista da reprodução humana, necessitando aprender o olhar sobre aspectos das transformações sociais ${ }^{16}$.

"Só que era mais um na família, minha preocupação era no sustento da criança, pois meu marido ganhava muito pouco e minha gravidez não foi planejada" (Anita Garibaldi).

“Foi um momento difícil, pois meu marido estava desempregado e passamos por dificuldades financeiras, inclusive ganhei cesta básica do Trevo[...]" (Evita Peron).

“Foi um momento difícil, pois não tinha dinheiro, morava de aluguel, parei de trabalhar e minha família não mora aqui. Então, uma amiga me abrigou na casa dela [...]" (Carlota Joaquina).

Neste contexto, as mulheres ficam fragilizadas, necessitando de um acompanhamento e apoio mais efetivo para ter capacidade de enfrentamento do momento vivenciado. Além de todo enquadramento no aspecto social, o parto configura-se um momento que a mulher passa por um desgaste físico, com dificuldade de locomoção, sangramentos, cuidados pós-cirúrgicos, à responsabilização de cuidar do recém-nascido. As mulheres sentem-se emocionalmente abaladas com tantas mudanças simultâneas.

“É um período de muitas mudanças!! A gente se sente feia, maltratada, não quer 
nem ver o marido chegar perto [...]" (Madre Teresa de Calcutá).

A saúde materna pode ficar comprometida em decorrência de um problema de saúde pública denominado de depressão pós-parto (DPP), além de um risco para desenvolvimento da criança, levando em consideração que a mãe não terá condições de cuidar do seu filho. As evidências do quadro clínico são caracterizadas com episódios depressivos, geralmente, fortemente estabelecidos após o nascimento do bebê, entre a quarta e a oitava semana após o parto ${ }^{17}$.

"Comecei uma depressão que não queria nem ver o bebê" (Cleópatra).

Houve expressões referentes a dificuldades com os cuidados com as crianças, relacionados com aspectos de higiene e amamentação, mesmo sendo o segundo filho para a maioria das mulheres. Essas dificuldades eram presentes, principalmente, nos casos de crianças prematuras.

“Tive dificuldade em cuidar do bebê, pois ele era muito prematuro e não sabia fazer as coisas direito, tinha medo de pegar, não sabia banhar, colocar no peito direito, não tinha jeito" (Cleópatra).

“No começo não estava conseguindo amamentar, meu peito ficou duro e tive febre" (Irmã Dulce).

0 aleitamento materno constitui-se temática bastante discutida entre mulheres e familiares no intuito de fortalecimento da Estratégia Nacional para Promoção do Aleitamento e Alimentação Complementar Saudável no SUS. Esta qualifica os profissionais da atenção básica com o intuito de reforçar e incentivar a promoção do aleitamento materno $0^{18}$. Porém, um dos resultados deste estudo mostra uma fragilidade no estabelecimento da amamentação, trazendo necessidades de efetivação de estratégias de acompanhamento no período puerperal, momento este que efetivamente acontece o estabelecimento do ato de amamentar. E, a interação do profissional de saúde com a usuária exerce forte influência no estabelecimento do aleitamento materno, pincipalmente, quando é realizada desde o pré-natal até o puerpério ${ }^{19}$.

Diante do exposto, as mães sociais são inseridas

\section{A falta de apoio \\ familiar foi um \\ fator determinante \\ para a atuação $e$ \\ acompanhamento da \\ mãe social...}

nos domicílios diante de todas as dificuldades imposta pelo período puerperal, adaptações de uma nova fase e adversidades sociais, possibilitando auferir uma dimensão do contexto comunitário em que elas atuam com o intuito promover a saúde materna e infantil.

\section{0 papel da estratégia trevo e a atuação das mães sociais}

A falta de apoio familiar foi um fator determinante para a atuação e acompanhamento da mãe social em todos os casos, ainda mais que algumas mulheres possuíam crianças menores de cinco anos, estando impossibilitadas de realizar os cuidados da prole e, em alguns casos, do seu autocuidado. Além disso, não podiam desenvolver as atividades domésticas, o que dificultava o enfrentamento das adaptações impostas pela nova fase, potencializado com todos os outros problemas singulares de cada situação, seja de aspectos clínicos e/ou social.

“Não tinha ninguém para ficar comigo, pois meu marido trabalhava e passava o dia todo fora de casa, ainda tinha meu outro filho pequeno" (Anita Garibaldi).

“Eu me senti sozinha, só eu e a minha filha pequena, sem apoio da minha família que é de outra cidade" (Joana D`arc).

A família configura-se pela complexidade e dinamismo que assume às diversas situações que surgem em seu cotidiano, sendo a matriz da aprendizagem humana com significados e práticas culturais próprias que geram modelos de relação interpessoal e de construção individual e coletiva. Assim, na ausência de representação familiar de forma congruente para o bom viver dos seus entes, fazse necessário o uso de estratégias como a realizada pelo Trevo, por meio do apoio social, quando essa puérpera ou gestante apresenta risco clínico e/ou 
social e não conta com apoio familiar ${ }^{20-10}$.

A prestação desse serviço impõe condições como contrapartida das famílias assistidas que nos casos puerperais, estimulam: aleitamento materno exclusivo até os seis meses de vida, realização do registro de nascimento, além da caderneta de vacinação da criança em dia e assiduidade nas consultas de puericultura.

As mulheres, ao se referirem ao trabalho dessa profissional, indicam que elas realizam as atividades domésticas, cuidam das crianças e delas próprias de acordo com a necessidade de cada uma. Isso repercutia em um olhar interprofissional do cuidado prestado pela Estratégia e potencializado pela presença das mães sociais no domicílio.

“A mãe social fazia tudo aqui, cuidava dele e do meu outro filho, limpava a casa, fazia almoço" (Cleópatra).

“0 pessoal do trevo veio aqui, a enfermeira e assistente social. Perguntava a ela como eu estava e mandava qualquer coisa ligar e comunicar ao posto de saúde logo" (Irmã Dulce).

Diante da necessidade de um comprometimento com a saúde materna e infantil, por meio da proposta inovadora da Estratégia Trevo de Quatro Folhas, as mães sociais selecionadas para serem cuidadoras passam por todo um processo de seleção e capacitação realizado pela estratégia. 0s momentos de educação permanente com essas profissionais foram construídos a partir das experiências das mães sociais nos territórios sobralenses, sendo abordados assuntos relevantes para facilitar suas práticas assistenciais com a saúde materna e infantil e auxiliar nas tomadas de decisões efetivas e resolutivas frente ao problema encontrado ${ }^{10}$.

“Ela fazia os cuidados com meu filho e depois me ensinava a fazer e dizia que eu tinha que aprender, pois logo ela iria embora. Me ensinou a dar banho que eu não sabia, limpar o umbigo, cuidar dele em geral" (Cleópatra).

As mães sociais atuam como educadoras a mediar, junto às puérperas, práticas mais adequadas do ser mãe e do cuidar de um filho, frentes às dificuldades e necessidades identificadas. Assim, há uma pretensão de emergir a autonomia das mães, uma vez que é transitório o trabalho destas nos domicílios.

\section{Mães sociais... Significados atribuídos pelas mulheres}

0 ponto que se passa a refletir é sobre os sentimentos afetivos desvelados pelas mulheres sobre suas vivências com as mães sociais. Relataram que não teriam capacidade de enfrentar o momento puerperal sozinhas, desprendendo em destaque aspectos de gratidão e comparação de uma parente ou familiar.

"Se ela não tivesse vindo para minha casa teria sido pior, ela me ajudou bastante mesmo. Ela foi uma segunda mãe para mim" (Cleópatra).

“Tenho muita gratidão a ela, pois ela cuidou do meu filho como se fosse dela. Não sei como teria sido sem ela. Agradeço demais por ter tido ela aqui" (Rainha Vitória).

No que concerne à atuação dessas profissionais, as mulheres julgam ser eficientes, experientes e consideram que sua presença transmite segurança, sendo visivel nos relatos um atendimento empático e humanizado, respeitando as mulheres e suas subjetividades, além de oferecer conforto e companhia, suprindo carências, por vezes, presentes na fase do pós-parto.

“Ela é uma ótima pessoa, bem eficiente, me ajudou muito, nunca vou esquecer o apoio que ela me deu num momento que a gente se sente tão frágil e com muitas dificuldades" (Irmã Dulce).

“Ela é muito boa, gostei, não tive nenhum problema, é simpática, conversa com a gente. Só queria às vezes uma conversa. Só tenho agradecer a ela e todo mundo do

\section{As mães sociais atuam como educadoras ao} mediar (...) práticas mais adequadas do ser mãe e do cuidar de um filho... 
Trevo que deixou ela vim" (Madre Teresa de Calcutá).

“[...]Mesmo pagando uma pessoa para colocar na sua casa não é como ela que é uma ótima pessoa, é experiente, muito paciente, cuidadosa[...]" (Irmã Dulce).

Nas entrevistas, chama-se atenção para o fato que uma mulher do estudo não gostou do trabalho desenvolvido pela mãe social que estava em sua casa, verbalizando ser uma atividade que precisa ser melhorada e que não desejava a mesma em sua residência, momento que não trouxe nenhuma significação para sua vida nem para seus filhos.

“Não queria e botaram, mas era porque não tinha ninguém para ficar comigo e tinha outros problemas com a saída da escola com minha outra filha" (Joana D'arc).

Percebe-se que a necessidade de uma companhia neste período é mais preponderante do que a vontade da mulher, pois aceitou o apoio social, mesmo não sendo algo confortável para o seu convívio e das suas relações familiares, sendo agravado com o descontentamento da relação estabelecida e do serviço prestado que de sua forma singular foi insatisfatório para as necessidades daquele momento.

Em conformidade com a ideologia formadora das mães sociais a experiência negativa, em um caso particular, representa controvérsia da propagação do trabalho que deveria ter sido desenvolvido. Muito embora, a rejeição inicial pode ter repercutido no estabelecimento dos vínculos, criando barreiras para não expor a vida familiar e todos os problemas enfrentados.

Analisando os resultados, pode inferir que a concepção e significância do trabalho das mães sociais para puérperas são de reconhecimento de uma assistência baseada de uma profissional experiente, possuindo competências para identificar alterações clínicas e acometimentos sociais deste público, servindo de suporte e confiabilidade da família cuidada, mesmo que a realidade descrita não tenha sido unânime. Assim, pode-se identificar em dados concretos os resultados desse trabalho desenvolvido que por meio da redução da Taxa de Mortalidade Infantil (TMI) de 26,9 em 2001 para 18,2 em 20116.

A representação desta profissional amenizou as angústias, ansiedades e medos com cuidados com

\author{
...a figura de \\ cuidadora inserida \\ no real contexto \\ social viabiliza \\ um elo de \\ comunicação...
}

os recém-nascido, preocupando-se ao mesmo tempo com a saúde das mulheres atendidas, melhorando a vida destas que são potencialmente frágeis para acometimentos. Apesar de identificarmos no estudo dificuldade em estabelecimento de relação pessoal das mães sociais com uma mulher cuidada, mas que repercute em insatisfação da puérpera e dificuldades para estas trabalhadoras da saúde desenvolver suas habilidades e competência. Por outro lado, a figura de cuidadora inserida no real contexto social viabiliza um elo de comunicação para Estratégia Trevo de Quatro Folhas para uma articulação nos diversos pontos da rede de saúde para buscar um cuidado humanístico, integral e acessível.

\section{CONCLUSÃO}

0 estudo possibilitou refletir que o trabalho das mães sociais é um diferencial da Estratégia Trevo de Quatro Folhas na tentativa de diminuir a mortalidade materna e infantil, auxiliando nos casos de perigo iminentes e/ou eminentes e ensinando as famílias no cuidado com os seus filhos.

A proximidade com este grupo de mulheres proporcionou discussões sobre a vivência do período puerperal, partindo das dificuldades de aspectos fisiológicos até os empecilhos de uma dimensão social, repercutindo diretamente no nível de significação do vivenciado como uma experiência positiva ou negativa. A mãe social foi incorporada nesse período, sendo na maioria dos casos, uma trabalhadora de saúde que se tornou referência de um serviço que se pode contar.

A oportunidade sugere que a Estratégia de Trevo de Quatro Folhas proporcione alguns momentos de escuta para as puérperas, como de todo o público atendido, sobre os serviços ofertados para que ocorra um alinhamento da assistência, evitando casos de conceituação negativa sobre o desempenho das mães sociais, além de conseguir identificar os principais 
entraves para a atuação destas profissionais na comunidade.

Em suma, o fortalecimento dessa ideia inovadora possibilita a consolidação da ideologia em curso, ao encontro do apoio de outras organizações de saúde como as Unidades Básicas de Saúde, auxiliando no desenvolvimento e identificação destas pessoas no território, na busca de melhores indicadores maternos e infantis e buscando assumir a maternidade segura. A inovação e tomada de decisão da reestruturação e organização de um novo modelo assistencial para a mulher e a criança foi uma aposta exitosa, com ênfase para busca de um cuidado efetivo, resolutivo e integral, assegurando os direitos deste público.

\section{CONTRIBUIÇÃO DAS AUTORAS}

Patricia Pimentel Alves contribuiu no delineamento, realização da pesquisa e redação do manuscrito. Maria da Conceição Coelho Brito realização da pesquisa, redação e revisão final do manuscrito. Maria Adelane Monteiro da Silva contribuiu com delineamento da pesquisa, redação e revisão final do manuscrito. Heliandra Linhares Aragão contribuiu com delineamento da pesquisa, redação e revisão final do manuscrito. Lielma Carla Chagas da Silva contribuiu na redação e revisão final do manuscrito.

\section{REFERÊNCIAS}

1. Brasil. Ministério da Saúde. Secretaria de Atenção à Saúde. Pré-natal e Puerpério: atenção qualificada e humanizada. Manual técnico. Brasília: Ministério da Saúde; 2006 . [cited 2015 mar 21]. Available from: https://www.nescon.medicina.ufmg.br/biblioteca/ registro/Pre natal e puerperio atencao qualificada e humanizada manual tecnico /56

2. Brasil. Ministério da Saúde. Secretaria de Políticas de Saúde. Manual dos Comitês de Mortalidade materna. 3 ed. Brasília: Ministério da Saúde; 2009. [cited jun 24]. Available from: http:// bvsms.saude.gov.br/bvs/publicacoes/manual comites mortalidade materna.pdf

3. Brasil. Ministério da Saúde. Portal da Saúde. Razão da mortalidade materna. Departamento de Informática do SUS; 2014. [cited 2014 nov 23]. Available from: http://tabnet.datasus.gov.br/cgi/ idb2012/C03b.htm

4. World Health Organization. (WHO). Verbal autopsy standards: ascertaining and attributing cause of death. Geneva: World Health Organization; 2007. [cited 2016 jan 22]. Available from: https://www.who. int/healthinfo/statistics/verbalautopsystandards/ en/
5. Brasil. Ministério da Saúde. Secretária de Vigilância em Saúde. Secretária de Atenção à Saúde. Manual de vigilância do óbito Infantil e fetal e do comitê de Prevenção do óbito infantil e fetal. Brasília: Ministério da Saúde; 2009 . [cited 2014 jul 23]. Available from: http://bvsms.saude.gov.br/bvs/ publicacoes/manual obito infantil fetal 2ed.pdf

6. Sousa FJS, et al. Programa Trevo de Quatro Folhas: Uma ação efetiva para a redução da mortalidade materna e infantil em Sobral- Ceará. Sanare (Sobral, online) [serial on the internet]. 2012 [cited 2016 mai 23];11(1):60-65. Available from: https://sanare. emnuvens.com.br/sanare/article/view/268

7. Marulanda NR, Tancredi FB. Trevo de Quatro Folhas - Estratégia de Redução da Morbimortalidade Materna, Perinatal e Infantil, Brasil. In: Da Inovação Social à Política Pública: Histórias de êxito na América Latina e no Caribe, 2009.

8. Krieger N. Theories for social epidemiology in the 21st century: an ecosocial perspective. Int J Epidemiol [serial on the internet]. 2001 [cited 2016 mai 23];30(4):668-77. Available from: https://doi. org/10.1093/ije/30.4.668

9. Arcos E, Munõz LA, SánchezX, et al. Vulnerabilidad Social en mujeres embarazadas de una comuna de la Región Metropolitana. Rev Med Chile [serial on the internet]. 2011 [cited 2016 mai 24];139(6):739-47. Available from: http://dx.doi.org/10.4067/S003498872011000600007

10. Sousa FJS, Sucupira ACSL. Guia Estratégia Trevo de Quatro Folhas. Sobral (CE); 2010.

11. Mitsuhiro SS, Chalem E, Barros MM, Guinsburg $R$, Laranjeira R. Teenage pregnancy: use of drugs in the third trimester and prevalence of psychiatric disorders. Rev Bras Psiquiatr. [serial on the internet]. 2006 [cited 2016 mai 23];28(2):122-5. Available from: http://dx.doi.org/10.1590/S151644462006000200009

12. Minayo MCS. 0 desafio do conhecimento: pesquisa qualitativa em saúde. São Paulo: Hucitec, 2007.

13. Schoeps D, et al. Fatores de riscos para mortalidade neonatal precoce. Revista Saúde Pública [serial on the internet]. 2007 [cited 2016 mai 23];41(6):1013-22. Available from: http://dx.doi. org/10.1590/S0034-89102007000600017

14. Piccinini CA, Tudge J, Marin AH, et al. The Impact of Socio-Demographic Variables, Social Support, and Child Sex on Mother-Infant and Father-Infant Interaction. Revista Interamericana de Psicologia. [serial on the internet]. 2010 [cited 2016 mai 24];44(2):203-12. Available from: http://www. redalyc.org/articulo.oa? id $=28420641019$ 
15. Nascimento RM, Leite ÁJM, Almeida NMGS, et al. Determinantes da mortalidade neonatal: estudo caso controle em Fortaleza, Ceará, Brasil. Cad Saúde Pública [serial on the internet]. 2012 [cited 2016 mai 23];28(3):559-72. Available from: www.scielo. $\mathrm{br} / \mathrm{pdf} / \mathrm{csp} / \mathrm{v} 28 \mathrm{n} 3 / 16 . \mathrm{pdf}$

16. Reis AT, Santos RS, Paschoal Júnior A. 0 cuidado à mulher na contemporaneidade: reflexões teóricas para o exercício da enfermagem transcultural. REME - Rev Min Enferm [serial on the internet]. 2012 [cited 2016 mai 23];16(1):129-35. Available from: http://www.dx.doi.org/S1415-27622012000100018

17. Schwengber DDS, Piccinini CA. A experiência da maternidade no contexto da depressão materna no final do primeiro ano de vida do bebê. Estud Psicol (Campinas, online) [serial on the internet]. 2005 [cited 2016 jun 02];22(2):143-56. Available from: http://dx.doi.org/10.1590/S0103$166 \times 2005000200004$.

18. Brasil. Ministério da Saúde. Estratégia Amamenta e Alimenta Brasil. Brasília: Ministério da Saúde; 2016. [cited 2015 jul 25]. Avaiable from: http://dab. saude.gov.br/portaldab/amamenta.php

19. Joventino ES, Dodt RCM, Araújo TL, et al. Tecnologias de enfermagem para promoção do aleitamento materno: revisão integrativa da literatura. Rev Gaúch Enferm [serial on the internet]. 2011 [cited 2016 jul 12];32(1):176-84. Available from: http://dx.doi.org/10.1590/S1983$\underline{14472011000100023}$

20. Dessen MA, Polonia AC. A família e a escola como contexto de desenvolvimento humano. Paidéia [serial on the internet]. 2007 [cited 2016 mai 22];17(36):21-32. Available from: www.scielo.br/ pdf/paideia/v17n36/v17n36a03.pdf
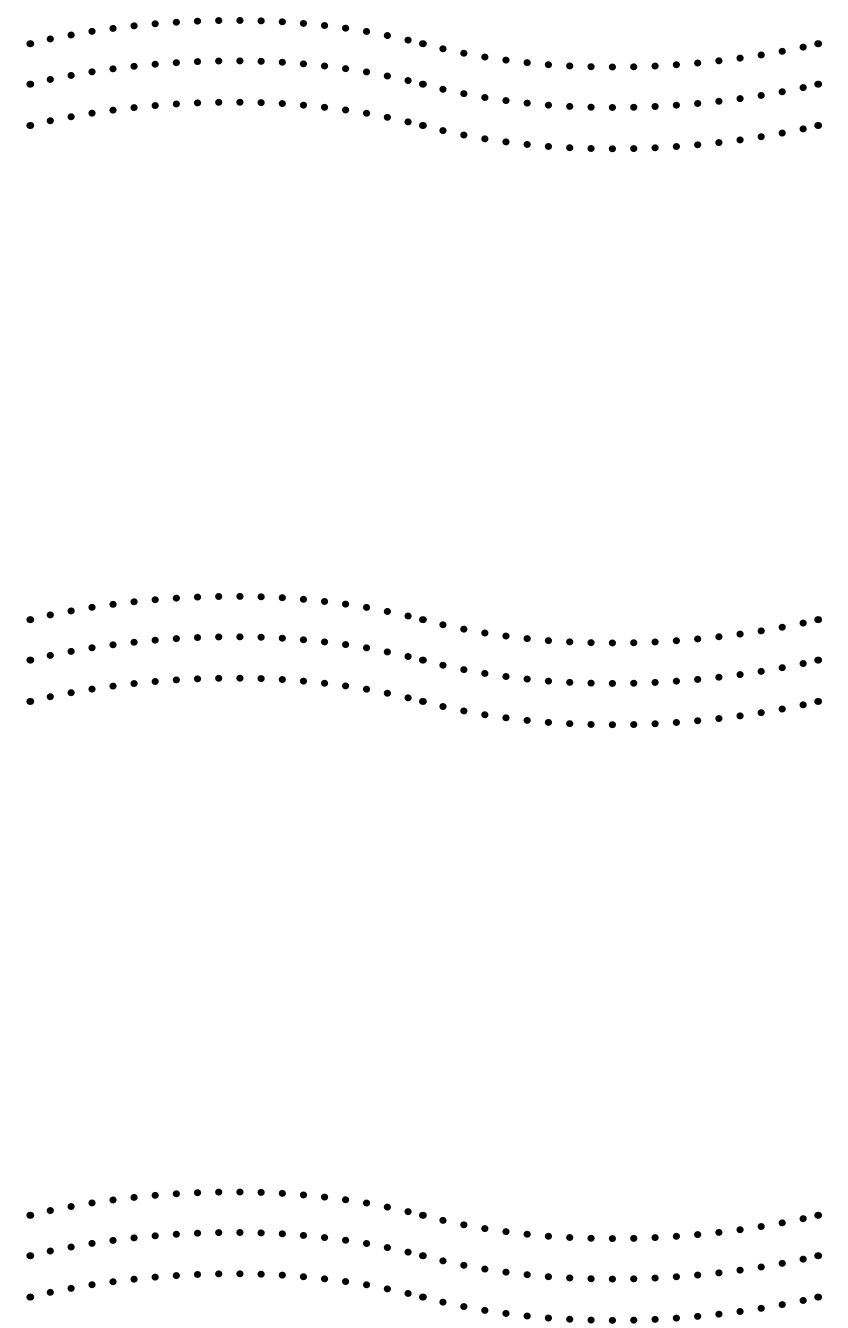
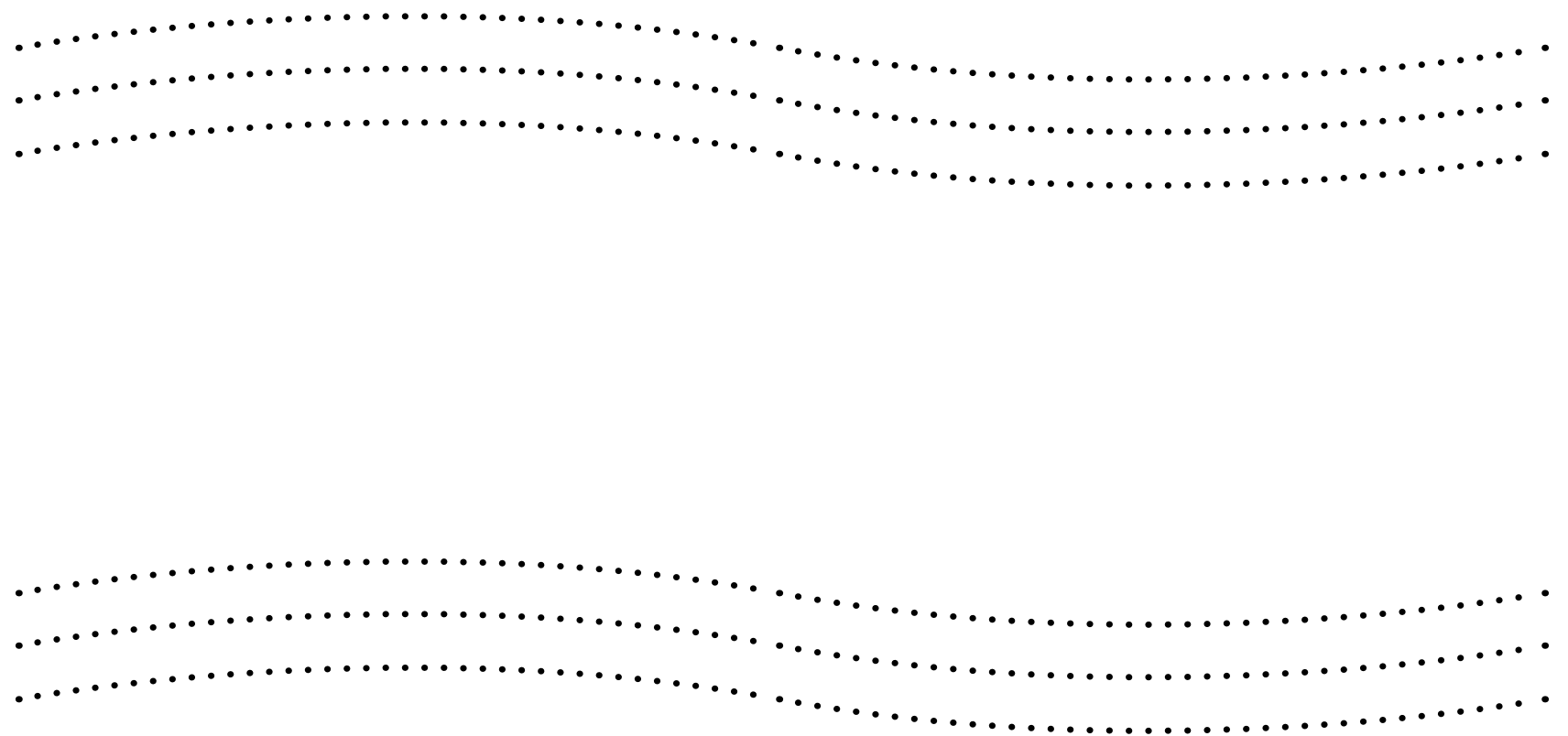


\title{
ESTADO NUTRICIONAL DE MENORES DE 5 ANOS DE IDADE EM SOBRAL-CE
}

NUTRITIONAL STATUS OF CHILDREN UNDER 5 YEARS OF AGE IN SOBRAL, CEARÁ, BRAZIL

ESTADO NUTRICIONAL DE MENORES DE 5 AÑOS DE EDAD EN SOBRAL, CEARÁ, BRASIL

Beatriz Mendes Alves João Vitor Souza Marques 2 Cynara Carvalho Parente ${ }^{3}$ Marcos Vinícius Souza Marques 4 Francisco Plácido Nogueira Arcanjo ${ }^{5}$ Karyne Gomes Cajazeiras 6

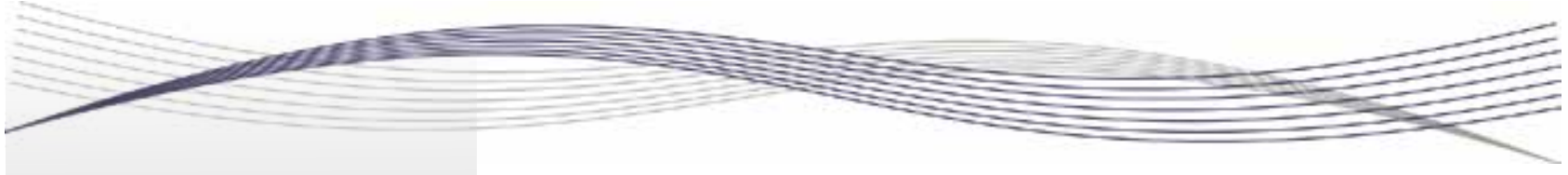

Palavras-chave:

Estado Nutricional; Criança; Atenção Primária à Saúde.

Keywords: Nutritional Status; Child; Primary Health Care.

Palabras clave: Estado Nutricional; Niño; Atención Primaria de Salud.

Submetido: $14 / 01 / 2019$

\section{RESUMO}

Este estudo teve por objetivo avaliar o estado nutricional de menores de 5 anos de idade em Sobral-CE, no período entre 2013 e 2017. Para tanto, foram usados dados dos seguintes indices nutricionais disponiveis no Sistema de Vigilância Alimentar e Nutricional do Ministério da Saúde (SISVAN/MS): a) peso-para-altura; b) peso-para-idade; c) idade-para-altura; e d) IMC-paraidade. Nesse período, constatou-se que o número de crianças acometidas por magreza e magreza acentuada aumentou no município, porém, o agravo nutricional com crescimento mais acentuado foi o sobrepeso (aumento de $58,2 \%)$. Constatou-se, ainda, aumento do número de crianças com altura baixa e muito baixa para a idade, além do peso baixo e muito baixo. 0 IMC-para-idade indicou aumento do sobrepeso e da obesidade. Diante do aumento tanto da magreza e magreza acentuada quanto do sobrepeso e da obesidade entre crianças menores de 5 anos, concluiu-se que coexistem em Sobral diversos agravos nutricionais nessa população. Portanto, mostra-se necessário adotar ações na atenção primária à saúde (APS) para reduzir e corrigir as carências nutricionais, além de investir em pesquisas voltadas à promoção de hábitos saudáveis desde a mais tenra infância.
\end{abstract}

Aprovado: $14 / 05 / 2019$

Autor(a) para Correspondência: Beatriz Mendes Alves Av. Dr. Guarani, 307, apto. 104, Derby Clube - Sobral (CE) CEP: 62042-030. E-mail: beatriz_mendes.a@ outlook.com

\footnotetext{
1. Aluna de Graduação em Medicina na Universidade Federal do Ceará (UFC). Sobral (CE), Brasil.

2. Aluno de Graduação em Medicina na UFC. Sobral (CE), Brasil.

3. Professora no Curso de Graduação em Medicina da UFC. Sobral (CE), Brasil.

4. Aluno de Graduação em Medicina na UFC. Sobral (CE), Brasil.

5. Professor no Curso de Graduação em Medicina da UFC. Sobral (CE), Brasil.

6. Aluna de Graduação em Medicina na UFC. Sobral (CE), Brasil.
} 


\section{ABSTRACT}

This study aimed to assess the nutritional status of children under 5 years of age in Sobral, Ceará, Brazil, within the period from 2013 to 2017. To do so, data from the following nutritional indexes available on the Food and Nutrition Surveillance System of the Brazilian Ministry of Health (Sistema de Vigilancia Alimentar e Nutricional do Ministério da Saúde - SISVAN/MS) were used: a) weight-for-height; b) weight-for-age; c) age-for-height; and d) BMI-for-age. Within this period, it was found that the number of children affected by thinness and marked thinness increased in the municipality, but overweight (a 58.2\% increase) was the most significant nutritional issue. An increased number of children with low height and very low height for age was also observed, in addition to low weight and very low weight. The BMI-for-age indicated an increase in overweight and obesity. Given the increase in both thinness and marked thinness, as well as overweight and obesity, among children under 5 years of age, it was concluded that many nutritional issues coexist in Sobral in this population. Therefore, it is necessary to adopt primary health care (PHC) actions to reduce and correct nutritional deficiencies, besides investing in research aimed at promoting healthy habits from the earliest childhood.

\section{RESUMEN}

Este estudio tuvo como objetivo evaluar el estado nutricional de menores de 5 años de edad en Sobral, Ceará, Brasil, en el período de 2013 a 2017. Para ello, datos de los siguientes índices nutricionales disponibles en el Sistema de Vigilancia Alimentaria y Nutricional del Ministerio de Salud de Brasil (Sistema de Vigilância Alimentar e Nutricional do Ministério da Saúde - SISVAN/MS): a) peso-para-altura; b) peso-para-edad; c) edad-para-altura; y d) IMC-para-edad. Dentro de este período, se constató que el número de niños afectados por delgadez y delgadez marcada aumentó en el municipio, pero el sobrepeso (aumento de 58,2\%) fue el problema nutricional más importante. También se constató un aumento del número de niños con altura baja y muy baja para la edad, además de peso bajo y peso muy bajo. El IMC-para-edad indicó aumento del sobrepeso y de la obesidad. Dado el aumento tanto de la delgadez y de la delgadez marcada como del sobrepeso y de la obesidad entre niños menores de 5 años, se concluyó que en Sobral coexisten muchos problemas nutricionales en esta población. Por lo tanto, es necesario adoptar acciones de atención primaria de salud (APS) para reducir y corregir las deficiencias nutricionales, además de invertir en investigaciones dirigidas a promover hábitos saludables desde la más tierna infancia.

\section{INTRODUÇÃ O}

0 Brasil vem passando por uma transição nutricional, evidenciada pelo aumento da prevalência de obesidade e sobrepeso em crianças e, em paralelo, pela redução da desnutrição infantil. As carências nutricionais se relacionam a fatores socioeconômicos; por outro lado, o sobrepeso e a obesidade refletem maior disponibilidade de alimentos processados industrialmente, com elevado teor de gorduras e açúcares, acarretando inadequado aumento de peso das crianças ${ }^{1}$.

Por dependerem da situação socioeconômica e cultural das crianças, a desnutrição e a obesidade devem ser avaliadas na atenção primária à saúde (APS), visto que é no âmbito da Política Nacional de Atenção Básica (PNAB) que se encontra a Política Nacional de Alimentação e Nutrição (PNAN) aprovada em 1999, com o intuito de desenvolver ações para respeitar, proteger, promover e prover os direitos humanos à saúde e à alimentação².

0 Sistema de Vigilância Alimentar e Nutricional do Ministério da Saúde (SISVAN/MS) disponibiliza relatórios em formato eletrônico, contendo dados como medidas antropométricas e consumo alimentar, para a avaliação nutricional nos serviços de saúde da APS. Ademais, apresenta informações gerais, como faixa etária, sexo, escolaridade, raça e cor, que possibilitam a visualização dos grupos de pacientes com obesidade, sobrepeso e desnutrição ${ }^{3}$.

A desnutrição é uma condição de alta letalidade, decorrente de inúmeros fatores, que leva à adaptação do organismo por meio de mudanças fisiológicas para tentar suprir a falta de nutrientes. Desigualdades sociais, saúde precária e moradias de difícil acesso estão entre os principais aspectos que impactam o estado nutricional dos indivíduos ${ }^{4,5}$.

0 estado nutricional materno pode acarretar agravos alimentares ao(s) filho(s), pois há associação significativa entre a desnutrição da mãe e a desnutrição aguda global da(s) criança(s) ${ }^{6}$. Para combater e prevenir a desnutrição infantil, fazse necessária uma intervenção nutricional voltada não só às crianças desnutridas, mas, também, às 
mulheres em período reprodutivo e às gestantes.

De acordo com a Organização das Nações Unidas para a Alimentação e a Agricultura (Food and Agriculture Organization of the United Nations FA0), no Brasil, a subnutrição caiu de $4,6 \%$ para menos de 2,5\%, comparando o triênio 2004-2006 ao triênio 2015-20177. Segundo dados do SISVAN/MS, em 2017, o Ceará tinha 6.904 crianças com baixo peso para a idade - esse número correspondia a $2,4 \%$ da população infantil do estado com essa condição ${ }^{3}$.

No Município de Sobral, a desnutrição também vem apresentando declínio. Provavelmente, essa queda se deve a melhorias na qualidade de vida da população, bem como à implantação de programas de suplementação alimentar ${ }^{8}$.

A avaliação do estado nutricional de crianças de 0 a 5 anos de idade, recomendada pela Organização Mundial da Saúde (OMS), deve ser realizada por meio dos dados de peso/estatura, estatura/idade, índice de massa corpórea (IMC)/idade e peso/idade e o tratamento recomendado para crianças com desnutrição visa à estabilização hemodinâmica, hidroeletrolítica e acidobásica, seguida pela terapia nutricional propriamente dita ${ }^{9}$.

Por outro lado, no mundo, o número de crianças e adolescentes com obesidade cresceu 10 vezes nos últimos 40 anos. Se essa realidade se mantiver, no Brasil, até 2022, haverá mais crianças e adolescentes com obesidade do que crianças desnutridas. Esse preocupante aumento da obesidade resulta das políticas alimentares que encarecem os produtos nutritivos e saudáveis, dificultando o acesso das comunidades carentes a eles. Apesar do crescimento da obesidade entre crianças no mundo inteiro, a desnutrição moderada ou grave ainda é um grande problema de saúde pública ${ }^{10}$.

A introdução precoce do leite não materno na dieta da criança tem sido um fator que contribui para a obesidade infantil, assim como o aumento do IMC materno e do peso ao nascer. Vale atentar que a introdução precoce de leite não materno, ainda que em aleitamento materno misto, pode diminuir o efeito protetor à obesidade do leite materno no desenvolvimento infantili1.

Em Sobral, um estudo realizado pela Escola de Formação em Saúde da Família Visconde de Sabóia (EFSFVS) observou que $16,7 \%$ dos atendimentos realizados por nutricionistas junto à população infantil, no período entre 2008 e 2010 , ocorreram em virtude de obesidade e $12,5 \%$ devido a sobrepeso, mostrando, assim, alta incidência de obesidade ${ }^{12}$.

\section{A introdução precoce do leite não materno na dieta da criança tem sido um fator que contribui para a obesidade infantil...}

Os períodos críticos para o desenvolvimento de obesidade são, principalmente, o intrauterino, 0 primeiro ano de vida, dos 5 aos 6 anos de idade e a adolescência. Para a abordagem de crianças com obesidade, é imprescindivel identificar os fatores de risco. Além disso, é necessário que as metas em saúde pública priorizem as definições de intervenção, para propiciar a prevenção e o manejo dessa condição. As ações para evitar a obesidade de crianças devem ter início no pré-natal, observando os fatores de risco familiares e a orientação e o cuidado nutricional da gestante ${ }^{13}$.

Nesse sentido, com a tendência dos agravos alimentares entre as crianças, avaliar o estado nutricional de menores de 5 anos de idade viabiliza a adoção de estratégias de saúde que promovam a prevenção e o cuidado de condições relacionadas à má qualidade nutricional.

Diante desse cenário, este estudo teve por objetivo:

- Avaliar o estado nutricional de menores de 5 anos de idade em Sobral, no período entre 2013 e 2017.

\section{METODOLOGIA}

Trata-se de pesquisa documental, descritiva e retrospectiva que analisa uma amostra de dados do estado nutricional de crianças do Município de Sobral, menores de 5 anos de idade, cadastradas no SISVAN/MS no período entre 2013 e 2017. Essas informações estão disponíveis nos relatórios de acompanhamento do SISVAN/MS, no Sistema de Gestão do Bolsa Família (SIGPBF), bem como na estratégia e-SUS Atenção Básica (e-SUS AB).

Sobral se localiza no norte do Ceará, às margens do Rio Acaraú, a $231 \mathrm{~km}$ de distância da capital, Fortaleza. De acordo com a divisão territorial datada de 1993, esse município é constituído por 11 distritos: a) Sobral; b) Aracatiaçu; c) Bonfim; d) 
(aioca; e) (aracará;f) Jaibaras; g) Jordão; h) Rafael Arruda; i) Patriarca; j) São José do Torto; k) e Taperuaba. Sua população é estimada em 206.644 habitantes. Tem clima seco e quente, com temperatura média acima de $26^{\circ} \mathrm{C}^{14}$.

Os relatórios do SISVAN/MS relativos às crianças de ambos os sexos, residentes nas zonas rurais e urbanas do município, foram avaliados por meio dos índices nutricionais: a) peso-para-altura; b) peso-para-idade; c) idade-para-altura; e d) IMC-para-idade. Dados secundários extraídos do SISVAN/MS foram usados para identificar os principais perfis nutricionais e incentivar o desenvolvimento de pesquisas e ações de atenção à saúde junto a crianças com agravos nutricionais.

Os dados foram compilados no programa computacional Microsoft Excel, versão 2010. Neste estudo, as variáveis foram organizadas por ano e por categoria dos índices nutricionais que indicam as crianças com magreza acentuada, sobrepeso e obesidade. 0 programa computacional Microsoft PowerPoint, versão 2010, foi usado para estruturar os gráficos e as tabelas deste artigo.

Por usar informações contidas no SISVAN/MS, com dados de livre acesso disponíveis na internet, este estudo não foi submetido a comitê de ética em pesquisa com seres humanos.

\section{RESULTADOS E DISCUSSÃO}

A Tabela 1 apresenta o índice nutricional calculado pela relação peso $X$ altura ( $\mathrm{X} A)$, usado para identificar tanto o emagrecimento quanto o excesso de peso das crianças. Nesse cálculo, a altura é medida em centímetros, com o indivíduo deitado até os 2 anos e em pé a partir dos 2 anos. 0 peso é registrado em quilos. A massa corpórea (em quilos) é dividida pela altura em centímetros, segundo métodos preconizados pelo Ministério da Saúde (MS), e registrada em gráficos que identificam a faixa de percentil na qual se encontra o indivíduo ${ }^{15}$.

Tabela 1 - Relação peso $X$ altura entre menores de 5 anos de idade em Sobral.

\begin{tabular}{lccccccc}
\hline \multicolumn{1}{c}{ Peso } & $\mathbf{X}$ Altura \\
\hline Ano & $\begin{array}{c}\text { Magreza } \\
\text { acentuada }\end{array}$ & Magreza & Eutrófico & $\begin{array}{c}\text { Risco de } \\
\text { Sobrepeso }\end{array}$ & Sobrepeso & Obesidade & Total \\
\hline 2013 & 119 & 117 & 2.766 & 1.137 & 517 & 629 & 5.285 \\
2014 & 147 & 121 & 3.137 & 1.317 & 627 & 651 & 6.000 \\
\hline 2015 & 152 & 142 & 3.468 & 1.370 & 687 & 630 & 6.449 \\
2016 & 151 & 137 & 3.899 & 1.600 & 801 & 728 & 7.316 \\
\hline 2017 & 138 & 158 & 3.835 & 1.584 & 818 & 814 & 7.347 \\
\hline Total & 707 & 675 & 17.105 & 7.008 & 3.450 & 3.452 & 32.397 \\
\hline
\end{tabular}

Fonte: Elaborada pelos autores.

A Tabela 1 indica evidente predomínio da obesidade e do sobrepeso entre os agravos nutricionais no período estudado. 0 sobrepeso foi o distúrbio nutricional com maior aumento do número de crianças acometidas $(58,2 \%)$. A magreza (35\%) e a magreza acentuada (15\%) também aumentaram - apesar desse crescimento não ser tão acentuado quanto o do sobrepeso e da obesidade, isso deve chamar a atenção dos profissionais da saúde, uma vez que tal fenômeno pode modificar o metabolismo das crianças e levar à redução do ritmo de crescimento. Os casos de desnutrição grave podem interromper o desenvolvimento estatural ${ }^{16}$.

0 aumento do número de crianças obesas em Sobral é compatível com a realidade do país. Na Pesquisa Nacional de Demografia de Saúde da Criança e da Mulher de 2006 (PNDS-2006), o Brasil já apresentava 7\% de crianças obesas e esse percentual se elevou nos últimos anos ${ }^{17}$.

Uma pesquisa realizada em 2014, nas 5 regiões do Brasil, identificou $12 \%$ de crianças obesas. Nesse estudo, a obesidade e o sobrepeso foram relacionados a maiores pesos das crianças ao nascer e, também, a amamentação exclusiva por menor tempo. Essas também são algumas das causas que podem levar ao aumento da obesidade em Sobral. A falta de informação das mães contribui para a redução do tempo de amamentação exclusiva. De acordo com o relato do serviço de enfermagem de um centro da Estratégia Saúde da Família (ESF) nesse município, as mães foram orientadas quanto à importância e à técnica da amamentação no ano de 2011 - isso proporcionou melhores índices de adesão ao aleitamento exclusivo ${ }^{18,19}$. 
A Tabela 2 apresenta a relação altura $X$ idade ( $X$ X I), que expressa o crescimento linear das crianças e corresponde aos dados que melhor demonstram os efeitos adversos em termos de crescimento. Trata-se do índice mais sensivel para aferir a qualidade de vida infantil. A altura é aferida em centímetros e a idade é registrada em meses. Segundo o MS, os gráficos que ilustram esses dados refletem o crescimento de uma população de referência e, a partir deles, pode-se obter a classificação do estado nutricional das crianças, segundo o percentil calculado de altura e idade.

Tabela 2 - Relação altura idade entre menores de 5 anos de idade em Sobral

\begin{tabular}{lcccc}
\hline \multicolumn{5}{c}{ Altura Idade } \\
\hline Ano & $\begin{array}{c}\text { Altura muita baixa } \\
\text { para a idade }\end{array}$ & $\begin{array}{c}\text { Altura baixa para a } \\
\text { idade }\end{array}$ & $\begin{array}{c}\text { Altura adequada para a } \\
\text { idade }\end{array}$ & Total \\
\hline 2013 & 244 & 410 & 4.631 & 5.285 \\
2014 & 293 & 513 & 5.194 & 6.000 \\
2015 & 292 & 530 & 5.627 & 6.449 \\
2016 & 373 & 600 & 6.343 & 7.316 \\
2017 & 406 & 589 & 6.352 & 7.347 \\
Total & $\mathbf{1 . 6 0 8}$ & $\mathbf{2 . 6 4 2}$ & $\mathbf{2 8 . 1 4 7}$ & $\mathbf{3 2 . 3 9 7}$ \\
\hline
\end{tabular}

Fonte: Elaborada pelos autores.

A Tabela 2 indica que, no período estudado, a maior parte das crianças do município apresentou altura adequada para a idade; o número de crianças com altura baixa e muito baixa para a idade cresceu durante praticamente todo o período. Esses números são bastante relevantes, pois, em 2017, identificou-se o maior número de crianças com altura inadequada (13,5\% do total). Um dos fatores relacionados à baixa estatura das crianças é o precário nível econômico de suas famílias, como observado por estudo realizado no Estado da Paraíba em 2016, no qual a ocorrência de baixa estatura foi 2 vezes maior entre crianças com renda per capita familiar menor do que 0,5 salário mínimo em comparação às famílias com renda per capita entre 0,5 e 1 salário mínimo. A baixa estatura e o baixo peso das mães também influenciam a reduzida estatura das crianças. No mesmo estudo, constatou-se que $10 \%$ das crianças de mães com baixa estatura também apresentavam déficit de estatura, ao passo que apenas $5 \%$ das crianças de mães com estatura normal apresentavam baixa estatura. Já em relação às mães com baixo peso, $15 \%$ delas tiveram filhos com baixa estatura, enquanto apenas $6 \%$ das mães com peso normal tiveram filhos com baixa estatura ${ }^{20}$. Outro estudo realizado no Estado da Paraíba detectou que o baixo peso das crianças está fortemente relacionado à idade das mães menores de 20 anos e, ainda, ao baixo peso materno ${ }^{21}$.

$\mathrm{Na}$ Tabela 3 se observa a relação entre a massa corpórea e a idade cronológica das crianças (P X I). Esse índice nutricional é usado, principalmente, para a caracterização do baixo peso e é calculado dividindo a massa corpórea (em quilos) pela idade (em meses), como preconiza o MS. Tal índice está presente na caderneta da criança, distribuída nas maternidades e nos estabelecimentos de saúde ${ }^{15}$.

Tabela 3 - Relação peso X idade entre menores de 5 anos de idade em Sobral

\begin{tabular}{lccccc}
\hline \multicolumn{5}{c}{ Peso $\times$ Idade } \\
\hline Ano & $\begin{array}{c}\text { Peso muito baixo } \\
\text { para a idade }\end{array}$ & $\begin{array}{c}\text { Peso baixo para a } \\
\text { idade }\end{array}$ & $\begin{array}{c}\text { Peso adequado ou } \\
\text { eutrófico }\end{array}$ & $\begin{array}{c}\text { Peso elevado } \\
\text { para a idade }\end{array}$ & Total \\
2013 & 32 & 97 & 4.484 & 672 & 5.285 \\
2014 & 48 & 131 & 5.158 & 663 & 6.000 \\
2015 & 45 & 113 & 5.592 & 699 & 6.449 \\
2016 & 59 & 124 & 6.320 & 813 & 7.316 \\
\hline 2017 & 56 & 177 & 6.300 & 814 & 7.347 \\
\hline Total & 240 & 642 & 27.854 & 3.661 & 32.397 \\
\hline
\end{tabular}

Fonte: Elaborada pelos autores. 
A Tabela 3 aponta que o número de crianças com peso elevado para a idade aumentou no período estudado e manteve-se estável entre 2016 e 2017. 0 maior número de crianças com peso elevado para a idade foi observado em 2017. Em relação ao peso baixo e muito baixo para a idade, os maiores aumentos ocorreram entre 2016 e 2017 - evidenciando que, apesar da transição nutricional no país, Sobral ainda apresenta certo aumento do número de crianças com peso muito baixo e baixo para a idade.

0 baixo peso das crianças pode relacionar-se ao baixo peso materno, como demonstrado por estudo realizado no Estado de Pernambuco, em 2015 - constatou-se que o aumento do peso dos filhos era diretamente proporcional ao aumento do peso materno. A assistência ao pré-natal influencia os bons indicadores nutricionais entre as crianças $^{22}$.

Um estudo realizado em São Paulo, em 2011, observou que mães com baixo peso apresentam quase 3 vezes mais chances de ter seus filhos com peso inadequado ao nascer ${ }^{23}$, corroborando a relação entre o estado nutricional materno e o da criança.

Além disso, vale ressaltar que gestantes adolescentes também apresentam maiores chances de ter filhos com baixo peso, segundo estudo realizado na Bahia, entre 2006 a 2012 - isso demonstra a ligação entre os distúrbios nutricionais neonatais e a idade das mães, pois mães adolescentes são suscetíveis a condições sociais, econômicas e educacionais que podem constituir fatores de risco para as crianças recém-nascidas e aquelas na primeira infância ${ }^{24}$. Pesquisas apontam que fatores como assistência pré-natal inadequada, recusa da gestação pela família ou pelo parceiro ou ausência do parceiro afetam o bem-estar e a saúde da gestante adolescente, contribuindo negativamente para o crescimento e desenvolvimento fetal ${ }^{25}$. Crianças com baixo peso ao nascer demandam atenção, pois apresentam maior risco nutricional no primeiro ano de vida ${ }^{26}$ es riscos de peso inadequado tendem a se manter ao longo da infância.

Na Tabela 4 se observam os dados do IMC $x$ Idade - essa análise é relevante, pois possibilita identificar condições para avaliar o estado nutricional das crianças pelos percentis que relacionam 3 medidas antropométricas (peso, altura e idade). 0 IMC é calculado dividindo a massa corpórea em quilos pela altura em metros elevada ao quadrado. Pode-se classificar o estado nutricional das crianças pelo IMC.

Tabela 4 - Relação IMC x Idade entre menores de 5 anos de idade em Sobral

\begin{tabular}{lccccccc}
\hline \multicolumn{10}{c}{ IMC x Idade } \\
\hline Ano & $\begin{array}{c}\text { Magreza } \\
\text { acentuada }\end{array}$ & Magreza & Eutrofia & $\begin{array}{c}\text { Risco de } \\
\text { sobrepeso }\end{array}$ & Sobrepeso & Obesidade & Total \\
2013 & 166 & 139 & 2.599 & 1.194 & 582 & 605 & 5.285 \\
2014 & 200 & 147 & 2.929 & 1.355 & 730 & 639 & 6.000 \\
\hline 2015 & 195 & 139 & 3.263 & 1.441 & 762 & 649 & 6.449 \\
2016 & 197 & 154 & 3.628 & 1.690 & 919 & 728 & 7.316 \\
\hline 2017 & 169 & 155 & 3.624 & 1.620 & 893 & 886 & 7.347 \\
\hline Total & 927 & 734 & 16.043 & 7.300 & 3.886 & 3.507 & 32.397 \\
\hline
\end{tabular}

Fonte: Elaborada pelos autores.

A Tabela 4 destaca, a partir da relação do IMC $\times$ Idade, o risco de sobrepeso, o sobrepeso e a obesidade como agravos entre as crianças nesse período. 0 risco de sobrepeso cresceu no período de 2013 a 2016 , porém, de 2016 a 2017, esse número diminuiu 4,1\%. 0 número de crianças com sobrepeso também aumentou no período de 2013 a 2016; já no período de 2016 a 2017 houve redução de 2,8\%. Vale salientar que o número de crianças obesas cresceu durante todo o período estudado: de 2013 a 2017 houve aumento de $46 \%$ do número de crianças com obesidade. 0 aumento dos índices de obesidade em Sobral não difere dos resultados de outros municípios do Brasil, como Campina Grande, que também apresenta crescimento desse distúrbio nutricional entre crianças, consequência do maior consumo de alimentos ricos em açúcar, como doces, salgadinhos e refrigerantes. A substituição do café da manhã e de outras refeições por lanches ao longo do dia também se apresenta como fator de risco para a obesidade ${ }^{20}$.

Um estudo realizado em Minas Gerais relacionou a alimentação inadequada das crianças à baixa ingestão de frutas, verduras e leguminosas e aos altos índices de obesidade detectados entre escolares nesse estado 
no ano de $2015^{27}$.

A má qualidade alimentar também é uma das causas do aumento dos índices de obesidade em Sobral. Nesse município, as refeições das crianças incluem alimentos ricos em gorduras e açúcares, como pizzas, refrigerantes e salgadinhos ${ }^{28}$.

A ausência de atividade física contribui para 0 aumento do número de crianças obesas, pois estudos apontam que essa prática assume papéis na prevenção e no tratamento do sobrepeso e da obesidade: a) restaura o perfil lipídico; b) melhora a composição corpórea; e c) restaura o metabolismo adequado ${ }^{29}$.

\section{CONCLUSÃO}

Este estudo analisou a transição nutricional que o Município de Sobral vem enfrentando, caracterizada por diversos estados nutricionais em menores de 5 anos de idade, adotando o SISVAN/MS como fonte de dados no período entre 2013 e 2017.

Os resultados mostram que o número de crianças acometidas por magreza e magreza acentuada, além de altura baixa e altura muito baixa para a idade, cresceu no município. 0s índices de peso baixo e peso muito baixo para a idade também aumentaram na população estudada. Contudo, o agravo nutricional com crescimento mais acentuado foi o sobrepeso e a obesidade.

Diante da coexistência das diversas condições relacionadas à alimentação em menores de 5 anos de idade, conclui-se que Sobral passa por um processo de transição nutricional. Urge, assim, a necessidade de implementar ações na APS, além de investir em pesquisas voltadas a reduzir e corrigir as carências nutricionais, promovendo hábitos saudáveis desde a mais tenra infância.

\section{CONTRIBUIÇÃO DOS AUTORES}

Beatriz Mendes Alves contribuiu com a realização da pesquisa, o delineamento do estudo e a redação do manuscrito. João Vitor Souza Marques contribuiu com a realização da pesquisa e a redação do manuscrito. Cynara Carvalho Parente contribuiu com a redação e revisão crítica do manuscrito. Marcos Vinicius Souza Marques contribuiu com a realização da pesquisa. Francisco Plácido Nogueira Arcanjo e Karyne Gomes Cajazeiras contribuíram com a revisão crítica do manuscrito.

\section{REFERÊNCIAS}

1. Pereira IFS. Estado nutricional em menores de 5 anos de idade no Brasil: evidências de polarização epidemiológica nutricional. Ciênc Saúde Colet [serial on the internet]. 2017 [cited 2018 Nov 19];22(10):3341-52. Available from: http://www.scielo.br/pdf/csc/v22n10/1413-8123csc-22-10-3341.pdf

2. Brasil. Política Nacional de Alimentação e Nutrição. Brasília (DF): Ministério da Saúde; 2012.

3. Sistema de Vigilância Alimentar e Nutricional [homepage on the internet]. c2004 [cited 2018 Nov 27]. Available from: http://dab.saude. gov.br/portaldab/ape vigilancia alimentar. php?conteudo=sisvan

4. Sarni R0, Munekata RV. Terapia nutricional na desnutrição energético-proteica grave. In: Lopez FA, Sigulem DM, Taddei JA, editors. Fundamentos da terapia nutricional em pediatria. São Paulo: Sarvier; 2002. p. 115-32.

5. Araújo ST, Oliveira CSM, Muniz PT, Nunes MS, Cardoso MA. Desnutrição infantil em um dos municípios de maior risco nutricional do Brasil: estudo de base populacional na Amazônia ocidental brasileira. Rev Bras Epidemiol [serial on the internet]. 2016 [cited 2018 Nov 19];19(3):554-66. Available from: http://www.scielo.br/pdf/rbepid/ v19n3/1980-5497-rbepid-19-03-00554.pdf

6. Oliveira ACM, Pereira LA, Ferreira RC, Clemente APG. Estado nutricional materno e sua associação com o peso ao nascer em gestações de alto risco. Ciênc Saúde Colet [serial on the internet]. 2018 [cited 2018 Nov 19];23(7):2373-82. Available from: http://www.scielo.br/pdf/csc/v23n7/1413-8123csc-23-07-2373.pdf

7. Organización de las Naciones Unidas para la Alimentación y la Agricultura. El estado de la seguridad alimentaria y la nutrición en el mundo. Roma: FA0; 2018.

8. Sucupira ACSL, Andrade LOM, Barreto ICHC, Lima JW, Santiago AV, Santiago AX. Determinantes sociais da saúde de crianças de 5 a 9 anos da zona urbana de Sobral, Ceará, Brasil. Rev Bras Epidemiol [serial on the internet]. 2018 [cited 2018 Nov 26];(17):160-77. Available from: http://www.scielo.br/pdf/rbepid/ v17s2/pt 1415-790X-rbepid-17-s2-00160.pdf

9. Brasil. Manual de terapia nutricional na atenção especializada hospitalar. Brasília (DF): Ministério da Saúde; 2016. 
10. NCD Risk Factor Collaboration. Worldwide trends in body-mass index, underweight, overweight, and obesity from 1975 to 2016: a pooled analysis of 2416 population-based measurement studies in 128.9 million children, adolescents, and adults. J Lancet [serial on the internet]. 2017 [cited 2018 Nov 27];(390):2627-42. Available from: https://www.thelancet.com/action/showPdf?pii $=$ S0140-6736\%2817\%2932129-3

11. Nascimento VG. Aleitamento materno, introdução precoce de leite não materno e excesso de peso na idade pré-escolar. Rev Paul Pediatr [serial on the internet]. 2016 [cited 2018 Nov 29];34(4):4549. Available from: http://www.scielo.br/pdf/rpp/ v34n4/pt 0103-0582-rpp-34-04-0454.pdf

12. Barbosa MIS. O nutricionista na Estratégia de Saúde da Família. Rio de Janeiro: Ed. UERJ; 2016.

13. Brasil. Manual de diretrizes para o enfretamento da obesidade na saúde suplementar brasileira. Rio de Janeiro: Agência Nacional de Saúde Suplementar; 2017.

14. Instituto Brasileiro de Geografia e Estatística [homepage on the internet]. Brasil/Ceará: Sobral. c2019 [cited 2018 Dec 2]. Available from: https://cidades.ibge.gov.br/brasil/ce/sobral/ pesquisa $/ 32 / 28163$

15. Brasil. SISVAN: notas técnicas [document on the internet]. 2004 [cited $2018 \mathrm{Dec} 4$ ]. Available from: http://tabnet.datasus.gov.br/cgi/SISVAN/CNV/ notas sisvan.html

16. Alecrim JS, Sousa LF, Castro JM, Borja GPC, Castro LLB, Bastos $V C$, et al. Prevalência de obesidade infantil em uma escola pública da Cidade de Ipatinga (MG). Ensaios e Ciência: Biológicas, Agrárias e da Saúde [serial on the internet]. 2018 [cited 2018 Dec 5];22(1):22-6. Available from: http://pgsskroton. com.br/seer/index.php/ensaioeciencia/article/ view/4501/4267

17. Monteiro CA, Conde WL, Konno SC, Lima AL, Silva $A C$, Benicio MH. Avaliação antropométrica do estado nutricional de mulheres em idade fértil e crianças menores de cinco anos. In: Brasil. Pesquisa Nacional de Demografia e Saúde da Criança e da Mulher - PNDS 2006: dimensões do processo reprodutivo e da saúde da criança. Brasília (DF): Ministério da Saúde; 2009. p. 213-30.

18. Muller MR, Tomasi E, Facchini LA, Piccini RX, Silveira DS, Siqueira FV, et al. Excesso de peso e fatores asociados em menores de 5 anos em populações Urbanas no Brasil. Rev Bras Epidemiol [serial on the internet]. 2014 [cited 2018 Dec 5];17(2):285-96. Available from: http://www.scielo.br/pdf/rbepid/ v17n2/pt 1415-790X-rbepid-17-02-00285.pdf
19. Martins QPM. Fatores que influenciam no aleitamento materno exclusivo: um relato de experiência. II Congresso Brasileiro de Enfermagem Neonatal; 2012; Fortaleza, BR [document on the internet]. 2012 [cited 2018 Dec 6]. Available from: http://www.abenfoce.org.br/sites/default/ files/FATORES $\% 20$ QUE $\% 2$ OINFLUENCIAM $\% 20$ N0\%20 ALEITAMEN T $0 \% 20$ MATERN $0 \% 20$ EXCLUSIV $0 \% 20$ $\underline{U M \% 20} 0 . p \mathrm{df}$

20. Pedraza DF, Sales MC, Menezes TN. Fatores associados ao crescimento linear de crianças socialmente vulneráveis do Estado da Paraíba, Brasil. Ciênc Saúde Colet [serial on the internet]. 2016 [cited 2018 Dec 6];21(3):935-45. Available from: http://www.scielo.br/pdf/csc/v21n3/14138123-csc-21-03-0935.pdf

21. Souza MM, Pedraza DF, Menezes TN. E s t a d o nutricional de crianças assistidas em creches e situação de (in)segurança alimentar de suas famílias. Ciênc Saúde Colet [serial on the internet]. 2012 [cited 2018 Dec 6];17(12):3425-36. Available from: https://www.scielosp.org/pdf/csc/2012. v17n12/3425-3436

22. Miglioli TC. Fatores associados ao estado nutricional de crianças menores de cinco anos. Rev Saúde Pública [serial on the internet]. 2015 [cited 2018 Dec 6];(49):[about 8 pages]. Available from: http://www.scielo.br/pdf/rsp/v49/pt 0034-8910rsp-S0034-89102015049005441.pdf

23. Fonseca MRCC, Laurenti R, Marin CR, Traldi MC. Ganho de peso gestacional e peso ao nascer do concepto: estudo transversal na região de Jundiaí, São Paulo, Brasil. Ciênc Saúde Colet [serial on the internet]. 2014 [cited 2018 Dec 6];19(5):1401-7. Available from: https://www.scielosp.org/article/ ssm/content/raw/?resource ssm path $=/ \mathrm{media} /$ assets/csc/v19n5/1413-8123-csc-19-05-01401.pdf

24. Santos NLAC, Costa MCO, Amaral MTR, Vieira G0, Bacelar EB, Almeida AHV. Gravidez na adolescência: análise dos fatores de risco para baixo peso, prematuridade e cesariana. Ciênc Saúde Colet [serial on the internet]. 2014 [cited 2018 Dec 6];19(3):71926. Available from: http://www.scielo.br/scielo. php?pid =S1413-81232014000300719\&script=sci abstract\&tlng $=p t$

25. Chen XK, Wen SW, Fleming N, Demissie K, Rhoads GG, Walker M. Teenage pregnancy and adverse birth outcomes: a large population based retrospective cohort study. Int J Epidemiol. 2007;36(2):368-73.

26. Motta MEFA, Silva GAP, Araújo OC, Lira PI, Lima MC. 0 peso ao nascer influencia o estado nutricional ao final do primeiro ano de vida? J Pediatr (Rio J) [serial on the internet]. 2005 [cited 2018 Dec 6];81(5):377-82. Available from: http://www.scielo. $\mathrm{br} / \mathrm{pdf} / \% 0 \mathrm{D} / \mathrm{jped} / \mathrm{v} 81 \mathrm{n} 5 / \mathrm{v} 81 \mathrm{n} 5 \mathrm{a} 07 . \mathrm{pdf}$ 
27. Paiva ACT, Couto CC, Masson APL, Monteiro CAS, Freitas CF. Obesidade infantil: análises antropométricas, bioquímicas, alimentares e estilo de vida. Rev Cuid (Bucaramanga 2010) [serial on the internet]. 2018 [cited 2018 Dec 6];9(3):113. Available from: https://www.researchgate. net/publication/327494328 0besidade Infantil analises antropometricas bioquimicas alimentares e estilo de vida

28. Lira RCM, Antunes LR, Mesquita K0. Experiência de abordagem sobre alimentação entre crianças. Sanare (Sobral, Online) [serial on the internet]. 2016 [cited 2018 Dec 7];15(1):69-73. Available from: https://sanare.emnuvens.com.br/sanare/article/ viewFile/930/559

29. Paes ST, Marins JCB, Andreazzi AE. Efeitos metabólicos do exercício físico na obesidade infantil: uma visão atual. Rev Paul Pediatr [serial on the internet]. 2015 [cited 2018 Dec 7];33(1):1229. Available from: http://www.scielo.br/pdf/rpp/ v33n1/pt 0103-0582-rpp-33-01-00122.pdf
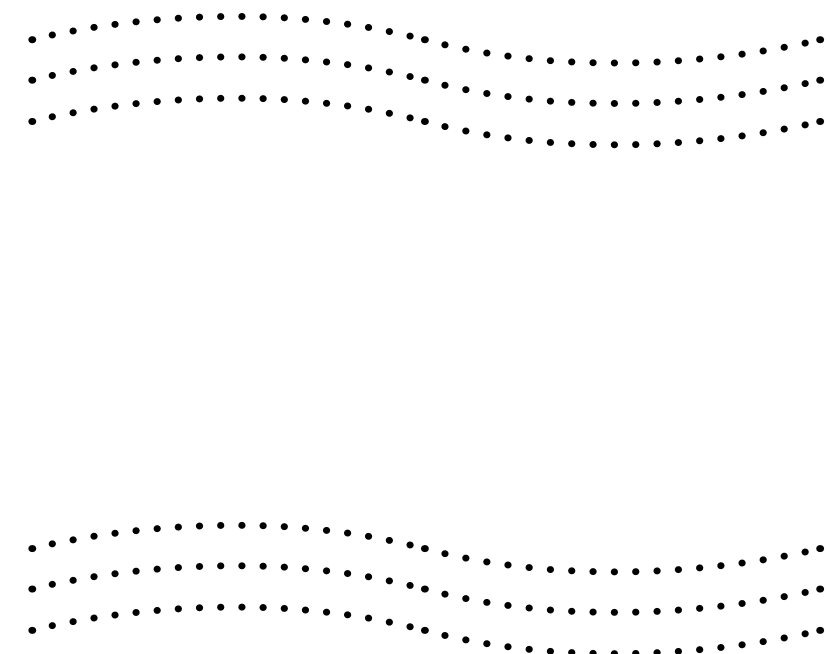
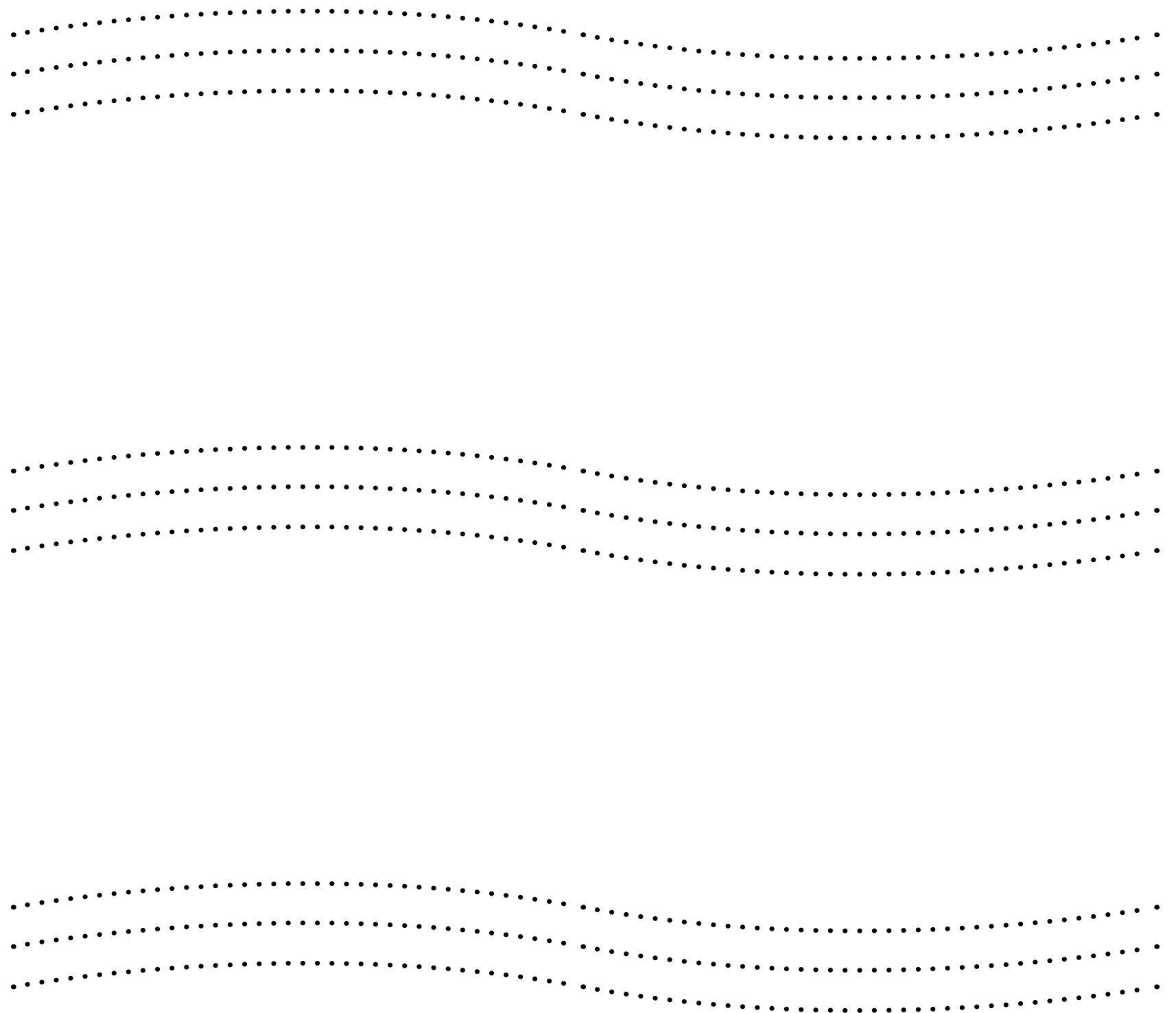


\section{EDUCAÇÃO ALIMENTAR E NUTRICIONAL COMO INTERVENÇÃO EM HÁBITOS ALIMENTARES SAUDÁVEIS NO AMBIENTE ESCOLAR}

FOOD AND NUTRITION EDUCATION AS AN INTERVENTION IN HEALTHY EATING HABITS IN THE SCHOOL ENVIRONMENT

EDUCACIÓN ALIMENTARIA Y NUTRICIONAL COMO INTERVENCIÓN EN HÁBITOS ALIMENTARIOS SALUdABLES EN EL AMBIENTE

ESCOLAR

Quitéria Vanessa Brito Magalhães ${ }^{1}$

Jorge Luís Pereira Cavalcante ${ }^{2}$

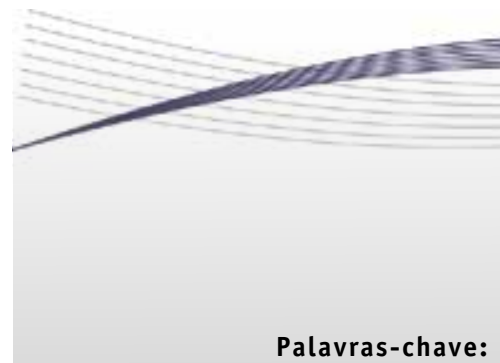

Educação Alimentar e Nutricional; Hábitos Alimentares; Saúde Escolar.

Keywords:

Food and Nutrition Education; Eating Habits; School Health.

Palabras clave: Educación Alimentaria y Nutricional; Hábitos Alimentarios; Salud Escolar.

Submetido: 02/09/2018 Aprovado: 20/02/2019

Autor(a) para Correspondência: Quitéria Vanessa Brito Magalhães R. Inácio Alves de Mesquita, 578 Piracicaba - Santa Quitéria (CE) CEP: 62280-000 E-mail:vanessanutriris@gmail.com

\section{RESUMO}

Este estudo teve por objetivo analisar na literatura a influência das ações de educação alimentar e nutricional (EAN) como intervenção em hábitos alimentares no ambiente escolar. Trata-se de revisão integrativa, realizada com 10 artigos originais publicados em português no período de 2008 a 2017, no Brasil, disponíveis nas bases de dados Lilacs, MedLine e SciELO. Os artigos selecionados foram catalogados e identificados por título, autor, base de dados, ano de publicação, local, metodologia, objetivo do estudo, resultados e conclusões. A pesquisa mostrou similaridade de pensamento entre os autores ao identificar a EAN como estratégia que deve ser amplamente empregada no ambiente escolar com vistas a influenciar as escolhas alimentares e a formação de hábitos alimentares saudáveis. Constatou-se a necessidade de conduzir novas pesquisas para atualização dos dados disponíveis na literatura, relativas a ações de EAN voltadas aos escolares, em busca da construção de hábitos alimentares saudáveis e da melhoria da qualidade de vida.

1. Nutricionista. Especialista em Saúde da Família e Comunidade pela Escola de Saúde Pública do Ceará (ESP/ CE). Santa Quitéria (CE), Brasil.

2. Nutricionista. Aluno de Doutorado em Nutrição na Universidade Internacional Iberoamericana (UNINI México). Professor no Curso de Bacharelado em Nutrição do Centro Universitário Inta (UnInta). Sobral (CE), Brasil. 


\section{ABSTRACT}

This study aimed to analyze in the literature the influence of food and nutrition education (FNE) actions as an intervention in eating habits in the school environment. This is an integrative review, carried out with 10 original articles published in Portuguese within the period from 2008 to 2017, in Brazil, available on the databases LILACS, MedLine, and SciELO. The selected articles were cataloged and identified by title, author, database, year of publication, location, methodology, study objective, results, and conclusions. The research showed a similarity of thought between the authors when identifying FNE as a strategy that must be widely used in the school environment with a view to influencing food choices and the adoption of healthy eating habits. There was a need to conduct further research to update the data available in the literature, regarding FNE actions aimed at school students, seeking the construction of healthy eating habits and an improved quality of life.

\section{RESUMEN}

Este estudio tuvo como objetivo analizar en la literatura la influencia de acciones de educación alimentaria y nutricional (EAN) como una intervención en los hábitos alimentarios en el ambiente escolar. Esta es una revisión integradora, realizada con 10 artículos originales publicados en portugués en el período de 2008 a 2017, en Brasil, disponibles en las bases de datos LILACS, MedLine y SciELO. Los artículos seleccionados fueron catalogados e identificados por título, autor, base de datos, año de publicación, lugar, metodología, objetivo del estudio, resultados y conclusiones. La investigación mostró una similitud de pensamiento entre los autores cuando identificaron la EAN como una estrategia que debe ser ampliamente utilizada en el ambiente escolar con el fin de influir en la elección de alimentos y la adopción de hábitos alimentarios saludables. Se constató la necesidad de conducir nuevas investigaciones para actualizar los datos disponibles en la literatura, relativas a acciones de EAN dirigidas a los escolares, en busca de la construcción de hábitos alimentarios saludables y de la mejora de la calidad de vida.

\section{INTRODUÇÃ $O$}

0 quadro epidemiológico nutricional da população brasileira advém da coexistência de carências nutricionais e doenças infecciosas, bem como de um gradativo aumento dos índices de obesidade/ sobrepeso e de doenças crônicas não transmissíveis em todas as faixas etárias ${ }^{1}$. A obesidade/sobrepeso tem-se revelado um grande desafio para a saúde pública mundial, sendo que nas últimas três décadas suas taxas de incidência e prevalência apresentaram um aumento significativo, confirmando os dados da Organização Mundial da Saúde $(0 M S)^{2}$. A obesidade, inclusive em crianças e adolescentes, configura um dos maiores problemas de saúde pública e suas causas são multifatoriais: a) consumo excessivo e/ou desbalanceado de alimentos; b) condições socioeconômicas e culturais; c) sedentarismo; e d) contexto de insegurança alimentar e nutricional ${ }^{3}$.

No Brasil, a insegurança alimentar e nutricional foi avaliada pela Pesquisa Nacional por Amostra em Domicílios (PNAD), em 2013. Constatou-se que 52 milhões de pessoas $(25,8 \%)$ vivenciavam a insegurança alimentar - a maioria destas morava em zona urbana (40 milhões) e o Nordeste apresentou o maior número de domicílios em contexto de insegurança alimentar $(44,2 \%)^{4}$.
Considerando o aumento da incidência da obesidade, tem-se fomentado discussões sobre a adoção de ações em saúde no ambiente escolar, com destaque para a educação alimentar e nutricional (EAN). É importante entender que essas condutas buscam reverter o quadro de excesso de peso proporcionando meios para alcançar um peso ideal e uma alimentação e nutrição adequada, em especial junto à criança em idade escolar ${ }^{5}$. Nesse sentido, a EAN constitui uma estratégia que incorpora ações de prevenção de agravos, promoção da saúde e controle de problemas alimentares e nutricionais - como obesidade, doenças crônicas não transmissíveis e deficiências nutricionais ${ }^{6}$.

Um estudo ${ }^{7}$ apontou ser a infância o período de formação dos hábitos nutricionais da vida adulta, assim, trata-se da fase decisiva para estabelecer as bases de uma alimentação adequada e saudável. Nesse sentido, os autores de outro estudo ${ }^{8}$ afirmam que as instituições escolares, em especial as creches, exercem grande influência nos hábitos alimentares em decorrência do longo período de permanência das crianças no espaço educacional. É nesse contexto que a EAN se consolida como modo de reverter o quadro de obesidade via mudança de hábitos alimentares, devendo abranger todas as faixas etárias da educação formal ${ }^{9}$. 
Mostra-se necessário adotar ações de EAN baseadas em diferentes abordagens educacionais e pedagógicas, favorecendo o diálogo e a reflexão sobre aspectos da alimentação, nutrição e saúde ${ }^{10}$. Logo, a escola proporciona um espaço indispensável às ações de EAN, promovendo hábitos alimentares saudáveis que visam à promoção da saúde. A oferta de uma alimentação equilibrada e o estímulo à adoção de bons hábitos alimentares no ambiente escolar são fundamentais para minimizar a insegurança alimentar e nutricional e auxiliar o aluno a garantir seu bemestar e sua qualidade de vida, com capacidade satisfatória de aprendizado e desenvolvimento ${ }^{7}$.

De acordo com a Política Nacional de Alimentação e Nutrição (PNAN), as ações de alimentação e nutrição devem ser concomitantes às de saúde, em caráter complementar, com formulação, execução e avaliação no âmbito do Sistema Único de Saúde (SUS) ${ }^{6}$. Assim, a EAN assume importante papel na promoção de hábitos alimentares saudáveis e proporciona conhecimentos importantes para a tomada de decisões nesse sentido ${ }^{7}$.

0 uso de ferramentas como a EAN constitui um desafio tanto para os nutricionistas e professores quanto para a população, além de estabelecer ações de extrema importância. Diante do cenário observado, levantou-se a seguinte questão de pesquisa:

- Como as ações de educação alimentar podem influenciar os hábitos alimentares de escolares?

Logo, para ampliar as discussões relativas ao tema, este estudo teve por objetivo:

- Analisar na literatura a influência das ações de educação alimentar e nutricional como intervenção em hábitos alimentares no ambiente escolar.

\section{METODOLOGIA}

Trata-se de revisão integrativa de literatura, baseada em artigos disponíveis nas bases de dados Lilacs, MedLine e SciELO. Os critérios de inclusão foram: a) artigos originais; b) estudos produzidos no Brasil; c) publicações em língua portuguesa; e d) datas de publicação entre 2008 e 2017. Já os critérios de exclusão foram: a) artigos de revisão; e b) estudos científicos indisponíveis em formato de artigo (monografias, dissertações e teses).

A busca de artigos ocorreu entre junho de 2016 e maio de 2017, com uso dos seguintes descritores em ciências da saúde (DeCS), de modo isolado ou cruzado: a) "educação alimentar e nutricional"; b) "hábitos alimentares"; e c) "saúde escolar". 0 cruzamento dessas palavras-chave se deu da seguinte forma: a) "educação alimentar e nutricional versus saúde escolar"; b) "hábitos alimentares versus saúde escolar"; e c) "educação alimentar e nutricional versus hábitos alimentares".

A aplicação dos critérios de inclusão resultou na seleção de 23 dos 47 artigos identificados. Esses 23 artigos foram submetidos a leitura integral e 13 deles foram excluídos por não estarem plenamente de acordo com a temática em análise, além de não serem artigos originais. Assim, a amostra final desta revisão integrativa consistiu em 10 artigos catalogados e identificados por título, autor, base de dados, ano de publicação, local, metodologia, objetivo do estudo, resultados e conclusões. Posteriormente, estabeleceu-se um paralelo entre os estudos, interpretando e interconectando os achados de pesquisa e apresentando-os sob a forma de sintese do conhecimento.

Este estudo se manteve fiel às opiniões dos autores das obras consultadas e respeitou suas definições, seus conceitos, suas ideias e seus princípios.

\section{RESULTADOS}

0 Quadro 1 sintetiza os 10 artigos incluídos na amostra final desta revisão integrativa (5 selecionados na base Lilacs, 1 na base MedLine e 4 na base SciELO. 


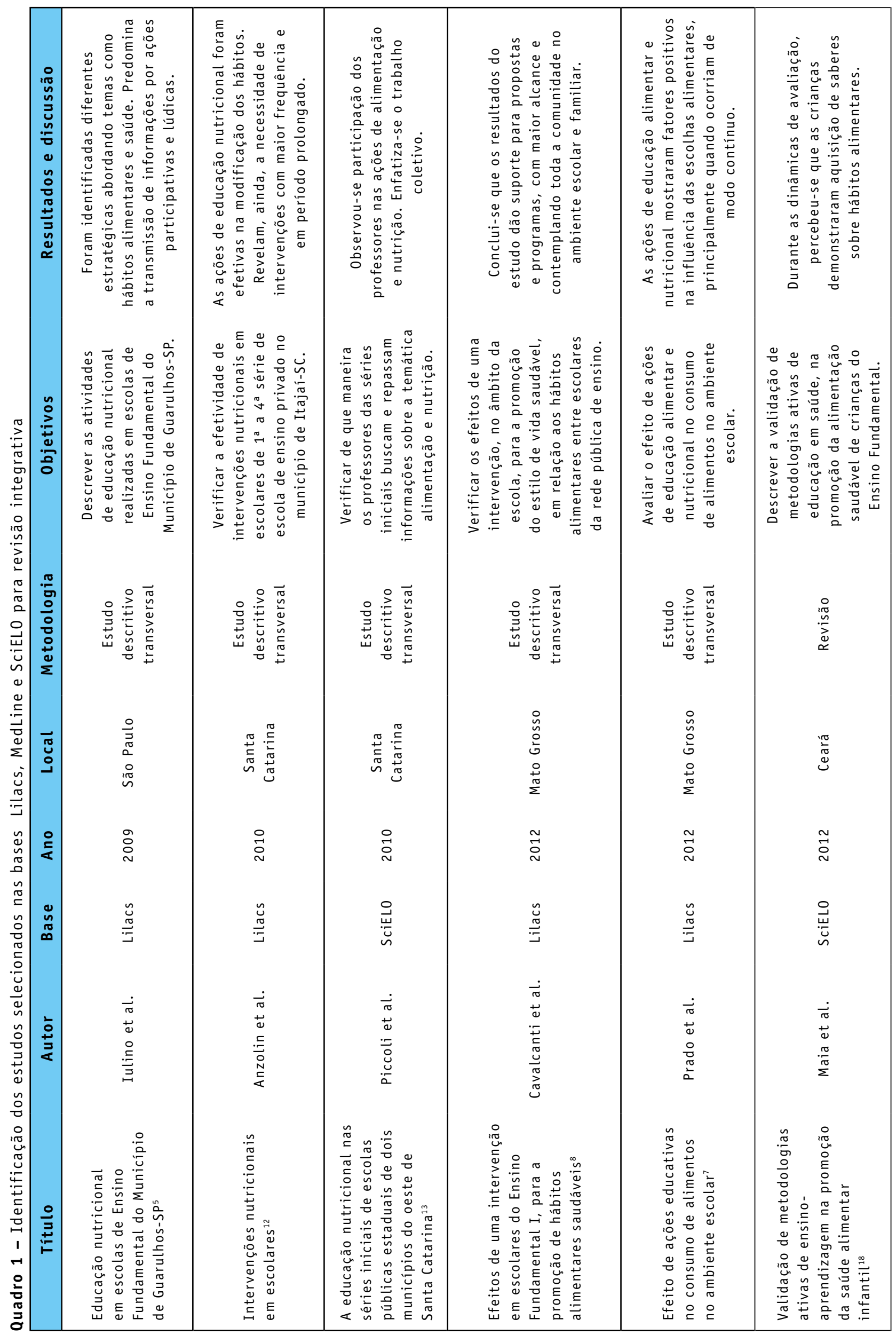

62 - SANARE, Sobral - V.18 n.01,p.59-67, Jan./Jun. - 2019 


\begin{tabular}{|c|c|c|c|c|}
\hline 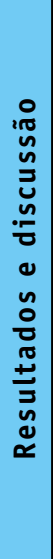 & 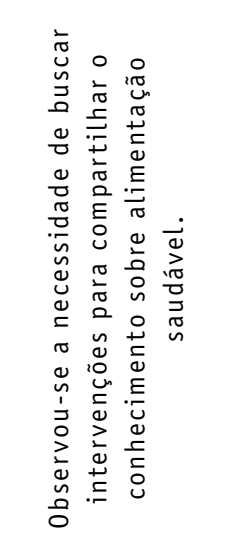 & 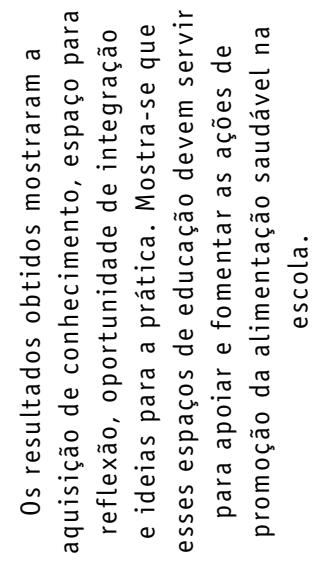 & 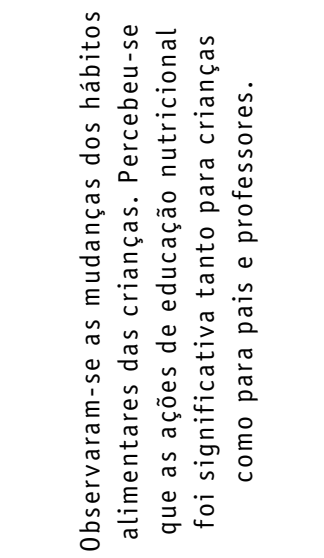 & 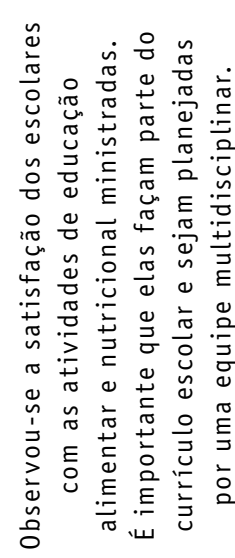 \\
\hline : & 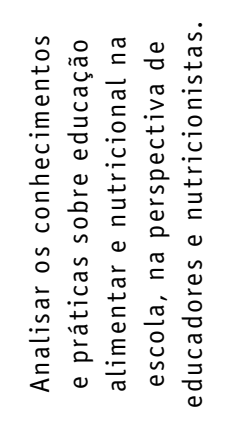 & 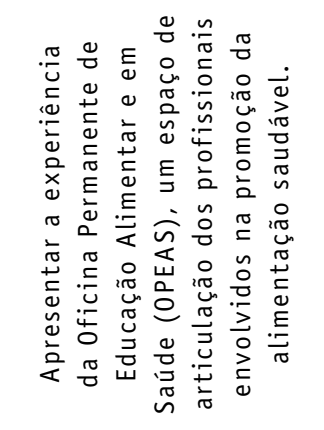 & 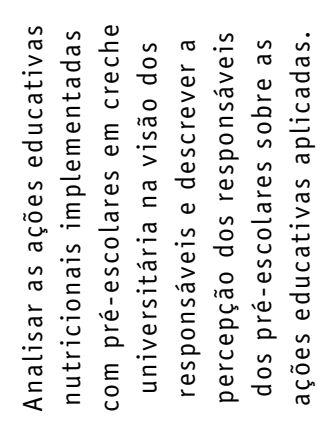 & 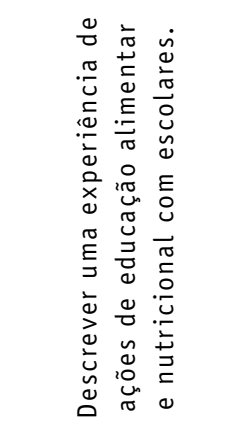 \\
\hline $\begin{array}{l}\frac{\pi}{5} \\
\frac{\pi}{0} \\
0 \\
\frac{0}{0} \\
\frac{0}{2}\end{array}$ & 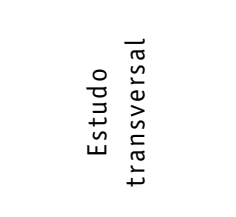 & 焉 & 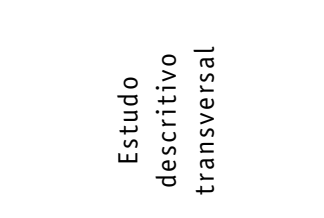 & 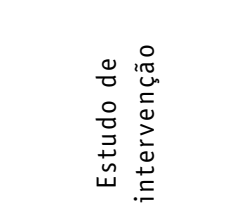 \\
\hline 芯 & 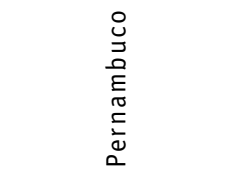 & 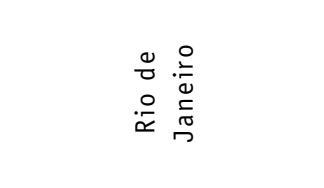 & 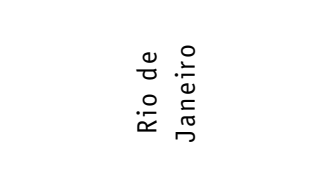 & 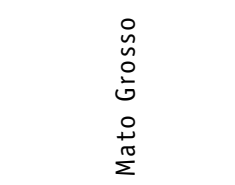 \\
\hline$\stackrel{\circ}{\frac{1}{<}}$ & $\stackrel{m}{\stackrel{n}{\sim}}$ & $\stackrel{m}{\stackrel{m}{\sim}}$ & $\stackrel{+}{\stackrel{D}{N}}$ & $\stackrel{0}{\stackrel{0}{\sim}}$ \\
\hline 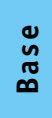 & 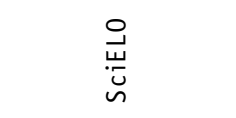 & 号 & $\begin{array}{l}\stackrel{0}{\Xi} \\
\overline{\vec{z}} \\
\frac{0}{\Sigma}\end{array}$ & $\begin{array}{l}\stackrel{\tilde{\sigma}}{\Xi} \\
\stackrel{\Xi}{ت}\end{array}$ \\
\hline $\begin{array}{l}\stackrel{+}{+} \\
\stackrel{+}{*}\end{array}$ & 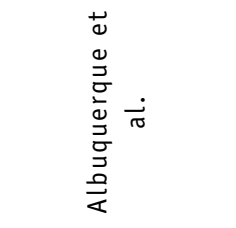 & 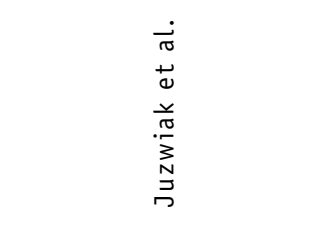 & 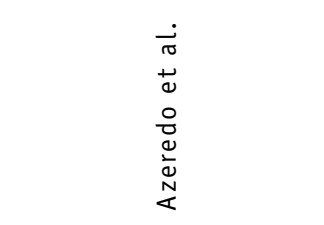 & 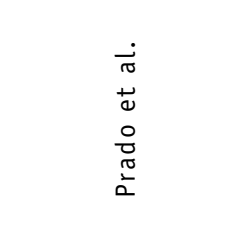 \\
\hline $\begin{array}{l}\stackrel{\circ}{\Xi} \\
\stackrel{⿱ 艹 冖}{*}\end{array}$ & 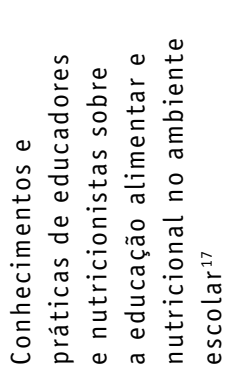 & 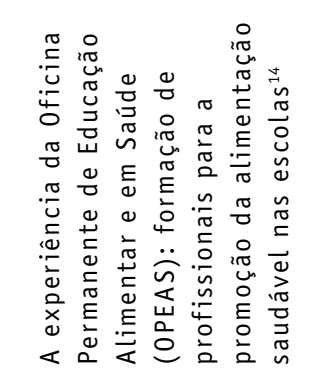 & 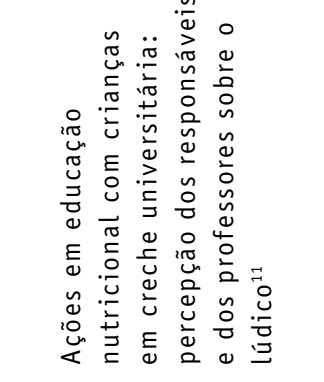 & 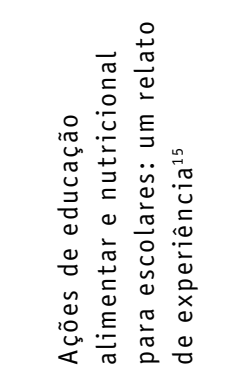 \\
\hline
\end{tabular}


Como se observa no Quadro 1, inicialmente em relação ao ano de publicação, vale destacar que $90 \%$ dos estudos selecionados foram publicados de 2010 a 2017 e $70 \%$ nos últimos 5 anos do período. Além disso, $60 \%$ dos artigos selecionados foram publicados em periódicos da área de Nutrição e $40 \%$ em periódicos de Saúde Pública e Coletiva.

A maioria dos estudos foi publicada no CentroSul do Brasil - 30\% em Mato Grosso, 20\% em Santa Catarina, $20 \%$ no Rio de Janeiro e $10 \%$ em São Paulo. No entanto, quanto à metodologia adotada, predominaram os estudos de intervenção $(90 \%)$ e os relatos de experiência (10\%).

Finalmente, observou-se baixo número de publicações sobre ações de EAN com escolares na promoção de hábitos alimentares saudáveis. Por isso, mostra-se necessário conduzir novos estudos voltados a essa temática e esse público para aprimorar o conhecimento sobre o assunto.

\section{DISCUSSÃO}

A maioria dos autores reforça a importância das ações de EAN na modificação dos hábitos alimentares de escolares no decorrer do estudo ${ }^{11,12}$. Outros autores mencionam que a pesquisa voltada à eficácia de ações de EAN apresentou dificuldades, pois grande parte dos autores menciona a escassez de estudos sobre o tema. Assim, faz-se necessário realizar novos estudos que esclareçam as ações relativas a alimentação e nutriçã $0^{13}$.

De todo modo, os artigos selecionados possibilitaram apontar que a intervenção nutricional por meio da EAN influencia os hábitos alimentares saudáveis, especialmente quando abordada de modo continuado no ambiente escolar - espaço favorável para os escolares adotarem uma alimentação saudável?.

Como registra o Quadro 1, a EAN tem sido a atividade de promoção da saúde mais frequente nas escolas de acordo com profissionais das mais diversas áreas da saúde ${ }^{14}$. Contudo, a EAN compreende a transmissão de conhecimentos relativos à promoção dos hábitos alimentares entre os escolares, considerando a interdisciplinaridade dos pesquisadores e da equipe multidisciplinar, que modifica o comportamento dos escolares diante dos hábitos alimentares saudáveis ${ }^{15}$.

Alguns estudos indicam uma relação entre 0 aumento do índice de obesidade e os estados mais desenvolvidos do Brasil, com maior abrangência em

\section{...a EAN tem sido a atividade de promoção da saúde mais frequente nas escolas...}

estados do Centro-Sul ${ }^{8,15}$. Um estudo ${ }^{7}$ com intervenção junto a escolares de 8 a 14 anos de 2 escolas públicas de Cuiabá-MT avaliou o efeito de ações de EAN no consumo de alimentos no ambiente escolar - essa intervenção identificou um efeito positivo nas escolhas alimentares saudáveis, indicando que o consumo de alimentos em cantinas escolares e estabelecimentos comerciais nas proximidades da escola constitui uma preocupação de EAN. Ou seja, os hábitos alimentares precisam mudar, pois os escolares consomem o que se encontra disponivel e, normalmente, cantinas escolares e as chamadas "vendinhas" comercializam alimentos com alta densidade calórica, ricos em gorduras e açúcares.

Outros estudos realizados com escolares ${ }^{8,12}$ corroboram que os alimentos mais adquiridos pelos escolares são doces, refrigerantes e salgadinhos. Observou-se, ainda, alto consumo de merenda escolar pela maioria dos escolares, que se mostra mais saudável, porém, sua preferência recai sobre os produtos disponíveis em cantinas e vendinhas considerados mais saborosos ${ }^{12}$.

Observaram-se melhorias em relação à qualidade dos alimentos consumidos pelos escolares após ações de $E N^{13}$ e os professores vêm trabalhando a temática da alimentação saudável, mas indicam a necessidade de recorrer à EAN de modo coletivo, junto com outros profissionais.

A promoção de atividades de EAN nas escolas (como orientações, jogos, palestras, atividades lúdicas e criação de hortas) deve ser fruto de ação conjunta de educadores e nutricionistas, que passam a ser responsáveis pela intermediação de saberes e assumem papéis determinantes na adoção de hábitos alimentares saudáveis na escola ${ }^{5}$. Acrescenta-se que os pais são os primeiros agentes a lidar com as práticas alimentares dos escolares ${ }^{11}$.

A EAN é um campo de ação da segurança alimentar e nutricional (SAN), que almeja auxiliar nas mudanças alimentares pessoais e da sociedade ${ }^{5,7,12}$. Comenta-se, ainda, que a EAN tem sido considerada 
uma estratégia para construção do conhecimento e motivação para a alimentação saudável, a promoção de saúde e a SAN, destacando-se, também, o controle dos problemas alimentares e nutricionais contemporâneos.

Outros estudos ${ }^{7,11}$ consideram as ações de EAN fundamentais para implementar a prevenção primária no controle e na redução das taxas de sobrepeso e obesidade, além de outros distúrbios alimentares. 0s autores salientam que a escola deve trabalhar junto com todos envolvidos na educação para alcançar esses objetivos, firmando parcerias com os pais e a comunidade.

A inserção da EAN no currículo escolar, em consonância com os parâmetros curriculares nacionais (PCNs) e as diretrizes da PNAN, sugere que toda a escola integrada (profissionais da saúde e da educação, pais e alunos) realize ações diversas que favoreçam os princípios de promoção da saúde indicados pela $0 \mathrm{MS}^{6}$. A perspectiva da promoção da saúde se apresenta e é apontada como hábitos alimentares saudáveis, garantia da qualidade dos alimentos e prevenção de distúrbios nutricionais (desde a desnutrição até a obesidade ${ }^{16}$.

As intervenções de EAN devem ser disciplinares e envolventes, reforçando o esclarecimento de que o ensino sobre alimentação e nutrição nas escolas deve ser incentivado pelos órgãos públicos, mediante cursos de capacitação para os professores, de modo que estes sejam facilitadores das modificações no comportamento alimentar ${ }^{14}$.

Outro ponto a destacar é a realização das ações de EAN junto aos escolares com uso de vídeos, dinâmicas, antropometria e atividades lúdicas, como caça-palavras, jogo da memória, oficinas e teatro de fantoches. Já se mencionou que as estratégias educativas são fundamentais para a promoção da saúde, a conscientização quanto à prática de hábitos alimentares saudáveis, principalmente diante dos escolares, mas que refletiram em seus familiares e em toda comunidade escolar, proporcionando os conhecimentos necessários para mudar hábitos alimentares ${ }^{5,15}$.

Elaborar ou escolher uma metodologia visando a adotar ações de EAN e promover a saúde escolar constitui um desafio. Isso se dá, muitas vezes, porque os escolares já tinham concepções relativas a fatores psicológicos, familiares, sociais e econômicos ${ }^{17}$. As estratégicas metodológicas são importantes ferramentas para efetivar a prevenção de agravos e a promoção da saúde, principalmente em

\section{As intervenções \\ de EAN devem ser disciplinares \\ e envolventes...}

ambientes que possam estimular o compartilhamento de informações, o ensino e a aprendizagem no âmbito escolar ${ }^{15,18}$.

Esta pesquisa constatou que a implementação de ações de EAN como estratégia de intervenção em hábitos alimentares saudáveis vai além dos debates teóricos e ações de curto prazo. Isso foi citado em dois estudos ${ }^{7,15}$ que evidenciaram que as ações de EAN voltadas à alimentação saudável parecem influenciar as escolhas alimentares, especialmente em caráter continuado e rotineiro nessa etapa da vida em que se formam os hábitos alimentares. Na mesma linha de pensamento, outros estudos ${ }^{8,17}$ constataram que a EAN desempenha um importante papel no processo de transformação, recuperação e promoção de hábitos alimentares saudáveis, proporcionando os conhecimentos necessários para a tomada de decisões alimentares adequadas.

A maioria dos resultados das ações de EAN no âmbito escolar foi expressa por estudos de intervenção, observando-se similaridade entre as linhas de pensamento sobre a eficácia de estratégias de intervenção para a adoção de hábitos alimentares saudáveis entre escolares ${ }^{17}$. Quanto aos métodos de avaliação das intervenções, um estudo ${ }^{8}$ de avaliação nutricional com ações de educação nutricional e alimentar não apresentou efeito significativo na redução do índice de massa corporal (IMC) nas fases pré e pós-intervenção. Tal resultado sugere que o método de avaliação nutricional não é adequado para ações de curto prazo, pressupondo que estas sejam realizadas em longo prazo, ocasionando significativa redução do IMC.

Uma experiência de oficina permanente de EAN realizada com escolares reuniu várias classes de profissionais, como professores, gestores, equipes pedagógicas e nutricionistas. Constatou-se a sensibilização dos profissionais quanto à necessidade de entenderem que todos estão envolvidos na construção de conhecimentos voltados à promoção da alimentação saudável nas escolas, além do 
distanciamento entre alguns profissionais, o que dificulta as ações interprofissionais no ambiente escolar ${ }^{14}$. Nessa mesma linha de raciocínio, alguns estudos $5,9,17,19,20$ concordam quanto à necessidade de manter uma participação ativa entre todas as partes interessadas para alcançar a efetividade educativa em nutrição.

Desse modo, outros estudos ${ }^{7,17}$ enfatizam que, para a promoção da saúde, a EAN deve buscar ações nutricionais relativas tanto a hábitos alimentares saudáveis quanto à prevenção de doenças. Também se acredita na importância do ambiente escolar como cenário oportuno não só por promover ações educativas, mas para ampliar o acesso a uma alimentação saudável mediante estratégias de intervenção nutricional em hábitos alimentares.

\section{CONCLUSÃO}

0 uso da EAN como modo de intervenção, via ações e práticas, visa à promoção de hábitos alimentares saudáveis entre os escolares para o controle de obesidade e doenças crônicas não transmissíveis. Esses fatores se tornaram os problemas de saúde pública mais graves do século XXI em nível nacional e global.

A ampliação do conhecimento sobre nutrição, por parte de todos os profissionais que atuam nos campos da educação e da alimentação, mostrou a importância do empenho e da dedicação de todas as pessoas envolvidas na EAN junto aos escolares. Assume destaque a atuação dos pais e familiares nesses processos, proporcionando ações de longo prazo que potencializam os resultados na formação do comportamento alimentar das crianças.

Destaca-se que são notáveis as mudanças em termos de perfil alimentar, estilo de vida e padrão de saúde da população diante das ações de EAN postas em prática com escolares. Portanto, torna-se importante o uso de materiais lúdicos para as ações, a fim de esclarecer dúvidas e trocar experiências ao promover uma alimentação saudável.

Vale ressaltar que ainda há inúmeros caminhos a percorrer para consolidar a EAN no ambiente escolar, com pleno entendimento do papel do alimento e das mudanças no perfil alimentar, no estilo de vida e no padrão de saúde. Assim, espera-se que as ações sejam efetivas, contínuas e permanentes, possibilitando a redução dos índices epidemiológicos de obesidade.

Constatou-se a necessidade de realizar novas pesquisas acerca dos aspectos nutricionais de

\section{Assume destaque a atuação dos pais e familiares nesses processos...}

escolares. Isso possibilitará o direcionamento de metodologias de tratamento de fácil acesso; a melhora da qualidade de vida bem; e a atualização dos dados disponíveis na literatura. Como a quantidade de artigos sobre o tema ainda é considerada pequena diante dos danos que os hábitos alimentares causam aos escolares, novos achados de pesquisa tendem a apontar novos caminhos em busca de uma qualidade de vida estável por meio da alimentação saudável.

\section{CONTRIBUIÇÃO DOS AUTORES}

Quitéria Vanessa Brito Magalhães e Jorge Luís Pereira Cavalcante contribuíram com a realização da pesquisa, o delineamento do estudo e a redação e revisão crítica do manuscrito.

\section{REFERÊNCIAS}

1. Pimenta TAM, Rocha RA. Obesidade infantil no Brasil: um estudo comparativo entre a PNSN/1989 e a POF/200809 entre crianças de 5 a 9 anos de idade. FIEP Bulletin [serial on the internet]. 2012 [cited $2016 \mathrm{Jul} 12$ ];82(Spec):[about 5 pages]. Available from: $\quad$ http://www.fiepbulletin.net/index.php/ fiepbulletin/article/viewFile/2224/4310

2. Instituto Brasileiro de Geografia e Estatística. Pesquisa de orçamentos familiares 2008-2009: antropometria e estado nutricional de crianças, adolescentes e adultos no Brasil. Rio de Janeiro: IBGE; 2011.

3. Levy RB, Claro RM, Sichieri R, Monteiro CA, Mondini L. Distribuição regional e socioeconômica da disponibilidade domiciliar de alimentos no Brasil em 2008-2009. Rev Saúde Pública [serial on the internet]. 2012 [cited 2017 May 9];46(1):615. Available from: http://www.scielo.br/pdf/rsp/ v46n1/3014.pdf

4. Instituto Brasileiro de Geografia e Estatística. Pesquisa Nacional por Amostra de Domicílios - PNAD 2013 [document on the internet]. 2014 [cited 2017 May 27]. Available from: https://ww2.ibge.gov.br/ home/estatistica/pesquisas/pesquisa resultados. php?id pesquisa $=40$ 
5. Iulino BA, Mancuso AMC, Gambardella AMD. Educação nutricional em escolas de Ensino Fundamental do Município de Guarulhos-SP. Mundo Saúde [serial on the internet]. 2009 [cited 2017 May 7];33(3):264-72. Available from: http://www. saocamilo-sp.br/pdf/mundo saude/69/264a272.pdf

6. Brasil. Política Nacional de Alimentação e Nutrição [document on the internet]. 2013 [cited 2017 Aug 20]. Available from: http://bvsms.saude. gov.br/bvs/publicacoes/pnan.pdf

7. Prado BG, Guimarães LV, Lopes MAL, Bergamaschi DP. Efeito de ações educativas no consumo de alimentos no ambiente escolar. Nutrire (Online) [serial on the internet]. 2012 [cited 2017 May 5];37(3):281-92. Available from: http://docs. bvsalud.org/biblioref/2017/05/322082/artigo.pdf

8. Cavalcanti LA, Carmo Júnior TR, Pereira LA, Asano RY, Garcia MCL, Cardeal CM, et al. Efeitos de uma intervenção em escolares do Ensino Fundamental I, para a promoção de hábitos alimentares saudáveis. Rev Bras Ciênc Mov [serial on the internet]. 2012 [cited 2017 May 3];20(2):5-13. Available from: http://cev.org.br/biblioteca/efeitos-umaintervencao-escolares-ensino-fundamental-l-parapromocao-habitos-alimentares-saudaveis

9. Boog MCF. Programa de educação nutricional em escola de Ensino Fundamental de zona rural. Rev Nutr [serial on the internet]. 2010 [cited 2017 Mar 20];23(6):1005-17. Available from: http://www. scielo.br/pdf/rn/v23n6/07.pdf

10. Barbosa NVS, Machado NMV, Soares MCV, Pinto ARR. Alimentação na escola e autonomia: desafios e possibilidades. Ciênc Saúde Colet [serial on the internet]. 2013 [cited 2017 May 5];18(4):93745. Available from: http://www.scielo.br/pdf/csc/ v18n4/05.pdf

11. Azeredo OEA, Sá SPC, Lavoyer CE. Ações em educação nutricional com crianças em creche universitária: percepção dos responsáveis e dos professores sobre o lúdico. Rev Pesqui Cuid Fundam (Online) [serial on the internet]. 2014 [cited 2016 Jul 10];6(4):1419-36. Available from: http://seer. unirio.br/index.php/cuidadofundamental/article/ view $/ 3106 / p d f 734$

12. Anzolin C, Ouriques CM, Höfelmann DA, Mezadri T. Intervenções nutricionais em escolares. Rev Bras Pesqui Saúde [serial on the internet]. 2010 [cited 2017 May 3];23(4):297-306. Available from: https:// periodicos.unifor.br/RBPS/article/view/2030/2325

13. Piccoli L, Johann R, Corrêa EN. A educação nutricional nas séries iniciais de escolas públicas estaduais de dois municípios do oeste de Santa Catarina. Nutrire [serial on the internet]. 2010 [cited 2017 May 7];35(3):1-15. Available from: http://sban. cloudpainel.com.br/files/revistas publicacoes/295. $\underline{p d f}$
14. Juzwiak CR, Castro PM, Batista SHS. A experiência da Oficina Permanente de Educação Alimentar e em Saúde (OPEAS): formação de profissionais para a promoção da alimentação saudável nas escolas. Ciênc Saúde Colet [serial on the internet]. 2013 [cited 2017 Apr 14];18(4):1009-18. Available from: http://www.scielo.br/pdf/csc/v18n4/14.pdf

15. Prado BG, Fortes ENS, Lopes MAL, Guimarães LV. Ações de educação alimentar e nutricional para escolares: um relato de experiência. Demetra: Alimentação, Nutrição \& Saúde [serial on the internet]. 2016 [cited 2017 May 7];11(2):369-82. Available from: https://www.e-publicacoes.uerj.br/ index.php/demetra/article/view/16168/17722

16. Brasil. Guia alimentar para a população brasileira [document on the internet]. 2015 [cited 2017 Aug 20]. Available from: http://bvsms.saude.gov. br/bvs/publicacoes/guia alimentar populacao brasileira 2ed.pdf

17. Albuquerque AG, Cerqueira MMO. Conhecimentos e práticas de educadores e nutricionistas sobre a educação alimentar e nutricional no ambiente escolar [document on the internet]. 2012 [cited 2019 May 27]. Available from: https://repositorio.ufpe.br/ bitstream/123456789/9087/1/arquivo9584 1.pdf

18. Maia ER, Lima Junior JF, Pereira JS, Eloi AC, Gomes CC, Nobre MMF. Validação de metodologias ativas de ensino-aprendizagem na promoção da saúde alimentar infantil. Rev Nutr [serial on the internet]. 2012 [cited 2017 Feb 22];25(1):79-88. Available from: http://www.scielo.br/pdf/rn/v25n1/ a08v25n1.pdf

19. Câmara Interministerial de Segurança Alimentar e Nutricional. Estratégia intersetorial de prevenção e controle da obesidade: recomendações para estados e municípios [document on the internet]. 2014 [cited 2017 Aug 20]. Available from: http://www.mds.gov. br/webarquivos/publicacao/seguranca alimentar/ estrategiaobesiddade.pdf

20. Lira RCM, Antunes LR, Mesquita K0. Experiência de abordagem sobre alimentação em crianças. Sanare (Sobral, Online) [serial on the internet]. 2016 [cited 2018 Mar 8];15(1):69-73. Available from: https://sanare.emnuvens.com.br/sanare/article/ view $/ 930 / 559$
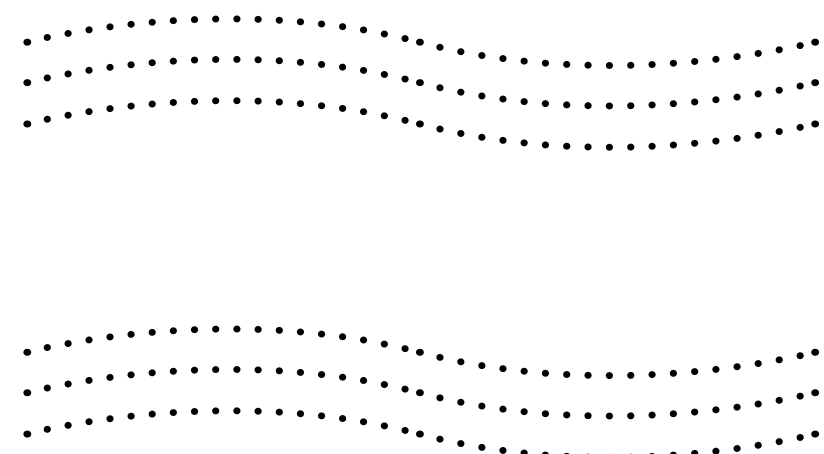


\title{
EMERGÊNCIA DE UM "CAMPO DE AÇÃO ESTRATÉGICA": ORDENAMENTO DA FORMAÇÃO E EDUCAÇÃ̃O PERMANENTE EM SAÚDE
}

EMERGENCE OF A "STRATEGIC ACTION FIELD": FORMATION PLANNING AND CONTINUING EDUCATION IN HEALTH

EMERGENCIA DE UN “CAMPO DE ACCIÓN ESTRATÉGICA”: ORDENACIÓN DE LA FORMACIÓN Y EDUCACIÓN PERMANENTE EN SALUD

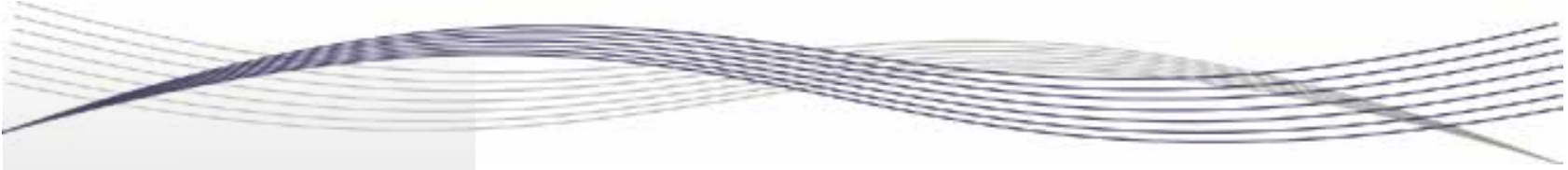

Palavras-chave:

Saúde Pública; Educação; Política Pública; Educação Continuada; Recursos Humanos.

Public Health; Education; Public Policy; Continuing Education; Human Resources.

Palabras clave: Salud Pública; Educación; Política Pública; Educación Continua; Recursos Humanos.

Submetido:

\section{RESUMO}

Trata-se de um ensaio teórico, extraído de um estudo de caso em análise de políticas públicas, do qual o autor foi avaliador em diferentes etapas (da proposição de pesquisa à relatoria científica). Aborda a Política Nacional de Educação Permanente em Saúde como caso singular ao surgimento, na política pública de saúde brasileira, de um "Campo de Ação Estratégica", segundo os termos da Teoria dos Campos, de Neil Fligstein. De uma política nacional a um campo de ação estratégica, distinguiram-se a habilidade social dos atores da formulação da política, a condição de abranger uma rede de interações novas, segundo o compartilhamento/identificação na trama social de desdobramento da política, e a emergência de atores na sociedade. A estabilização da política se deu mesmo em face das substituições de projeto no governo e da substituição dos atores de formulação da política. A Educação Permanente em Saúde se apresentou como projeto conceitual e operacional de compreensão rápida, com potencial de comunicação e tradução social, além de identificação como bandeira de luta por uma educação com os princípios do Sistema Único de Saúde.
\end{abstract} $17 / 04 / 2019$ Aprovado: $21 / 05 / 2019$

Autor(a) para Correspondência: Ricardo Burg Ceccim. Rua Doutor Raul Moreira, 550. Bairro Cristal. Porto Alegre (RS). CEP 90820-160

E-mail:burgceccim@gmail.com

\footnotetext{
1. Sanitarista, Mestre em Educação, Doutor em Psicologia Clínica, Pós-Doutor em Antropologia Médica. Professor Titular de Educação em Saúde na Universidade Federal do Rio Grande do Sul, Programa de PósGraduaçãoem Educação.E-mail: burgceccim@gmail.com
} 


\section{ABSTRACT}

This is a theoretical essay, extracted from a case study in public policy analysis, of which the author was an evaluator in different stages (from the research proposal to the scientific report). It addresses the National Policy on Permanent Education in Health as a singular case for the emergence in Brazilian public health policy of a "Strategic Action Field", according to Neil Fligstein's Theory of Fields. From a national policy to a strategic action field, the actors' social skills were distinguished from the policy formulation, the requirement of covering a network of new interactions, according to the sharing/identification in the social weft of unfolding politics, and the emergence of actors in society. The stabilization of this policy occurred even in the face of project replacements in the government as well as the replacement of policy-making actors. The Permanent Education in Health revealed itself as a conceptual and operational project to be readily understood, allowing potential communication and social translation, in addition to being identified as a flag of fight for an education with principles of the Brazilian Health System.

\section{RESUMEN}

Este trabajo presenta un ensayo teórico que se extrajo de un estudio de caso en análisis de políticas públicas, del que el autor fue evaluador en diferentes etapas (desde la proposición de investigación a la relatoría científica). Se aborda la Política Nacional de Educación Permanente en Salud como caso singular del surgimiento, en la política pública de salud brasileña, de un "campo de acción estratégica", con base en los términos de la Teoría de los Campos, de Neil Fligstein. De una política nacional a un campo de acción estratégica, se distinguieron las habilidades sociales de los actores de la formulación de la política, la condición de abarcar una red de interacciones nuevas, según el compartir/identificar en la trama social de desdoblamiento de la política, y la emergencia de actores en la sociedad. La estabilización de la política se produjo incluso frente a las sustituciones de proyecto en el gobierno y a la sustitución de los actores de formulación de la política. La Educación Permanente en Salud se presentó como un proyecto conceptual y operacional de comprensión rápida, con potencial de comunicación y traducción social, además de identificación como bandera de lucha por una educación con los principios del Sistema Brasileño de Salud.

\section{INTRODUÇÃ 0}

0 presente debate é proveniente de uma pesquisa a que tive oportunidade de acompanhar, na condição de avaliador, em suas diversas etapas: relevância da proposta de estudo, mérito do projeto de pesquisa, pertinência da análise de resultados e qualidade do relatório final. A pesquisa foi realizada na área de Saúde Coletiva e Políticas Públicas, empreendida pela professora de Políticas Públicas e Sistemas de Saúde, Lisiane Böer Possa, e pela mestranda em Saúde Coletiva, Sharlene Goulart Rodrigues, supervisionadas pela professora de Sociologia $e$ Políticas Públicas, Soraya Côrtes ${ }^{1}$. A pesquisa foi realizada na Universidade Federal do Rio Grande do Sul, envolvendo os Programas de Pós-Graduação em Saúde Coletiva, em Políticas Públicas e em Educação, sendo concluída e publicada como dissertação de mestrado em dezembro de 2015. A investigação se exerceu como análise de política e a metodologia adotada foi a do estudo de caso, por se tratar do estudo da atuação de indivíduos e de grupos na condução estatal nacional de uma política pública, aprofundando conhecimentos sobre o surgimento de um "campo de ação estratégica" em políticas públicas. Foram considerados os aspectos de "habilidades sociais dos atores" e de "estabilidade" (e sua reprodução) da política, fazendo emergir, como se detectou, um novo "Campo de Ação Estratégica"2.

A política analisada se instaurou no contexto de criação da Secretaria de Gestão do Trabalho e da Educação na Saúde (Sgtes), no Ministério da Saúde, em 2003, e de implementação do mandato constitucional ao ordenamento da formação de recursos humanos da área, entre 2003 e 2007. Trata-se do estudo (análise de políticas públicas) da proposta de uma Política Nacional de Educação e Desenvolvimento para o Sistema Único de Saúde, apresentada pelo governo federal como "Caminhos para a Educação Permanente em Saúde" ${ }^{3}$. Observouse que as prerrogativas de criação de uma Secretaria e o mandato constitucional à ação do setor sanitário nacional reorganizaram o campo da “educação de profissionais de saúde". No campo da educação de profissionais de saúde estão a relação entre os setores de saúde e de educação, a relação das 
instituições formadoras com os serviços de saúde, a educação em serviço destinada aos trabalhadores já inseridos no ambiente produtivo, a relação ensinosociedade e a relação educativa que constrói as interações profissionais-usuários ${ }^{4}$. Verificou-se, na atuação dos atores dirigentes da Secretaria de Gestão do Trabalho e da Educação na Saúde, no período da sua criação e da formulação da Política Nacional de Educação Permanente em Saúde (Pneps) - como estratégia do sistema sanitário nacional para a formação e o desenvolvimento de trabalhadores para o setor -, a conformação de um novo "campo de ação estratégica". 0 ordenamento da formação de recursos humanos na área da saúde foi transposto de uma normativa constitucional e legal (Constituição Federal, Art. 200)5 a um campo de ação estratégica em políticas públicas, conforme o referencial da Teoria dos Campos ${ }^{2,6}$.

A criação da Secretaria de Gestão do Trabalho e da Educação na Saúde e a formulação, pela primeira vez, de uma política nacional à educação na saúde constituíram as condições de viabilidade para 0 surgimento de um "campo de ação estratégica" neste âmbito, nesse setor. Importante apontar que diversos antecedentes da Política podem ser arrolados sob a forma de programas, projetos, planos de ação e mesmo a elaboração de uma Norma Operacional Básica de Recursos Humanos do Sistema Único de Saúde (NOB-RH/SUS) ${ }^{7}$, sem que se pudesse, entretanto, até então, referir uma Política Nacional de Educação na Saúde. Em todos os documentos relativos aos Recursos Humanos da Saúde, o rol de itens relativos à "Educação" acompanhava a "dimensão da formação" (valorização dos trabalhadores e valorização do trabalho por meio da elevada qualificação dos trabalhadores), não o “campo educativo" (o complexo de relações de aprendizagem e processo pedagógico interinstitucional). A NOB-RH/SUS, construída ao longo de 4 anos pela Comissão Intersetorial de Recursos Humanos e Relações do Trabalho (Cirhrt), do Conselho Nacional de Saúde, configurou a proposta de uma Política Nacional de Gestão do Trabalho na Saúde, nela incluída a formação, mas verificou-se a Gestão da Educação (não a Gestão do Trabalho) na Saúde como política pública específica e sua análise como correspondente à evidência do surgimento de um novo "campo de ação estratégica" em política pública.

0 surgimento do campo de ação estratégica da educação na saúde ensejou repercussão nos setores da Saúde e da Educação, no controle social em saúde e

\section{0 surgimento do campo de ação estratégica da educação na saúde ensejou repercussão nos setores da Saúde e da Educação...}

na gestão pública interfederativa. Ao se tornar campo de ação estratégica, a política proposta ao campo sanitário deixava de ser uma política de governo, ascendendo a uma política de Estado e de importante defesa por atores sociais não governamentais, assim como de atores governamentais distintos dos atores de formulação da política em causa. Se notará, por exemplo, muito mais tarde, em 2017, já diante de um governo instaurado por força de um processo de impeachment da presidenta eleita, a emissão de portaria ministerial para o "Fortalecimento das Práticas de Educação Permanente no Sistema Único de Saúde", cujo objetivo fora o de "retomar o processo de implementação da Política Nacional de Educação Permanente em Saúde", incentivando ao desenvolvimento de ações para a educação e - desenvolvimento dos trabalhadores em saúde necessários ao SUS ${ }^{8}$.

$\mathrm{Na}$ pesquisa de base do presente artigo, as teorias da análise de políticas públicas informaram o delineamento das perguntas investigativas centrais, compondo o enquadramento do estudo. A pesquisa indicou “a emergência do campo da educação permanente em saúde no Brasil", relativo ao “ordenamento da formação de recursos humanos no Sistema Único de Saúde, 2003-2007"1. Foi investigada a implantação da política pública, foi explorado o seu desenvolvimento na construção de interações sociais, foram buscados os atores e a historicidade da ação dos atores, os processos de disputa e a articulação dos envolvidos, reconhecendo-se evidências à emergência de um "campo" na cena da saúde e da educação nacionais. Um estudo anterior, também com fulcro na formulação da política nacional de educação permanente em saúde foi apresentado em $2008^{9}$ e um artigo em $2009^{10}$, que articulavam referências de educação na saúde, saúde coletiva e ciências políticas, tratando da análise da "educação e desenvolvimento para o Sistema Único de Saúde" no âmbito das políticas públicas. 
Uma política pública é um conjunto de programas, projetos e planos de ação implementados pelo Estado, com participação de entes públicos e/ou privados, destinando-se a assegurar o bem-estar, a justiça social e os direitos de cidadania. A política de educação na saúde gerou programas, projetos e planos de ação relativos à formação, à interação da política de saúde com as políticas de educação, à integração do sistema sanitário com as instituições formadoras de educação profissional e educação superior, à articulação com as entidades de educação popular em saúde, à criação de programas de residência em área profissional da saúde e à interlocução com o movimento estudantil. A Política Nacional de Educação Permanente em Saúde tornava-se campo à ação estratégica do ordenamento da formação de recursos humanos na área de saúde, assim, da mesma forma que o sistema sanitário nacional ganhou nome no Brasil, Sistema Único de Saúde - SUS, a política nacional de educação na saúde ganhava nome: Educação Permanente em Saúde - EPS.

\section{Educação Permanente em Saúde como campo à ação estratégica do ordenamento da formação de recursos humanos na área de saúde}

Conforme a Constituição Federal, ao sistema sanitário nacional compete, além de outras atribuições, nos termos da lei, "ordenar a formação de recursos humanos na área de saúde" (Art. 200, Inciso III $)^{5}$. Conforme a Lei Orgânica da Saúde, nos objetivos e atribuições do sistema sanitário nacional está incluída, como terreno de atuação, "a ordenação da formação de recursos humanos na área de saúde" (Título II - Do Sistema Único de Saúde, Capítulo I - Dos Objetivos e Atribuições, Art. $6^{\circ}$, Inciso III ${ }^{11}$. Da Lei, constam a determinação de criação de "Comissões Permanentes de integração entre os serviços de saúde e as instituições de ensino profissional e superior". Essas Comissões têm "a finalidade de propor prioridades, métodos e estratégias para a formação e educação continuada dos recursos humanos do Sistema Único de Saúde, assim como em relação à pesquisa e à cooperação técnica entre essas instituições" (Título II, Capítulo III - Da Organização, da Direção e da Gestão, Art. 14). A União, os Estados, o Distrito Federal e os Municípios deveriam exercer, em seu âmbito administrativo, “a atribuição de participação na formulação e na execução da política de formação e desenvolvimento de recursos humanos para a

\section{... ao sistema sanitário \\ nacional compete, além \\ de outras atribuições, nos \\ termos da lei, "ordenar \\ a formação de recusrsos \\ humanos na área da \\ saúde" ...}

saúde" (Título II, Capítulo IV - Da Competência e das Atribuições, Seção I - Das Atribuições Comuns, Art. 15, Inciso IX). Segundo a Lei, “à direção nacional do SUS compete promover articulação com os órgãos educacionais e de fiscalização do exercício profissional, bem como com entidades representativas de formação de recursos humanos na área de saúde" (Título II, Capítulo IV, Seção II Da Competência, Art. 16, Inciso IX). 0 Título IV é específico, "Dos Recursos Humanos", e em seu Art. 27 está definido que "a política de recursos humanos na área da saúde será formalizada e executada, articuladamente, pelas diferentes esferas de governo", atendendo ao objetivo de organizar "um sistema de formação de recursos humanos em todos os níveis de ensino, inclusive de pós-graduação, além da elaboração de programas de permanente aperfeiçoamento de pessoal". 0 Art. 27 destaca que os serviços integrantes do SUS "constituem campo de prática para o ensino e a pesquisa, mediante normas específicas, elaboradas conjuntamente com o sistema educacional".

Com a criação da Sgtes, em 2003, uma política de educação na saúde, a Política de Educação e Desenvolvimento para o Sistema Único de Saúde: Caminhos para a Educação Permanente em Saúde foi negociada e aprovada pelo Conselho Nacional de Saúde, bem como negociada e pactuada com a Comissão Intergestores Tripartite. Da mesma forma, foi submetida (tendo sido referendada) à $12^{\mathrm{a}}$ Conferência Nacional de Saúde, no final do mesmo ano $0^{3,12,13}$. Ao longo desse período, foi marcante a explicitação de método em uma política do campo sanitário em interface com o campo educativo: a Educação Permanente em Saúde. A educação permanente em saúde deveria ser entendida como aprendizagem-trabalho, ou seja, formação que acontece no cotidiano dos trabalhadores e do trabalho, segundo os problemas enfrentados na realidade e levando em consideração os conhecimentos e as 
experiências distribuídos nas equipes em colaboração e cooperação $0^{3,14}$. Contrapunha-se aos treinamentos e às capacitações (treinamento e capacitação são linguagem clássica dos programas centralizados e verticais), de forma que as qualificações devessem ser orientadas pelas necessidades de saúde da população, do próprio setor da saúde e do controle social, segundo duas indagações: o que é ou quais são os problemas que afastam nossa prática da atenção integral à saúde e de qualidade? Como mudar essa situação ${ }^{14,15}$ A educação na saúde precisa construir, de modo aliado ao conhecimento técnico, a defesa do sistema sanitário nacional, especialmente quanto à integralidade da atenção, participação popular e descentralização da gestão. 0 processo aprendente seria aquele da busca de soluções criativas para os problemas encontrados, o desenvolvimento do trabalho em equipe matricial, a melhoria permanente da qualidade do cuidado à saúde e a humanização do atendimento. 0s serviços de saúde não deveriam ser serviços de "assistência técnica autorizada", mas de cuidado, proteção e defesa da vida ${ }^{14}$.

Foi assim que a Resolução CNS n 335, de 27 de novembro de $2003^{12}$, afirmou a aprovação da "Política Nacional de Formação e Desenvolvimento para o SUS: Caminhos para a Educação Permanente em Saúde", a Portaria n 198, de 13 de fevereiro de $2004^{16}$ - Ministério da Saúde, instituiu a "Política Nacional de Educação Permanente em Saúde como estratégia do Sistema Único de Saúde para a formação e o desenvolvimento de trabalhadores para o setor", a Portaria $n^{0} 1.996$, de 20 de agosto de $2007^{17}$ Ministério da Saúde, dispôs sobre as "Diretrizes para a Implementação da Política Nacional de Educação Permanente em Saúde" e a Portaria $n^{\circ} 3.194$, de 28 de novembro de $2017^{8}$ - Ministério da Saúde, dispôs sobre o "Programa de Fortalecimento das Práticas de Educação Permanente no Sistema Único de Saúde" (Pró-EPS/SUS). Há uma sutil, mas interessante diferença nas quatro nomeações: compreensão inicial dos atores da formulação; escolha por um nome "fantasia" (objeto de melhor comunicação, compreensão rápida e bandeira de luta por uma educação com os princípios do SUS); a persistência no nome "fantasia", agora já sob a condição de ascensão à campo de ação estratégica; anúncio de reedição ou retomada (nesta última designada por Educação Permanente no Sistema Único de Saúde).

A Política Nacional de Educação Permanente em Saúde foi discutida durante todo o ano de 2003, tendo sido aprovada em plenário do Conselho Nacional de

\section{Os serviços de saúde não deveriam ser serviços de "asssitância técnica autorizada", mas de cuidado, proteção e defesa da vida.}

Saúde (CNS) em 04 de setembro de 2003. Em 17 de setembro de 2003, foi aprovado pelo plenário do Conselho Nacional de Representantes Estaduais do Conselho Nacional de Secretarias Municipais de Saúde (Conares/Conasems). Foi, então, pactuada como integrante da política nacional de saúde na plenária da Comissão Intergestores Tripartite (CIT), em 18 de setembro de 2003 , e aprovada por esta instância em 23 de outubro de 2003 quanto aos recursos financeiros e sua forma de distribuição. Em 27 de novembro de 2003, o Conselho Nacional de Saúde deliberou, por meio da Resolução no 335/2003, pelo reconhecimento da criação dessa Política Nacional. Essa Política também foi referendada pelo plenário da $12^{a}$ Conferência Nacional de Saúde, em 11 de dezembro de 2003. Finalmente, em 13 de fevereiro de 2004, foi publicada como Portaria, a Portaria $n^{\circ}$ 198/2004 - Ministério da Saúde. Embora a maioria das publicações sobre o tema indique o nascimento da Pneps em 13 de fevereiro de 2004, sua "ata de nascimento", como vimos, é a aprovação pelo CNS em 04 de setembro de 2003 (Ata da 134 Reunião Ordinária do CNS). 0 conjunto de documentos citados pode ser encontrado no livro de documentos da Política ${ }^{3}$.

\section{Conquista da adesão ampliada, ação coletiva e meta de estabilidade na construção de uma política pública}

Como referido ao início deste texto, a pesquisa de análise de política contou com a convergência das áreas de Saúde Coletiva, de Políticas Públicas e de Educação, tendo sido intitulada por “A emergência do campo da educação permanente em saúde no Brasil: o ordenamento da formação de recursos humanos no Sistema Único de Saúde, 2003-2007". Na análise dos dados e no relatório final, o estudo chegou à Teoria dos Campos ("Habilidade Social e Campos de Ação Estratégica"), de Neil Fligstein ${ }^{2}$. A teoria e o autor 
não faziam parte do escopo inicial da pesquisa. 0 objetivo das pesquisadoras havia sido analisar as condições de possiblidade que deram emergência a uma política pública apresentada ao país em 2003, e seu desdobramento em três momentos: projeto de uma equipe de governo, nova equipe de governo com posições divergentes e novo governo. Como ou por que a proposta se estabilizara? Da situação de uma política de governo para a situação de uma política de Estado, constatou-se a elevação de uma "proposta de política pública" à constituição de um "campo de ação estratégica em política pública", não mais iniciativa de governo, mas luta e defesa de diversos atores na arena das políticas públicas de saúde e de educação.

A Teoria dos Campos distingue a habilidade social dos atores da formulação da política e a condição de abranger uma rede de interações, destacando o interacionismo simbólico, ou seja, - forte compartilhamento/identificação na trama social de desdobramento da política pública. A habilidade social também é a capacidade de mobilizar motivações e conquistar adesões ou engajamento. A habilidade social dos atores é a de motivar outros a tomarem parte em uma ação política. 0 surgimento de um "campo" ocorre quando uma quantidade expressiva de atores sociais de diferentes grupos reconhece e deseja as oportunidades ensejadas e postas em acontecimento (produção de realidades). 0s "atores sociais hábeis" orientarão suas ações para estabilizar oportunidades na introdução de campos sensíveis à adesão ou campos estratégicos à ação.

A Política Nacional de Educação Permanente em Saúde foi apresentada à sociedade em 2003, ano da posse de um governo discursivamente aliado aos movimentos da Reforma Sanitária, tal como desencadeados no país nas décadas de 70 e 80, do século passado, que culminaram com o texto constitucional que instaurou o Sistema Único de Saúde como o sistema sanitário brasileiro. Ao longo de 2003, o governo conversou com toda a sociedade: instituições de ensino superior e técnico, movimento estudantil, associações de ensino, gestores estaduais e municipais e movimentos populares de mediação pedagógica, todos em seus segmentos de atuação ou presença na área do conhecimento em ciências da saúde, pertinência ao setor de execução das políticas públicas em saúde ou envolvimento na aplicação de saberes ao campo sanitário ${ }^{18}$.

Verificou-se dois momentos importantes de quebra no projeto de governo que serviram, de certa
A habilidade social dos atores é a de motivar outros a tomarem parte em uma ação política.

maneira, para "testar" a imposição de um projeto de governo ou o surgimento de um novo campo de ação estratégica: a substituição da equipe de governo com a troca de ministro no ano de 2005 e o início de outro projeto de governo em saúde a partir de 2007. Em 2005, no exercício do primeiro mandato, o presidente eleito compôs o Ministério da Saúde com parte expressiva da membros que haviam sido convidados à equipe de estudos da transição de governo. A criação da Secretaria de Gestão do Trabalho e da Educação na Saúde (Sgtes) foi proposta absolutamente inovadora. Composta por dois departamentos, a gestora da Secretaria e os dois gestores de Departamento compunham o staff dirigente principal, todos participantes da equipe de transição. 0 Ministro havia sido o coordenador da área social e sanitária na transição, proveniente da mesma região de origem do presidente (Estado de Pernambuco). Na condução da Sgtes, uma equipe de gestores com experiência na gestão pública, na docência, na pesquisa e na atuação em redes pela mudança na educação dos profissionais de saúde. Passados 2,5 anos, o Ministro foi substituído, como parte dos acordos de governabilidade com o Congresso Nacional, sendo afastados os gestores da Secretaria e do Departamento de Gestão da Educação na Saúde. A pesquisa citada analisou os perfis de história da formação, atuação e habilidades sociais dos atores de 2003 a 2007, justamente em busca de evidências à análise de políticas públicas, chegando à Teoria dos Campos. A pesquisa não abrangeu o Departamento de Gestão e Regulação do Trabalho em Saúde - Degerts, tendo em vista a precisão de seu recorte ao Departamento de Gestão da Educação na Saúde - Deges.

0 Departamento de Gestão da Educação na Saúde possuía, em 2003, três Coordenações-Gerais: Ações Estratégicas de Educação na Saúde, Ações Técnicas de Educação na Saúde e Ações Populares de Educação em Saúde. Na direção das três coordenações um perfil de 
docentes pesquisadores com bagagem de militância em movimentos sociais e de educação popular, de luta pela interprofissionalidade e pela mudança na clínica (da "assistência técnica autorizada" para a "abordagem de integralidade da atenção"). Esses atores e esse staff saem em 2005, entrando uma equipe mais identificada com a consultoria científica e/ou de agência internacional. A Coordenação de Ações Populares de Educação em Saúde é extinta e suas atribuições, sob outra construção conceitual, são destinadas à Secretaria de Gestão Estratégica e Participativa em Saúde. Em 2007, inicia outra gestão de governo federal e em agosto de 2007 é publicada uma nova portaria ministerial à Educação Permanente em Saúde. A pesquisa citada abrangeu apenas o período 2003-2007, por isso se ocupou do reconhecimento do "surgimento" de um "campo" com força de "ação estratégica".

A estabilidade do campo se verificou, entretanto, por um outro corte, este em 2017, quando do impeachment da presidenta eleita, tendo assumido o vice-presidente eleito, mas sob um projeto de governo declarado em ruptura, tanto por participar da defesa do impeachment, quanto pelo projeto em contraponto apresentado ao Congresso Nacional para o período até as novas eleições presidenciais. Em que pese a ruptura deliberada do governo em exercício com o governo interrompido, a política nacional de educação permanente em saúde foi recomposta. Importante lembrar que era já o terceiro período de governo após o lançamento precursor da Pneps.

Conforme a pesquisa, foi verificado, na formulação da Política Nacional de Educação Permanente em Saúde, a conformação de um "campo de ação estratégica", atores sociais hábeis e estabilidade com base na adesão ampliada de variados grupos de atores sociais. A pesquisa caracterizou grupos e instituições convergentes à emergência desse "núcleo de política" anteriormente ao ano de 2003 e a emergência de novos atores a

$$
\begin{aligned}
& \text { As redes IDA e } \\
& \text { UNI, após avaliações } \\
& \text { em conjunto, se } \\
& \text { "reuniram" em } \\
& \text { Rede UNI/IDA e, } \\
& \text { finalmente, na Rede } \\
& \text { UNIDA. }
\end{aligned}
$$

partir de 2003. As categorias do "ordenamento da formação dos trabalhadores de saúde" e da "educação e desenvolvimento para o SUS" foram sistematizadas como: educação superior, educação técnica, educação popular e educação em serviço a fim de buscar os atores individuais, institucionais e coletivos. Organizações e atores que atuavam politicamente nesses segmentos em educação foram partícipes do processo que culminou com a criação da Sgtes e a formulação da Pnpes.

\section{Antecedentes, condições de possibilidade e acontecimento da Política Nacional de Educação Permanente em Saúde}

0 tema da formação dos profissionais foi intenso, por exemplo, nos anos 1980 e $1990^{19,20}$, especialmente com os Projetos de Integração Docente-Assistencial (Rede IDA), os Projetos Uma Nova Iniciativa: a Integração com a Comunidade (Rede UNI), o Movimento Participação, que culminou nos Seminários Nacionais de Diretrizes da Educação em Enfermagem (Senaden) e a Comissão Interinstitucional Nacional de Avaliação do Ensino Médico (Cinaem). As redes IDA e UNI, após avaliações em conjunto, se "reuniram" em Rede UNI/IDA e, finalmente, na Rede UNIDA. É importante lembrar da Rede de Educação Popular em Saúde (RedePop) que, especialmente nos anos 1990, reunia militantes - acadêmicos ou não - interessados ou atuantes em movimentos de base, nas periferias urbanas e na zona rural, vinha pautando a mudança na formação em busca da inclusão das populações nos modos de ensinar, aprender e fazer saúde. Em 1986 e 1993 ocorreram a $1^{\text {a }}$ e a $2^{\text {a }}$ Conferências Nacionais de Recursos Humanos em Saúde. Entre 1996 e 2000, houve a discussão de um documento de referência nacional, a ser adotado pelo Sistema Único de Saúde como marco ao ordenamento de políticas relativas ao trabalho no setor: a Norma Operacional Básica para os Recursos Humanos no SUS (NOB/RH-SUS), necessidade deliberada na $10^{\text {a }}$ Conferência Nacional de Saúde e documento final aprovado na $11^{\text {a }}$ Conferência Nacional de Saúde. Adotado, em 2003, pelo Conselho Nacional de Saúde como instrumento ordenador de política para a área de gestão do trabalho, praticamente não abordava o tema da Educação, exceto sob a condição de valorização e direito dos trabalhadores. Neste mesmo ano, o Ministério da Saúde criou a Secretaria de Gestão do Trabalho e da Educação na Saúde Sgtes, modificando o enunciado "Recursos Humanos 
da Saúde" para o enunciado "Trabalho e Educação na Saúde"13. A organização em dois segmentos (Trabalho e Educação) aponta a distinção entre administração do trabalho e formação de trabalhadores, mas a designação Educação e não Formação, também carrega uma noção abrangente das práticas pedagógicas em serviços de saúde, das estratégias educativas na formação do pensamento e das metodologias de ensino para a mudança das práticas sociais e técnicas (uma complexidade do campo educativo, não do campo sanitário, ou seja, uma especificidade emergente no pensamento científico).

A separação dos segmentos Gestão do Trabalho e Gestão da Educação organizou dois segmentos de interlocução, interacionismo simbólico específico, influência social e produção de significados. $\mathrm{Na}$ Gestão do Trabalho, os interlocutores eram os Conselhos de Regulação do Exercício Profissional e os Sindicatos das Categorias Profissionais, assim como as instâncias de negociação do trabalho. Uma agenda relativa ao dimensionamento de pessoal, aos planos de cargos e carreiras, aos sistemas de recrutamento e seleção, sistemas de credenciamento e acreditação do trabalho, políticas e sistemas de regulação do trabalho, regulamentação de profissões e ocupações, entre outras estratégias, inclusive a articulação com o Ministério ou os Setores do Trabalho. Na Gestão da Educação os interlocutores eram as Universidades, Escolas Técnicas, Associações de Ensino, Movimento Estudantil, Programas de Residência, Hospitais/ Serviços-Escola, Programas de Pós-Graduação, instâncias de mediação pedagógica em saúde nos movimentos sociais e populares, articulação com a avaliação institucional educativa em saúde, rede de escolas do SUS e rede de escolas de saúde pública, entre outras estratégias, inclusive a articulação com - Ministério ou os Setores da Educação.

0 Ministério da Saúde, no período anterior à criação da Sgtes, coordenava diversas estratégias de formação e desenvolvimento de pessoal, envolvendo cursos de curta ou longa duração, capacitações e qualificações, assim como cursos de especialização e residências em Saúde da Família e de aperfeiçoamento de equipes gestoras, programa de incentivo para a reforma curricular dos cursos de graduação em medicina, mestrados profissionais, profissionalização dos trabalhadores de nível médio, formação de professores para a educação profissional em saúde e formação de conselheiros, entre outros ${ }^{18}$. Em suma, o Ministério da Saúde se ocupava de cursos de formação, mas não de uma

\section{A habilidade social dos atores envolve o poder de negociar e pactuar...}

política de educação na saúde. A Educação Nacional também tem reformulações a partir da Constituição de 1988 e sua Lei de Diretrizes e Bases (LDB) ${ }^{21}$, aprovada em 1996, obrigou a pensar o ensino sob diretrizes curriculares e não sob currículos mínimos. Com a LDB, ficou indicado ao setor da Educação a construção de Diretrizes Curriculares Nacionais (DCN) aos cursos técnicos e de graduação.

Uma particularidade da área da saúde foi a mobilização de atores sociais das diversas profissões para o diálogo com a área da educação, a partir de 1997. Entre os anos de 2001 e 2004 , foram publicadas as DCN para o grupo de cursos designados como "ciências biológicas e da saúde", donde um conjunto mais fortemente identificado com a "atenção à saúde", que culminou com um bloco comum de texto, onde se identificava a orientação de uma formação com ênfase no trabalho em equipe, à integralidade da atenção e à apropriação do sistema de saúde vigente no país ${ }^{22}$. Rompia-se com a noção de currículo mínimo obrigatório para cada carreira, regulado com base em conteúdos e cargas horárias, e impunham-se "diretrizes", reguladas com base no perfil de egresso.

Para a Teoria dos Campos, de Neil Fligstein e Doug McAdam ${ }^{6}$, as condições de viabilidade, mas, principalmente, os "atores sociais hábeis". Para os autores, as habilidades de comunicação, interação, identificação discursiva, afinidade simbólica e produção coletiva de significados são fatores de influência relevantes para o surgimento de novos campos de ação estratégica. A habilidade social dos atores envolve o poder de negociar e pactuar, uma competência honesta às interações com a sociedade (Conselhos de Saúde, no caso em tela), a ressonância diante de vozes anteriormente silenciadas e que alcançam poder de expressão e vocalização em territórios moventes. Uma tradição na formação em saúde é o diálogo com os cursos de medicina e entidades da corporação médica, os atores da formulação falavam em equipe multiprofissional e interdisciplinar em qualquer 
discurso. 0 conservadorismo da saúde vocaliza o trabalho centrado no médico e em procedimentos, os atores da formulação falavam em equipe matricial e escuta de necessidades. A tradição do ensino da saúde enseja os hospitais universitários, os atores da formulação introduziram a noção de rede SUSescola.

A cooperação dos atores de interlocução pode ampliar o poder de disseminação e convencimento de uma proposta política, abrindo terreno para novos campos de ação estratégica. Um dado apontado por Fligstein é que atores sociais hábeis podem ajudar a produzir quadros culturais completamente novos para seus campos, o que seria feito construindo-se identidades de comprometimento que unam muitos grupos. Nesse processo, podem ser transformadas todas as identidades e os interesses de um grupo. Junto com a Pneps surgiram novos e relevantes atores sociais, por exemplo: a Comissão Nacional de Representação do Movimento Estudantil da Saúde, resultante da união das representações estudantis dos cursos da área; o Fórum Nacional de Educação das Profissões da Área da Saúde (Fnepas), aglutinador das associações de ensino da área da saúde; a Articulação Nacional de Movimentos e Práticas de Educação Popular em Saúde (Aneps), congregando, além dos movimentos de educação popular as práticas emancipadoras em defesa da vida; a articulação de projetos de ensino da integralidade dos cursos de graduação da área da saúde (EnsinaSUS), que gerou um livro de teoria, um livro de relatos de experiência e um documentário de 50 min com visita às 5 regiões do país; o Projeto de Vivências e Estágios na Realidade do Sistema Único de Saúde (VER-SUS); o Fórum Nacional de Coordenadores de Residências em Saúde; o Fórum Nacional de Residentes em Saúde; o Fórum Nacional de Tutores e Preceptores de Residências em Saúde; o Curso de Formação de Ativadores de Processos de Mudança na Graduação; - Curso de Formação de Facilitadores de Educação Permanente em Saúde e o Projeto Formação Técnica em Itinerários no SUS (FORTI-SUS), orientado à construção de itinerários formativos ensino-serviço para a profissionalização nas carreiras do nível médio (especialmente os Técnicos em Saúde Bucal, os Agentes Comunitários de Saúde e os Agentes de Combate às Endemias).

Uma outra condição de atores sociais hábeis é a capacidade para reproduzir seu poder, gerando, assim, "grupos responsáveis", "campos estáveis" e "recursos de acesso e consulta". A presença

\section{Junto com a Pneps surgiram novos $e$ relevantes atores sociais...}

bibliográfica dos atores da formulação de 2003 é intensa e, considerando apenas o período 2003-2005 houve publicação nas revistas Interface, Ciência \& Saúde Coletiva, Physis, Brasileira de Saúde da Família, da Associação Brasileira de Ensino Odontológico e Brasileira de Enfermagem, dois Livros da Associação Brasileira de Educação Médica (2 capítulos em cada livro), cinco livros do Laboratório de Pesquisas sobre Práticas da Integralidade em Saúde (Lappis), além do livro de documentos sobre o lançamento da Pneps ${ }^{3}$ e a cartilha A Educação Permanente entra na Roda ${ }^{14}$. Foram organizados eventos nacionais com recurso às metodologias participativas e foram apoiados eventos do movimento estudantil e das associações de ensino. Além disso, os atores da formulação estiveram em todos os eventos das associações de ensino e do movimento estudantil ocorridos de 2003 a 2005 .

0 s atores sociais em grupos, entidades e interesses em oposição às propostas emanadas pelos atores da formulação se manifestaram de múltiplas formas: em audiência com os Gabinetes dos Ministros da Saúde e da Educação, em manifestações junto ao plenário do Conselho Nacional de Saúde, em revistas e boletins das próprias entidades e em denúncias à imprensa sobre a divergência de compreensão sobre o desenvolvimento do trabalho e dos trabalhadores. As ações dos atores de formulação, nesse caso, abriam novas frentes: com gestores, com docentes, com estudantes e com pesquisadores, abrindo rodas de conversa, presença nas plenárias dos conselhos de saúde, publicando informes com a articulação de dados e conceitos. Era regra a presença pessoal dos atores da formulação em frentes de conversa, em debates e no apoio à gestão e à criação de ações, projetos e programas de Educação na Saúde. Foram inúmeras as monografias, dissertações e teses publicadas no Brasil entre 2005 e 2007 sobre a Política Nacional de Educação Permanente em Saúde, além de pesquisas contratadas pelo governo federal de 2005 a 2007 para avaliação da Política e seus produtos ${ }^{23}$. 


\section{Campo de Ação Estratégica e Articulações de Educação na Saúde}

Segundo a Teoria dos Campos ${ }^{6}$, campos de ação estratégica modelam e mantêm uma determinada ordem à participação política, estruturam lógicas de cooperação ou competição e delineiam engajamentos em favor ou em contrariedade, ajudando a compreender os movimentos dos atores, os modos de pensar a ação organizacional ou a intervenção política quando no papel de agentes institucionais, de representantes, de lideranças ou de gestores/ governantes. Muitas profissões da saúde, seguindo uma tradição internacional da medicina ou buscando um lugar de interlocutor estratégico junto às agendas coletivas da Rede UNIDA ou ainda buscando configurar um lugar protagonista dos docentes junto ao debate das Diretrizes Curriculares Nacionais constituíram suas Associações de Ensino. Tendo em vista a Pneps, algumas categorias profissionais alteraram estatutos ou personalidade de suas entidades e outras criaram ou reorganizaram associações de ensino. 0 mesmo com os estudantes, onde grupos estudantis não estruturados em entidades nacionais, o fizeram em busca de interlocução organizada. Quanto à educação profissional técnica, o engajamento se fez por escolas, reunidas em torno da Rede de Escolas Técnicas do SUS, representando um arco menor de atores que na educação superior, uma vez que, em uma, era o grupo social de escolas e, na outra, o grupo social de docentes e de estudantes por cursos de graduação. Já na educação popular, a Aneps começa uma estrutura por estados e regiões e ativa processos autônomos de gestão e representação. Por fim, a educação em serviço tem representação direta na gestão do sistema de saúde, uma vez que se apresenta junto às câmaras técnicas de gestão do trabalho e da educação na saúde, integrantes da lógica organizativa do Conselho Nacional de Secretários de Saúde e Conselho Nacional de Secretarias Municipais de Saúde.

Um destaque na educação superior da saúde são as residências, distribuídas entre Residência Médica, exclusiva para médicos, e Residência em Área Profissional da Saúde - multi ou uniprofissionais, destinadas a todas as categorias profissionais atuantes na saúde, exceto a medicina. A Residência Médica foi criada por lei em $1977^{24}$ e a Residência em Área Profissional da Saúde por lei em 200525, integrando a política nacional de educação na saúde. De particular interesse é que a regulamentação da

\section{... a educação \\ em serviço tem \\ representação \\ direta na gestão do \\ sistema de saúde...}

Residência em Área Profissional da Saúde somente teve início em 2007 e seus documentos registraram como necessário à organização curricular a consideração da Educação Permanente em Saúde e para o credenciamento das instituições ofertantes a existência de proposta de educação permanente em saúde na gestão institucional ${ }^{26}$.

\section{CONCLUSÃO}

Considerando o que foi exposto, é possivel verificar que, até o início de 2003, havia dois tipos de antecedentes a uma política de educação na saúde e suas mais efetivas condições de viabilidade: antes da Constituição de 1988 e desde a Constituição Federal até a aprovação da Pneps. A evidência de acumulação anteriormente à Constituição Federal é a presença no texto constitucional e na Lei Orgânica da Saúde do tema da educação de profissionais de saúde, do ordenamento da formação, da articulação dos sistemas sanitário e de ensino e do reconhecimento da rede de serviços de saúde como local de ensino e de pesquisa (ou rede-escola, nos termos de hoje). Entre a Constituição e a PNEPS, a evidência de acumulação vem pela densidade do processo de formulação e aprovação da Norma Operacional Básica de Recursos Humanos no Sistema Único de Saúde, que envolveu duas Conferências Nacionais de Saúde.

Apesar do lugar de autoridade do governo entre 2003 e 2007 na apresentação e defesa da Pneps, a relação entre governo e esferas não estatais não é unidirecional e nem há na sociedade apenas a boa vontade para com o acolhimento das propostas de governo. É comum que a sociedade seja reativa às propostas de governo, mais ainda que as esferas estadual e municipal sejam reativas à esfera federal. Igualmente é comum que os governos e a sociedade sejam reativos às iniciativas dos movimentos populares e por direitos em criar novos territórios sociais. É quando se criam territórios sociais e de ação governamental em interface que ganha 
vigor o surgimento de um campo e sua chance de estabilização e reprodução. Da Teoria dos Campos se pode extrair o papel dos atores da formulação da política, que efetivamente correspondem aos desígnios de atores sociais hábeis ou atores sociais com domínio ampliado de seu objeto e com capacidade e disposição à interação, mas a estabilização da política foi decorrência da adesão dos atores não governamentais à proposta já vigente na sociedade como elencado nas evidências anteriores e posteriores à formulação da política. A reprodução da política se deu tanto pela ação governamental, como pela ação social. Quando diversos tipos de agrupamento social anteriores ou emergentes passam a defender a proposta, já não importa mais se é ou não uma ação do governo, mas interessa que seja uma ação de Estado, pois se espera recursos de financiamento e respaldo estatal.

Pode-se arrolar que a emergência de agrupamentos sociais foi ativada pelos "atores habilidosos" em apresentar, defender e coordenar uma política, que, afinal, foi capaz de gerar identificação simbólica, convocação à produção de sentidos e engajamento por afinidade de planos estratégicos de futuro do trabalho e da pesquisa em saúde. Os segmentos da sociedade afirmaram lugares e se organizaram com a finalidade de terem as suas demandas atendidas. É destes entendimentos que se pensa o surgimento de um novo campo, uma questão da sociedade ou uma questão de Estado.

0 que se pode observar somente em 2017 é que o governo federal, quando demandado por apresentar os destinos da Política Nacional de Educação Permanente em Saúde, convocando para conversa os gestores estaduais e municipais de saúde, escuta que o desejo é, não só de continuidade e retomada da estabilidade, como ênfase na retomada e aprofundamento das condições de possibilidade à sua execução. É simbólico que surja o Pró-EPS/SUS. Um governo que, em projeto governamental, se opõe aos governos anteriores, lança um programa "pró-EPS". A linguagem da Educação Permanente em Saúde, a linguagem das rodas de conversa, a linguagem da educação como processo coletivo não traduzido por cursos, mas por iniciativas de mobilização do pensamento e do corpo, ocupa o discurso que prega atualidade. Hoje, gestores, estudantes, docentes, conselheiros, trabalhadores, entidades, setores de gestão da política de saúde e da política de educação referem a Educação Permanente em Saúde como a política de educação na saúde para o SUS.

\section{Os segmentos da sociedade afirmaram lugares e se organizaram com a finalidade de terem as suas demandas
atendidas.}

A Educação Permanente em Saúde passou de conceito pedagógico à signo da educação no SUS, um descritor que arrasta uma agenda política ao ensino das profissões de saúde, à formação de conselheiros, à composição de estruturas de gestão nos estados e municípios, à recomposição das práticas de atenção, segundo a construção dos valores da integralidade, e à gestão participativa em todos os aspectos do trabalho em saúde. Essa amplitude, coerente com a proposta da Política de Educação e Desenvolvimento para o SUS: Caminhos da Educação Permanente em Saúde, deixa de se identificar com os governos no Ministério da Saúde, passando a se identificar com a necessidade de responder às reivindicações da sociedade por profissionais e serviços que sejam vivos, criativos e em afinidade com seus usuários, capazes de construir soluções cuidadoras e terapêuticas eficazes e inclusivas de ampliado escopo de tecnologias.

Um "campo", segundo a teoria, pressupõe a existência de um conjunto de atores que se relacionam entre si em função de um determinado objeto. A teia relacional de membro de um campo é estabelecida pelo compartilhamento de entendimentos que dizem respeito ao objeto de disputa; aos atores participantes do campo (dentro ou fora das esferas de governo) e que ocupam papel de apresentação de conceitos e modos de fazer; à clareza quanto aos "adversários" (o que há por combater na ciência, na política, na gestão, no ensino); à quais as regras e formas de ação consideradas legítimas e à quais quadros interpretativos estão aderidos aqueles que orientam os atores do campo. Atores habilidosos são aqueles que possuem a capacidade de induzir cooperação, criando significados compartilhados e ações coletivas, por isso são tão importantes. Também são estes que constroem caminhos e alternativas entre "desafiadores" (aqueles que combatem as propostas da política) e "formuladores" (aqueles que lideram a proposta que ganhou tradução ampliada na 
sociedade), produzindo potência à ação estratégica de determinados indivíduos, instituições e coletivos.

Da mesma forma que aconteceu de os militantes por saúde no Brasil citarem "Sistema Único de Saúde", não "sistema sanitário nacional", por entenderem que apenas a primeira fórmula contempla a estratégia de organização e gestão decorrente das lutas pela Reforma Sanitária e os resultados políticos da $8^{a}$ Conferência Nacional de Saúde ${ }^{27}$, aconteceu de os militantes pela educação do SUS citarem a Educação Permanente em Saúde como a estratégia de organização e gestão que identifica ensino e aprendizagem com os princípios e diretrizes do SUS. É por isso que a Pneps representa o principal dispositivo do mandato constitucional de ordenamento da formação de recursos humanos da área de saúde $^{28}$, ela é a tradução primeira, campo de ação estratégica em política pública para a educação e desenvolvimento dos profissionais de saúde.

\section{CONTRIBUIÇÃO DO AUTOR}

Ricardo Burg Ceccim foi responsável pela concepção e preparação do manuscrito, assim como por sua revisão final.

\section{REFERÊNCIAS}

1. Rodrigues SG. A emergência do "campo" da educação permanente em saúde no Brasil: o ordenamento da formação de recursos humanos no Sistema Único de Saúde, 2003-2007. Dissertação (Mestrado). 2015. Universidade Federal do Rio Grande do Sul, Programa de Pós-Graduação em Saúde Coletiva. Porto Alegre: UFRGS, 2015.

2. Fligstein N. Habilidade social e a teoria dos campos. RAE - Revista de Administração de Empresas. 2007; 47(2):61-80.

3. Brasil. Ministério da Saúde. Secretaria de Gestão do Trabalho e da Educação na Saúde. Departamento de Gestão da Educação na Saúde. Política de Educação e Desenvolvimento para o SUS: caminhos da educação permanente em saúde. Brasília: Ministério da Saúde; 2004.

4. Ceccim RB. A emergência da educação e ensino da saúde: interseções e intersetorialidades. Rev Cien Saude. 2008: 1(1):9-23.

5. Brasil. Constituição da República Federativa do Brasil, Brasília; 1988.

6. Fligstein N, McAdam D. A theory of fields. New York: Oxford University Press, 2012.
7. Brasil. Conselho Nacional de Saúde. Princípios e diretrizes para a gestão do trabalho no SUS: Norma Operacional Básica de Recursos Humanos do Sistema Único de Saúde (NOB/RH-SUS). Brasília: Ministério da Saúde; 2001.

8. Brasil. Portaria $\mathbf{n}^{\circ} \mathbf{3 . 1 9 4}$, de 28 de novembro de 2017 - Ministério da Saúde, dispõe sobre o "Programa de Fortalecimento das Práticas de Educação Permanente no Sistema Único de Saúde". Diário Oficial [da República Federativa do Brasil], Brasília, DF; 2017.

9. Bravin FP. Política e ação pública: análise da política nacional de educação permanente em saúde. Dissertação (Mestrado). 2008. Universidade de Brasília, Programa de Pós-Graduação em Política Social. Brasília: UnB, 2008.

10. Ceccim RB, Bravin FP, Santos AA. Educação na saúde, saúde coletiva e ciências políticas: uma análise da formação e desenvolvimento para o Sistema Único de Saúde como política pública. Lugar Comum. 2009; 28:159-180.

11. Brasil. Lei Orgânica da Saúde. Lei $\mathbf{n}^{\circ} \mathbf{8 . 0 8 0}$, de 19 de setembro de 1990. Dispõe sobre as condições para a promoção, proteção e recuperação da saúde, a organização e o funcionamento dos serviços correspondentes e dá outras providências. Diário Oficial [da República Federativa do Brasil], Brasília, DF; 1990.

12. Brasil. Conselho Nacional de Saúde. Resolução $\mathbf{n}^{\circ}$ 335, de 27 de novembro de 2003, afirma a aprovação da Política Nacional de Formação e Desenvolvimento para o SUS: Caminhos para a Educação Permanente em Saúde. Brasília: Ministério da Saúde; 2003.

13. Brasil. Ministério da Saúde. Conferência Nacional de Saúde: Conferência Sergio Arouca, 12., 2003. Relatório Final.

14. Brasil. Ministério da Saúde. Secretaria de Gestão do Trabalho e da Educação na Saúde. Departamento de Gestão da Educação na Saúde. A educação permanente entra na roda: conceitos e caminhos a percorrer. Brasília: Ministério da Saúde; 2005.

15. Ceccim RB. Educação permanente em saúde: descentralização e disseminação de capacidade pedagógica na saúde. Ciênc. saúde coletiva. 2005; $10(4): 975-986$.

16. Brasil. Portaria $n^{0}$ 198, de 13 de fevereiro de 2004 - Ministério da Saúde, institui a Política Nacional de Educação Permanente em Saúde como estratégia do Sistema Único de Saúde para a formação e o desenvolvimento de trabalhadores para o setor. Diário Oficial [da República Federativa do Brasil], Brasília, DF; 2004. 
17. Brasil. Portaria $\mathbf{n}^{\circ} \mathbf{1 . 9 9 6}$, de 20 de agosto de 2007 - Ministério da Saúde, dispõe sobre as Diretrizes para a Implementação da Política Nacional de Educação Permanente em Saúde. Diário Oficial [da República Federativa do Brasil], Brasília, DF; 2007.

18. Ceccim RB, Feuerwerker LCM. 0 quadrilátero da formação para a área da Saúde: ensino, gestão, atenção e controle social. Physis: rev. de saúde coletiva. $2004 ; 14(1): 4-65$.

19. Ceccim RB, Carvalho YM. Ensino da saúde como projeto da integralidade: a educação dos profissionais de saúde no SUS. In: Pinheiro R, Ceccim RB, Mattos RA organizadores. Ensinar saúde: a integralidade e o SUS nos cursos de graduação em saúde. Rio de Janeiro: Abrasco; 2006. p. 69-92.

20. Ceccim RB, Carvalho YM. Formação e educação em saúde: aprendizados com a saúde coletiva. In: Campos GWS, Minayo MCS, Akerman M, Drumond Jr M, Carvalho YM organizadores. Tratado de saúde coletiva. Rio de Janeiro: Hucitec; 2006. p. 149-182.

21. Brasil. Lei de Diretrizes e Bases da Educação Nacional. Lei $\mathbf{n}^{\circ}$ 9.394, 20 de dezembro de 1996. Estabelece as Diretrizes e Bases da Educação Nacional. Diário Oficial [da República Federativa do Brasil], Brasília, DF; 1996.

22. Ceccim RB, Feuerwerker LCM. Mudança na graduação das profissões de saúde sob o eixo da integralidade. Cad. Saúde Pública. 2004b; $20(5): 1400-1410$.

23. Ceccim RB relator. Avaliação de processos formativos segundo a modelagem da Educação Permanente em Saúde: AvaliaEPS. - Relatório Final (Edital MCT/CNPq/MS-SCTIE-DECIT 23/2006 - Estudo da Gestão em Saúde). Porto Alegre: UFRGS; 2009.

24. Brasil. Decreto-Lei $\mathbf{n}^{\circ} \mathbf{8 0 . 2 8 1}$, de 05 de setembro de 1977 Regulamentação da Residência Médica e criação da Comissão Nacional de Residência Médica. Diário Oficial [da República Federativa do Brasil], Brasília, DF; 1977.

25. Brasil. Lei 11.129, de 30 de junho de 2005. Institui o Programa Nacional de Inclusão de Jovens - ProJovem; cria o Conselho Nacional da Juventude CNJ e a Secretaria Nacional de Juventude e dá outras providências. Diário Oficial [da República Federativa do Brasil], Brasília, DF; 2005. (Cria a Residência em Área Profissional em Saúde e cria a Comissão Nacional de Residência Multiprofissional em Saúde)

26. Brasil. Comissão Nacional de Residência Multiprofissional em Saúde. Resolução $\mathbf{n}^{0}$ 2, de 13 de abril de 2012, dispõe sobre diretrizes gerais para os Programas de Residência em Área Profissional da Saúde. Diário Oficial [da República Federativa do Brasil], Brasília, DF; 2012.

27. Brasil. Ministério da Saúde. Conferência Nacional de Saúde, 8., 1986. Relatório final.

28. Ceccim RB. Ordenamento. In: Ceccim RB, Dallegrave D, Amorim ASL, Portes VM, Amaral BP organizadores. EnSiQlopedia das residências em saúde [recurso eletrônico]. Porto Alegre: Rede UNIDA; 2018. p. 190-197.
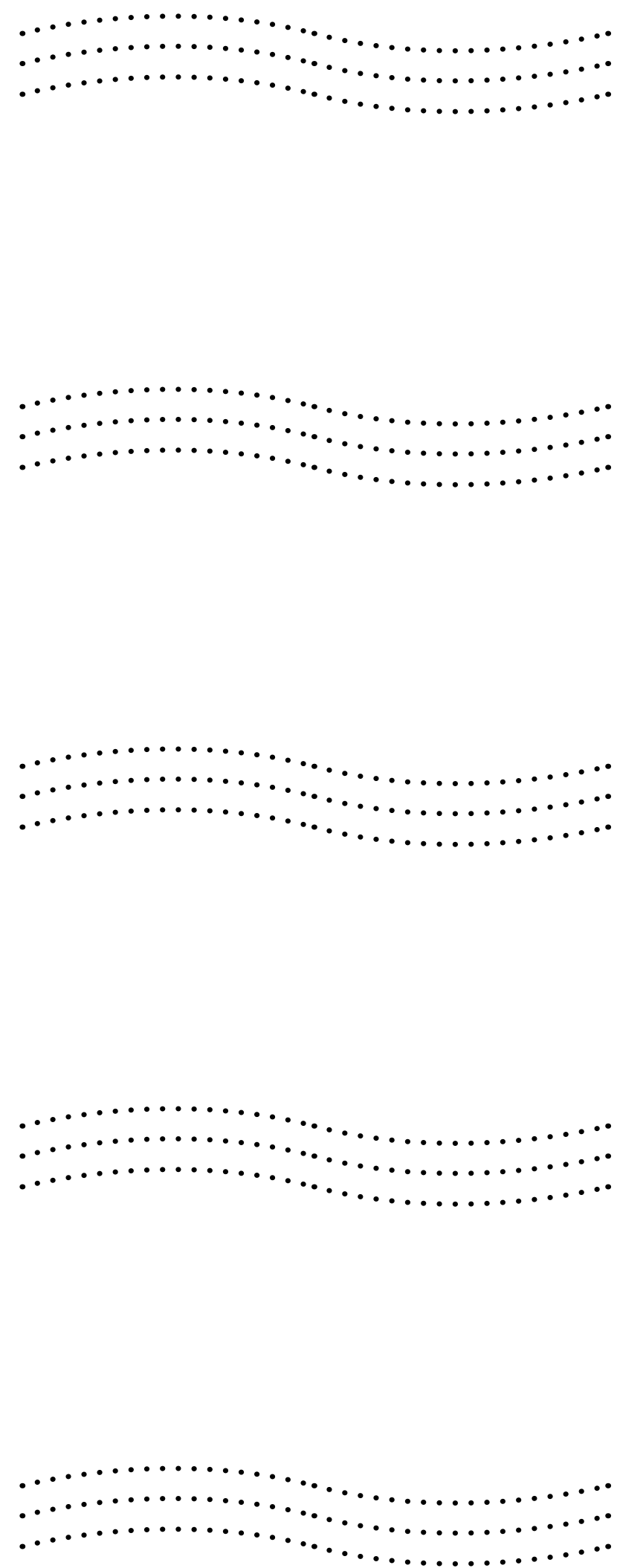


\section{PSICOLOGIA E CUIDADOS PALIATIVOS NA ATENÇÃO PRIMÁRIA À SAÚDE: REVISÃO INTEGRATIVA}

PSYCHOLOGY AND PALLIATIVE CARE IN PRIMARY HEALTH CARE: AN INTEGRATIVE REVIEW

PSICOLOGÍA Y CUIDADOS PALIATIVOS EN ATENCIÓN PRIMARIA DE SALUD: UNA REVISIÓN INTEGRADORA

Ana Carina Rodrigues Gois 1

Joyce Hilario Maranhão ${ }^{2}$

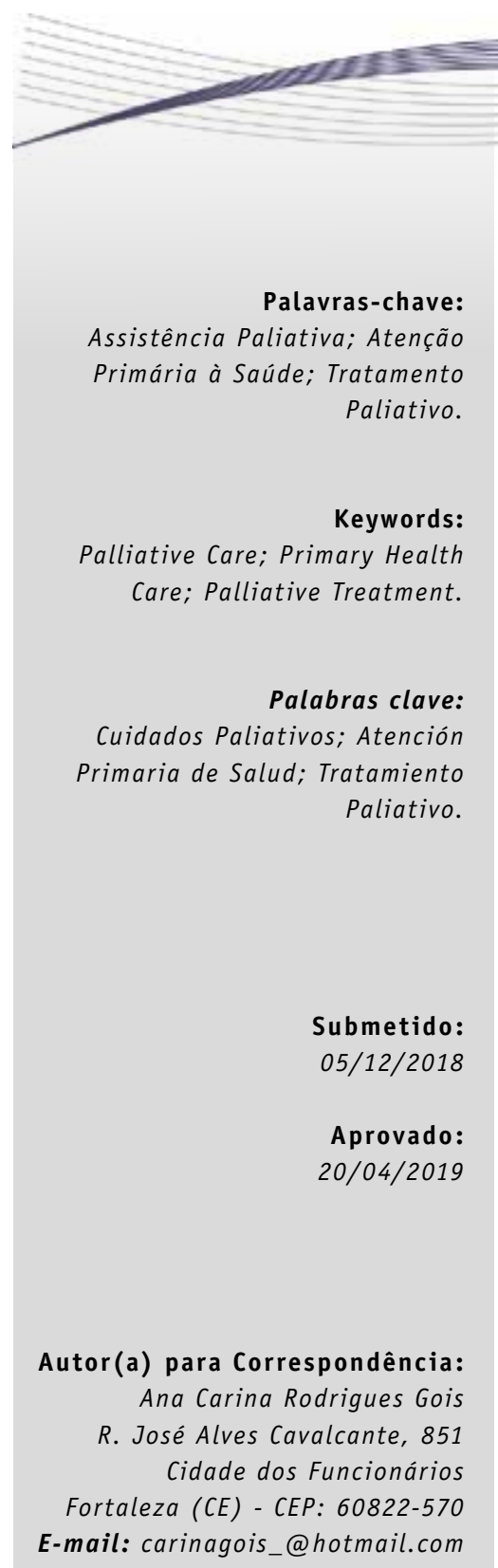

\section{RESUMO}

Este artigo descreve o conhecimento produzido na literatura acerca do cuidado paliativo na atenção primária à saúde e as possibilidades de atuação da psicologia. Realizou-se uma revisão integrativa nas bases de dados SCIELO, Lilacs, BVS Saúde e BVS Psi, por meio das palavras-chave "psicologia e cuidados paliativos", "psicologia e atenção primária" e "psicologia, cuidados paliativos e atenção primária". Incluíram-se artigos completos produzidos no Brasil em um período de 10 anos (de 2008 a 2018) e excluíram-se teses e dissertações, com base na leitura do título e resumo de todos os estudos e do texto integral dos artigos. A análise identificou 4 categorias: a) Vozes dos cuidados paliativos; b) Cuidado ao cuidador; c) Expressões de sentimentos de pacientes em cuidados paliativos; $e d$ ) Serviços de cuidados paliativos na atenção primária à saúde. A seleção final resultou em 14 artigos e evidenciou-se maior produção de estudos referentes ao cuidado ao familiar (7 artigos) e à equipe de saúde (5 artigos) - em detrimento de pesquisas voltadas aos pacientes (2 artigos). Constatou-se a necessidade de que os psicólogos desenvolvam novos estudos teóricos e práticos sobre essa modalidade de cuidado em outros tipos de serviços de saúde, tendo em vista a escassa produção científica nacional sobre o tema.

\footnotetext{
1. Psicóloga Clínica. Graduada em Psicologia pela Universidade Estadual do Ceará (UECE). Fortaleza (CE), Brasil. 2. Mestra em Saúde da Família pela Universidade Federal do Ceará (UFC). Professora de Graduação em Psicologia no UniAteneu Centro Universitário e no Centro Universitário Maurício de Nassau (UniNassau).
} 


\section{ABSTRACT}

This article describes the knowledge produced in the literature about palliative care in primary care and the possibilities of working in psychology. An integrative review was conducted in the databases SciELO, LILACS, BVS Saúde, and BVS Psi, using the keywords 'psychology and palliative care,' 'psychology and primary care,' and 'psychology, palliative care, and primary care.' Complete articles produced in Brazil within a 10-year period (from 2008 to 2018) were included and theses and dissertations were excluded, based on reading of the title and abstract of all studies and the full text of articles. The analysis identified 4 categories: a) Voices of palliative care; $b$ ) Care for the caregiver; c) Feelings expressed by patients receiving palliative care; and d) Palliative care services in primary health care. The final selection resulted in 14 articles and a higher production of studies related to family care (7 articles) and the health team (5 articles) was evidenced - to the detriment of patient-driven research (2 articles). The need for psychologists to develop new theoretical and practical studies on this modality of care in other types of health services was found, due to the scarce national literature on the theme.

\section{RESUMEN}

Este artículo describe el conocimiento producido en la literatura sobre cuidados paliativos en atención primaria y las posibilidades de actuación en psicología. Se realizó una revisión integradora en las bases de datos SciELO, LILACS, BVS Saúde y BVS Psi, mediante las palabras clave 'psicología y cuidados paliativos', 'psicología y atención primaria' y 'psicología, cuidados paliativos y atención primaria'. Se incluyeron artículos completos producidos en Brasil en un período de 10 años (de 2008 a 2018) y se excluyeron tesis y disertaciones, con base en la lectura del título y del resumen de todos los estudios y del texto integral de los artículos. El análisis identificó 4 categorías: a) Voces de los cuidados paliativos; b) Cuidado del cuidador; c) Sentimientos expresados por pacientes que reciben cuidados paliativos; y d) Servicios de cuidados paliativos en atención primaria de salud. La selección final resultó en 14 artículos y se evidenció una mayor producción de estudios relacionados con la atención familiar (7 artículos) y el equipo de salud (5 artículos) - en detrimento de investigaciones dirigidas a los pacientes (2 artículos). Se constató la necesidad de que los psicólogos desarrollen nuevos estudios teóricos y prácticos sobre esta modalidad de atención en otros tipos de servicios de salud, debido a la escasa literatura nacional sobre el tema.

\section{INTRODUÇÃ 0}

A psicologia em saúde é uma especialidade que se preocupa com a inserção dos psicólogos em espaços de cuidado em saúde e com a produção da subjetividade diante de eventos de adoecimento e de tratamento de doenças agudas e crônicas. 0 especialista em psicologia em saúde atua em equipes multiprofissionais e interdisciplinares e seu trabalho visa a estabelecer estratégias de intervenção com os pacientes, com as famílias, com os profissionais da saúde, em caráter individual, e com a coletividade ${ }^{1}$.

As experiências individuais dos psicólogos nas diversas instituições de saúde pública têm criado um volume de produções que orienta a práxis profissional e oferece maior consistência para esse campo teórico. 0 s diversos estudos abordam questões referentes às áreas da ética, da bioética, dos cuidados paliativos, do atendimento em domicílio, da saúde mental, entre outras pertinentes ao trabalho do psicólogo com os demais profissionais que participam das equipes de saúde $e^{2}$.

Para a Organização Mundial da Saúde (OMS), o cuidado paliativo (CP) é uma abordagem promotora da qualidade de vida de pacientes com doenças crônicas, evolutivas e progressivas que ameaçam a continuidade da vida. Realizam-se intervenções que buscam a prevenção da dor e o alívio do sofrimento, por meio de ações que envolvem a identificação precoce, a avaliação e o tratamento da dor e de outros problemas relacionados aos aspectos físicos, sociais, psicológicos e espirituais dos pacientes ${ }^{3,4}$.

No Brasil, o Sistema Único de Saúde (SUS) almeja ser um sistema público e universal de saúde que oferece assistência de modo equânime e integral ao indivíduo e às coletividades por meio de programas e ações de prevenção, promoção, proteção e recuperação da saúde. A atenção primária à saúde (APS) é a porta de entrada para os usuários do SUS e caracteriza-se por ações desenvolvidas pelas equipes da Estratégia de Saúde da Família (ESF) e pelas equipes do Núcleo Ampliado à Saúde da Família (NASF), com o propósito de contribuir para o cuidado em saúde da comunidade local, preservando a autonomia e corresponsabilidade dos sujeitos ${ }^{5}$.

A APS é um espaço que acolhe um número mais amplo de indivíduos adoecidos. Uma das situações que podem surgir como demanda para os profissionais 
de saúde da ESF e para o NASF são as experiências de CP em domicílio, seja por doenças crônicas, a exemplo de diabetes, hipertensão, neoplasias, cardiopatias congênitas, doenças neurológicas, seja por doenças agudas com risco iminente de morte, nas quais não há possibilidade de tratamento curativo. Ainda podem surgir casos em que o processo de elaboração da perda e do luto para os familiares requer intervenções de $C P$ mesmo que o paciente não esteja mais presente ${ }^{3,6}$.

Estudos apontam que, comumente, os pacientes em CP acompanhados na APS estão em seu domicílio, acamados ou com dificuldades de locomoção. 0 acolhimento da equipe de saúde voltado a esses usuários que se encontram em CP ou a seus familiares garante uma relação humanizada, com escuta qualificada. Nessa situação, o papel de familiares e cuidadores se torna essencial para a manutenção do cuidado, junto com o da equipe de saúde responsável pelo acompanhamento da situação clínica ${ }^{7}$. A família do paciente se envolve no processo de CP e suas experiências são diferentes daquelas dos pacientes e dos profissionais da equipe de saúde ${ }^{8}$.

Indica-se que o paciente, ao se deparar com o diagnóstico de uma doença grave e sem possibilidade de cura, pode defrontar-se com sentimentos como angústia, desespero, tristeza e incerteza. Nesse momento, cabe à equipe de psicologia proporcionar um lugar de escuta, com a finalidade de ressignificar sua vida e a proximidade da morte ${ }^{8}$.

A intervenção dos profissionais de psicologia se mostra importante para garantir a integralidade do cuidado ao paciente e a qualidade de vida dos familiares e amigos. 0 cuidado do psicólogo deve facilitar as relações entre equipe, família e paciente e propiciar a comunicação eficaz, a escuta ativa, compreensiva e reflexiva das questões abordadas pelos membros envolvidos no processo ${ }^{9}$. Sob essa perspectiva, este estudo objetivou:

- Descrever o conhecimento produzido na literatura sobre o cuidado paliativo na atenção primária à saúde e as possibilidades de atuação da psicologia.

\section{METODOLOGIA}

Este estudo adotou a seguinte questão orientadora: Quais são as possibilidades de atuação da psicologia junto aos pacientes e aos familiares em cuidados paliativos na atenção primária à saúde? Tal pergunta se baseou na relevância do

\section{...cabe à equipe de psicologia proporcionar um lugar de escuta...}

profissional de psicologia no contexto da APS, com vistas a garantir a integralidade do cuidado e a qualidade de vida do paciente ${ }^{5}$.

A revisão integrativa de literatura é o método de escolha diante do objetivo proposto neste artigo. Tal metodologia se mostra expressiva devido à sua grande relevância no campo da saúde, uma vez que proporciona uma análise criteriosa da produção científica existente e sintetiza evidências de determinado tema, contribuindo para a ampliação de discussões e reflexões ${ }^{10}$. Desse modo, o referido método busca facilitar a identificação de resultados relevantes e o direcionamento de futuras pesquisas sobre a temática investigada.

A coleta de dados ocorreu em março de 2018. As palavras-chave adotadas foram: a) "psicologia e cuidados paliativos"; b) "psicologia e atenção primária"; e c) "psicologia, cuidados paliativos e atenção primária". E as bases consultadas foram: a) SciELO; b) Lilacs; c) BVS Saúde; e d) BVS Psi.

Como critério de inclusão, optou-se por artigos publicados em um período de 10 anos (de 2008 a 2018), que deveriam estar completamente disponiveis em formato eletrônico, com acesso gratuito, redigidos em língua portuguesa e versando sobre experiência no Brasil, tendo em vista que a temática aborda as necessidades da população brasileira. A seleção dos artigos se baseou na leitura de título, resumo e texto completo. Incluíram-se os estudos que retratam a atuação da psicologia nos CPs, a atuação de profissionais de saúde na APS e a percepção dos familiares e pacientes sobre os CPs. Além das teses e dissertações, excluíram-se os artigos que contemplam a temática em questão e os artigos identificados em duplicidade.

\section{RESULTADOS E DISCUSSÃO}

Aplicando os critérios da pesquisa, identificaramse 60 artigos na base SciELO; 16 artigos na base 
Lilacs; 65 artigos na base BVS Saúde; e 11 artigos na base BVS Psi - o que totaliza 152 artigos. Após a leitura dos títulos, excluíram-se os artigos que não contemplam a temática em questão, obtendo 44 publicações, como indica a Tabela 1.

Tabela 1 - Artigos identificados nas bases de dados e palavras-chave adotadas

\begin{tabular}{|lccc|}
\hline Base de dados & Palavras-chave & Encontrados & Selecionados \\
\hline SciELO & Psicologia e cuidados & 60 & 27 \\
BVS Saúde & paliativos e atenção primária à & 65 & 11 \\
BVS Psi & saúde & 11 & 5 \\
Lilacs & & 16 & 1 \\
\hline Total & & 152 & 44 \\
\hline
\end{tabular}

Fonte: Elaborado pelas autoras.

Procedeu-se a uma segunda seleção, fundamentada na leitura dos resumos dos artigos identificados. Novamente, selecionaram-se apenas os estudos que remetem à temática em questão, finalizando a seleção com 14 artigos, como registra o Quadro 1.

Quadro 1 - Sínteses das publicações incluídas na revisão integrativa.

\begin{tabular}{|c|c|c|c|c|}
\hline $\begin{array}{l}\text { Ano de } \\
\text { publicação }\end{array}$ & Autor & Titulo & $\begin{array}{l}\text { Tipo de } \\
\text { estudo }\end{array}$ & Principais conclusões \\
\hline 2008 & Silva et al. ${ }^{13}$ & $\begin{array}{c}0 \text { câncer entrou em } \\
\text { meu lar: sentimentos } \\
\text { expressos por familiares } \\
\text { de clientes }\end{array}$ & $\begin{array}{l}\text { Pesquisa } \\
\text { qualitativa }\end{array}$ & $\begin{array}{l}\text { Sentimentos vivenciados pelas } \\
\text { famílias expressam angústia, } \\
\text { tristeza, incerteza e desejo de } \\
\text { estar com o ente querido. }\end{array}$ \\
\hline 2010 & Oliveira et al. ${ }^{17}$ & $\begin{array}{l}\text { Apoio psicológico na } \\
\text { terminalidade: } \\
\text { ensinamentos para a } \\
\text { vida }\end{array}$ & $\begin{array}{l}\text { Relado de } \\
\text { experiência }\end{array}$ & $\begin{array}{l}\text { A importância do } \\
\text { acompanhamento de pacientes } \\
\text { em processo de finitude. }\end{array}$ \\
\hline 2010 & Simino et al. ${ }^{18}$ & $\begin{array}{c}\text { Acompanhamento de } \\
\text { usuários, portadores } \\
\text { de câncer, por } \\
\text { trabalhadores da saúde } \\
\text { da família }\end{array}$ & $\begin{array}{l}\text { Pesquisa } \\
\text { qualitativa }\end{array}$ & $\begin{array}{c}\text { Necessidade e possibilidades } \\
\text { nas ESF para realizar } \\
\text { acompanhamento de pacientes } \\
\text { em cuidados paliativos. }\end{array}$ \\
\hline 2010 & Sorato et al. ${ }^{14}$ & $\begin{array}{c}\text { Cuidar e ser cuidado pelo } \\
\text { grupo de apoio protege }\end{array}$ & $\begin{array}{l}\text { Pesquisa } \\
\text { descritivo- } \\
\text { qualitativa }\end{array}$ & $\begin{array}{l}\text { Benefícios que os grupos de } \\
\text { cuidadores podem gerar para } \\
\text { o cuidado de pacientes em } \\
\text { cuidados paliativos. }\end{array}$ \\
\hline 2011 & Palmeira et al. ${ }^{20}$ & $\begin{array}{c}\text { Cuidados paliativos } \\
\text { no Brasil: revisão } \\
\text { integrativa da literatura } \\
\text { científica }\end{array}$ & $\begin{array}{c}\text { Revisão } \\
\text { integrativa }\end{array}$ & $\begin{array}{l}\text { Escassa produção de artigos } \\
\text { acerca de pacientes em } \\
\text { cuidados paliativos. }\end{array}$ \\
\hline 2013 & Gorayeb et al. ${ }^{24}$ & $\begin{array}{l}\text { Psicologia na atenção } \\
\text { primária: ações e } \\
\text { reflexões em programa } \\
\text { de aprimoramento } \\
\text { profissional }\end{array}$ & $\begin{array}{l}\text { Pesquisa } \\
\text { descritivo- } \\
\text { qualitativa }\end{array}$ & $\begin{array}{c}\text { Importância de ações da } \\
\text { psicologia na atenção básica } \\
\text { ao trabalhar fatores de risco à } \\
\text { saúde da população. }\end{array}$ \\
\hline 2013 & $\begin{array}{l}\text { Combinato e } \\
\text { Martins }^{22}\end{array}$ & $\begin{array}{l}\text { (Em defesa dos) } \\
\text { Cuidados paliativos na } \\
\text { atenção primária à saúde }\end{array}$ & $\begin{array}{l}\text { Pesquisa } \\
\text { descritivo- } \\
\text { qualitativa }\end{array}$ & $\begin{array}{l}\text { Entende-se que a finalidade } \\
\text { da atividade do profissional } \\
\text { da saúde seja promover a } \\
\text { dignidade e a qualidade } \\
\text { de vida no processo de morte. }\end{array}$ \\
\hline
\end{tabular}




\begin{tabular}{|c|c|c|c|c|}
\hline $\begin{array}{l}\text { Ano de } \\
\text { publicação }\end{array}$ & Autor & Titulo & $\begin{array}{l}\text { Tipo de } \\
\text { estudo }\end{array}$ & Principais conclusões \\
\hline 2013 & Costa et al. ${ }^{15}$ & $\begin{array}{c}\text { Doença crônica da } \\
\text { criança: necessidades } \\
\text { familiares e a relação } \\
\text { com a Estratégia Saúde } \\
\text { da Família }\end{array}$ & $\begin{array}{l}\text { Pesquisa } \\
\text { descritivo- } \\
\text { qualitativa }\end{array}$ & $\begin{array}{c}\text { Importância do vínculo entre a } \\
\text { equipe de saúde e os usuários } \\
\text { da APS para o alívio do } \\
\text { sofrimento emocional. }\end{array}$ \\
\hline 2013 & Queiroz et al. ${ }^{16}$ & $\begin{array}{c}\text { Percepção de familiares } \\
\text { e profissionais de saúde } \\
\text { sobre os cuidados no } \\
\text { final da vida no âmbito } \\
\text { da atenção primária à } \\
\text { saúde }\end{array}$ & $\begin{array}{l}\text { Pesquisa } \\
\text { qualitativa }\end{array}$ & $\begin{array}{c}\text { Pouca melhora na qualidade de } \\
\text { vida de pacientes em cuidados } \\
\text { paliativos que estão em seu } \\
\text { domicílio. }\end{array}$ \\
\hline 2014 & Kovács ${ }^{21}$ & $\begin{array}{l}\text { A caminho da morte com } \\
\text { dignidade no século XXI }\end{array}$ & $\begin{array}{l}\text { Pesquisa } \\
\text { descritiva }\end{array}$ & $\begin{array}{l}\text { Reflexões sobre os caminhos } \\
\text { da morte no século XXI e a } \\
\text { importância de programas de } \\
\text { cuidados paliativos. }\end{array}$ \\
\hline 2015 & Marchi et al. ${ }^{25}$ & $\begin{array}{l}\text { Ser-cuidador de } \\
\text { familiar com câncer e } \\
\text { dependente: um olhar } \\
\text { para a temporalidade }\end{array}$ & $\begin{array}{l}\text { Pesquisa } \\
\text { descritiva }\end{array}$ & $\begin{array}{c}\text { As dificuldades dos familiares } \\
\text { que acompanham pacientes } \\
\text { em terminalidade podem gerar } \\
\text { adoecimento. }\end{array}$ \\
\hline 2015 & Delalibera ${ }^{11}$ & $\begin{array}{l}\text { Sobrecarga no cuidar e } \\
\text { suas repercussões nos } \\
\text { cuidadores de pacientes } \\
\text { em fim de vida: revisão } \\
\text { sistemática da literatura }\end{array}$ & $\begin{array}{c}\text { Revisão } \\
\text { sistemática }\end{array}$ & $\begin{array}{c}\text { Maiores níveis de sobrecarga } \\
\text { física e emocional de } \\
\text { cuidadores e familiares. }\end{array}$ \\
\hline 2017 & Benites et al. ${ }^{19}$ & $\begin{array}{l}\text { Significados da } \\
\text { espiritualidade para } \\
\text { pacientes com câncer em } \\
\text { cuidados paliativos }\end{array}$ & $\begin{array}{l}\text { Pesquisa } \\
\text { descritivo- } \\
\text { qualitativa }\end{array}$ & $\begin{array}{l}\text { Estar próximo da morte leva ao } \\
\text { sujeito a veneração da vida, } \\
\text { remetendo crenças pessoais e } \\
\text { busca de sentido da vida. }\end{array}$ \\
\hline 2017 & $\begin{array}{c}\text { Combinato e } \\
\text { Martins }\end{array}$ & $\begin{array}{l}\text { Necessidades da vida na } \\
\text { morte }\end{array}$ & $\begin{array}{l}\text { Pesquisa } \\
\text { descritivo- } \\
\text { qualitativa }\end{array}$ & $\begin{array}{l}\text { As necessidades dos pacientes } \\
\text { e familiares não são restritas } \\
\text { à proximidade da morte, mas } \\
\text { se referem às condições de } \\
\text { vulnerabilidade social. }\end{array}$ \\
\hline
\end{tabular}

Fonte: Elaborado pelas autoras.

Verifica-se que os temas prevalentes nas bases de dados se referem ao trabalho do psicólogo junto à Estratégia Saúde da Família (ESF) em suas diversas possibilidades de atuação e às diversas atividades destes profissionais no campo da APS. Embora consideremos que as temáticas abordadas são relevantes para a atuação do psicólogo, uma vez que remetem à realidade do trabalho na saúde pública e às demandas diante do trabalho comunitário com os usuários, percebe-se que há poucos estudos referentes ao processo de adoecimento crônico e agudo e à morte.

No Quadro 1 se observa que existe prevalência de 50\% (7 artigos) relativa à palavra-chave “psicologia e cuidados paliativos", assim como considerável déficit em publicações que enfocam a temática "psicologia, cuidados paliativos e atenção primária à saúde", com 14,2\% (2 artigos). Esse achado demonstra a escassez da literatura nacional que debate a atuação da psicologia com foco em CP na APS, apesar desse âmbito da atenção ser considerado pela legislação da saúde pública brasileira um espaço ordenador das ações e dos serviços de saúde, com o intuito de proporcionar um cuidado universal, acessível, contínuo, integral, humanizado, equânime e coerente com as necessidades da população. Os princípios dos CPs corroboram o mesmo posicionamento diante do cuidado dos indivíduos, buscando a promoção da qualidade de vida dos pacientes e de seus familiares, mediante prevenção, alívio do sofrimento, identificação precoce e tratamento da dor $r^{4}$.

Após a análise integral dos conteúdos das publicações referidas no Quadro 1, emergiram 4 categorias 
temáticas, com base na análise de conteúdo temáticocategorial: a) Vozes dos cuidados paliativos; b) Cuidado ao cuidador; c) Expressões de sentimentos de pacientes em cuidados paliativos; e d) Serviços de cuidados paliativos na atenção primária à saúde.

\section{Vozes dos cuidados paliativos}

$\mathrm{Na}$ literatura consultada, observou-se que a maior parte dos artigos aborda os sentimentos dos familiares e cuidadores de pacientes em CPs (50\%). Também se enfoca o modo como os profissionais da saúde percebem sua atuação nos CPs na APS (35\% dos artigos). Percebe-se uma limitação do número de artigos voltados ao cuidado e à percepção de como o paciente vivencia os CPS ( $15 \%$ dos artigos).

A família do paciente se apresenta ativamente no contexto do adoecimento, seja no âmbito hospitalar, seja no domiciliar (50\% dos artigos). Responsáveis por cuidados de higiene, administração de medicação, marcação de consultas, apoio emocional ao paciente, custos, logística do tratamento, entre outros fatores, os familiares tendem a apresentar sobrecarga decorrente do cuidado e do adoecimento do ente querido ${ }^{11}$. 0 s artigos analisados abordam as repercussões desse cuidado, assim como as consequências emocionais ao vivenciar a terminalidade do ente querido. Analisa-se, ainda, a criação de grupos de apoio junto aos acompanhantes, proposta pela equipe de saúde, bem como a percepção desse grupo sobre o serviço oferecido pela APS ${ }^{12}$.

No mais, esse achado apresenta considerável distanciamento das pesquisas da abordagem dos sentimentos do paciente nos CPs - esse sujeito deveria ser o foco principal no contexto envolvido. Percebese que esse número pouco expressivo pode deverse ao diagnóstico tardio de doenças ameaçadoras à vida, o que justificaria o pouco contato com os pacientes, tendo em vista que podem encontrar-se em processo de finitude avançado, com dificuldades de locomoção e verbalização e reduzidos níveis de consciência e lucidez, o que inviabiliza a realização de entrevistas. Tal escassez também pode decorrer de CPs tardios, uma vez que, às vezes, o paciente é diagnosticado com uma doença crônica e submete-se a procedimentos invasivos, sem encaminhamento ao serviço de CPs.

Ademais, o enfoque nos profissionais da saúde é destacado nas publicações identificadas. A percepção da equipe de saúde sobre sua atuação, a dificuldade de trabalhar com a iminência da morte do ...atenção dos profissionais para com eles contribui para melhorar sua saúde mental e física...

paciente, a importância do vínculo com a família e o entrave para se comunicar com os demais níveis de atenção são as principais considerações observadas ${ }^{8}$. Desse modo, como debatido na Política Nacional de Atenção Básica $(P N A B)^{5}$, evidencia-se a importância da integração entre as ações e os serviços da rede de saúde pública, com suas diversas tecnologias que proporcionam bem-estar e qualidade de vida.

\section{Cuidado ao cuidador}

Dentre os artigos analisados, $50 \%$ enfocam os familiares. Após a leitura e análise de seu conteúdo, revelou-se que os principais sentimentos expressos pelos familiares são de incerteza, angústia e tristeza, bem como de esperança e desejo de estar com o ente querido ${ }^{12}$. Assim, o familiar que assume o papel de principal cuidador de pacientes com doenças ameaçadoras à vida apresenta maior risco de sobrecarga emocional e mobilidade física ${ }^{13}$.

Evidenciou-se, ainda, a importância de grupo de apoio aos cuidadores, seja no âmbito hospitalar ou na APS, tendo em vista que podem propiciar a elaboração de sentimentos e sensações por parte dos familiares e a valorização da família nos momentos difíceis, além de auxiliar a propagação de informações e orientações sobre o cuidado ao paciente ${ }^{14}$.

Observaram-se alterações nos diferentes aspectos da vida do cuidador durante o adoecimento do ente querido, como abandono de emprego e distanciamento de atividades de lazer e de outros familiares. A depender da estrutura funcional da família, podem existir fatores que tendem a ser complicadores ou facilitadores do processo de cuidado ${ }^{8}$.

Em 28,6\% dos artigos analisados, os cuidadores também destacaram que a atenção dos profissionais para com eles contribui para melhorar sua saúde mental e física ${ }^{14}$. Na assistência domiciliar, a equipe de saúde deve buscar a colaboração da família e trabalhar em parceria com a comunidade. Em 
$14,3 \%$ dos artigos analisados a percepção familiar quanto à ESF é atrelada ao curso da doença e ao processo de vinculação com a equipe ${ }^{15}$. A boa relação entre profissionais e familiares é essencial para a construção de um cuidado em consonância com os diversos saberes, proporcionando bem-estar aos envolvidos - isso é considerado um facilitador, já que os envolvidos são informados sobre o caso clínico e recebem apoio e informações acerca do trabalho desempenhado ${ }^{16}$.

\section{Expressões de sentimentos de pacientes em cuidados paliativos}

Apenas $28,2 \%$ dos artigos contemplaram essa temática. As publicações analisadas destacam a importância do atendimento psicológico ao paciente em processo de finitude e a elaboração de experiências emocionais vivenciadas por ele antes da morte ${ }^{17}$. Ao receber o diagnóstico de uma doença grave e ao se deparar com os CPs, o paciente pode apresentar sentimentos diversos que necessitam ser elaborados ${ }^{12}$. Vale destacar que cada sofrimento é singular, não há um protocolo ou manual sobre o modo como o paciente pode reagir diante de tal situação. Assim, mostra-se a relevância dos CPs se basearem em princípios ${ }^{4}$. Evidenciou-se um atendimento psicológico com elaboração de experiências emocionais vivenciadas pelo paciente durante o processo de finitude. Dessa forma, analisaram-se as contribuições que tal atendimento proporcionou para o paciente e a relação dele com a equipe de saúde ${ }^{17}$.

Ressalta-se a relevância das intervenções psicológicas nos fatores de risco à saúde da população atendida na rede de saúde. É papel da equipe de psicologia do serviço oferecer um lugar de escuta, com a finalidade de ressignificar a vida do sujeito e a proximidade de sua morte ${ }^{12}$. Também se faz necessário proporcionar autonomia na tomada de decisões e voz ativa durante o tratamento da dor ${ }^{18}$.

Revela-se nos artigos que o atendimento aos usuários da APS tem possibilitado enfocar o cuidado emocional e biológico da doença, porém, por vezes, a equipe de saúde que presta assistência tende a destacar o apoio ao paciente nas esferas psicológica, biológica e social, mas isso diminui a importância de contemplar a dimensão espiritual do paciente ${ }^{18}$. Assim, os artigos consideram que o conhecimento das especificidades da dimensão espiritual na interface com a unidade de cuidado pode aprimorar as práticas

\author{
...cada \\ sofrimento \\ é singular, não \\ há um protocolo \\ ou manual...
}

de humanização e atenção integral ao paciente com uma doença que ameaça a continuidade de sua vida ${ }^{19}$.

\section{Serviços de cuidados paliativos na atenção primária à saúde}

Em relação à importância de efetivo desenvolvimento de programas de CPs no Brasil, assim como à compreensão da morte com dignidade, constatou-se considerável demanda de usuários na APS diagnosticados com doenças crônicas que ameaçam a continuidade de sua vida e que necessitam da assistência integral por parte de equipe multidisciplinar6. No entanto, observou-se nos artigos que, às vezes, a equipe de saúde não detém o conhecimento necessário para avaliar tais usuários e proporcionar acompanhamento especializado e individualizado para eles e seus familiares ${ }^{9}$.

Essa carência de conhecimento técnico que fundamenta a prática de cuidado em saúde se reflete na escassez de estudos em CPs no Brasil ${ }^{20}$. Com frequência, os estudos identificados enfatizam os CPs em oncologia $(35,7 \%)$, o que compromete o conhecimento sobre outros tipos de doença que demandam atenção paliativa, como cardiopatias, doenças neuromusculares e doenças crônicas não transmissiveis ${ }^{21}$. Constata-se a necessidade de desenvolver estudos sobre a atuação em diferentes áreas e a articulação entre elas, com a finalidade de aprimorar e intensificar a discussão sobre CPs em domicílio, no ambulatório e na APS, considerando a perspectiva das diversas profissões em saúde, dos usuários e de seus familiares.

Aposta-se que a implementação de serviços de CPs na APS, considerando as necessidades e a realidade sanitária e social dos usuários, é relevante na abordagem da perda, do luto e do processo de morte e morrer ${ }^{22}$. Ademais, nas capacitações dos estudantes universitários e dos profissionais da saúde já inseridos na rede pública, não se observa estímulo à construção de espaços onde se busque 
ampla reflexão entre os profissionais e a população - tal como propõe a educação permanente em saúde ${ }^{23}$.

Ressalta-se que a oferta de CP nos serviços de saúde depende de uma postura bioética dos profissionais da saúde e de uma postura política em defesa de uma saúde pública que acolha as demandas da população e a singularidade de cada um diante de questões complexas, como o processo de adoecimento e morte, além de uma formação em saúde qualificada, interdisciplinar e interprofissional².

\section{CONCLUSÃO}

Verifica-se que tanto o conhecimento acerca dos CPs na APS produzido na literatura no período de 10 anos (de 2008 a 2018) quanto as possibilidades de atuação da psicologia apontam uma baixa produção sobre a prática dos CPs na APS e, especificamente, quanto às contribuições da psicologia com essa abordagem. Assim, urge a necessidade de que essas temáticas sejam estudadas por psicólogos na saúde pública brasileira.

Ademais, observa-se que tal achado sinaliza a necessidade de maior investimento em estudos no campo acadêmico sobre a atuação dos profissionais da saúde nos CPs na APS. No que concerne ao profissional de psicologia, pontua-se que a escassa produção científica pode relacionar-se a certa dificuldade dos psicólogos para descrever e refletir sobre seu trabalho no âmbito dos serviços de CPs e sua possivel resistência para fazer parte de equipe multiprofissional de tais serviços.

Concluiu-se ser necessário desenvolver novos estudos sobre a abordagem dos CPs em outros tipos de serviço na rede de saúde pública e é indispensável que os psicólogos exponham suas contribuições teóricas e práticas nessa modalidade de atenção à saúde.

\section{CONTRIBUIÇÃO DAS AUTORAS}

Ana Carina Rodrigues Gois contribuiu com a realização da pesquisa, o delineamento do estudo e a redação do manuscrito. Joyce Hilario Maranhão contribuiu com a redação e revisão crítica do manuscrito.

\section{REFERÊNCIAS}

1. Conselho Federal de Psicologia. Resolução n. 03/2016. Altera a Resolução CFP n. 013/2007, que institui a Consolidação das Resoluções relativas ao Título Profissional de Especialista em Psicologia e dispõe sobre normas e procedimentos para seu registro [document on the internet]. 2016 [cited 2018 Mar 4]. Available from: https:// site.cfp.org.br/wp-content/uploads/2016/04/ Resolu\%C3\%A7\%C3\%A30-003-2016.pdf

2. Souza ARB. 0 fazer do psicólogo na saúde. Cadernos de Graduação: Ciências Biológicas e da Saúde Fits [serial on the internet]. 2013 [cited 2019 May 24];1(2):79-87. Available from: https:// periodicos.set.edu.br/index.php/fitsbiosaude/ article/viewFile/620/368

3. Kubler-Ross E. Sobre a morte e o morrer: o que os doentes têm para ensinar a médicos, enfermeiras, religiosos e aos seus próprios parentes. São Paulo: Martins Fontes; 1996.

4. World Health Organization. Definition of palliative care [document on the internet]. 2017 [cited 2019 May 24]. Available from: http://www. who.int/cancer/palliative/definition/en/

5. Brasil. Portaria n. 2436, de 21 de setembro de 2017. Aprova a Política Nacional de Atenção Básica, estabelecendo a revisão de diretrizes para a organização da Atenção Básica, no âmbito do Sistema Único de Saúde (SUS) [document on the internet]. 2017 [cited 2018 Feb 28]. Available from: http:// bvsms.saude.gov.br/bvs/saudelegis/gm/2017/ prt2436 2209 2017.html

6. Marcucci FCI, Perilla AB, Brun MM, Cabrera APS. Identificação de pacientes com indicação de cuidados paliativos na Estratégia Saúde da Família: estudo exploratório. Cad Saúde Colet [serial on the internet]. 2016 [cited 2019 May 24];24(2):145-52. Available from: http://www.scielo.br/pdf/cadsc/ v24n2/1414-462X-cadsc-24-2-145.pdf

7. Barros MMAF, Mendes MLC, Frota LMA, Almeida JRS. Acolhimento em unidade de atenção primária à saúde: potencialidades e desafios. Sanare (Sobral, Online) [serial on the internet]. 2018 [cited 2019 May 18];13(2):114-9. Available from: https://sanare. emnuvens.com.br/sanare/article/view/1269/677

8. Franco MHP. Luto em cuidados paliativos. São Paulo: Conselho Regional de Medicina do Estado de São Paulo; 2008.

9. Silva MLS. 0 papel do profissional da atenção primária à saúde em cuidados paliativos. Rev Bras Med Fam Comunidade [serial on the internet]. 2014 [cited 2019 May 24];9(30):45-53. Available from: https://www.rbmfc.org.br/rbmfc/article/ view $/ 718 / 595$ 
10. Soares CB, Hogo LAK, Peduzzi M, Sangaleti C, Yonekura T. Revisão integrativa: conceitos e métodos utilizados na enfermagem. Rev Esc Enferm USP [serial on the internet]. 2014 [cited 2019 May 24];48(2):335-45. Available from: http:// www.scielo.br/pdf/reeusp/v48n2/pt 0080-6234reeusp-48-02-335.pdf

11. Delalibera M. Sobrecarga no cuidar e suas repercussões nos cuidadores de pacientes em fim de vida: revisão sistemática da literatura. Ciênc Saúde Colet [serial on the internet]. 2015 [cited 2019 May 24];20(9):2731-47. Available from: http://www. scielo.br/pdf/csc/v20n9/1413-8123-csc-20-09-2731. $\underline{\mathrm{pdf}}$

12. Combinato DS, Martins STF. Necessidades da vida na morte. Interface Comun Saúde Educ [serial on the internet]. 2017 [cited 2019 May 24];21(63):86980. Available from: http://www.scielo.br/pdf/icse/ v21n63/1807-5762-icse-1807-576220160649.pdf

13. Silva MRB, Borgognoni K, Rorato C, Morelli S, Silva MRV, Sales CA. O câncer entrou em meu lar: sentimentos expressos por familiares de clientes. Rev Enferm UERJ. 2008;16(1):70-5.

14. Sorato DB, Peres SV, Mitsuyuki MC. Cuidar e ser cuidado pelo grupo de apoio protege. Psicol. Estud [serial on the internet]. 2010 [cited 2019 May 24];15(4):751-9. Available from: http://www.scielo. $\mathrm{br} / \mathrm{pdf} / \mathrm{pe} / \mathrm{v} 15 \mathrm{n} 4 / \mathrm{v} 15 \mathrm{n} 4 \mathrm{a} 10 . \mathrm{pdf}$

15. Costa EA0, Dupas G, Sousa EFR, Wernet M. Doença crônica da criança: necessidades familiares e a relação com a Estratégia Saúde da Família. Rev Gaúch Enferm [serial on the internet]. 2013 [cited 2019 May 24];34(3):72-8. Available from: http:// www.scielo.br/pdf/rgenf/v34n3/a09v34n3.pdf

16. Queiroz AHAB, Pontes RJS, Souza AMA, Rodrigues TB. Percepção de familiares e profissionais de saúde sobre os cuidados no final da vida no âmbito da atenção primária à saúde. Ciênc Saúde Colet [serial on the internet]. 2013 [cited 2019 May 24];18(9):261523. Available from: http://www.scielo.br/pdf/csc/ v18n9/v18n9a16.pdf

17. Oliveira EA, Santos MA, Mastropietro AP. Apoio psicológico na terminalidade: ensinamentos para a vida. Psicol Estud [serial on the internet]. 2010 [cited 2019 May 24];15(2):235-44. Available from: http://www.scielo.br/pdf/pe/v15n2/a02v15n2.pdf

18. Simino GPR, Santos CB, Mishima SM. Acompanhamento de usuários, portadores de câncer, por trabalhadores da Saúde da Família. Rev Latinoam Enferm [serial on the internet]. 2010 [cited 2019 May 24];18(5):17-26. Available from: http://www. scielo.br/pdf/rlae/v18n5/pt 04.pdf

19. Benites AC, Neme CMB, Santos MA. Significados da espiritualidade para pacientes com câncer em cuidados paliativos. Estud Psicol [serial on the internet]. 2017 [cited 2019 May 24];34(2):269-79. Available from: http://www.scielo.br/pdf/estpsi/ v34n2/0103-166X-estpsi-34-02-00269.pdf

20. Palmeira HM, Scorsolini-Comin F, Peres RS. Cuidados paliativos no Brasil: revisão integrativa da literatura científica. Aletheia [serial on the internet]. 2011 [cited 2019 May 24];35(36):179-89. Available from: http://pepsic.bvsalud.org/scielo.php?script=sci ar ttext\&pid=S1413-03942011000200014

21. Kovács MJ. A caminho da morte com dignidade no século XXI. Rev Bioét [serial on the internet]. 2014 [cited 2019 May 24];22(1):94-104. Available from: http://www.scielo.br/pdf/bioet/v22n1/a11v22n1. $\mathrm{pdf}$

22. Combinato DS, Martins STF. (Em defesa dos) cuidados paliativos na atenção primária à saúde. Mundo Saúde [serial on the internet]. 2013 [cited 2019 May 24];36(3):433-41. Available from: http:// www.saocamilo-sp.br/pdf/mundo saude/95/5.pdf

23. Brasil. Portaria n. 198/GM/MS, de 13 de fevereiro de 2004. Institui a Política Nacional de Educação permanente em saúde [document on the internet]. 2004 [cited 2018 Feb 28]. Available from: http:// bvsms.saude.gov.br/bvs/saudelegis/gm/2017/ MatrizesConsolidacao/comum/13150.html

24. Gorayeb R, Borges CD, Oliveira CM. Psicologia na atenção primária: ações e reflexões em programa de aprimoramento profissional. Psicol. cienc. prof. 2012;32(3):674-685 Available from: http://www. scielo.br/pdf/pcp/v32n3/v32n3a12.pdf

25. Marchi JA, Carreira L, Sales CA. Ser-cuidados de familiar com câncer e dependente: um olhar para a temporalidade. Rev Eletr Enf. 2015;17(3). Available from: https://www.fen.ufg.br/revista/v17/n3/pdf/ v17n3a15.pdf
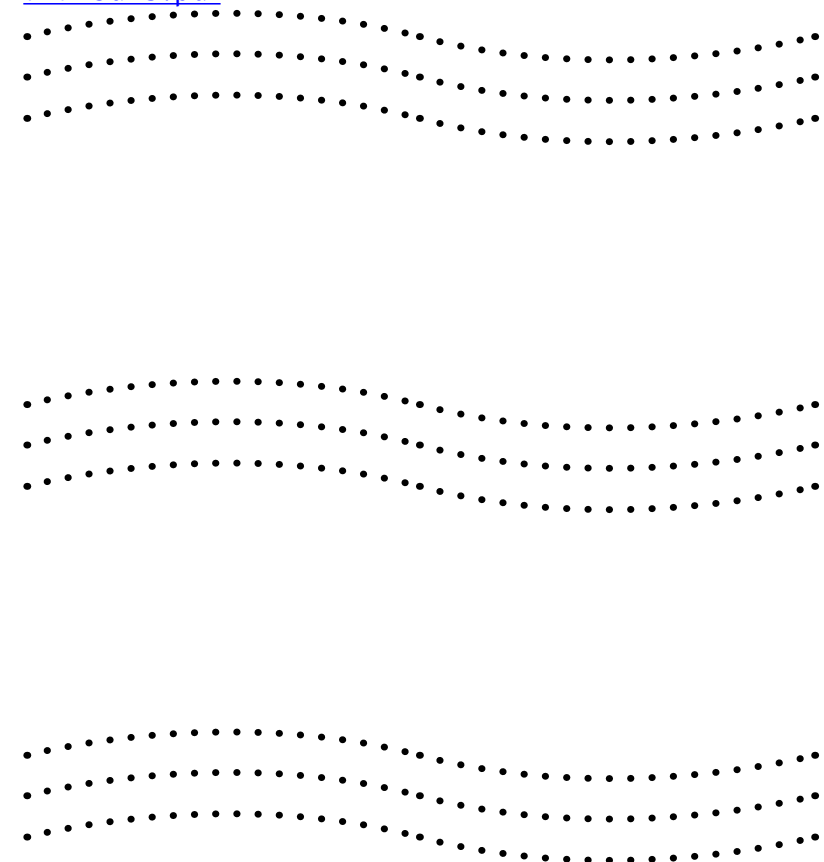


\section{ATENÇÃO DOMICILIAR EM SAÚDE BUCAL: EXPERIÊNCIA DE INTEGRAÇÃO ENSINO-SERVIÇO-COMUNIDADE EM CENTRO DE SAÚDE DA FAMÍLIA}

HOME CARE IN ORAL HEALTH: TEACHING-SERVICE-COMMUNITY INTEGRATION EXPERIENCE AT A FAMILY HEALTH CENTER

ATENCIÓN DOMICILIARIA EN SALUd BUCAL: EXPERIENCIA DE INTEGRACIÓN ENSEÑANZA-SERVICIO-COMUNIDAD EN UN CENTRO DE SALUD DE LA FAMILIA

André Pereira de Lima ${ }^{1}$

Timóteo Sousa Lopes 2

Atanara Freires Aguiar de Lima ${ }^{3}$

Mariana Ramalho de Farias ${ }^{4}$

Jacques Antonio Cavalcante Maciel ${ }^{5}$

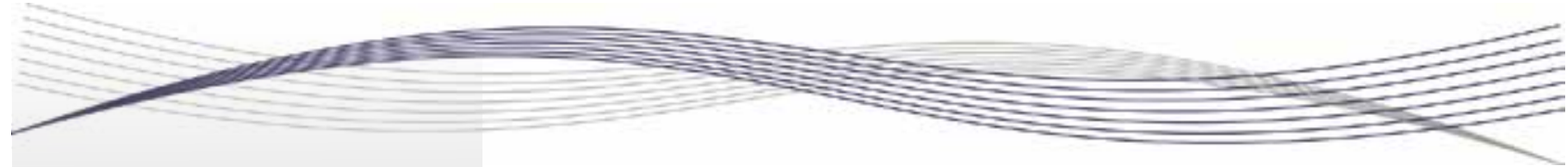

Palavras-chave:

Visita Domiciliar; Saúde Bucal; Atenção Primária à Saúde.

Keywords: Home Visit; Oral Health; Primary Health Care.

Palabras clave: Visita Domiciliaria; Salud Bucal; Atención Primaria de Salud.

Submetido: 28/12/2018

Aprovado: 21/04/2019

Autor(a) para Correspondência: Jacques Antonio Cavalcante Maciel

R. Lourenço Guimarães, 250

Paulo Ximenes do Prado Groairas (CE) - CEP: 62190-000

E-mail: jacques.maciel@sobral. ufc.br

\section{RESUMO}

Este estudo objetivou estabelecer um protocolo de atenção domiciliar (AD) em saúde bucal para pacientes restritos ao lar. Trata-se de relato de experiência baseado em uma ação de intervenção realizada por alunos de Graduação em Odontologia em Sobral-CE. Nesse contexto, mostrou-se necessária a criação do protocolo para a realização de visitas e a proposição de planos de tratamento, visando à prevenção de agravos e à promoção da saúde. A elaboração do instrumento buscou facilitar a abordagem durante as visitas e estratificar as prioridades de atenção aos pacientes restritos ao lar. 0 protocolo aborda aspectos de saúde geral relativos à saúde bucal e informações sobre o território de abrangência da equipe de saúde bucal (ESB), bem como o estabelecimento de um plano de tratamento integral. Este estudo evidenciou que a $A D$ em saúde bucal contribui para minimizar iniquidades em saúde bucal decorrentes da dificuldade de acesso aos serviços de saúde. A curto e longo prazos, espera-se garantir a continuidade das visitas, a realização das intervenções que cada paciente necessita e a diminuição da demanda de procedimentos curativistas.

1. Cirurgião-Dentista graduado pela Universidade Federal do Ceará (UFC). Sobral (CE), Brasil. E-mail: Lima. andre2011@gmail.com

2. Cirurgião-Dentista graduado pela UFC. Sobral (CE),Brasil.E-mail: timoteo.sous@hotmail.com

3. Enfermeira graduada pela Universidade Estadual Vale do Acaraú (UVA). Sobral (CE), Brasil. E-mail: atanara_ aguiar@hotmail.com

4. Cirurgiã-Dentista. Professora no Curso de Odontologia da UFC. Sobral (CE), Brasil. E-mail: marifarias_ odonto@yahoo.com.br

5. Cirurgião-Dentista. Professor no Curso de Odontologia da UFC. Groaíras (CE), Brasil. E-mail: jacques.maciel@ sobral.ufc.br 


\section{ABSTRACT}

This study aimed to establish a home care (HC) protocol in oral health for home-restricted patients. This is an experience report based on an intervention action carried out by undergraduate Dentistry students in Sobral, Ceará, Brazil. In this context, it was necessary to create a protocol for visits and treatment plan proposals, aiming at the prevention of illnesses and the promotion of health. The instrument's design sought to facilitate the approach during visits and to stratify the priorities of care for home-restricted patients. The protocol addresses general health aspects related to oral health and information about the territory covered by the oral health team $(\mathrm{OHT})$, as well as the establishment of a comprehensive treatment plan. This study showed that HC in oral health contributes to minimize inequities in oral health due to difficulty of access to health services. In the short and long terms, it is expected to guarantee the continuity of visits, the accomplishment of interventions that each patient needs, and the decreased need for cure-driven procedures.

\section{RESUMEN}

Este estudio tuvo como objetivo establecer un protocolo de atención domiciliaria (AD) en salud bucal para pacientes restringidos al hogar. Este es un informe de experiencia basado en una acción de intervención realizada por estudiantes de Pregrado en Odontología en Sobral, Ceará, Brasil. En este contexto, se mostró necesaria la creación del protocolo para visitas y la proposición de planes de tratamiento, con miras a la prevención de agravios y la promoción de la salud. La elaboración del instrumento buscó facilitar el abordaje durante las visitas y estratificar las prioridades de cuidado a los pacientes restringidos al hogar. El protocolo aborda aspectos de salud general relacionados con la salud bucal e información acerca del territorio cubierto por el equipo de salud oral (ESO), así como el establecimiento de un plan de tratamiento integral. Este estudio demostró que la AD en salud bucal contribuye a minimizar inequidades en salud bucal debido a la dificultad de acceso a los servicios de salud. A corto y largo plazo, se espera que garantice la continuidad de las visitas, el cumplimiento de las intervenciones que cada paciente necesita y menor necesidad de procedimientos curativistas.

\section{INTRODUÇÃ O}

No Sistema Único de Saúde (SUS), a organização da Estratégia Saúde da Família (ESF) em equipes multiprofissionais tem sido o pilar de um modo de pensar e praticar saúde distinto do modelo tradicional, pautado pelos princípios da atenção primária à saúde (APS). Inicialmente implementado como Programa Saúde da Família (PSF), o Brasil recorreu à ESF como opção preferencial para a APS, tendo como desafio estabelecer as inovadores diretrizes do SUS ${ }^{1}$.

A ESF prevê a atenção domiciliar (AD) como forma de assistência aos usuários que demandam cuidados contínuos, sobretudo como instrumento de diagnóstico local e programação de ações a partir da realidade, com ênfase na redução de desigualdades na atenção à saúde. A AD se caracteriza por ações sistematizadas, articuladas e regulares e pela integralidade das ações de promoção, recuperação e reabilitação da saúde e, além disso, seu principal objetivo é assistir ao paciente restrito ao lar, visando a potencializar sua autonomia e ampliar o leque de possibilidades de intervenção em domicílio com base em planejamento adequado para cada situaçã $0^{2}$.
A AD tem a visita domiciliar (VD) como um dos principais mecanismos para estabelecer vínculos com a população e seu caráter estratégico voltado à integralidade e humanização das ações de saúde traz maior proximidade e, consequentemente, corresponsabilização dos profissionais da saúde diante das demandas da população, em seu contexto social e familiar ${ }^{2}$. A AD voltada à saúde bucal na ESF qualifica a promoção da saúde bucal e a prevenção de doenças advindas da cavidade oral, além de possibilitar a realização de procedimentos odontológicos no ambiente domiciliar e de oferecer um cuidado que amplia a autonomia por meio da integração paciente-cuidador ${ }^{2,3}$.

No contexto da $A D$, os cuidados domiciliares em saúde bucal são definidos como o conjunto de ações de educação em saúde, com orientações sobre autocuidado, prevenção de agravos e assistência odontológica em domicílio. Diante do desafio de proporcionar cuidados domiciliares em saúde bucal, deve-se considerar que, na maioria das vezes, esse tipo de assistência exige equipamentos e instrumentos e impõe condições de biossegurança e de ergonomia que dificilmente são plenamente viáveis em domicílio. Com tais dificuldades em vista, 
o consultório odontológico dos serviços de saúde é o espaço privilegiado para as atividades clínicas a assistência odontológica em domicílio deve ficar restrita a casos específicos nos quais a equipe que acompanha o paciente julgar necessário, priorizando as necessidades do usuário do serviço de saúde ${ }^{4}$.

A Política Nacional de Atenção Básica (PNAB) estabelece como uma das responsabilidades comuns a todos os profissionais da ESF a realização de $A D$ voltada a pessoas com problemas de saúde controlados/compensados, com algum grau de dependência para as atividades da vida diária, que não podem deslocar-se até a unidade básica de saúde (UBS). Essa estratégia é considerada promotora de acesso às políticas públicas, mediante relação que se estabelece entre os diversos sujeitos do processo, constituindo um dos instrumentos fundamentais para a atenção integral5. Por outro lado, as diretrizes da Política Nacional de Saúde Bucal (PNSB) indicam as visitas domiciliares como um componente mais relacionado às ações educativas e preventivas, como um procedimento realizado preferencialmente pelo agente comunitário de saúde $(A C S)^{5}$.

Embora configurem práticas essenciais na APS, poucos estudos buscam a identificação e a caracterização da VD e dos cuidados domiciliares em saúde bucal no âmbito da ESF. Um desses raros estudos sobre a temática evidenciou a preocupação de que, em geral, os profissionais da equipe de saúde bucal (ESB) ainda reproduzem o modelo assistencial curativo, clínico, individualizado, pautado por tecnologias duras, enfrentando entraves para mudar tal modelo com a incorporação de práticas de prevenção de agravos e promoção da saúde e recorrendo à VD com pouca frequência ${ }^{5}$.

$\mathrm{Na}$ prática, observa-se carência de diretrizes e protocolos para a $A D$ voltada à saúde bucal. A partir dessa contextualização, constatou-se a necessidade da criação de um protocolo de AD em saúde bucal,

\section{Essa estratégia \\ é considerada promotora de acesso às políticas públicas...}

a partir da realização de VD pela ESB, visando à prevenção de agravos e promoção da saúde, bem como à redução no número de intervenções curativistas.

0 estudo objetivou estabelecer um protocolo de $A D$ em saúde bucal para pacientes restritos ao lar; assim, este artigo relata a experiência baseada em uma ação de intervenção realizada por alunos de Graduação em Odontologia em Sobral-CE.

\section{METODOLOGIA}

Trata-se de relato de experiência baseado na vivência de estágio supervisionado de alunos de Graduação em Odontologia da Universidade Federal do Ceará (UFC), realizado em Sobral no período de fevereiro a junho de 2018. Esse estágio contou com a participação de profissionais dos serviços de saúde e a supervisão de professores da UFC.

Sobral, município localizado no norte do Ceará, constitui um cenário de práticas que integra serviços de saúde e instituições de ensino - o curso de Graduação em Odontologia da UFC propicia, via atividades curriculares do “Estágio em Atenção Primária", a elaboração e execução de projetos de intervenção que busquem aprimorar a atuação da ESB no território de abrangência da ESF.

A experiência deste estudo parte de um problema observado nas primeiras visitas e por meio de relatos dos ACS e dos cirurgiões-dentistas do Centro de Saúde da Família (CSF) “Dr. Grijalba Mendes Carneiro" - conhecido como CSF Coelce -, que relataram a existência de considerável quantidade de pacientes restritos ao lar com necessidade de acompanhamento. A partir de uma primeira VD solicitada por familiares de um paciente, dos relatos da ESB e da observação dessa realidade, constatou-se a realização de poucas VDs pela ESB. Estas, em geral, ocorriam apenas quando solicitadas pelas famílias de pacientes acamados - principalmente em casos de dor. 0s ACS relataram, ainda, que muitos pacientes restritos ao lar no território coberto pelo CSF Coelce demandam maior acompanhamento por parte da ESB, mas que esta não dispunha de recursos para priorizar a quantidade estimada de casos.

\section{RESULTADOS}

Para otimizar as ações em saúde bucal junto a essa população, planejou-se a elaboração de um protocolo baseado no prontuário clínico utilizado pela Clínica Odontológica da UFC no Campus Sobral. 
Foram realizadas adaptações no protocolo para uso em ambiente domiciliar, com informações de saúde relativas às demandas dos pacientes restritos ao lar obtidas a partir das visitas; elas estratificaram a prioridade e viabilidade de assistência clínica domiciliar.

Participaram da elaboração desse instrumento: a) os alunos de Graduação em Odontologia da UFC; b) a ESB; e c) os ACS. Em um primeiro momento, realizou-se uma reunião com todos os envolvidos para elaborar perguntas que deveriam constar no protocolo e para agendar visitas a alguns dos pacientes restritos ao lar (com o propósito de ouvir o que tanto os pacientes como os cuidadores têm a dizer sobre a necessidade de tais visitas).

Em seguida, a equipe realizou visitas no território coberto pelo CSF Coelce, ouvindo pacientes, cuidadores e familiares e tomando conhecimento de algumas das necessidades desses usuários do serviço de saúde, como orientações ao cuidador sobre a saúde bucal do paciente. Uma segunda reunião foi realizada entre a ESB e os ACS para analisar as visitas realizadas e verificar a real necessidade da implementação do protocolo.

Essa intervenção se desenvolveu nos domicílios de pacientes restritos ao Lar adscritos ao CSF Coelce no início do primeiro semestre de 2018. Antes mesmo da elaboração e padronização do instrumento, as seguintes ações ocorreram nos domicílios: a) busca ativa de lesões e alterações de tecidos bucais na cavidade oral (incluindo o autoexame da cavidade oral); b) vigilância e educação em saúde bucal, com orientações sobre medidas de higiene oral (incluindo modos de escovação dentária e desinfecção de prótese); e c) encaminhamento para a atenção especializada, com participação ativa do cirurgiãodentista que atua no território.

A partir desse contato inicial, em sua composição consolidada, o protocolo aborda aspectos de saúde geral, com informações que abrangem: a) os dados pessoais; b) o território de abrangência da ESF; e c) o perfil da saúde bucal: i) histórico de assistência odontológica; ii) condições de saúde bucal; iii) possibilidades de intervenção clínica em domicílio por parte da ESB; iv) necessidade de ações de educação em saúde (coletivas ou voltadas ao paciente e/ou cuidador); v) necessidade de intervenção por parte de outros profissionais da ESF; e vi) necessidade de encaminhamento para um serviço de atenção secundária (Figura 1 ).

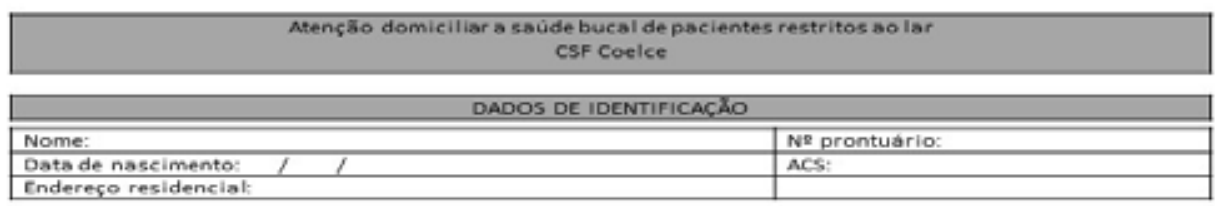

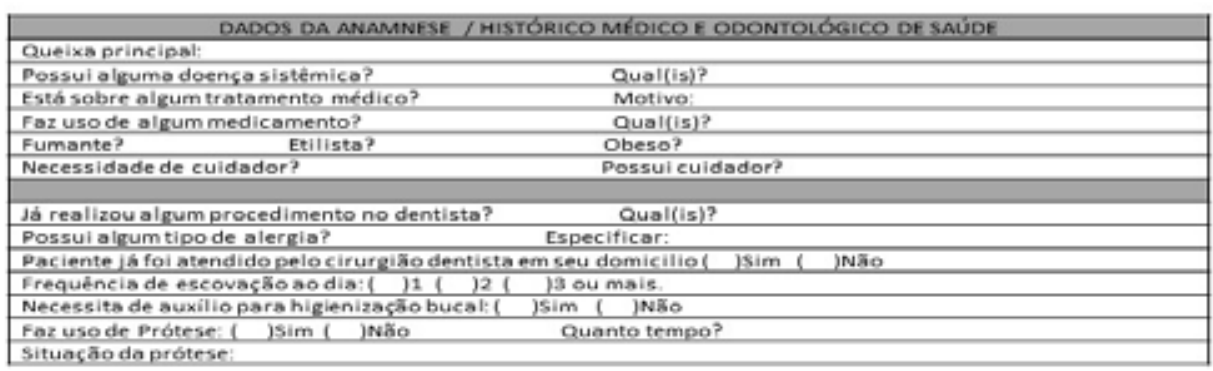
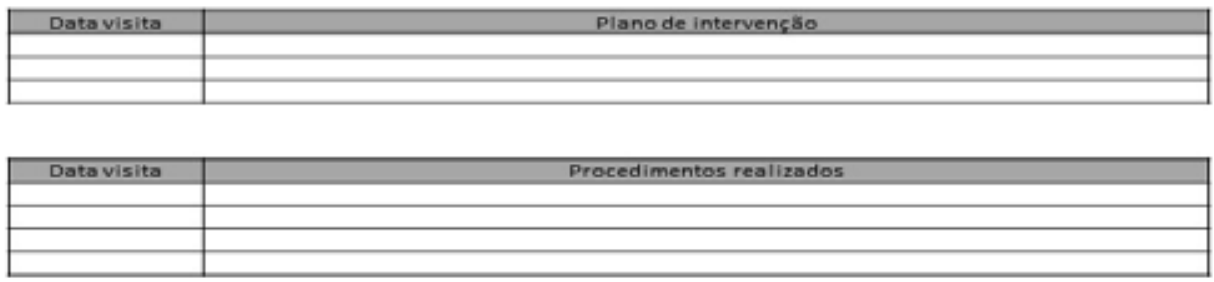

OBS:

Figura 1. Ficha utilizada nas visitas domiciliares. Sobral, 2018.

Fonte: Elaborada pelos autores. 
No período de intervenção, 16 pacientes foram examinados por meio de VD com uso desse protocolo entre esses usuários havia crianças, adultos e idosos, sendo este último o grupo prevalente de pacientes restritos ao lar. Todos os idosos se submeteram a exame clínico para prevenção do câncer de boca, com busca de alterações potencialmente malignas e das demais patologias que pudessem demandar encaminhamento para a atenção especializada. Além disso, os usuários que faziam uso de prótese receberam orientações acerca da higiene delas.

0 protocolo possibilita a elaboração de um planejamento que objetiva intervenções integrais, para melhoria da saúde bucal e global do paciente baseada em dados individuais e relacionadas ao contexto do paciente, realizadas em caráter individual ou coletivo.

Durante a experiência das visitas domiciliares, observou-se que as condições odontológicas estão diretamente relacionadas às condições socioeconômicas, ambientais, psicológicas e nutricionais. Piores condições socioeconômicas se relacionam a baixo nivel de escolaridade do paciente e/ou cuidador e esse contexto influencia o grau de compreensão da importância de manter a saúde bucal. Tais condições acabam repercutindo nas condições de moradia, já que, para a população idosa e/ou portadora de alguma deficiência física ou mental, uma casa segura, com corrimões, barras de segurança, escadas adequadas, boa iluminação, entre outros recursos, contribui para evitar acidentes domésticos que, muitas vezes, envolvem graves riscos aos moradores ${ }^{6-10}$.

0 cirurgião-dentista, enquanto profissional da saúde, assume papel fundamental na VD mediante atividades de promoção da saúde, motivação e educação em saúde voltada ao paciente e à sua família. Ele enfoca a proteção e prevenção em saúde bucal, com orientações acerca de higiene bucal e cuidados com prótese, aplicação tópica de flúor e escovação supervisionada, além de tratamento clínico após a identificação de lesões orais potencialmente malignas. Esse profissional estabelece uma rede de comunicação participativa com a família e com os demais profissionais da ESF, coordenando o cuidado do paciente restrito ao lar $^{6}$.

Durante o período de vivência, observou-se que a maioria dos pacientes restritos ao lar estava acamada no momento da visita, com limitação de movimentos e da capacidade funcional que gera empecilhos ao deslocamento para a realização de

\section{Esse profissional estabelece uma rede de comunicação participativa com a família e com os demais profissionais $d a$ ESF...}

suas atividades de vida diária ${ }^{11}$. Esse indivíduo lida com alguma fragilidade decorrente de doenças crônicas ou de outras patologias que ameaçam sua integridade física, social e econômica, suscitando situações que demandam a presença de outrem por longos períodos ${ }^{12}$.

Essas impressões relativas à dificuldade de acesso ao serviço de saúde também podem ser decorrentes de fatores como falta de meio de transporte, precária malha viária urbana, violência urbana e tráfico de drogas, o que pode aumentar ainda mais a quantidade de pacientes com restrição ao $\operatorname{lar}^{6}$. Um estudo sobre o processo de AD nas unidades da ESF que aderiram ao Programa Nacional de Melhoria do Acesso e da Qualidade da Atenção Básica (PMAQ-AB) constatou que, na prática, o cuidado em domicílio é oferecido por cerca de $50 \%$ dos profissionais das ESBs, o que evidencia que estas precisam superar desafios para implementar novas práticas de $A D$ no âmbito da APS 5 .

Ações de $A D$ no território priorizam a minimização de iniquidades resultantes de uma atenção à saúde desigual, cuja origem é a dificuldade de acesso aos serviços. 0 acesso se mostra um conceito complexo, relacionado tanto ao ato de ingressar, entrar, quanto ao termo acessibilidade, que corresponde à capacidade da população usar os recursos disponiveis. Assim, a acessibilidade é um fator da oferta para explicar as variações no uso de serviços por grupos populacionais, representando uma dimensão relevante em estudos sobre a equidade nos sistemas de saúde?

0 itinerário do território de abrangência da ESF assume vital importância na avaliação da equidade de acesso dos pacientes restritos ao lar, valendose de fatores individuais (in)capacitantes para analisar o uso de serviços de saúde. A presença de outros preditores de uso, além das demandas de saúde e dos aspectos demográficos, denota uma situação de iniquidade ${ }^{7} 0$ recorte mais adequado ao 
exame das desigualdades sociais parece relacionarse com a identificação de situações que envolvem algum grau de injustiça com determinados coletivos populacionais - como os usuários visitados durante a realização deste estudo. 0 conceito de iniquidade ganhou forma e firmou-se como sinônimo de toda e qualquer "desigualdade injusta" a ser evitada ou combatida ${ }^{8,9}$.

0 cuidado domiciliar no âmbito da ESF é mais frequente no processo de trabalho de enfermeiros, médicos e técnicos/auxiliares de enfermagem em comparação ao trabalho de cirurgiões-dentistas e técnicos/auxiliares de saúde bucal, possivelmente em virtude de fatores como a inserção tardia da ESB na ESF e a dependência estrutural de tecnologias duras, associadas ao paradigma biomédico, ainda predominante na formação em Odontologia, que resulta em dificuldade de trabalhar em equipe e de lidar com ações coletivas ${ }^{13,14}$, mesmo que as diretrizes da PNSB, de 2004, estabeleçam a reorientação do modelo assistencial, com a ampliação do acesso à saúde bucal e a oferta de cuidado em todos os níveis de atenção à saúde ${ }^{15,16}$.

Vale ressaltar que, neste estudo, o êxito das VDs foi viabilizado pela mediação dos ACS, que favorece a execução das intervenções, as articulações locais e, em especial, o vínculo entre o CSF e o território, entre os serviços de saúde e a comunidade. A mediação dos ACS potencializa o acesso dos usuários, aumenta sua compreensão dos serviços e identifica as demandas de saúde, possibilitando um ajuste adequado entre os profissionais da saúde e a comunidade ${ }^{17}$.

Um importante achado da experiência aqui relatada foi a autopercepção negativa evidenciada por pacientes e cuidadores em termos de saúde bucal. Apesar de dores e infecções bucais terem o potencial de agravar condições sistêmicas, infelizmente, a saúde bucal ainda é considerada de baixa prioridade em comparação aos demais cuidados médicos voltados a esses usuários ${ }^{9}$. A vivência sinalizou que a maioria dos pacientes restritos ao lar não veem importância nos cuidados de saúde bucal. Mostrase indispensável difundir melhor as atribuições do cirurgião-dentista como profissional de saúde e não só como alguém que "cuida dos dentes"; seu paciente recebe uma assistência integral que melhora sua saúde como um todo.

Nas atividades formativas que têm os serviços de saúde e a comunidade como espaços de ensinoaprendizagem, é fundamental que professores e alunos aprofundem a humanização da atenção à

\section{...a saúde bucal ainda é considerada de baixa prioridade em comparação aos demais cuidados...}

saúde e elaborem estratégias para que o atendimento proposto pelo curso de Graduação em Odontologia possa dar respostas efetivas à comunidade, uma conquista ainda distante da realidade da própria ESF em grande parte dos municípios brasileiros ${ }^{13}$.

Por se tratar de um relato de experiência, este artigo apresenta a limitação de não fornecer resultados do uso do protocolo em questão a longo prazo, visto que o período de intervenção foi de um semestre. No entanto, o instrumento foi bem aceito pela equipe de saúde e pode ser monitorado em outras vivências no âmbito dos cursos de Graduação em Odontologia. Outra limitação se refere à não visitação de todos os pacientes restritos ao lar durante a intervenção, em virtude da alta demanda de trabalho dos profissionais do CSF. Isso torna necessário recorrer a um acompanhamento posterior para avaliar a exequibilidade desse protocolo.

\section{CONCLUSÃO}

Constatou-se que a $A D$ em saúde bucal apresenta pontos positivos, pois leva assistência a uma parcela da população que não teria acesso a serviços de saúde, devido à sua condição de restrição ao lar. Por meio da VD, os membros da ESB podem refletir sobre seu processo de trabalho com vistas a desenvolver estratégias que viabilizem as ações de saúde na comunidade e reduzam as desigualdades de acesso aos serviços de saúde.

Os resultados do uso do protocolo apontaram o fortalecimento do vínculo entre a população e a ESB. A inserção da AD nas atividades da ESB se encontra em evolução e é importante ressaltar que tais ações devem inserir-se no processo de trabalho para alcançar um vínculo mais efetivo entre a ESB e a comunidade assistida, viabilizando uma maior humanização da atenção à saúde e dos cuidados em saúde bucal.

Essa integração ensino-serviço-comunidade se 
mostra crucial para aumentar o número de visitas domiciliares a pacientes restritos ao lar no território, mediante ações de prevenção de agravos e promoção da saúde que facilitem a elaboração de um plano de cuidado para cada paciente. A longo prazo, esperase obter a continuidade das visitas a cada paciente, intensificar as intervenções necessárias e diminuir a demanda de procedimentos curativistas no âmbito da ESF.

\section{CONTRIBUIÇÃO DOS AUTORES}

André Pereira de Lima e Timóteo Sousa Lopes contribuíram com a realização da pesquisa, o delineamento do estudo e a redação do manuscrito. Atanara Freires Aguiar de Lima contribuiu com a redação do manuscrito. Mariana Ramalho de Farias e Jacques Antonio Cavalcante Maciel contribuíram com a redação e revisão crítica do manuscrito.

\section{REFERÊNCIAS}

1. Barbosa DCM, Mattos ATR, Corrêa MH, Faria M, Ribeiro LC, Santos LL, et al. Visita domiciliar sob a percepção dos usuários da ESF. Medicina (Ribeirão Preto) [serial on the internet]. 2016 [cited 2019 May 27];49(4):360-6. Available from: http://revista. fmrp.usp.br/2016/vol49n4/DMT-Visita-domiciliarsob-a-percepcao-dos-usuarios-da-ESF.pdf

2. Cunha MS, Sá MC. A visita domiciliar na Estratégia de Saúde da Família: os desafios de se mover no território. Interface Comun Saúde Educ [serial on the internet]. 2013 [cited 2019 May 27];17(44):6173. Available from: http://www.scielo.br/pdf/icse/ v17n44/a06v17n44.pdf

3. Maciel JAC, Almeida AS, Menezes AKA, Oliveira Filho IL, Teixeira AKM, Castro-Silva II, et al. Quando a saúde bucal bate à porta: protocolo para a atenção domiciliar em odontologia. Rev Bras Promoç Saúde [serial on the internet]. 2016 [cited 2019 May 27];29(4):614-20. Available from: https:// periodicos.unifor.br/RBPS/article/view/5463/pdf

4. Nishide $R$, Mizutani $M$, Tanimura $S$, Kudo $\mathrm{N}$, Nishii T, Hatashita H. Homecare protective and risk factors for early childhood caries in Japan. Environ Health Prev Med. 2018;23(1):57.

5. De-Carli AD, Santos MLM, Souza AS, Kodjaoglanian VL, Batiston AP. Visita domiciliar e cuidado domiciliar na atenção básica: um olhar sobre a saúde bucal. Saúde Debate [serial on the internet]. 2015 [cited 2019 May 27];39(105):441-50. Available from: http://www.scielo.br/pdf/sdeb/v39n105/0103-1104sdeb-39-105-00441.pdf
6. Bizerril D0, Saldanha KGH, Silva JP, Almeida JRS, Almeida MEL. Papel do cirurgião-dentista nas visitas domiciliares: atenção em saúde bucal. Rev Bras Med Fam Comunidade [serial on the internet]. 2015 [cited 2019 May 27];10(37):1-8. Available from: https:// www.rbmfc.org.br/rbmfc/article/view/1020/732

7. Travassos C, Martins M. Uma revisão sobre os conceitos de acesso e utilização de serviços de saúde. Cad Saúde Pública [serial on the internet]. 2004 [cited 2018 Dec 27];20(Suppl 2):S190-S198. Available from: http://www.scielo.br/pdf/csp/ v20s2/14.pdf

8. Barros FPC, Sousa MF. Equidade: seus conceitos, significações e implicações para o SUS. Saúde Soc [serial on the internet]. 2016 [cited 2019 May 27];25(1):9-18. Available from: http:// www.scielo.br/pdf/sausoc/v25n1/1984-0470sausoc-25-01-00009.pdf

9. Ferraz GA; Leite ICG. Instrumentos de visita domiciliar: abordagem da odontologia na estratégia saúde da família. Rev APS [serial on the internet]. 2016 [cited 2019 May 27];19(2):302-14. Available from: file:///D:/15647-Texto $\% 20$ do $\% 20$ artig 0-67104-1-10-20170118.pdf

10. Cheng YM, Ping CC, Ho CS, Lan SJ, Hsieh YP. Home-care aides' self-perception of oral health-care provision competency for community-dwelling older people. Int Dent J. 2019;69(2):158-64.

11. Souza DMM. A prática diária na Estratégia Saúde da Família. Juiz de Fora (MG): Ed. UFJF; 2011.

12. Silva LWS, Araújo TC, Santos FF, Lima AA, Santos GB, Lima LV. A família na convibilidade com o idoso acamado no domicílio. Rev Kairós [serial on the internet]. 2011 [cited 2019 May 27];14(3):75-87. Available from: https://revistas.pucsp.br/kairos/ article/view/6488/4704

13. Noro LRA, Torquato SM. Visita domiciliar: estratégia de aproximação à realidade social? Trab Educ Saúde [serial on the internet]. 2015 [cited 2019 May 27];13(1):145-57. Available from: http:// www.scielo.br/pdf/tes/v13n1/1981-7746-tes-19817746-sip00027.pdf

14. Aquilante AG, Silva GGA. 0 cuidado em saúde bucal após a Política Nacional de Saúde Bucal - "Brasil Sorridente": um estudo de caso. Ciênc Saúde Colet [serial on the internet]. 2015 [cited 2019 May 27];20(1):239-48. Available from: http:// www.scielo.br/pdf/csc/v20n1/pt 1413-8123csc-20-01-00239.pdf

15. Brasil. Diretrizes da Política Nacional de Saúde Bucal. Brasília (DF): Ministério da Saúde; 2004. 
16. Mattos GCM, Ferreira EF, Leite ICG, Greco RM. A inclusão da equipe de saúde bucal na Saúde da Família: entraves, avanços e desafios. Ciênc Saúde Colet [serial on the internet]. 2014 [cited 2019 May 27];19(2):373-82. Available from: http://www.scielo. $\mathrm{br} / \mathrm{pdf} / \mathrm{csc} / \mathrm{v} 19 \mathrm{n} 2 / 1413-8123-\mathrm{csc}-19-02-00373 . \mathrm{pdf}$

17. Muniz EA, Freitas CASL, Albuquerque IMN, Linhares MSC. Assistência domiciliar ao idoso no contexto da Estratégia Saúde da Família: análise da produção científica. Sanare (Sobral, Online) [serial on the internet]. 2014 [cited 2019 May 27];13(2):8691. Available from: https://sanare.emnuvens.com. br/sanare/article/view/578/311

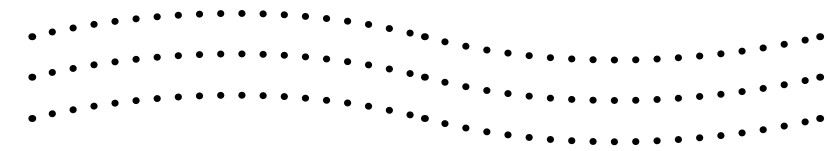

$\ldots \ldots \ldots \ldots \ldots \ldots \ldots \ldots \ldots \ldots \ldots \ldots \ldots \ldots \ldots \ldots \ldots \ldots$
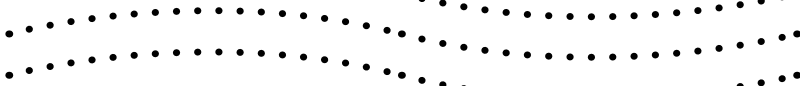
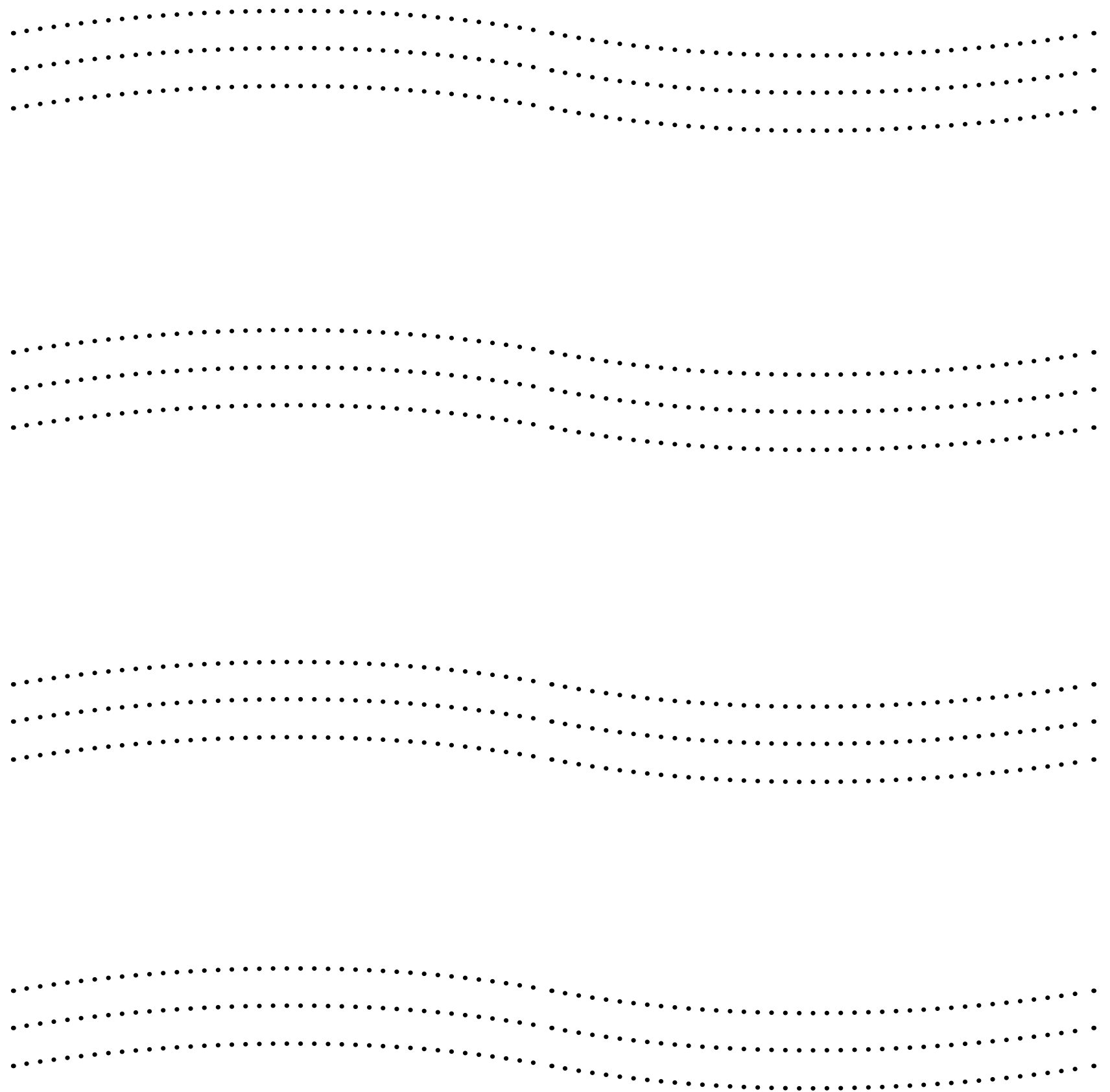


\section{PREENCHIMENTO DA CADERNETA DE SAÚDE DA PESSOA IDOSA: RELATO DE EXPERIÊNCIA}

COMPLETION OF THE ELDERLY PERSON'S HEALTH RECORD: AN EXPERIENCE REPORT

LLENADO DE LA LIBRETA DE SALUd DEL ANCIANO: UN RELATO DE EXPERIENCIA

Alessandra Schmidt ${ }^{1}$

Cenir Gonçalves Tier ${ }^{2}$

Maria Eduarda Deitos Vasquez ${ }^{3}$

Vanessa Alvez Mora da Silva 4

Caroline Bittencourt ${ }^{5}$

Bethânia Mesquita Cabeda Maciel 6

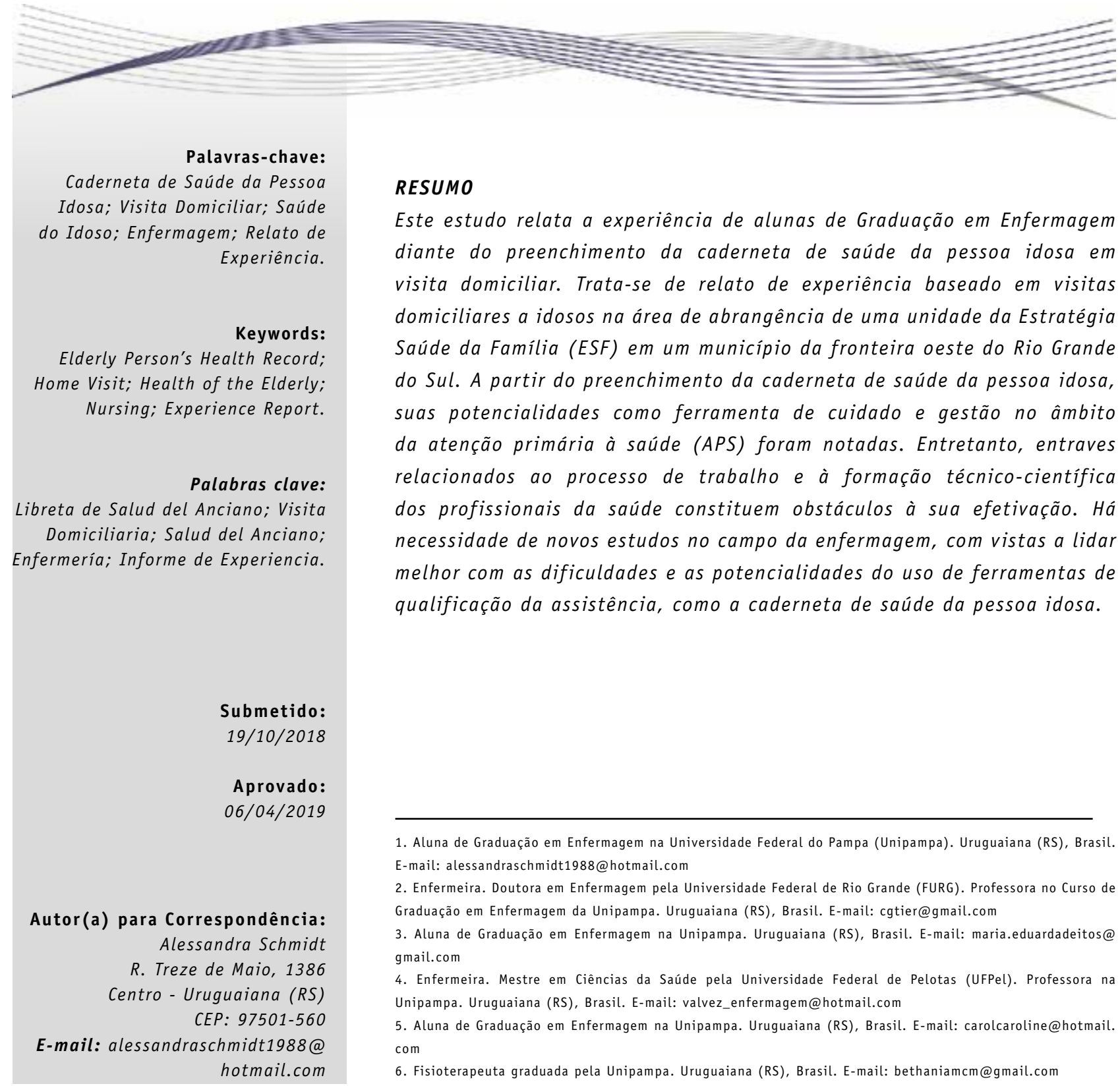

98 - SANARE, Sobral - V.18 n.01,p.98-106, Jan./Jun. - 2019 


\section{ABSTRACT}

This study reports the experience of female undergraduate Nursing students when completing the elderly person's health record during a home visit. This is an experience report based on home visits to the elderly within the area covered by a Family Health Strategy (FHS) center in a municipality located on the western border of the State of Rio Grande do Sul, Brazil. By completing the elderly person's health record, its potentialities as a tool for health care and management in the scope of primary health care (PHC) were noticed. However, hindrances related to the work process and to the technical-scientific qualification of health professionals constitute obstacles to its deployment. There is a need for further studies in the field of nursing, in order to better deal with the difficulties and potentialities of using health care qualification tools, such as the elderly person's health record.

\section{RESUMEN}

Este estudio relata la experiencia de alumnas de Graduación en Enfermería ante el llenado de la libreta de salud del anciano durante visita domiciliaria. Este es un informe de experiencia basado en visitas domiciliarias a ancianos en el área cubierta por un centro de la Estrategia Salud de la Familia (ESF) en un municipio ubicado en la frontera oeste del Estado de Rio Grande do Sul, Brasil. Al llenar la libreta de salud del anciano, sus potencialidades como herramienta para el cuidado y la gestión de la salud en el ámbito de la atención primaria de salud (APS) fueron percibidas. Sin embargo, trabas relacionadas con el proceso de trabajo y la calificación técnico-científica de profesionales de la salud constituyen obstáculos a su efectividad. Hay necesidad de nuevos estudios en el campo de la enfermería, con miras a lidiar mejor con las dificultades y las potencialidades del uso de herramientas de calificación de la atención, como la libreta de salud del anciano.

\section{INTRODUÇÃ O}

Segundo a Organização Mundial da Saúde (OMS), os idosos são definidos como pessoas com idade cronológica de 60 anos ou mais (em países em desenvolvimento) ou 65 anos ou mais (em países desenvolvidos) - mesmo que a idade cronológica não represente um marcador preciso das alterações decorrentes do envelhecimento, pois as mudanças relativas a estado de saúde, participação e nível de independência são perpassadas pelas singularidades dos indivíduos ${ }^{1}$.

As estimativas de recente estudo do Instituto Brasileiro de Geografia e Estatística (IBGE) refletem uma acelerada intensificação da proporção de idosos: demonstrou-se que, entre 2005 e 2015, esse grupo etário passou de $9,8 \%$ para $14,3 \%$ da população, em crescimento paralelo ao decréscimo do grupo etário de 0 a 14 anos - que passou de $26,5 \%$ para $21,0 \%{ }^{2}$.

Tais mudanças evidenciadas na composição demográfica já começam a provocar consequências sociais, culturais e epidemiológicas, sobretudo no que diz respeito ao perfil de morbimortalidade, a partir do aumento da incidência de doenças crônicodegenerativas. Esse fato suscita um olhar atento dos gestores e dos serviços de saúde, a fim de prevenir agravos e promover, proteger e recuperar a saúde da população idosa $a^{3,4}$.

A mudança do perfil de saúde da população idosa trouxe a necessidade de alterações nas formas de cuidado dessa população; uma delas foi o retorno ao modelo de cuidados domiciliares. Entre as diversas ações criadas para dar corpo a esse novo modelo, em consonância com a Política Nacional de Saúde da Pessoa Idosa (PNSPI), de 2006, destaca-se a prática sistemática de visitas domiciliárias, realizadas pelas equipes da Estratégia Saúde da Família (ESF) ${ }^{5}$.

Também em 2006, com o propósito de pactuar novos compromissos e responsabilidades entre as três esferas de gestão pública (federal, estadual e municipal), o Ministério da Saúde (MS) aprovou o "Pacto pela Saúde" do Sistema Único de Saúde (SUS), composto por: "Pacto em Defesa do SUS"; "Pacto de Gestão" e "Pacto pela Vida"6.

0 Pacto pela Vida indica a saúde do idoso como um de seus elementos prioritários, abrangendo diretrizes operacionais e ações estratégicas, coletivas e individuais. No conjunto de iniciativas por ele estabelecido, alinhado à implantação da PNSPI, encontra-se a implementação da caderneta de saúde da pessoa idosa ${ }^{7}$.

Esse instrumento configura-se como uma ferramenta para a qualificação da atenção e do manejo das demandas de saúde do idoso, uma vez que promove o levantamento periódico de determinadas condições e outros aspectos que possam interferir no bem-estar desse indivíduo, a fim de possibilitar que as ações necessárias sejam adotadas precocemente?.

A relevância deste estudo se justifica em tal contexto, tendo em vista que o profissional da ESF 
deve realizar a consulta de enfermagem e preencher a caderneta de saúde da pessoa idosa, contribuindo para a prevenção de agravos e a promoção e proteção da saúde, bem como para a recuperação e reabilitação do indivíduo, da família e da comunidade ${ }^{8}$.

Este artigo relata a experiência de alunas de Graduação em Enfermagem diante do preenchimento da caderneta de saúde da pessoa idosa em visita domiciliar.

\section{METODOLOGIA}

Trata-se de relato de experiência construído a partir das vivências de acadêmicas de Enfermagem de uma universidade federal localizada na fronteira oeste do Rio Grande do Sul, durante as aulas práticas da disciplina “Enfermagem no Cuidado à Saúde do Idoso", ambientadas em um serviço de atenção primária à saúde (APS).

Esse componente curricular tem por objetivos:

A. Capacitar os alunos para a assistência qualificada ao idoso nos diferentes níveis de atenção à saúde;

B. Fomentar reflexões sobre a inserção do idoso na sociedade contemporânea;

C. Conhecer as políticas públicas nacionais e os serviços de atenção ao idoso; e

D. Identificar o idoso ativo ou fragilizado/ doente, estimulando a promoção à sua saúde e a manutenção de sua funcionalidade e autonomia.

Assim, este relato se concentra em visitas domiciliares a idosos adstritos ao território de uma unidade da ESF, localizada na zona urbana do município, que conta com 2 equipes compostas por: 2 enfermeiros; 2 médicos generalistas; 3 técnicos de enfermagem; 1 nutricionista; 1 educador físico; e 8 agentes comunitários de saúde (ACS). Esse serviço de saúde abrange 13 microáreas e atende, segundo o Sistema de Informações da Atenção Básica (SIAB), uma população de 8.800 pessoas ( $35 \%$ delas com 60 anos ou mais).

Nesse serviço, o atendimento à comunidade ocorre em 2 turnos (das 7:30 às 11:30 e das 13:30 às 17:30) e estrutura-se mediante acolhimento à livre demanda, segundo os critérios da classificação de risco.

Para a operacionalização das atividades práticas, desenvolvidas em abril e maio de 2017, as acadêmicas se dividiram em duplas para as visitas domiciliares aos idosos, com o intuito de realizar o preenchimento da caderneta de saúde da pessoa

\section{...favorece ações de rastreamento e identificação da predisposição e do grau de fragilidade do idoso...}

idosa - em processo de implantação no município, mediante acompanhamento dos ACS e da professora responsável pela disciplina.

Ao longo desse período foram realizadas duas visitas a domicílio, de usuários adstritos no território. Na residência foram ofertadas ações de educação em saúde, imunização, aferição dos sinais vitais, além de distribuição, preenchimento e orientações a respeito da caderneta.

\section{RESULTADOS E DISCUSSÃO}

Optou-se por relatar as experiências das acadêmicas quanto ao preenchimento da caderneta de saúde da pessoa idosa agrupando aprendizados, resultados e limites identificados no desenvolvimento dessa atividade.

Discute-se o uso desse instrumento na APS destacando seu potencial enquanto ferramenta de cuidado e gestão, bem como os entraves observados no processo de sua implementação em uma unidade de ESF.

Apresentamos a seguir duas categorias temáticas oriundas das experiências das acadêmicas.

\section{Caderneta de saúde da pessoa idosa: ferramenta de cuidado e gestão}

No que concerne à caderneta de saúde da pessoa idosa, uma das potencialidades observadas pelas acadêmicas ao longo das atividades práticas na comunidade diz respeito à sua estruturação sistematizada, que favorece ações de rastreamento e identificação da predisposição e do grau de fragilidade do idoso a partir de seu preenchimento pela equipe da ESF, por concentrar informações de modo organizado e dinâmico.

Para fins operacionais, a PNSPI estratificou a população idosa em dois grupos compostos, respectivamente, por idosos independentes, ativos 
no meio familiar e social, e por aqueles considerados frágeis ou em processo de fragilização?.

0 segundo grupo vivencia certa dificuldade para realizar suas atividades da vida diária (AVD), o que pode resultar na perda de autonomia e na necessidade de cuidados e tratamentos contínuos ${ }^{10}$. As alterações funcionais próprias do envelhecimento, associadas à maior prevalência das doenças crônicodegenerativas, coadunam para a deterioração da independência, o que corrobora a diminuição do bem-estar e da qualidade de vida ${ }^{11}$.

Nesse sentido, a caderneta, como ferramenta do cuidado, surge com o propósito de identificar o grupo fragilizado no território, além de proporcionar - acompanhamento periódico de determinadas condições de saúde do idoso e outros aspectos que possam interferir em seu bem-estar, de modo a possibilitar o desenvolvimento de ações prioritárias de saúde voltadas à recuperação, promoção, atenção e prevenção de agravos entre esses indivíduos ${ }^{9}$.

0 primeiro contato das acadêmicas com a caderneta ocorreu ainda em sala de aula, durante uma dinâmica proposta pelas professoras. Nesse momento, a turma se organizou em duplas, que deveriam representar uma interação entre o enfermeiro e o idoso no contexto da visita domiciliar, para a simulação do preenchimento dos itens que compõem a caderneta.

No que diz respeito aos segmentos abarcados em sua estrutura, pode-se destacar, inicialmente, um espaço dedicado à obtenção de informações relativas à identificação do idoso que devem ser colhidas junto ao indivíduo, seus familiares e cuidadores, para garantir a veracidade dos dados. Esse fato dá início à execução do cuidado personalizado, uma vez que permite que as vulnerabilidades, sejam elas sociais, econômicas ou familiares, sejam explicitadas e (re)conhecidas pelos profissionais que realizam o acompanhamento periódico $0^{9,12,13}$.

$\mathrm{Na}$ sequência, o instrumento apresenta seções destinadas à coleta de informações individuais e familiares, objetivando o (re)conhecimento das redes de apoio, as interações e os relacionamentos. No espaço subsequente devem ser registradas informações estratégicas, que se relacionam às condições de saúde do idoso, especialmente, associadas a maior risco de desfechos adversos, considerando as intervenções preventivas de declínio funcional, hospitalização ou óbito ${ }^{9,12,13}$.

Ao longo do preenchimento da caderneta surgem questões gerais para a avaliação da saúde do idoso, que incluem o uso de medicamentos,

\section{...o instrumento \\ apresenta seções destinadas à coleta de informações individuais $e$ familiares...}

fitoterápicos, suplementos e vitaminas, em caráter contínuo ou ocasional; diagnósticos e internações prévias; procedimentos cirúrgicos realizados; reações adversas ou alergia a fármacos; e dados antropométricos ${ }^{9}$.

0 caderno de envelhecimento e saúde da pessoa idosa de 2007, em paralelo à caderneta, igualmente ratifica a importância do registro das medicações, considerando a necessidade de prevenção da ocorrência de iatrogenias medicamentosas, relacionadas à polifarmácia, ou uso concomitante de cinco medicamentos ou mais, comum diante da terapêutica de doenças crônicas ${ }^{12}$. Nesse sentido, um estudo descritivo realizado no Estado do Ceará junto a 134 idosos adstritos em uma unidade básica de saúde (UBS) constatou prevalência de polifarmacoterapia em $82,1 \%$ dos casos, referindo como condições crônicas mais comuns a hipertensão arterial $(59,1 \%)$ e o diabetes mellitus $(25,2 \%)^{14}$.

Por sua vez, uma pesquisa piauiense revelou que $62,5 \%$ dos participantes, com idades entre 60 e 80 anos utilizam medicamentos sem prescrição e que $42,5 \%$ responderam positivamente quanto à dificuldade para o uso de medicações nos horários e nas doses corretas. Logo, conhecer as práticas de administração dos fármacos e suas características nos idosos é essencial para que os profissionais da saúde possam prestar orientações efetivas a essa população ${ }^{15}$.

Outros pontos em evidência nesta seção se relacionam à aplicação do protocolo de identificação do idoso vulnerável (VES-13), no qual se utiliza um questionário que busca identificar o idoso vulnerável residente na comunidade, com base em idade, autopercepção da saúde, presença de limitações físicas e incapacidades. Há informações complementares, relativas ao humor e ao esquecimento autorreferidos; à avaliação ambiental, associada a elementos externos capazes de precipitar quedas; às quedas, ao histórico de quedas 
e aos desfechos associados; à identificação de dor crônica; e aos hábitos de vida ${ }^{12}$.

Um estudo realizado em Pernambuco, em maio de 2016, baseado no protocolo do instrumento VES-13, revelou que sua aplicação se mostrou confiável em termos da solidez e consistência de suas medidas, apresentando uma estrutura simples e de fácil execução que auxilia na identificação de pessoas idosas vulneráveis que necessitam de acompanhamento prioritário e constante dos serviços de saúde ${ }^{16}$. Outro estudo aponta a importância da autoavaliação como ferramenta de investigação ampliada do estado de saúde do idoso, auxiliando a compreensão do processo saúde-doença sob a ótica do próprio indivíduo ${ }^{17}$.

No que tange à avaliação ambiental, percebe-se que os fatores de risco ambientais ou extrínsecos, que aumentam a propensão dos idosos a quedas e acidentes domésticos, como iluminação, tapetes soltos, degraus altos ou estreitos, demandam verificação contínua por parte dos profissionais das equipes de saúde, com o objetivo de prevenir quedas e orientar quanto às modificações necessárias para obter maior segurança.

Nesse sentido, uma pesquisa realizada com 251 idosos identificou que $54 \%$ das quedas apresentadas por esse grupo tiveram como principal causa o ambiente doméstico inadequado, como piso escorregadio $(26 \%)$, objetos no chão $(22 \%)$ e problemas em degraus $(7 \%)$, entre outras. 0 principal ambiente das quedas foi o próprio lar, em $66 \%$ dos casos, contra apenas $22 \%$ na rua e na casa de parentes ${ }^{18}$.

Convém apontar a existência de seções destinadas ao acompanhamento longitudinal dos valores de pressão arterial sistêmica, controle da glicemia capilar e calendário de imunizações. Por fim, ressalta-se um espaço específico para avaliação de periodicidade anual da saúde bucal e identificação de necessidades de saúde a ela relacionadas pela equipe de saúde bucal presentes no território ${ }^{12}$.

Depreende-se, portanto, que esse instrumento, quando empregado em sua totalidade e de modo adequado, favorece a articulação dos saberes e das práticas na APS, tendo em vista o atendimento integral das necessidades dos usuários. Ponderase, assim, sua concordância com os pressupostos da Política Nacional da Humanização da Atenção e Gestão do SUS (Humaniza-SUS), no que se refere à corresponsabilidade entre os atores presentes no cuidado, ao vínculo entre profissionais e usuários,

\section{...essa ferramenta é instituída enquanto mecanismo para a cidadania e o empoderamento dos sujeitos...}

à garantia de direitos dos usuários enquanto protagonistas no processo de cuidar, uma vez que prevê como imperativo para o bom manejo da saúde da pessoa idosa, seu uso tanto pelas equipes de saúde quanto pelos idosos e por seus familiares e cuidadores $^{9,19}$.

Nessa vertente, outro aspecto positivo relativo à experiência das acadêmicas diante do uso da caderneta diz respeito à possibilidade de socialização das informações educativas obtidas. Tais informações remetem a questões como direitos da pessoa idosa, pontuando o estatuto e as políticas vigentes; às orientações sobre o uso e armazenamento de medicamentos; ao acesso a medicamentos no SUS, explicitando os mecanismos para acesso aos medicamentos e/ou correlatos no âmbito do Programa Farmácia Popular; às etapas pertinentes a uma alimentação saudável; além de orientações sobre saúde bucal, prevenção de quedas, realização de atividades físicas e sexualidade ${ }^{12}$.

De modo semelhante, um estudo nacional revelou, segundo relatos de profissionais da saúde, que, mediante recebimento da caderneta, os idosos aderiram a seu uso com satisfação e sempre que vão ao serviço de saúde eles a levam como se fosse um documento, pois foram orientados pelos enfermeiros, no território, acerca de sua importância e da necessidade de mantê-la sempre à mão ${ }^{20}$.

Pode-se inferir que essa ferramenta é instituída enquanto mecanismo para a cidadania e o empoderamento dos sujeitos, processo por meio do qual as pessoas adquirem domínio sobre suas vidas e obtêm conhecimento para a tomada de decisões acerca de sua saúde e seu bem-estar ${ }^{21,22}$.

Posteriormente, discutindo a aplicabilidade dessa ferramenta com a enfermeira de uma das equipes de saúde, identificou-se a presença de outra potencialidade de sua implementação: o entendimento desse instrumento enquanto ferramenta de gestão na APS. 
Como pressupõe a PNSPI, de fato, a caderneta de saúde da pessoa idosa possibilita a organização do serviço, alinhando-se ao planejamento e à sistematização das ações destinadas à população idosa no território, a partir do acompanhamento dos registros e do (re)conhecimento do perfil e das demandas de cuidado desse grupo por parte das equipes da $\operatorname{ESF}^{23,24}$.

Essas informações são capazes de amparar a estruturação e o preparo de ações de prevenção de agravos e de promoção e reabilitação da saúde na comunidade ${ }^{9}$. Na unidade da ESF em questão, podem ser destacadas as estratégias de educação em saúde sob a forma de grupos educativos, fundamentadas no sentido de elucidar questões que perpassam o viver com limitações e comorbidades que se relacionam ao avanço da idade, para fortalecer o envelhecimento ativo ${ }^{25}$.

Para tanto, as ações do serviço destinadas à população idosa se encontram ancoradas em um projeto de extensão universitária denominado “Envelhecer com Arte e Saúde", vinculado à universidade federal em questão, que vem sendo desenvolvido na unidade da ESF desde o início de 2016, quinzenalmente, com a participação de 12 idosos. Logo, o grupo representa uma proposta interativa e dinâmica, que possibilita a abordagem de diversas temáticas, em um espaço perpassado pela troca de saberes e experiências entre usuários, familiares, cuidadores e profissionais, sob uma perspectiva de autonomização em resposta às dúvidas e necessidades percebidas ${ }^{26}$.

\section{Entraves na implementação do instrumento}

Como explicitado, objetivando aprimorar os cuidados à população idosa, ferramentas como a caderneta de saúde da pessoa idosa foram criadas com base na legislação brasileira. No entanto, percebe-se que importantes desafios ainda se mostram presentes para implementá-la ${ }^{27}$.

Dentre os entraves percebidos pelas acadêmicas nesse processo, pode-se destacar o desconhecimento do significado prático do preenchimento da caderneta, observado na conduta dos profissionais que atuam na APS. Grande parte deles relaciona a caderneta apenas como um instrumento estático para a identificação sociodemográfica desse grupo, sem considerá-la uma ferramenta para o cuidado continuado, distanciando-a, ainda, da prática diária.

Em consonância com a afirmativa acima, um estudo desenvolvido junto aos enfermeiros da APS de

\section{...pode-se destacar o desconhecimento do significado prático do preenchimento da caderneta...}

Caririaçu-CE demonstra que, embora os profissionais estejam cientes de algumas das ações que constam nesse instrumento de monitoramento da saúde do idoso, em nenhum momento o preenchimento da caderneta é citado, de modo específico, como atividade realizada ${ }^{20}$.

Ademais, no que concerne ao preenchimento da caderneta, aponta-se que, apesar de sua estruturação em perspectiva multidisciplinar, esse processo de trabalho compartilhado não foi observado na prática, especialmente pelo entendimento errôneo de muitos profissionais da equipe de saúde de que, em geral, trata-se de uma tarefa exclusiva da enfermagem, deixando de cumpri-la.

Além das atribuições assistenciais, o enfermeiro desempenha uma série de outras atividades, que podem o sobrecarregá-lo enquanto profissional, impedindo-o de dedicar-se exclusivamente àquilo que compete à sua categoria - como é o caso da consulta de enfermagem ${ }^{28}$. No que diz respeito à saúde no país, inúmeros são os profissionais que relatam alta demanda e escassez de tempo para o cumprimento de suas atribuições, o que acaba por comprometer a qualidade do atendimento. Em consequência desses acontecimentos, frequentemente a promoção e prevenção de agravos voltadas à população idosa fica em segundo plano, comprometendo a implementação de ferramentas como a descrita ao longo deste $\operatorname{artigo} 0^{24,29}$.

Outra questão pertinente se relaciona às dificuldades para a realização das visitas no domicílio, ainda que este seja considerado o cenário ideal para o preenchimento da caderneta, como indica $0 \mathrm{MS}^{13}$. São apontados como impeditivos para essa prática a existência de ações programáticas, motivada por excessivo cumprimento de metas, sobrecarga de trabalho, anteriormente citada, e, sobretudo, falta de conhecimentos básicos em geriatria e gerontologia ${ }^{30}$.

Ainda que a população idosa seja frequentadora 
assídua do serviço de saúde, no contexto atual, percebe-se a necessidade de superar uma série de entraves nas unidades daESF, podendo-se citar, ainda, o panorama municipal de constantes substituições nas equipes de saúde, cujo trabalho deveria estar alicerçado na construção e no fortalecimento de vínculos entre o serviço e os idosos, a fim de consolidar o uso da caderneta enquanto ferramenta de cuidado e gestão de saúde.

\section{CONCLUSÃO}

Diante das considerações expostas, destacase importância da caderneta de saúde da pessoa idosa enquanto ferramenta para cuidado e gestão da assistência continuada e rastreio de condições agravantes na população idosa. Nesse sentido, pode-se inferir que cabe ao profissional habilitado multiplicar e fortalecer seu uso na prática, bem como utilizá-la como subsídio para o diagnóstico das necessidades da população e o planejamento de ações de prevenção de agravos e promoção e reabilitação da saúde consideradas pertinentes.

No que diz respeito aos entraves observados no processo de implementação desse instrumento em uma unidade da ESF do município em análise, pontua-se como impeditivos à sua efetivação: a) o desconhecimento dos objetivos e significados de seu uso prático; b) o entendimento da caderneta como mera tarefa a cargo do enfermeiro; c) a sobrecarga de trabalho; e d) as lacunas de conhecimento técnicocientífico nas áreas de geriatria e gerontologia entre os profissionais da equipe de saúde.

A manipulação dessa ferramenta fortaleceu as acadêmicas como profissionais de enfermagem, sob uma perspectiva holística e instrumentalizada que reitera a importância de proporcionar cuidados multiprofissionais e continuados à população. Ademais, destaca-se, em especial, a experiência das visitas domiciliares, que favorecem a aproximação com os usuários, personagens centrais no processo

\section{...caderneta de saúde da pessoa idosa enquanto ferramenta para cuidado e gestão da assistência...}

de cuidar levado a cabo pelos profissionais de enfermagem.

Pode-se apontar como limitações deste estudo o reduzido tempo em campo prático, considerado insuficiente para que os achados sejam passiveis de generalização. Sugere-se que novos estudos sejam conduzidos no campo da enfermagem, de modo a abordar, com maior propriedade, as dificuldades e as potencialidades do uso de ferramentas qualificadoras da assistência - como a caderneta de saúde da pessoa idosa.

\section{CONTRIBUIÇÃO DAS AUTORAS}

Alessandra Schmidt, Maria Eduarda Deitos Vasquez e Caroline Bittencourt contribuíram com a realização da pesquisa, o delineamento do estudo e a redação do manuscrito. Cenir Gonçalves Tier e Vanessa Alvez Mora da Silva contribuíram com a revisão crítica do manuscrito. Bethânia Mesquita Cabeda Maciel contribuiu com a redação e revisão crítica do manuscrito.

\section{REFERÊNCIAS}

1. Faleiros VP. Envelhecimento no Brasil do Século XXI: transições e desafios. Argumentum [serial on the internet]. 2014 [cited 2017 Aug 2];6(1):621. Available from: http://periodicos.ufes.br/ argumentum/article/view/7952

2. Instituto Brasileiro de Geografia e Estatística. Sintese de indicadores sociais (SIS): uma análise das condições de vida da população brasileira 2016. Rio de Janeiro: IBGE; 2016.

3. Küchemann BA. Envelhecimento populacional, cuidado e cidadania: velhos dilemas e novos desafios. Sociedade e Estado [serial on the internet]. 2012 [cited 2017 Aug 1];27(1):165-80. Available from: http://www.scielo.br/pdf/se/v27n1/09.pdf

4. Andrade LM, Sena EL, Pinheiro GM, Meira EC, Lira LS. Políticas públicas para pessoas idosas no Brasil: uma revisão integrativa. Ciênc Saúde Colet [serial on the internet]. 2013 [cited 2017 Aug 3];(18):354352. Available from: https://www.scielosp.org/scielo. php? pid $=$ S1413-81232013002000011\&script $=$ sci abstract \&thng $=p t$

5. Muniz EA, Freitas CASL, Albuquerque IMAN, Linhares MSC. Assistência domiciliar ao idoso no contexto da Estratégia Saúde da Família: análise da produção científica. Sanare (Sobral, 0nline) [serial on the internet]. 2014 [cited 2016 Sep 29];13(2):8691. Available from: https://sanare.emnuvens.com. br/sanare/article/view/578/311 
6. Brasil. Portaria n. 399/GM, de 22 de fevereiro de 2006. Divulga o Pacto pela Saúde 2006 -Consolidação do SUS e aprova as Diretrizes 0peracionais do Referido Pacto [document on the internet]. 2006 [cited 2017 Aug 4]. Available from: http://bvsms.saude.gov.br/ bvs/saudelegis/gm/2006/prt039922 02 2006.html

7. Brasil. Portaria n. 2.048, de 3 de setembro de 2009. Aprova o Regulamento do Sistema Único de Saúde (SUS) [document on the internet]. 2009 [cited 2017 Aug 2]. Available from: http://bvsms.saude.gov. br/bvs/saudelegis/gm/2009/prt2048 $03 \quad 092009$. $\underline{\text { html }}$

8. Brasil. Resolução n. 159/93, de 19 de abril de 1993. Dispõe sobre a consulta de enfermagem [document on the internet]. 1993 [cited 2017 Aug 3]. Available from: http://www.cofen.gov.br/ resoluo-cofen-1591993 4241.html

9. Brasil. Caderneta de Saúde da Pessoa Idosa: manual de preenchimento. Brasília (DF): Ministério da Saúde; 2008.

10. Camarano AA, Kanso S. As instituições de longa permanência para idosos no Brasil. Rev Bras Estud Popul [serial on the internet]. 2010 [cited 2017 Aug 2];27(1):232-5. Available from: http://www.scielo. br/pdf/rbepop/v27n1/14.pdf

11. Tavares DMS, Dias FA. Capacidade funcional, morbidades e qualidade de vida de idosos. Texto \& Contexto Enferm [serial on the internet]. 2012 [cited 2017 Aug 10];1;21(1):233-5. Available from: http://www.scielo.br/pdf/rbepop/v27n1/14.pdf

12. Brasil. Caderneta de Saúde da Pessoa Idosa. Brasília (DF): Ministério da Saúde; 2014.

13. Brasil. Caderneta de Saúde da Pessoa Idosa: manual de utilização. Brasília (DF): Ministério da Saúde; 2016.

14. Bezerra TA, Brito MA, Costa KN. Caracterização do uso de medicamentos entre idosos atendidos em uma unidade básica de Saúde da Família. Cogitare Enferm [serial on the internet]. 2016 [cited 2017 Aug 6];21(1):1-11. Available from: https://revistas. ufpr.br/cogitare/article/view/43011

15. Monteiro ORB, Figueiredo NR, Marreiros MDOC, Figueiredo MDLF, Lima NA, Carvalho Júnior JAM. The occurrence of polypharmacy among elderly assisted by the Family Health Strategy/Polifarmácia entre idosos assistidos pela estratégia saúde da família. Rev Enferm UFPI [serial on the internet]. 2014 [cited 2017 Aug 11];3(2):56-61. Available from: http://www.ojs.ufpi.br/index.php/reufpi/ article/view/1419

16. Lima CAB, Carvalho JL, Aquino RCA. Avaliação de vulnerabilidade do idoso através da adaptação transcultural do instrumento de identificação do idoso vulnerável VES-13. Revista Eletrônica da Estácio Recife [serial on the internet]. 2017 [cited 2017 Aug 9];3(1):[about 7 pages]. Available from: https://reer.emnuvens.com.br/reer/article/view/115

17. Silva IT, PINTO Junior EP, Vilela AB. Autopercepção de saúde de idosos que vivem em estado de corresidência. Rev Bras Geriatr Gerontol [serial on the internet]. 2014 [cited 2017 Aug 9];17(2):27587. Available from: http://www.redalyc.org/ pdf/4038/403838837006.pdf

18. Fabrício SC, Rodrigues RA, Costa Junior ML. Rev Saúde Pública [serial on the internet]. 2004 [cited 2017 Aug 6];(38):93-9. Available from: https://www. scielosp.org/article/rsp/2004.v38n1/93-99/

19. Brasil. Política Nacional de Humanização. Brasília (DF): Ed. Ministério da Saúde; 2004.

20. Barros TB, Maia ER, Pagliuca LMF. Facilidades e dificuldades na assistência ao idoso na Estratégia de Saúde da Família. Rev Rene [serial on the internet]. 2011 [cited 2017 Aug 3];12(4):732-41. Available from: http://www.redalyc.org/html/3240/324027977010/

21. Taddeo PD, Gomes KW, Caprara A, Gomes AM, Oliveira GC, Moreira TM. Acesso, prática educativa e empoderamento de pacientes com doenças crônicas. Ciênc Saúde Colet [serial on the internet]. 2012 [cited 2017 Aug 12];(17):2923-30. Available from: http://www.scielo.br/pdf/csc/v17n11/v17n11a08. pdf

22. Vieira RS, Souza Vieira R. Saúde do idoso e execução da política nacional da pessoa idosa nas ações realizadas na atenção básica à saúde. Rev Direito Sanit [serial on the internet]. 2016 [cited 2017 Aug 11];17(1):14-37. Available from: http:// www.periodicos.usp.br/rdisan/article/view/117042

23. Santos DA, Albuquerque AC. Ações e serviços oferecidos aos idosos atendidos pela atenção primária no município de Campina Grande-PB. Enferm Foco [serial on the internet]. 2013 [cited 2017 Aug 4];4(3-4):146-9. Available from: http:// revista.cofen.gov.br/index.php/enfermagem/ article/view/536

24. Silva KM, Santos SM. A práxis do enfermeiro da Estratégia de Saúde da Família e o cuidado a o idoso. Texto \& Contexto Enferm [serial on the internet]. 2015 [cited 2017 Aug 8];24(1):105-11. Available from: http://www.redalyc.org/pdf/714/71438421013.pdf

25. Machado ARM, Walterlânia SS, Dias FA, Tavares DMS, Munari DB. Potencializando um grupo de terceira idade de uma comunidade rural. Rev Esc Enferm USP [serial on the internet]. 2015 [cited 2017 Aug 15];49(1):96-103. Available from: http://www.scielo.br/scielo.php?script=sci arttext\&pid $=$ S0080-62342015000100096\&lng=en 
26. Neves RT, Laham CF, Aranha VC, Santiago A, Solimar F, Lucia MC. Envelhecimento e doenças cardiovasculares: depressão e qualidade de vida em idosos atendidos em domicílio. Psicol Hosp [serial on the internet]. 2013 [cited 2017 Aug 14];11(2):72-98. Available from: http://pepsic. bvsalud.org/scielo.php?script=sci arttext\&pid $=$ S1677-74092013000200006

27. Fernandes MTO, Soares SM. 0 estado das políticas públicas de atenção ao idoso no Brasil. Rev Esc Enferm USP [serial on the internet]. 2012 [cited 2017 Aug 15];46(6)1493-501. Available from: http:// www.redalyc.org/html/3610/361033321029/

28. Silva KM, Vicente FR, Santos SM. Consulta de enfermagem ao idoso na atenção primária à saúde: revisão integrativa da literatura. Rev Bras Geriatr Gerontol [serial on the internet]. 2014 [cited 2017 Aug 13];17(3):681-7. Available from: http://www. redalyc.org/pdf/4038/403838839020.pdf

29. Coutinho AT, Popim RC, Carregã K, Spiri WC. Integralidade do cuidado com o idoso na Estratégia de Saúde da Família: visão da equipe. Esc Anna Nery Rev Enferm [serial on the internet]. 2013 [cited 2017 Aug 10];17 (4):628-37. Available from: http://www.redalyc.org/pdf/1277/127729351005.pdf

30. Sossai LC, Pinto IC. A visita domiciliária do enfermeiro: fragilidades $x$ potencialidades. Ciênc Cuid Saúde [serial on the internet]. 2010 [cited 2017 Aug 8];9(3):569-76. Available from: http:// ojs.uem.br/ojs/index.php/CiencCuidSaude/article/ view/6856
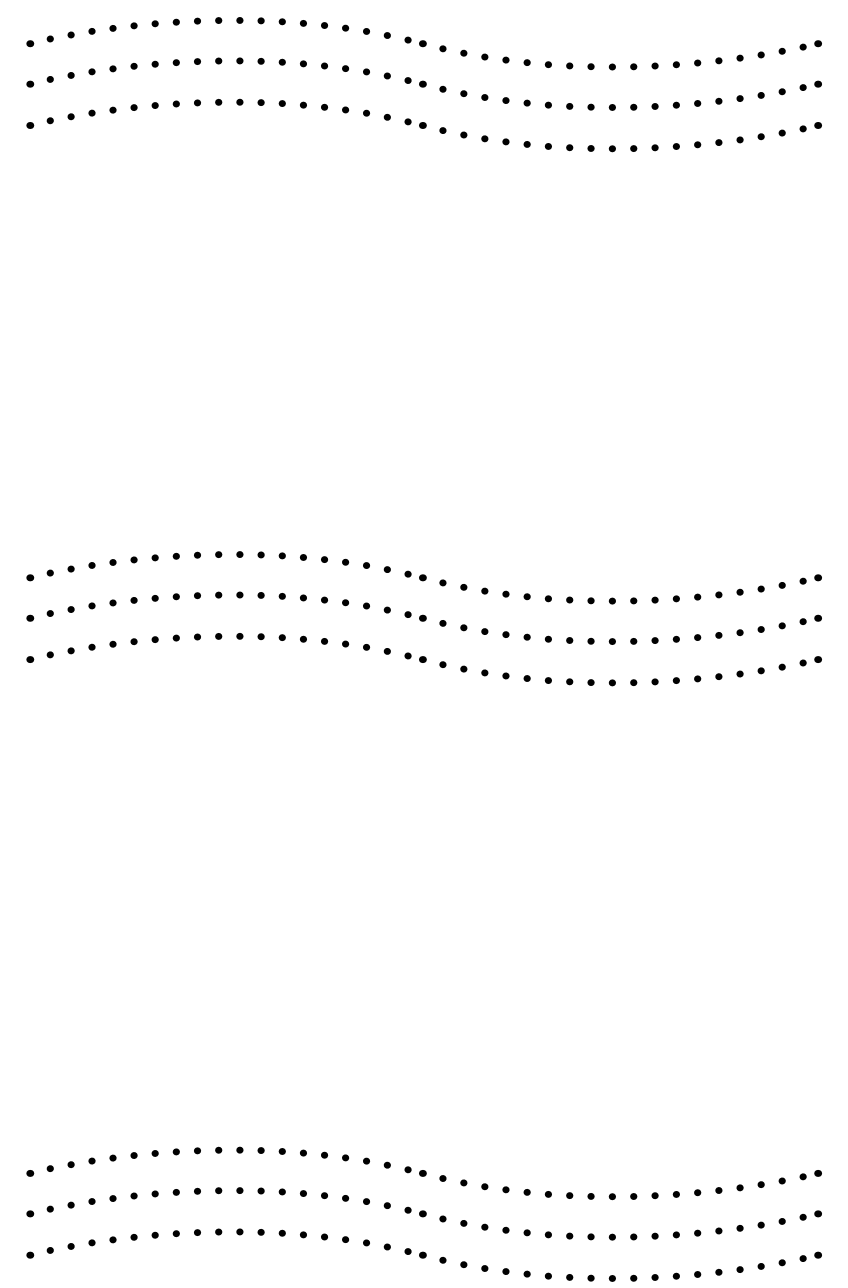
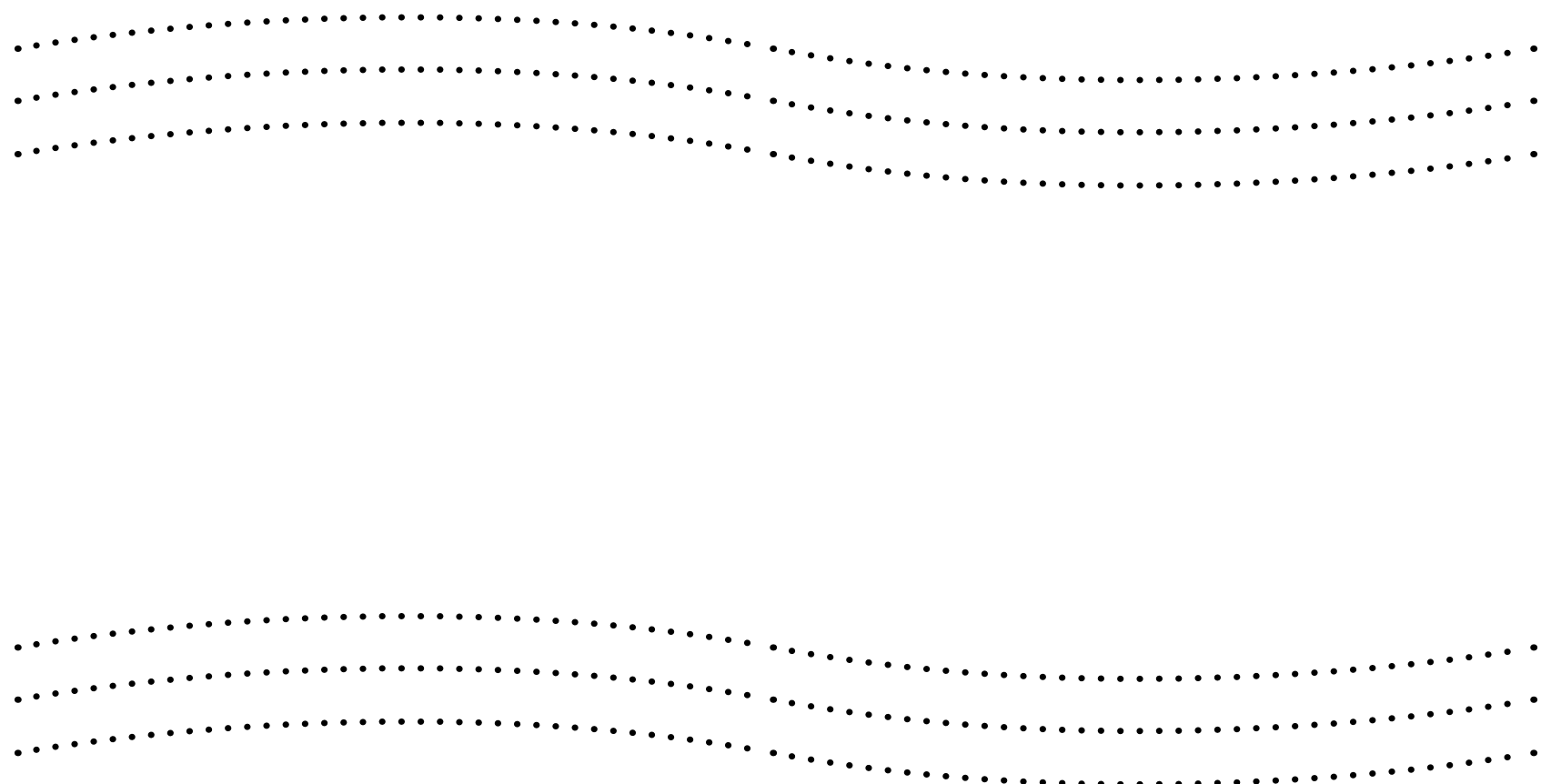
SANARE (tornar sã, em latim) é uma revista que tem por finalidade divulgar toda e qualquer experiência, prática e teórica, em políticas públicas na área de Saúde Coletiva, como forma de contribuir com o processo de elaboração e sistematização voltado para a construção de novos paradigmas sobre a gestão governamental. A Revista, de periodicidade semestral, publica artigos que contribuem com saberes e práticas na área da Saúde Coletiva passando pelo debate da construção da interdisciplinaridade nessa seara. A submissão dos artigos far-se-á pela plataforma online: $h t t p: / / s a n a r e . e m n u v e n s . c o m . b r$

\section{CATEGORIAS DE ARTIGOS}

ASANARE - Revista de Políticas Públicas publica artigos temáticos, originais, relatos de experiências, revisões sistemáticas e integrativas.

A apresentação dos manuscritos deve obedecer às regras de formatação definidas nessas Diretrizes para Autores, diferenciando-se apenas pelo número permitido de palavras em cada uma das categorias.

- $\quad$ Artigo Original: de caráter original, podendo ser revisão crítica, meta-análise ou resultado de pesquisas de natureza empírica, experimental ou conceitual sobre o assunto, avaliação de programas e análises de custo-efetividade. Cada artigo deve conter objetivos e/ou hipóteses claras, desenho e métodos utilizados, resultados, discussão e conclusões. Incluem também ensaios teóricos (críticas e formulação de conhecimentos teóricos relevantes) e artigos dedicados à apresentação e discussão de aspectos metodológicos e técnicas utilizadas na pesquisa em saúde coletiva. Neste caso, o texto deve ser organizado em tópicos para guiar os leitores quanto aos elementos essenciais do argumento desenvolvido (entre 4.000 a 5.000 palavras);

- Relatos de Experiência: São relatos curtos de achados que apresentam interesse para a saúde coletiva de caráter intervencionista, mas que não comportam uma análise mais abrangente e uma discussão de maior aprofundamento (entre 3.000 a 4.000 palavras).

- $\quad$ Artigos de Revisão ou Teóricos: compreende a análise da literatura sobre temas específicos. Deve incluir uma seção que descreva os métodos utilizados para localizar, selecionar, extrair e sintetizar os dados e as conclusões (entre 4.000 a 5.000 palavras).

\section{Do ineditismo do material}

O conteúdo dos artigos enviados para publicação não pode ter sido publicado anteriormente ou encaminhado simultaneamente a outro periódico. A identificação de plágio implica em exclusão imediata do sistema de avaliação. Por plágio considera-se copiar um estudo, ou parte dele, de outro autor ou mesmo de publicação própria (autoplágio). Para maiores informações sobre plágio, acesse o link http:// www.dsce.fee.unicamp.br/ antenor/Plagio.pdf

\section{Da autoria}

O número máximo de autores do manuscrito está limitado a seis (06).

As pessoas designadas como autores devem ter participado na elaboração dos artigos de modo que possam assumir publicamente a responsabilidade pelo seu conteúdo. A qualificação como autor deve basear-se nas deliberações do International Committee of Medical Journal Editors (http://www.icmje.org) que orienta os seguintes aspectos a serem considerados na contribuição substancial para o reconhecimento da autoria: 1. Concepção e o delineamento ou a análise e interpretação dos dados; 2 . Redação do artigo ou a sua revisão crítica relevante do conteúdo intelectual; e, 3. Aprovação da versão a ser publicada.

No final do texto, devem ser especificadas as contribuições individuais de cada autor na elaboração do artigo.

Importante!

Após a aprovação do Artigo e recebimento de Carta de Aprovação, os autores devem atender os seguintes passos:

- Confirmar a intenção de publicação dentro de 72 horas e, na sequência, cumprir os requisitos do processo de edição de texto, enviando o manuscrito para o Editor de Texto oficial da Revista.

A Revista não cobra taxas de submissão e publicação. Contudo, o processo de revisão da língua portuguesa e tradução dos títulos e resumos para o inglês e espanhol serão financiados pelos autores

\section{FORMA E PREPARO DOS MANUSCRITOS}

\section{Formato}

$\mathrm{O}$ arquivo contendo o manuscrito deve ser elaborado no Editor de Textos MS Word com a seguinte configuracão de página: papel tamanho A4, margens de $2 \mathrm{~cm}$ em todos os lados; fonte Times New Roman, tamanho 12 com espaçamento entrelinhas de 1,5 pt.

\section{Estrutura}

I. A ordem dos elementos que compõem o corpo do manuscrito deve obedecer ao seguinte padrão: título em português, inglês e espanhol; resumo e descritor; abstract e descriptor; resumen e descriptor; texto (introdução, metodologia, resultados, discussão e conclusão); contribuição dos autores e referências.

II. Deverá conter as seguintes informações no cabeçalho, nessa ordem: 1) título do artigo, com no máximo 15 palavras em cada idioma (Português, Inglês e Espanhol). 0 texto não deve incluir qualquer informação que permita a identificação de autoria; os dados de todos os autores deverão ser informados apenas nos campos específicos do formulário de submissão 
(Passo 3 - Inclusão de Metadados).

III. Resumo: Português/Inglês/Espanhol. O resumo deverá conter de 150 a 200 palavras em cada um dos idiomas, apresentando: objetivo da pesquisa, metodologia adotada, principais resultados e as conclusões. Deverão ser destacados os novos e mais importantes aspectos do estudo. Os resumos em inglês e espanhol são de responsabilidade dos autores. Porém, podem ser revistos e solicitadas modificações a partir do parecer do Conselho Editorial da SANARE - Revista de Políticas Públicas. Apresentar, sequencialmente, os resumos nesta página de identificação.

IV. Descritores: incluir 3 a 5 descritores segundo o índice dos Descritores em Ciências da Saúde - DeCS (http://decs.bvs.br), separados entre si por ponto-e-vírgula.

V. Às tabelas e quadros deve-se atribuir um título breve. Notas explicativas podem ser colocadas abaixo da tabela/quadro. Se houver tabela extraída de outro trabalho, previamente publicado, os autores devem fazer a citação do autor e revista; devem ser elaboradas para reprodução direta pelo Editor de Layout, sem cores, inseridas no texto, com a primeira letra da legenda em maiúscula descrita na parte superior, numeradas consecutivamente com algarismos arábicos na ordem em que foram citadas no texto. Conteúdo em fonte 12pt com a primeira letra em maiúscula, apresentadas em tamanho máximo de 14 x $21 \mathrm{~cm}$ (padrão da Revista) e comprimento não deve exceder 55 linhas, incluindo título.

VI. As ilustrações (fotografias, desenhos, gráficos, etc.) devem ser citadas como figuras. Devem ser numeradas consecutivamente com algarismos arábicos, na ordem em que foram citadas no texto; as ilustraç̃̃es devem ser suficientemente claras para permitir sua reprodução, utilize escala de cinza e outros recursos para impressão em preto e branco. Não se permite que figuras representem os mesmos dados de Tabela. Nas legendas das figuras, os símbolos, flechas, números, letras e outros sinais devem ser identificados e seu significado esclarecido. Se houver figura extraída de outro trabalho, previamente publicado, os autores devem fazer a citação do autor e revista.

VII. A quantidade de Tabelas e Figuras não deve ser superior a cinco (05).

VIII. Abreviaturas e símbolos: Não deve conter abreviações no título e no resumo. Os termos por extenso aos quais as abreviações correspondem devem preceder sua primeira utilização no texto, a menos que sejam unidades de medidas padronizadas.

IX. Aspectos Éticos: nas pesquisas que envolvem seres humanos, os autores deverão deixar claro que as mesmas atenderam à Resolução 466/12 do Conselho Nacional de Saúde (CNS). O documento de aprovação do Comitê de Ética em Pesquisa (CEP) deve ser encaminhado sob a forma de documento digitalizado via Documentos Suplementares (Passo 4 da submissão do artigo).

X. Citação de Referência: numerar as referências de forma consecutiva de acordo com a ordem em que forem mencionadas pela primeira vez no texto. Identificar as referências no texto por números arábicos sobrescritos e antes da pontuação necessária, sem a identificação do autor e ano, e sem uso de parênteses. Quando se tratar de citação sequencial, separe os números por traço (ex: 1-3); quando intercalados, use vírgula (ex: 1,3,5). Quando a citação for direta, deve acrescer o número da página (ex.: 4:54).

XI. NÃO USAR rodapé/notas/espaçamento entre parágrafos.

XII. Cada autor deverá assinar uma "Declaração de Responsabilidade" na qual seja especificada a contribuição de cada um, conforme modelo (Anexo 1), e anexada via Documentação Suplementar. Entretanto, no corpo do manuscrito deve conter a CONTRIBUIÇÃO DOS AUTORES; este item deve ser apresentado antes da seção "Referências".

Exemplo:

Paulo Átila da Silva Viana contribuiu com o delineamento e a realização da pesquisa e a redação do manuscrito. Joaquim David Carneiro Neto contribuiu com o delineamento da pesquisa e a revisão crítica do manuscrito. Camila Teles Novais, Isabelle Furquim Guimarães e Yan Sousa Lopes contribuíram com o delineamento e a realização da pesquisa e a redação do manuscrito. Breno Cotrim Reis contribuiu com a realização da pesquisa e a redação do manuscrito.

Referências

Serão aceitas, no máximo, 30 referências, orientando-se incluir apenas aquelas estritamente pertinentes e relevantes à problemática abordada. Deve-se evitar a inclusão de número excessivo de referências numa mesma citação. Os autores são os responsáveis pela exatidão das referências.

I. As referências seguem o estilo Vancouver, tendo como base as normas adotadas pelo Comitê Internacional de Editores de Revistas Médicas (estilo Vancouver), publicadas no ICMJE - Uniform Requirements for Manuscripts Submitted to Biomedical Journals (http://www.icmje.org/index.html).

II. Os títulos de periódicos devem ser referidos abreviados, de acordo com o Index Medicus: http://www.ncbi.nlm.nih.gov/ sites/entrez?db=journals.

III. Para abreviatura dos títulos de periódicos nacionais e latino-americanos, consultar o site: http://portal.revistas.bvs.br eliminando os pontos da abreviatura, com exceção do último ponto para separar do ano.

IV. As referências devem ser numeradas consecutivamente, conforme a ordem que foram mencionadas pela primeira vez no texto.

V. NÃO APRESENTAR referências de monografias, dissertações e teses (exceto quando a pesquisa incluir Banco de dissertações/ teses em pesquisas de Revisões). 


\section{Exemplos:}

- Livros como um todo:

Dias FAC, Dias MAS. Território, cultura e identidade. Rio de Janeiro: Abrasco; 2010.

- Capítulo de livro:

Lachapelle R. L'expertise Québécoise Dáction Territorialeen Promotion de La Santé. In: Dias FAC, Dias MSA, organizadores. Território, Cultura e Identidade. Rio de Janeiro (RJ): Abrasco; 2010. p. 48-79.

- Trabalhos apresentados em eventos científicos:

Moreira V. O método fenomenológico mundano na pesquisa em saúde. In: Anais do $4^{\circ}$ Congresso de Pesquisa Ibero americano de Pesquisa Qualitativa em Saúde; 2010; Fortaleza: Abrasco; 2010. p.143.

- $\quad$ Artigos de periódicos:

1) Artigo Padrão

Mendes EV. As redes de atenção à saúde. Cien Saude Colet 2010;15(5):2297-305.

2) Com mais de seis autores

Carneiro Neto MC, Carneiro JC, Moreira AP, Soares CHA, Pinto VPT, Melo MSS, et al. Aspectos jurídicos do enfrentamento da dengue no município de Sobral, Ceará. Sanare 2010;9(1):27-8.

3) Instituição como autor

Fundação Oswaldo Cruz. O legado de Oswaldo Cruz. Hist Cienc Saude Manguinhos. 2007;10:40-1.

- Material eletrônico

4) Artigo de revista em formato eletrônico

Vilela EM, Mendes IJM. Interdisciplinaridade e saúde: estudo bibliográfico. Rev Lat Am Enfermagem [Internet]. 2003 [cited 2012 Apr 21];11(4):525-31. Available from: $h t t p: / / w w w . s c i e l o . b r / p d f / r l a e / v 11 n 4 / v 11 n 4 a 16 . p d f$

Castro SS, Pelicioni AF, Cesar CLG, Carandina L, Barros MBA, Alves MCGP et al. Uso de medicamentos por pessoas com deficiências em áreas do estado de São Paulo. Rev saúde pública [Internet]. 2010 [cited 2012 Jun 10];44(4):601-10. Available from: http://www.scielo. $\underline{b r / p d f / r s p / v 44 n 4 / 03 . p d f}$

Rozenfeld M. Prevalência, fatores associados e mau uso de medicamentos entre os idosos: uma revisão. Cad saúde pública [Internet]. 2003 [cited 2012 May 10];19(3):717-24. Available from: http://www.scielosp.org/pdf/csp/v19n3/15875.pdf

Matéria publicada na Internet

Brasil. Ministério da Saúde. Centro Brasileiro de Análise e Planejamento. Pesquisa Nacional de Demografia e Saúde da Criança e da Mulher: Dimensões do Processo Reprodutivo e da Saúde da Criança - 2006 [home-page on the Internet]. [cited 2014 Mar 20]. Available from: http://bvsms.saude.gov.br/bvs/pnds

\section{ANEXO 1}

Declaração de Responsabilidade (MODELO)

Eu, (nome por extenso), certifico que participei da autoria do manuscrito intitulado (título) nos seguintes termos: "Certifico que participei suficientemente do trabalho para tornar pública minha responsabilidade pelo seu conteúdo".

"Certifico que o manuscrito representa um trabalho original e que nem este manuscrito, em parte ou na íntegra, nem outro trabalho com conteúdo substancialmente similar, de minha autoria, foi publicado ou está sendo considerado para publicação em outra revista, quer seja no formato impresso ou no eletrônico, exceto o descrito em anexo."

"Atesto que, se solicitado, fornecerei ou cooperarei totalmente na obtenção e fornecimento de dados sobre os quais o manuscrito está baseado, para exame dos editores."

Contribuição:

$$
\text { Local, data }
$$

$$
\text { Assinatura }
$$

OBS: A contribuição de cada um dos autores deve ser explicitada na declaração. Não se justifica a inclusão de nome de autores cuja contribuição não se enquadre nos critérios. 